\title{
Relationships between Western Area Power Administration's Power Marketing Program and Hydropower Operations at Salt Lake City Area Integrated Projects
}

Decision and Information Sciences Division

Argonne National Laboratory

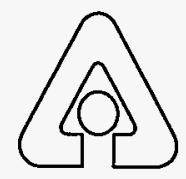

Operated by The University of Chicago, under Contract W-31-109-Eng-38, for the

United States Department of Energy 


\section{Argonne National Laboratory}

Argonne National Laboratory, with facilities in the states of Illinois and Idaho, is owned by the United States Government, and operated by the University of Chicago under the provisions of a contract with the Department of Energy.

This technical memo is a product of Argonne's Decision and Information Sciences (DIS) Division. For information on the division's scientific and engineering activities, contact:

Director, Decision and Information Sciences Division

Argonne National Laboratory

Argonne, Illinois 60439-4815

Telephone (708) 252-5464

Presented in this technical memo are preliminary results of ongoing work or work that is more limited in scope and depth than that described in formal reports issued by the DIS Division.

Publishing support services were provided by Argonne's Information and Publishing Division (for more information, see IPD's home page: http://www.ipd.anl.gov/).

\section{Disclaimer}

This report was prepared as an account of work sponsored by an agency of the United States Government. Neither the United States Government nor any agency thereof, nor any of their employees, makes any warranty, express or implied, or assumes any legal liability or responsibility for the accuracy, completeness, or usefulness of any information, apparatus, product, or process disclosed, or represents that its use would not infringe privately owned rights. Reference herein to any specific commercial product, process, or service by trade name, trademark, manufacturer, or otherwise, does not necessarily constitute or imply its endorsement, recommendation, or favoring by the United States Government or any agency thereof. The views and opinions of authors expressed herein do not necessarily state or reflect those of the United States Government or any agency thereof.

Reproduced directly from the best available copy.

Available to DOE and DOE contractors from the Office of Scientific and Technical Information, P.O. Box 62, Oak Ridge, TN 37831; prices available from (615) 576-8401.

Available to the public from the National Technical Information Service, U.S. Department of Commerce, 5285 Port Royal Road, Springfield, VA 22161. 
Relationships between Western Area Power Administration's Power Marketing Program and Hydropower Operations at Salt Lake City Area Integrated Projects

by T.D. Veselka, S. Folga, L.A. Poch, J.J. McCoy," S.C. Palmer, ${ }^{\star}$ R.G. Whitfield, J.C. VanKuiken, P.H. Kier, A.A. Novickas, and M. Absil

Systems Science Group,

Decision and Information Sciences Division,

Argonne National Laboratory, 9700 South Cass Avenue, Argonne, Illinois 60439

March 1995

Work sponsored by United States Department of Energy,

Western Area Power Administration

"McCoy and Palmer are affiliated with Western Area Power Administration, Salt Lake City, Utah. 
This report is printed on recycled paper. 


\section{FOREWORD}

This report is one of a series of technical memorandums prepared to support an environmental impact statement (EIS) on power marketing prepared by Argonne National Laboratory for the U.S. Department of Energy's Western Area Power Administration (Western). Western markets electricity produced at hydroelectric facilities operated by the Bureau of Reclamation. The facilities are known collectively as the Salt Lake City Area Integrated Projects (SLCA/P) and include dams equipped for power generation on the Colorado, Green, Gunnison, and Rio Grande rivers and on Plateau Creek in the states of Arizona, Colorado, New Mexico, Utah, and Wyoming.

Western proposes to establish a level of commitment (sales) of long-term firm electrical capacity and energy from the SLCA/IP hydroelectric power plants; the impacts of this proposed action are evaluated in the EIS. Of the SLCA/IP facilities, only the Glen Canyon Dam, Flaming Gorge Dam, and Aspinall Unit (which includes Blue Mesa, Morrow Point, and Crystal dams) are influenced by Western's power scheduling and transmission decisions. For this reason, the impacts of hydropower operations at these three facilities were examined in the EIS.

The technical memorandums present detailed findings of studies conducted by Argonne National Laboratory specifically for the EIS. These studies are summarized in the EIS, and the results were used to assess environmental impacts related to alternative commitment levels. Technical memorandums were prepared on a number of socioeconomic and natural resource topics. Staff members of Argonne National Laboratory's Decision and Information Sciences Division and Environmental Assessment Division prepared these technical memorandums and the EIS as part of a joint effort managed by the Environmental Assessment Division. 


\section{CONTENTS}

FOREWORD

iii

NOTATION xiii

ABSTRACT .

$1 \quad$ INTRODUCTION $\ldots \ldots \ldots \ldots \ldots \ldots \ldots \ldots \ldots \ldots \ldots \ldots \ldots \ldots \ldots \ldots \ldots \ldots \ldots$

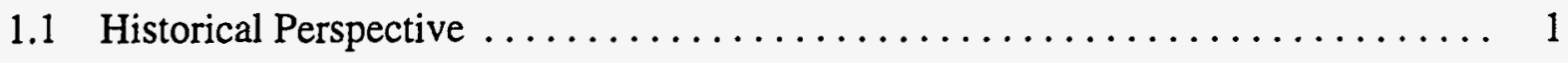

1.2 Report Format and Organization $\ldots \ldots \ldots \ldots \ldots \ldots \ldots \ldots \ldots \ldots \ldots \ldots, 4$

2 DESCRIPTION OF THE SALT LAKE CITY AREA

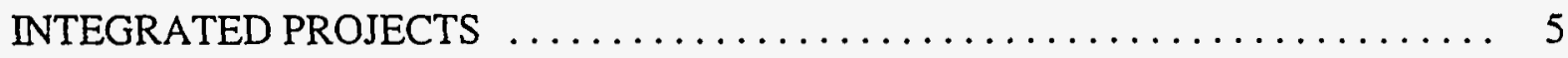

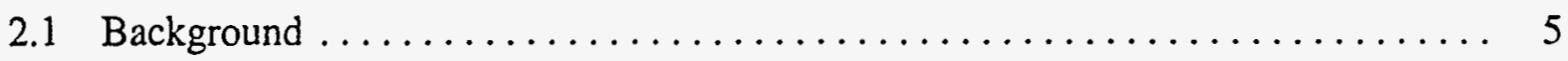

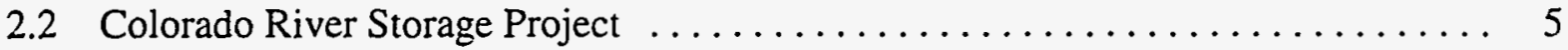

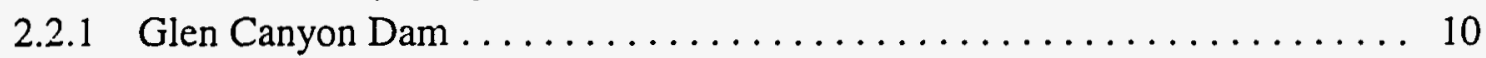

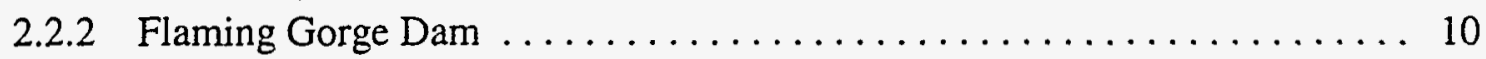

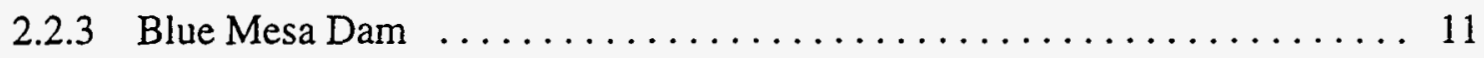

2.2.4 Morrow Point Dam ................................. 11

2.2.5 Crystal Dam ..................................... 11

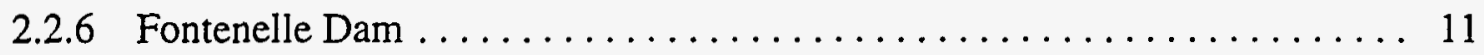

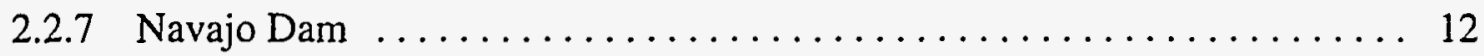

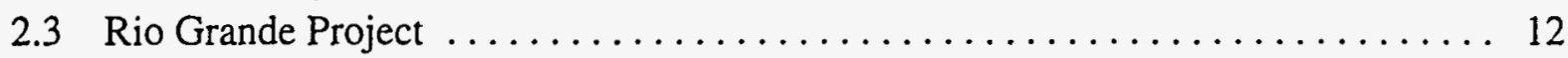

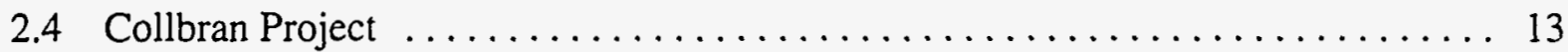

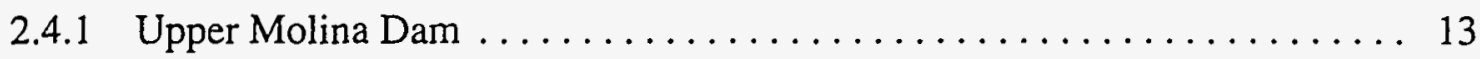

2.4.2 Lower Molina Dam ................................. 13

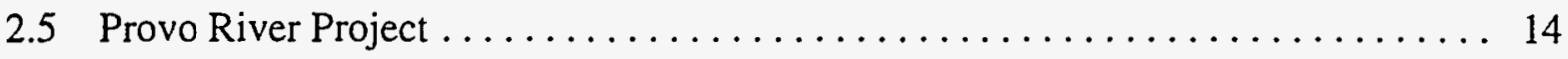

3 DESCRIPTION OF WESTERN'S PROGRAMS $\ldots \ldots \ldots \ldots \ldots \ldots \ldots \ldots \ldots \ldots$

3.1 Statutory Authorities and Agency Discretion $\ldots \ldots \ldots \ldots \ldots \ldots \ldots \ldots \ldots \ldots \ldots$

3.1.1 Primary Federal Power Marketing Policies $\ldots \ldots \ldots \ldots \ldots \ldots \ldots . \ldots \ldots$

3.1.1.1 Preference and the Reclamation Project Act of 1939 ........ 16

3.1.1.2 Widespread Use and the Flood Control Act of 1944 ......... 16

3.1.1.3 Lowest Possible Rate and Sound Business Principles ......... 17

3.1.2 Other Statutory Constraints .......................... 17

3.1.2.1 Administrative Procedures Act $\ldots \ldots \ldots \ldots \ldots \ldots \ldots \ldots \ldots$ 


\section{CONTENTS (Cont.)}

3.1.2.2 Paperwork Reduction Act of $1980 \ldots \ldots \ldots \ldots \ldots \ldots \ldots \ldots$

3.1.2.3 Regulatory Flexibility Act of $1980 \ldots \ldots \ldots \ldots \ldots \ldots \ldots \ldots$

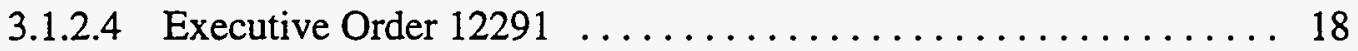

3.2 Obligations Affecting Hydropower Availability $\ldots \ldots \ldots \ldots \ldots \ldots \ldots \ldots \ldots$

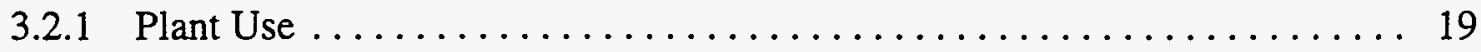

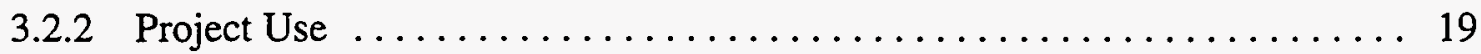

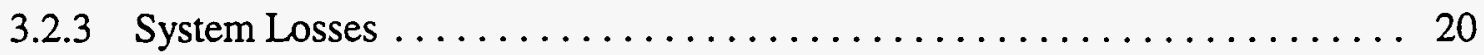

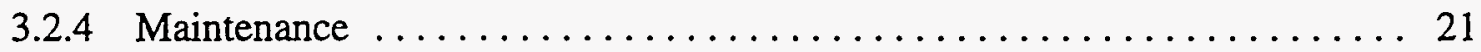

3.2.5 Control Area Functions, Reserves, and Power Pooling $\ldots \ldots \ldots \ldots \ldots 24$

3.2.5.1 Power Pooling ............................. 24

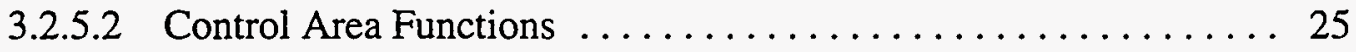

3.2.5.3 Operating Reliability Criteria and Reserves $\ldots \ldots \ldots \ldots \ldots 26$

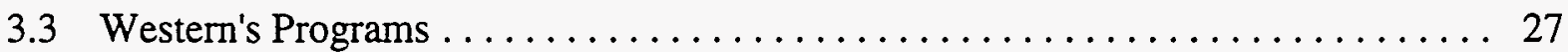

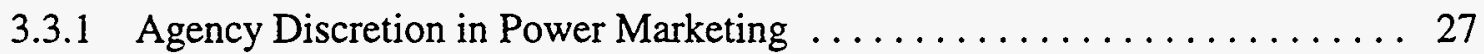

3.3.2 Long-Term Firm Electric Service $\ldots \ldots \ldots \ldots \ldots \ldots \ldots \ldots \ldots \ldots \ldots \ldots$

3.3.3 Short-Term Firm Electric Service $\ldots \ldots \ldots \ldots \ldots \ldots \ldots \ldots \ldots \ldots . \ldots \ldots$

3.3.4 Short-Term Non-Firm Energy Service $\ldots \ldots \ldots \ldots \ldots \ldots \ldots \ldots \ldots \ldots$

3.3.5 Interchange of Energy . . . . . . . . . . . . . . . . . . . . 33

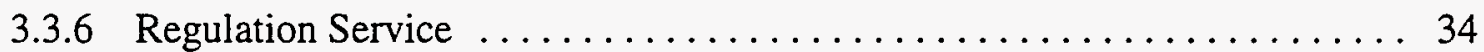

3.3.7 Breakdown or Emergency Service .................... 34

3.3.7.1 Assistance to Non-Independent Power Producers . . . . . . . . . . 34

3.3.7.2 Assistance to Independent Power Producers ............ 35

3.3.8 Firm and Non-Firm Transmission Service ................. 35

3.3.9 Generation Displacement Service: Salt River Project

Exchange Agreement ............................ 37

3.3.10 Conservation and Renewable Energy Program ................ 37

4 HYDROPOWER AUGMENTATION AND MARKETING FIRM

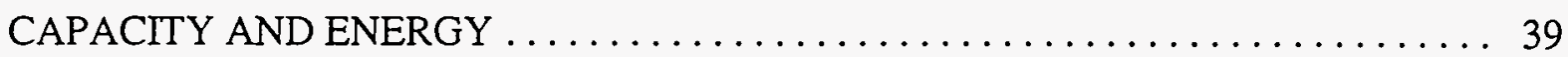

4.1 Historical CRSP Hydropower Variability and Hourly Operations $\ldots . \ldots \ldots \ldots 39$

4.2 Projected SLCA/IP Capacity and Energy Resource Variability ............. 44

4.2.1 CRSP and Seedskedee Hydropower Variability ................. 44

4.2.2 Hydropower Probability Distributions for the Collbran and

Rio Grande Projects ............................ 51

4.2.3 Combined Probability Distributions ..................... 51

4.3 Long-Term Firm Commitments and Hydrovariability ................ 51

4.3.1 Long-Term Firm Capacity Commitments .................... 52 


\section{CONTENTS (Cont.)}

4.3.2 Unscheduled Outages $\ldots \ldots \ldots \ldots \ldots \ldots \ldots \ldots \ldots \ldots \ldots \ldots \ldots \ldots$

4.3.3 Long-Term Firm Energy Commitments $\ldots \ldots \ldots \ldots \ldots \ldots \ldots \ldots \ldots$

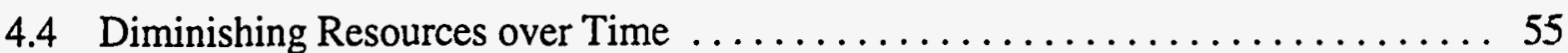

4.5 Monthly Hydrological Variability and Marketing Risks $\ldots \ldots \ldots \ldots \ldots \ldots . \ldots 7$

4.6 Monthly Long-Term Firm Capacity and Energy Allocations ............. 59

5 PURCHASE FLEXIBILITY AND HYDROPOWER OPERATIONS $\ldots \ldots \ldots \ldots \ldots 65$

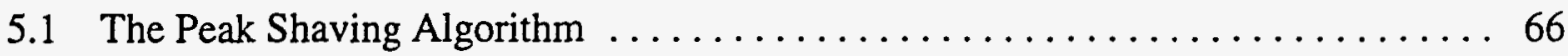

5.2 Purchases for Meeting Long-Term Contracts .................... 67

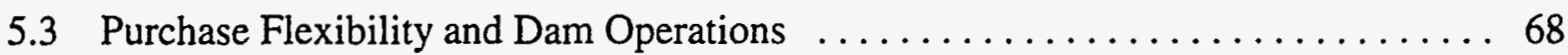

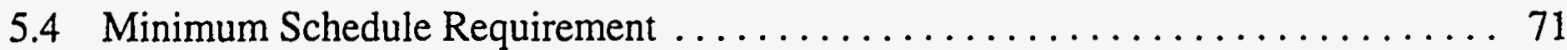

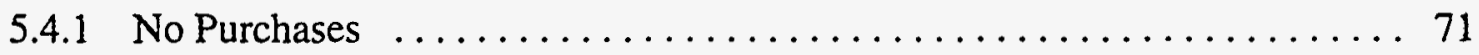

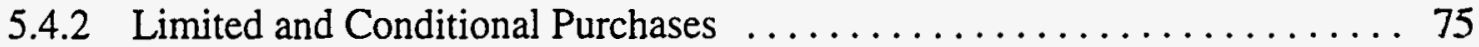

5.5 Effects of Firm Capacity Sales on Hydropower Plant Operations . . . . . . . . . 77

5.5.1 No Spot Market or Reserve Capacity Sales ................... 77

5.5.2 No Spot Market and Reserve Capacity Sales with Baseload Purchases ........................... 78

5.6 Combinations of Minimum Schedule Requirements and Long-Term Firm

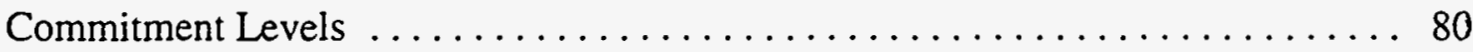

5.7 Maximum Schedule Change $\ldots \ldots \ldots \ldots \ldots \ldots \ldots \ldots \ldots \ldots \ldots \ldots \ldots \ldots \ldots$

5.7 .1 No Purchases .................................. 87

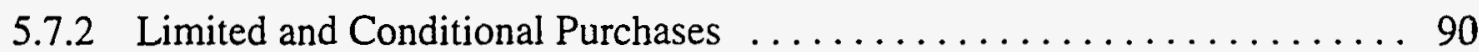

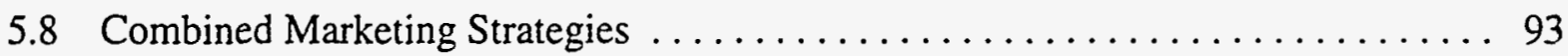

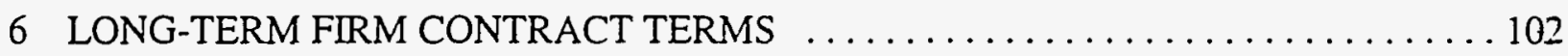

6.1 Modified Pass-through Costs Compared with Blended Costs . ............. 102

6.2 Length of Contract and Contract Adjustment ...................... 103

6.3 North and South Allocations .................................. 103

7 SERVICES PROVIDED BY WESTERN AND SLCA/IP HYDROPOWER

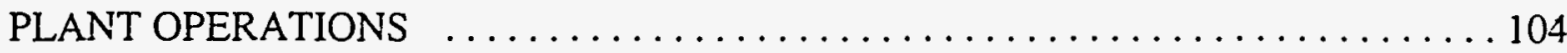

7.1 Area Load Control . ...................................... 104

7.2 Spinning Reserve Requirements and Outage Assistance $\ldots \ldots \ldots \ldots \ldots \ldots \ldots$

7.3 Short-Term Firm Capacity and Energy Commitments ................. 105

7.4 Transmission and Generation Displacement Services $\ldots \ldots \ldots \ldots \ldots \ldots \ldots$ 


\section{CONTENTS (Cont.)}

7.4.1 Contractual Power Flow Model $\ldots \ldots \ldots \ldots \ldots \ldots \ldots \ldots \ldots . \ldots \ldots$

7.4.2 Effects of Transmission Services and Generation Exchanges on Summer Peak Power Flows and Dam Operations ............ 106

7.4.3 Effects of Transmission Services and Generation Exchanges on Summer Off-Peak Power Flows and Dam Operations .......... 110

7.4.4 Effects of Transmission Services and Generation Exchanges on Winter Peak Power Flows and Dam Operations .............. 113

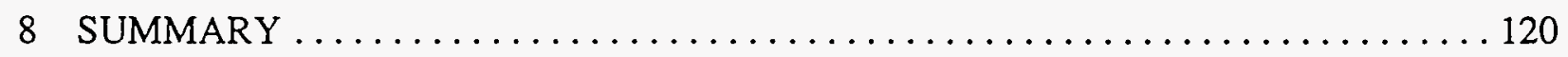

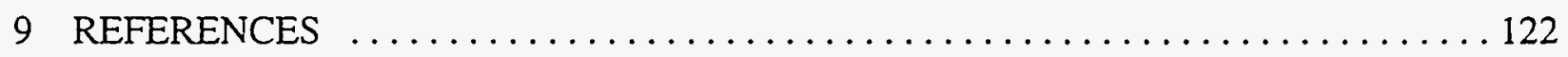

\section{TABLES}

1 Operational Characteristics of SLCA/IP Power Plants $\ldots \ldots \ldots \ldots \ldots \ldots \ldots \ldots$

2 Inland Power Pool Spinning Reserve Requirements $\ldots \ldots \ldots \ldots \ldots \ldots \ldots$

3 Long-Term Firm Capacity by Seasonal Capacity Augmentation Probability

Level under the Load-Following and Resource-Following Methods . . . . . . . . . 62

4 Long-Term Firm Energy by Seasonal Capacity Augmentation Probability Level under the Load-Following and Resource-Following Methods ............ 63

5 Summary of Project Generation for Combinations of Peak and Off-Peak Summer Scenarios ..................................... 114

\section{FIGURES}

1 Location of Salt Lake City Area Integrated Projects $\ldots \ldots \ldots \ldots \ldots \ldots$

2 Five-Year Average of Capacity on Scheduled Annual Routine Maintenance

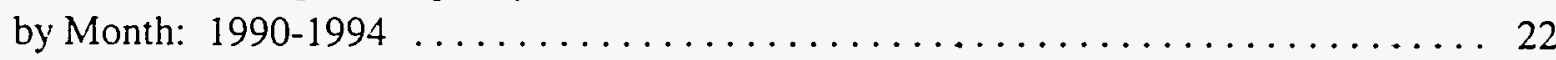




\section{FIGURES (Cont.)}

3 Maximum Weekly Capacity on Scheduled Routine and Nonroutine Maintenance

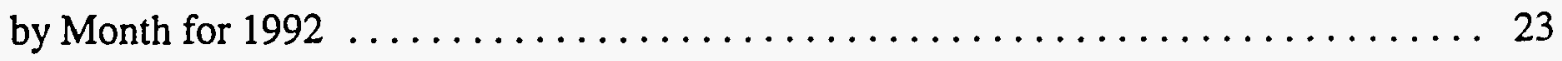

4 Historical Total Electricity Generation for CRSP: $1976-1992 \ldots \ldots \ldots \ldots \ldots \ldots \ldots 40$

5 Historical Hourly Flow Rates under High, Average, and Low Hydropower

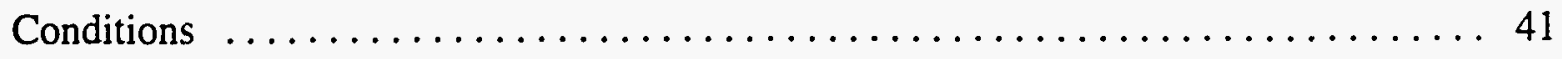

6 Frequency of Weekday Flow Rate Occurrences under Low, Average, and High Hydropower Conditions $\ldots \ldots \ldots \ldots \ldots \ldots \ldots \ldots \ldots \ldots . \ldots \ldots$

7 Frequency of Weekday Flow Rate Occurrences during Low Hydropower

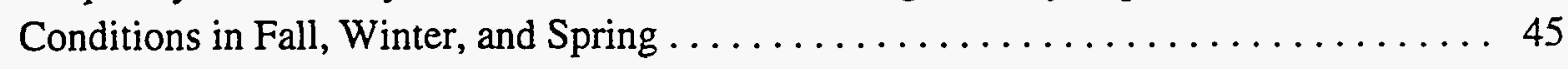

8 Total Hydropower Capacity Exceedance Probability Curves for July ............ 46

9 Total Hydropower Capacity Exceedance Probability Curves for January $\ldots \ldots \ldots 47$

10 Total Energy Production Exceedance Probability Curves for Summer Months . . . . . 48

11 Total Energy Production Exceedance Probability Curves for Winter Months ........ 49

12 Effects of Forced Outage Rates on Availability of Installed Capacity ............. 54

13 Comparison of Total Annual Flow before Dam Construction with Annual Electricity Generation after Dam Construction $\ldots \ldots \ldots \ldots \ldots \ldots \ldots \ldots \ldots$

14 Projected Energy Losses above 1990 Levels Due to Depletion Effects . . . . . . . . . . 57

15 Monthly Total Hydroelectric Capacity and Capacity Augmentation Probability ....... 58

16 Monthly Total Hydroelectric Generation and Energy Augmentation Probability . . . . 60

17 Inputs and Outputs of the Peak Shaving Algorithm $\ldots \ldots \ldots \ldots \ldots \ldots \ldots \ldots \ldots$

18 Hourly SLCA/P Electricity Generation and Sales for $35 \%$ and $50 \%$ Minimum Schedule Requirements . . . . . . . . . . . . . . . . . . . . . 69 


\section{FIGURES (Cont.)}

19 Amount of SLCA/IP Energy Remaining after Serving Minimum Schedule

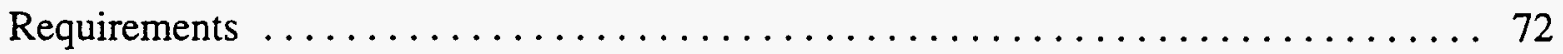

20 Usable SLCA/IP Capacity as a Function of Seasonal Minimum Schedule

Requirements ............................. 74

21 Probability of Energy Augmentation to Meet Long-Term Firm Energy

Commitments when Marketing at 50\% Exceedance Probability Levels

during Summer and Winter $\ldots \ldots \ldots \ldots \ldots \ldots \ldots \ldots \ldots \ldots \ldots \ldots$

22 Maximum Flow Rates from Glen Canyon Dam as a Function of Firm

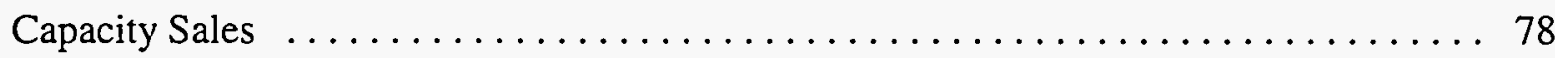

23 Maximum Hourly SLCA Hydroelectric Generation under Wet and Dry

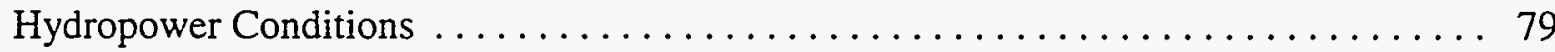

24 Effects of a Minimum Schedule Requirement of $562 \mathrm{MW}$ and an LTF

Capacity Level of $834 \mathrm{MW}$ on the Magnitude and Frequency

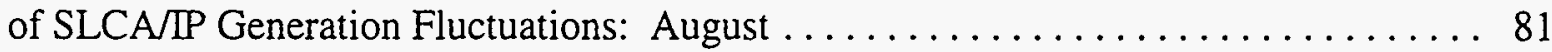

25 Effects of a Minimum Schedule Requirement of $597 \mathrm{MW}$ and an LTF

Capacity Level of $751 \mathrm{MW}$ on the Magnitude and Frequency of

SLCA/IP Generation Fluctuations: August $\ldots \ldots \ldots \ldots \ldots \ldots \ldots \ldots \ldots \ldots \ldots$

26 Effects of a Minimum Schedule Requirement of $626 \mathrm{MW}$ and an LTF

Capacity Level of $700 \mathrm{MW}$ on the Magnitude and Frequency of

SLCA/IP Generation Fluctuations: August $\ldots \ldots \ldots \ldots \ldots \ldots \ldots \ldots \ldots$

27 Effects of a Minimum Schedule Requirement of $652 \mathrm{MW}$ and an LTF

Capacity Level of $782 \mathrm{MW}$ on the Magnitude and Frequency of

SLCA/IP Generation Fluctuations: January $\ldots \ldots \ldots \ldots \ldots \ldots \ldots \ldots \ldots$

28 Effects of a Minimum Schedule Requirement of $672 \mathrm{MW}$ and an LTF

Capacity Level of $754 \mathrm{MW}$ on the Magnitude and Frequency of

SLCA/IP Generation Fluctuations: January $\ldots \ldots \ldots \ldots \ldots \ldots \ldots \ldots \ldots$

29 Effects of a Minimum Schedule Requirement of $690 \mathrm{MW}$ and an LTF

Capacity Level of $728 \mathrm{MW}$ on the Magnitude and Frequency of

SLCA/IP Generation Fluctuations: January 


\section{FIGURES (Cont.)}

30 Maximum Fluctuations in Generation from SLCA $/ P$ by Month under Three Restrictive Marketing Strategies $\ldots \ldots \ldots \ldots \ldots \ldots \ldots \ldots . \ldots 8$

31 Frequency of Baseload Generation from SLCA/IP by Month under Two Restrictive Marketing Strategies

32 On-Peak SLCA/IP Generation as a Function of Maximum Schedule

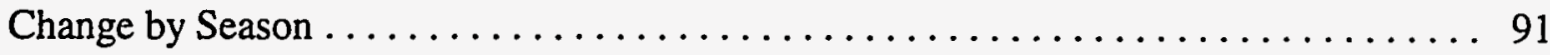

33 Usable SLCA/IP Capacity as a Function of Schedule Change by Season $\ldots \ldots \ldots \ldots 92$

34 Usable SLCA/IP Capacity as a Function of Minimum Schedule Requirement and Firm Capacity Level: Summer $\ldots \ldots \ldots \ldots \ldots \ldots \ldots \ldots$

35 Usable SLCA/IP Capacity as a Function of Minimum Schedule Requirement and Firm Capacity Level: Spring $\ldots \ldots \ldots \ldots \ldots \ldots \ldots \ldots \ldots$

36 On-Peak SLCA/IP Generation as a Function of Minimum Schedule Requirement and Firm Capacity Level: Summer $\ldots \ldots \ldots \ldots \ldots$

37 On-Peak SLCA/P Generation as a Function of Minimum Schedule Requirement and Firm Capacity Level: Spring

38 Usable SLCA/IP Capacity as a Function of Minimum Schedule Requirement and Firm Capacity Level: Summer $\ldots \ldots \ldots \ldots \ldots \ldots \ldots \ldots$

39 On-Peak SLCA/IP Generation as a Function of Minimum Schedule Requirement and Firm Capacity Level: Summer

40 Usable SLCA/IP Capacity as a Function of Minimum Schedule Requirement and Firm Capacity Level: Summer $\ldots \ldots \ldots \ldots \ldots \ldots \ldots \ldots$

41 On-Peak SLCA/IP Generation as a Function of Firm Capacity and Maximum Schedule Change: Summer .

42 CRSP Contractual Power Flow: Summer Peak, Including Transmission Services and Generation Exchanges 


\section{FIGURES (Cont.)}

43 CRSP Contractual Power Flow: Summer Peak, No Transmission Services or Generation Exchanges, and No Limit on the Glen Canyon-Shiprock Transmission Line

44 CRSP Contractual Power Flow: Summer Peak, No Transmission Services or Generation Exchanges, and Limit on the Glen Canyon-Shiprock Transmission Line

45 CRSP Contractual Power Flow: Summer Peak, No Transmission Services or Generation Exchanges, Limit on the Glen Canyon-Shiprock Transmission Line, and All Utah Loads Served through the Southern Utah Substation

46 CRSP Contractual Power Flow: Summer Off-Peak, No Transmission Services or Generation Exchanges

47 CRSP Contractual Power Flow: Winter Peak, Including Transmission Services and Generation Exchanges

48 CRSP Contractual Power Flow: Winter Peak, No Transmission Services or Generation Exchanges, and No Limit on the Glen Canyon-Shiprock

Transmission Line

49 CRSP Contractual Power Flow: Winter Peak, No Transmission Services or Generation Exchanges, and Limit on the Glen Canyon-Shiprock Transmission Line

50 CRSP Contractual Power Flow: Winter Peak, No Transmission Services or Generation Exchanges, Limit on the Glen Canyon-Shiprock Transmission Line, and All Utah Loads Served through the Southern Utah Substation 


\section{NOTATION}

AGC automatic generation control

APA Administrative Procedures Act

BCPA Boulder Canyon Project Act

C\&RE conservation and renewable energy

CROD contract rate of delivery

CRSP Colorado River Storage Project

CRSS Colorado River Simulation System

DOE U.S. Department of Energy

EIS environmental impact statement

IPP Inland Power Pool

LTF long-term firm

NERC North American Electric Reliability Council

NWF National Wildlife Federation

$\mathrm{OMB} \quad$ Office of Management and Budget

PNM Public Service of New Mexico

PTC pass-through cost

SLCA Salt Lake City Area

SLCA/IP Salt Lake City Area Integrated Projects

SRP Salt River Project

STF short-term firm

UP\&L Utah Power and Light Company

USFWS U.S. Fish and Wildlife Service

WAUC Western Area Upper Colorado

WSCC Western System Coordinating Council 


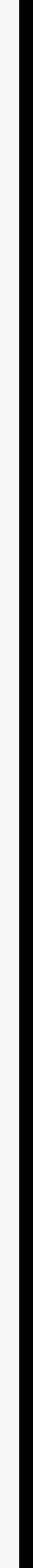




\title{
RELATIONSHIPS BETWEEN WESTERN AREA POWER ADMINISTRATION'S POWER MARKETING PROGRAM AND HYDROPOWER OPERATIONS AT SALT LAKE CITY AREA INTEGRATED PROJECTS
}

\author{
by \\ T.D. Veselka, S. Folga, L.A. Poch, J.J. McCoy, S.C. Palmer, R.G. Whitfield, \\ J.C. VanKuiken, P.H. Kier, A.A. Novickas, and M. Absil
}

\begin{abstract}
This technical memorandum provides background information on the Western Area Power Administration (Western) and the physical characteristics of the Salt Lake City Area Integrated Projects (SLCA/P) hydropower plants, which include the Colorado River Storage Project, the Rio Grande Project, and the Collbran Project. In addition, the history, electrical capacity, storage capacity, and flow restrictions at each dam are presented. An overview of Western's current programs and services, including a review of statutory authorities, agency discretion, and obligations, is also provided. The variability of SLCA/P hourly generation under various alternative marketing strategies and purchasing programs is discussed. The effects of Western's services, such as area load control, outage assistance, and transmission, on SLCA/IP power plant operations are analyzed.
\end{abstract}

\section{INTRODUCTION}

\subsection{HISTORICAL PERSPECTIVE}

The Western Area Power Administration (Western) is a power marketing organization within the U.S. Department of Energy (DOE). It was created in 1977 by the DOE Organization Act (42 USC 7152), which transferred power marketing and transmission functions associated with federal hydroelectric projects from the Secretary of the Interior (acting through the Bureau of Reclamation [Reclamation]) to the Secretary of Energy (acting through Western) (DOE 1990). The transfer of power marketing and transmission functions was further defined in a formal Memorandum of Understanding between Reclamation and Western, dated March 1980. 
Western allocates long-term firm (LTF) capacity and energy from the Colorado River Storage Project (CRSP), the Collbran Project, and the Rio Grande Project, known collectively as the Salt Lake City Area Integrated Projects (SLCA/IP). In addition, Western also markets capacity and energy from the Provo River Project. Marketing criteria instituted by Western provide an overview of LTF contracts and other services, including short-term firm (STF), firm, and non-firm transmission; maintenance or breakdown coverage; economy energy and fuel replacement; interchanges; area load control; and emergency assistance. The criteria also address the allocation methods to be used in determining individual allocations of power from SLCA/IP.

The following is a summary of the developments that led Western to prepare an environmental impact statement (EIS) on proposed power marketing criteria that were to be in effect from October 1, 1989, through September 30,2004. These power marketing criteria were published in DOE (1986a).

In December 1985, Western published an environmental assessment (DOE 1985a) concerning the potential environmental and socioeconomic impacts of implementing revised power marketing criteria. The assessment concentrated on estimated changes in retail rates and consumption at the consumer level. No physical impact was identified. DOE determined that these criteria would have no significant environmental impact. The environmental assessment and the Finding of No Significant Impact were approved on January 6, 1986.

In October 1986, the Utah Power and Light Company (UP\&L) and more than 150 of its full-service customers filed suit against Western in the U.S. District Court in Salt Lake City, Utah, before Judge Thomas Greene. The principal complaints by UP\&L and its co-plaintiffs related to the following areas:

- Western's decisions regarding allocation of SLCA/IP resources and the constitutionality of the preference provisions of federal reclamation law;

- Western's authority to purchase supplemental power; and

- Western's decision to prepare an environmental assessment rather than an EIS.

In April 1988, Judge Greene issued a decision resolving 15 of 17 issues in favor of Western as a matter of law. However, the court did not rule on the environmental claim, which was reserved for a full trial. A settlement was reached among UP\&L, its co-plaintiffs, and Western to dismiss the outstanding environmental and lack-of-authority claims in the district court, as well as the appeal to the Tenth Circuit Court.

In December 1988, the National Wildlife Federation (NWF) and several other environmental groups filed suit against Western, raising the same environmental issues as those 
raised by UP\&L. In February 1989, Western sought permission from the court to execute post-1989 power contracts. The court ruled in Western's favor, authorizing execution of the contracts with a reopener clause. This reopener clause permits the contract power allocations to be modified on the basis of later decisions made by Western. By April 1989, Western had executed all 81 power contracts. The court ordered a trial on the environmental issue to begin in late September 1989.

On September 18, 1989, Western announced that it would prepare an EIS on its post-1989 marketing criteria, following the August 1989 announcement by Reclamation that an EIS would be prepared on Glen Canyon Dam operations. With Western's decision to prepare an EIS, the scheduled trial before Judge Greene became a hearing on the NWF's motion for an injunction to halt execution of the post-1989 power contracts.

The court further issued an Order of Injunction on September 29, 1989, that accomplished the following:

- It halted the post-1989 marketing plan and contracts.

- It required Western to extend its existing power contracts (new customers added after October 1989 would be served on a short-term basis).

- It required preparation of an interim marketing plan and submission of the plan to the court for approval. The plan would not materially increase the level of LTF power marketed under the pre-1989 marketing criteria, and it would also "maintain the status quo as to water release patterns" under existing contractual arrangements.

Judge Greene also imposed several conditions on Western during the preparation of its EIS. Those conditions included a requirement that Western address the cumulative impacts of the post-1989 criteria on the environment and operations of CRSP dams, as well as alternatives to current operations.

In October 1989, an abbreviated public process was held regarding the development of alternative allocation approaches to accomplish the directives of the court order. On November 1, 1989, the interim marketing plan was submitted to the court. On November 22, 1989, Judge Greene issued an additional court order that accomplished the following:

- It accepted Western's interim marketing plan, which reflected a proportional reduction in individual allocations from the post-1989 to the pre-1989 commitment levels. 
- It imposed a revised reopener clause in power contracts.

- It reiterated the requirement that Western's EIS address cumulative impacts.

By December 1, 1989, approximately 80 long-term power contracts were modified to reflect the adjusted commitment level and to incorporate the revised court-approved reopener clause.

\subsection{REPORT FORMAT AND ORGANIZATION}

Section 2 of this technical memorandum provides background information on Western and the Salt Lake City Area (SLCA) Office. The section characterizes the Colorado River, its tributaries, and the SLCA/IP, which includes the CRSP, the Rio Grande Project, and the Collbran Project. In addition, the history, electrical capacity, storage capacity, and minimum and maximum flows for each dam are given.

Section 3 provides an overview of Western's current programs and services, including a review of statutory authorities, agency discretion, and obligations. Section 4 discusses SLCA/IP hydropower variability and other uncertainties in conjunction with LTF marketing programs. Sections 5 and 6 present a preliminary analysis of the effects of various alternative marketing strategies and purchasing programs on SLCA/IP operations. The effects of Western's services, such as area load control, outage assistance, and transmission, on SLCA/IP power plant operations are presented in Section 7. A summary is provided in Section 8. 


\section{DESCRIPTION OF THE SALT LAKE CITY AREA INTEGRATED PROJECTS}

\subsection{BACKGROUND}

Western's SLCA Office is responsible for the marketing of power from the CRSP, Collbran, Rio Grande, and Provo River Projects and from the Falcon and Amistad Dams. The SLCA/IP market area includes all or parts of six states and is divided into two divisions: Northern (Utah, Wyoming, New Mexico, and Colorado) and Southern (Arizona and Nevada). Figure 1 shows the locations of the dams. Before Western's creation in 1977, Reclamation marketed power from these projects in a different way.

As the CRSP storage units and hydroelectric generation facilities were constructed, CRSP hydroelectric resources were marketed through formal marketing criteria established by Reclamation. The marketing criteria allocated LTF electric service contracts in the early 1960s. When additional hydroelectric facilities were completed in the late 1970s, Reclamation allocated more peaking power to certain existing firm power customers.

The Collbran Project was authorized in 1952 and has been in service since 1962. Reclamation sold its entire output to a single customer, the Colorado-Ute Electric Association. Power generated from the Rio Grande Project became available in 1940 and was sold by Reclamation to two regional utilities: Plains Electric Generation and Transmission and the City of Truth or Consequences. All these firm electric service contracts expired in September 1989.

The following sections briefly describe the projects that make up SLCA/PP. Table 1 gives characteristics of the projects, including plant capacity, reservoir storage capacity, and maximum and minimum flow restrictions.

\subsection{COLORADO RIVER STORAGE PROJECT}

The source of the Colorado River is in the mountains of Colorado. The river flows generally southwest for approximately 1,450 miles through Colorado, Utah, and Arizona and along the Arizona-Nevada and Arizona-California boundaries before entering Mexico and emptying into the Gulf of California. Its arid basin, approximately one-twelfth the area of the contiguous United States, with boundaries defined by tributaries originating in Wyoming, Colorado, Utah, Nevada, New Mexico, and Arizona, has depended on water management practices to mitigate the effects of erratic river flow's. 


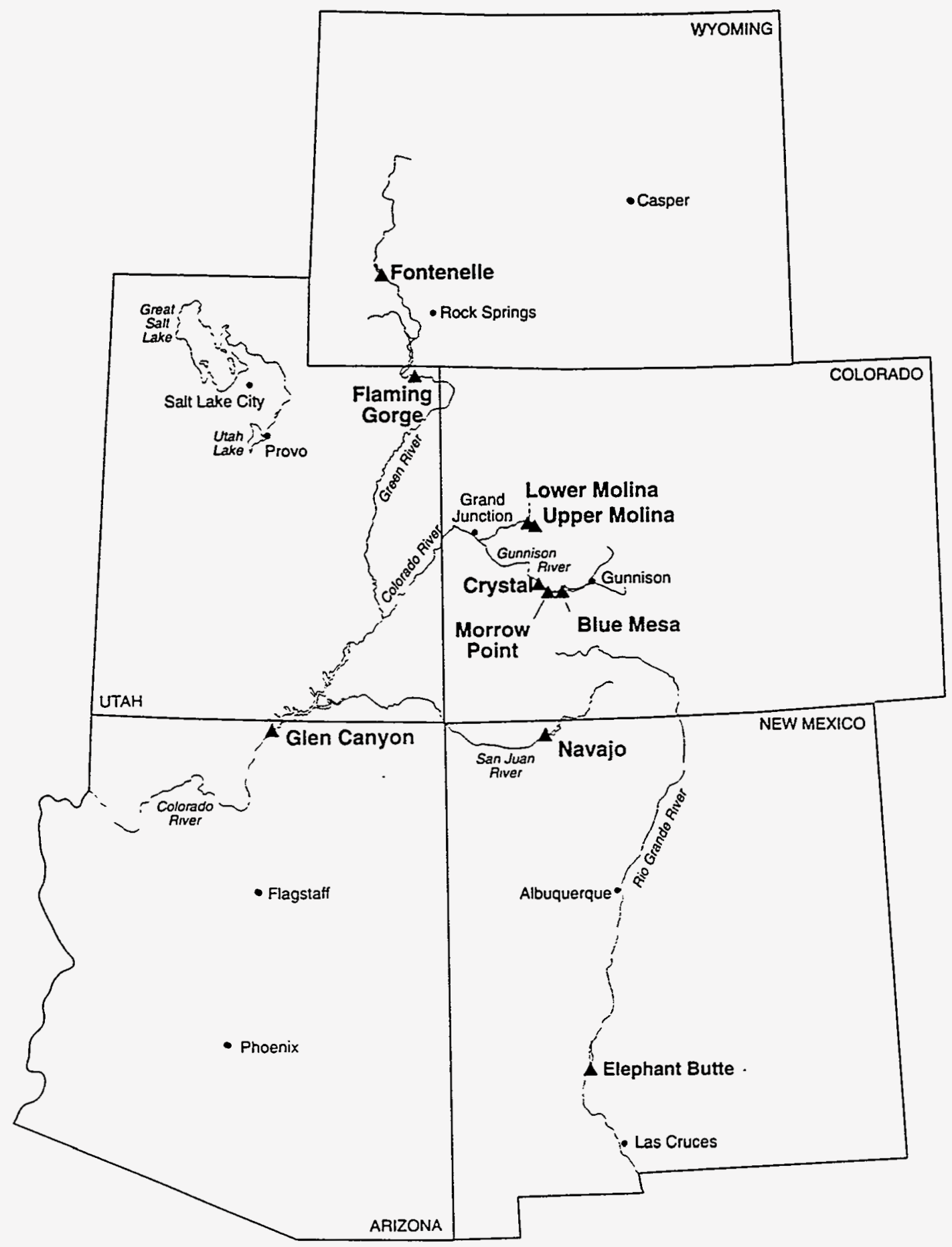

FIGURE 1 Location of Salt Lake City Area Integrated Projects 
TABLE 1 Operational Characteristics of SLCA/IP Power Plants

\begin{tabular}{|c|c|c|c|c|c|c|c|c|}
\hline Plant Name & $\begin{array}{l}\text { Number } \\
\text { of Units }\end{array}$ & $\begin{array}{l}\text { Total } \\
\text { Generating } \\
\text { Capacity } \\
\text { (MW) }\end{array}$ & $\begin{array}{l}\text { Total } \\
\text { Storage } \\
\text { Capacity } \\
\text { (million } \\
\text { acre-feet) }\end{array}$ & $\begin{array}{l}\text { Live } \\
\text { Storage } \\
\text { Capacity } \\
\text { (million } \\
\text { acre-feet) }\end{array}$ & $\begin{array}{c}\text { 10-Year } \\
\text { Average } \\
\text { (1980-1990) } \\
\text { Gross } \\
\text { Generation } \\
\text { (MWh) }\end{array}$ & $\begin{array}{c}\text { Minimum } \\
\text { Flow below } \\
\text { Power Plant } \\
\left(\mathrm{ft}^{3} / \mathrm{s}\right)\end{array}$ & $\begin{array}{l}\text { Maximum } \\
\text { Power } \\
\text { Release } \\
\left(\mathrm{ft}^{3} / \mathrm{s}\right)\end{array}$ & $\begin{array}{l}\text { Under } \\
\text { AGC }\end{array}$ \\
\hline Glen Canyon & 8 & $1,300^{\mathrm{z}}$ & 27 & 25 & $5,800,000$ & $\begin{array}{r}3,000 \\
\text { in summer, } \\
1,000 \\
\text { in winter }\end{array}$ & $31,500^{\mathrm{a}}$ & Yes \\
\hline Flaming Gorge & 3 & 145 & 3.79 & 3.75 & 540,000 & 800 & $4,900^{b}$ & Yes \\
\hline Blue Mesa & 2 & 96 & 0.941 & 0.829 & 292,000 & 0 & 3,000 & Yes \\
\hline Morrow Point & 2 & 146 & 0.117 & 0.117 & 398,000 & 0 & 5,000 & Yes \\
\hline Crystal & 1 & 28 & 0.025 & 0.018 & 189,000 & 300 & 1,700 & Yes \\
\hline Fontenelle & 2 & 13 & 0.345 & 0.151 & 39,200 & 400 & 1,700 & No \\
\hline Navajo & 0 & 0 & 1.71 & 1.70 & 0 & - & - & No \\
\hline Elephant Butte & 3 & 24 & 2.105 & 2.109 & 112,000 & 0 & 2,250 & No \\
\hline Upper Molina & 1 & 9 & 0 & 0 & 37,000 & $N A^{c}$ & $\mathrm{NA}$ & Yes \\
\hline Lower Molina & 1 & 5 & 0 & 0 & 22,000 & NA & $\mathrm{NA}$ & Yes \\
\hline \multicolumn{9}{|c|}{$\begin{array}{l}\text { a Installed capacity is } 1,356 \mathrm{MW} \text {. Capacity has been limited to } 1,300 \mathrm{MW} \text { because the maximum power release was limited to } \\
31,500 \mathrm{ft}^{3} / \mathrm{s} \text {. With interim test release constraints, capaciry is limited to } 740 \mathrm{MW} \text { at present reservoir elevations with a maximum release } \\
\text { of } 20,000 \mathrm{ft}^{3} / \mathrm{s} \text {. Interim test release minimum is } 5,000 \mathrm{ft}^{3} / \mathrm{s} \text { at night and } 8,000 \mathrm{ft}^{3} / \mathrm{s} \text { from 7:00 a.m. to 7:00 p.m. }\end{array}$} \\
\hline \multicolumn{9}{|c|}{$\begin{array}{l}\text { belease limit is about } 2,400 \mathrm{ft}^{3} / \mathrm{s} \text {. Under biological flow restrictions, however, maximum and minimum release limits vary significantly } \\
\text { according to time of year and hydropower conditions. }\end{array}$} \\
\hline
\end{tabular}

Rapid development of the basin at the end of the 19th century made it clear that storage dams, canals, and irrigation and electric power projects requiring the financial and engineering resources of the federal government were needed to make the basin productive and habitable. Inhibiting the development of federal projects, however, was a concern for the way the beneficial use of Colorado River water would be apportioned between the states of the Upper Basin (Wyoming, Colorado, Utah, and New Mexico) and the states of the Lower Basin (Arizona, Nevada, and California). Because the prevailing water law of the basin states was passed prior to appropriation ("first in time, first in right") rather than through riparian rights or equitable allotment, the Upper Basin states feared that surplus water stored by federal projects would initially be diverted to the more rapidly growing Lower Basin states, especially California, and that under the prior appropriation theory, the surplus waters would permanently be appropriated for use by the Lower Basin states. Therefore, interstate compacts governing the use of Colorado River water were needed.

The first such agreement, the Colorado River Compact, came in 1922. The compact did not allocate the waters on a state-by-state basis but did divide the basin into two parts: the Lower Basin and the Upper Basin. The Upper Basin and the Lower Basin were each apportioned the exclusive 
beneficial consumptive use of 7.5 million acre-feet of water per year. The dividing point (also called the compact point) on the Colorado River running between the basins was Lee's Ferry in northernmost Arizona. In addition, the Lower Basin was given the right to increase this apportionment by as much as 1 million acre-feet in any given year. However, the most important operating provision in the compact was the required delivery at the compact point of 75 million acrefeet for any period of 10 consecutive years. This delivery requirement has been strictly followed and is not likely to change in the future. Article IV9(b) of the compact provides that the impoundment and use of the waters for the generation of electrical power shall be subservient to the use and consumption of such water for agricultural and domestic purposes.

The next act to affect the Colorado River was the 1928 Boulder Canyon Project Act (BCPA), which authorized construction of Boulder Dam (now Hoover Dam) and other projects in the Lower Basin for flood control, reclamation, and hydroelectric power. It further provided congressional consent to the Colorado River Compact (but only if California and five of the other seven states agreed). This act required California to pass the California Limitation Act, March 4, 1929, which limited consumptive use to 4.4 million acre-feet of the 7.5 million acre-feet apportioned to the Lower Basin states, plus no more than half of any surplus. The BCPA also provided the following:

- Protection of the Upper Basin against unlimited development in the Lower Basin,

- Assurance that the Colorado River Compact would not be nullified,

- Requirement of a 50-year period for repayment for the construction of the project,

- Creation of the Colorado River Dam Fund,

- Disposition of energy by contract to preference entities, and

- Allocation of mainstream waters among the Lower Basin states, thereby resolving one hindrance to the development of Lower Basin resources.

Lower Basin resources developed rapidly with the construction of Parker and Davis Dams pursuant to the Boulder Canyon Adjustment Act of 1940. These dams and reservoirs provide water and power for Los Angeles and San Diego and for extensive agricultural districts in southern California and Arizona. However, development in the Upper Basin proceeded more slowly. Although the Colorado River was committed to deliver 16.5 million acre-feet, its annual flow has averaged only 14 million acre-feet since 1930 . Because of this erratic flow, it was impractical to 
meet the annual 7.5 million acre-feet obligation to the Lower Basin states without river control on a long-term basis. Holdover storage reservoirs were also needed because periods of high flow normally do not occur when demand is greatest. In addition, a 1944 treaty with Mexico guaranteed that country 1.5 million acre-feet of water per year.

With the ratification of the 1948 Upper Colorado River Basin Compact, which apportioned the consumptive use of the Upper Basin allocation among Arizona, Colorado, New Mexico, Utah, and Wyoming, a significant barrier to development of Upper Basin water resources was removed. The consumptive use of Colorado River water was fully apportioned among the states, and the stage was set for the CRSP, which authorized construction of projects for flood control, reclamation, extended irrigation, municipal and industrial water needs, and hydroelectric power.

The CRSP was authorized by a special congressional act on April 11, 1956. The purpose of the act was to develop the water resources of the Upper Basin. It provided a comprehensive, multiple-purpose, basinwide water resource development plan. The legislation authorized development of facilities for land reclamation, flood control, and hydroelectric power generation. Four storage projects were designated to regulate stream flows so that water commitments to the Lower Basin could be met in dry periods without curtailing the development of water resources apportioned to the Upper Basin, and to provide hydroelectric power and produce revenues to assist in the repayment of the participating projects. The act also authorized 11 participating projects for irrigation and related uses and established the Upper Colorado River Basin Fund. It further required that the hydroelectric plants and transmission lines be operated in conjunction with other federal power plants to produce the greatest practicable amount of firm power and energy that could be sold at firm power and energy rates, in consistence with laws and without impairing the use of the project for domestic and irrigation purposes. In addition, as stated in Section 8, 43 USC 620g, the Secretary of the Interior (now Western) is

... authorized and directed to investigate, plan, construct, operate, and maintain (1) public recreation facilities on lands withdrawn or acquired for the development of said project or of said participating projects, to conserve the scenery, the natural, historic, and archaeologic objects, and the wildlife of said lands, and to provide for public use and enjoyment of the same and of the water areas created by these projects by such means with the primary purposes of said projects; and (2) facilities to mitigate losses of, and improve conditions for, the propagation of fish and wildlife.

The CRSP consists of four storage units: Glen Canyon on the Colorado River in Arizona near the Utah border, Flaming Gorge on the Green River in Utah near the Wyoming border, Navajo on the San Juan River in New Mexico near the Colorado border, and Wayne N. Aspinall (formerly Curecanti) on the Gunnison River in west central Colorado. The Blue Mesa, Morrow Point, and Crystal power plants are associated with Aspinall. These projects regulate the flow of the Colorado 
River in such a way that irrigation, municipal, industrial, and other water uses in the Upper Colorado River Basin can be developed while water deliveries to the Lower Basin are maintained as required by the Colorado River Compact. Table 1 summarizes the operational characteristics of these plants.

\subsubsection{Glen Canyon Dam}

Reclamation built the Glen Canyon Dam on the Colorado River between 1956 and 1964. The total storage capacity of the reservoir is 27 million acre-feet, of which 25 million acre-feet is live storage capacity (to generate power). The eight generating units at the power plant initially had a combined total installed capacity of $1,160 \mathrm{MW}$; the first two units began generating power in September 1964, and the eighth unit came on-line in February 1966. Each unit was rewound and uprated by April 1987; approximately $200 \mathrm{MW}$ of additional capacity was installed at the power plant, which increased the generating capacity to approximately $1,356 \mathrm{MW}$. At that time, the maximum water release through the generators was about $33,000 \mathrm{ft}^{3} / \mathrm{s}$. However, in response to public concern, the maximum release has been administratively restricted to $31,500 \mathrm{ft}^{3} / \mathrm{s}$ (with a maximum operable capacity of 1,300 MW at full reservoir) until impacts associated with uprated unit performance and dam operations are completely analyzed in the ongoing environmental studies.

On August 1, 1991, Reclamation imposed interim test release constraints at Glen Canyon. These constraints further limited the maximum release rate at Glen Canyon Dam to $20,000 \mathrm{ft}^{3} / \mathrm{s}$, effectively reducing the maximum operable capacity to approximately $740 \mathrm{MW}$ at the present reservoir elevation. Hydropower conditions at Glen Canyon Dam are currently very dry; therefore, operable capacity under the interim test release is low. Under most hydropower conditions, the interim test release at Glen Canyon reduces the operational capacity to about $40 \%$ below the total installed capacity. Before these test releases, Glen Canyon constituted nearly $75 \%$ of the entire generating capacity of the CRSP.

From 1980 (when Lake Powell was filled for the first time) through 1990, the average annual gross generation at the Glen Canyon power plant was approximately 5,800,000 MWh. The minimum generation associated with the minimum annual objective release of 8.23 million acre-feet is approximately $3,700,000 \mathrm{MWh}$ at present reservoir elevations.

\subsubsection{Flaming Gorge Dam}

Built on the Green River in Utah, Flaming Gorge Dam created Flaming Gorge Reservoir. It has a total reservoir storage capacity of 3.79 million acre-feet, of which 3.75 million acre-feet is live storage capacity. Flaming Gorge has three generating units that came on-line in November 1963, which together had a maximum total generating capacity of $132 \mathrm{MW}$. Each of the three 44-MW units was uprated to about $52 \mathrm{MW}$ of rated capacity about 3 years ago; the total plant capacity has thereby 
been increased to $156 \mathrm{MW}$. From 1980 to 1990 , the average annual gross generation was approximately $540,000 \mathrm{MWh}$.

The Biological Opinion has significantly changed the operation of Flaming Gorge to protect endangered fish species below this dam. More detailed information is provided in Yin et al. (1995). However, when this study was conducted, the Biological Opinion had not yet been formulated; therefore, this analysis does not include Biological Opinion constraints.

\subsubsection{Blue Mesa Dam}

The Blue Mesa Dam is part of the Aspinall Project, which is on the Gunnison River in west central Colorado. The power plant began generating power in September 1967. It consists of two generating units, which together have a total capacity of $96 \mathrm{MW}$. The two 36-MW units were uprated to the present $48 \mathrm{MW}$ in 1989. From 1980 to 1990 , the average annual gross generation was approximately $292,000 \mathrm{MWh}$. The Blue Mesa Reservoir has a total storage capacity of 940,800 acrefeet, of which more than 829,000 acre-feet is live storage.

\subsubsection{Morrow Point Dam}

The Morrow Point Dam is also part of the Aspinall Project. The power plant began generating power in December 1970 and consists of two units, which together had a total capacity of $146 \mathrm{MW}$. One 73-MW unit was uprated to $86 \mathrm{MW}$, adding $13 \mathrm{MW}$ to the plant capacity. From 1980 to 1990 , the average annual generation was approximately $398,000 \mathrm{MWh}$. The Morrow Point Reservoir has a total storage capacity of 117,190 acre-feet, of which 117,025 acre-feet is live storage.

\subsubsection{Crystal Dam}

The third power plant of the Aspinall project is located at the Crystal Dam. This power plant has one 28-MW unit, which began generating power in August 1978. The Crystal Reservoir has a total storage capacity of 25,273 acre-feet, of which 17,573 acre-feet is live storage. The reservoir serves as a reregulation structure for Morrow Point releases to the Gunnison River. From 1980 to 1990 , the average annual generation was approximately $189,000 \mathrm{MWh}$.

\subsubsection{Fontenelle Dam}

Fontenelle Dam is on the Green River in Wyoming. The Fontenelle power plant, which is part of the Seedskedee Project, consists of two units, which together have a maximum total operating 
capacity of $13 \mathrm{MW}$. Fontenelle Dam created the Fontenelle Reservoir, which has a total storage capacity of 345,000 acre-feet. From 1980 to 1990, the average annual gross generation was approximately 39,200 MWh. However, because of dam repair, no generation was available from 1986 through 1988 . The long-term average annual gross generation (1968-1990) was 52,000 MWh.

\subsubsection{Navajo Dam}

The Navajo Dam is on the San Juan River in New Mexico near the Colorado border. The dam created the Navajo Reservoir, which has a total storage capacity of 1.71 million acre-feet, of which 1.70 million acre-feet is live storage. The City of Farmington has constructed a two-unit 32-MW power plant at this site.

\subsection{RIO GRANDE PROJECT}

The Rio Grande Project is located $125 \mathrm{mi}$ north of El Paso, Texas. It was initiated in February 1905 when a congressional act (Rio Grande Reclamation Project, February 25, 1905) established a much-needed irrigation project on the Rio Grande River in south central New Mexico and west Texas. The only dam with generating facilities at the Rio Grande Project is Elephant Butte Dam, which was completed in 1916. The power plant (constructed after completion of the Caballo Dam, approximately $25 \mathrm{mi}$ downstream) began generating power in 1940. It consists of three generating units (8.1 MW per unit), which together have a total operable capacity of approximately 24 MW. From 1980 to 1990 , the average annual generation was approximately $112,000 \mathrm{MWh}$. Table 1 summarizes the operational characteristics of the Elephant Butte plant.

Day-to-day operations and seasonal water planning activities at the plant are performed by Reclamation personnel. The monthly and yearly operations and release strategies are governed by water movement and storage for downstream irrigation requirements. Hourly, weekly, and even monthly operations can be influenced by power and energy demands. The units are generally block loaded at their most efficient operating point, and CRSP provides firming interchange and/or accepts

excess generation. However, Western's Montrose District Office has requested special operating patterns to provide reserves, relieve transmission problems, or coordinate with the generation patterns of CRSP plants. In this manner, the two projects (CRSP and Rio Grande) are integrated. The Rio Grande Project has also been included in the Inland Power Pool (IPP) resources for the Upper Colorado control area since the beginning of IPP. 


\subsection{COLLBRAN PROJECT}

The Collbran Project, located in west central Colorado about $35 \mathrm{mi}$ northeast of Grand Junction, was authorized by Congress in July 1952 (Collbran Project Act, July 3, 1952). The project consists of the Vega Dam, located in the Colorado Rocky Mountains on Plateau Creek, and it stores 34,000 acre-feet of water. The project develops a major part of the unused water of Plateau Creek and its principal tributaries for irrigation as well as for flood control and recreational, fish, and wildlife uses. It includes several diversion dams, $34 \mathrm{mi}$ of canal, $18 \mathrm{mi}$ of pipeline, and two power plants: Upper Molina and Lower Molina. Table 1 summarizes the operational characteristics of these plants.

Day-to-day operations are coordinated by Reclamation's Grand Junction Projects Office, which oversees the water movement from upstream reservoirs. Normal operations endeavor to generate a minimum of 3,350 MWh/mo from scheduled releases of 950 acre-feet/mo and to move sufficient water to minimize spills (i.e., nonpower water releases). From mid-May to mid-July, plants are block loaded around the clock at maximum capacity, which corresponds to 2,780 acre-feet/mo or 9,800 MWh/mo. The power plants are operated during other months from 8:00 a.m. Monday through 4:00 p.m. Friday at the point of best efficiency (approximately $10 \mathrm{MW}$ ). Capacity and energy are scheduled by Western's Montrose District Office to best coordinate with energy needs; CRSP firms the schedule if the Molina plants are not generating according to the schedule. The project operations have been integrated since about 1969.

\subsubsection{Upper Molina Dam}

The Upper Molina Dam power plant consists of one generating unit with a total operating capacity of $9 \mathrm{MW}$ (one unit at $8,640 \mathrm{~kW}$ ). The penstock has a maximum capacity of $50 \mathrm{ft}^{3} / \mathrm{s}$. The power plant has an effective head of 2,490 feet. The plant began generating power in December 1962 and was operated as a run-of-river plant. However, since May 1993, it has been operated as a peaking power plant. From 1980 to 1990, the average annual gross generation was approximately 37,000 MWh.

\subsubsection{Lower Molina Dam}

The Lower Molina Dam power plant consists of one generating unit with a total operating capacity of $5 \mathrm{MW}$ (one unit at $4,860 \mathrm{~kW}$ ). The penstock has a maximum capacity of $50 \mathrm{ft}^{3} / \mathrm{s}$. The power plant has an effective head of 1,400 feet. This plant began generating power in December 1962 and was operated as a run-of-river plant. However, since May 1993, it has been operated as a peaking power plant. From 1980 to 1990 , the average annual gross generation was approximately 22,000 MWh. 


\subsection{PROVO RIVER PROJECT}

Western is also responsible for marketing capacity and energy from the Provo River Project. This project consists of one small power plant, Deer Creek, which has a maximum output capacity of approximately $5 \mathrm{MW}$. Annual generation for Deer Creek is about $25 \mathrm{GWh}$. 


\section{DESCRIPTION OF WESTERN'S PROGRAMS}

This section describes current SLCA Office power marketing programs. The statutory constraints and other obligations that govern these programs are also reviewed.

\subsection{STATUTORY AUTHORITIES AND AGENCY DISCRETION}

In August 1977, Congress passed the DOE Organization Act, which transferred the power marketing function from Reclamation to Western, including the construction, operation, and maintenance of transmission lines and attendant facilities. In March 1980, Western and Reclamation (then the Water and Power Resource Service) entered into an agreement that defined the transfer of functions and property and the division of responsibilities between these agencies following the enactment of Public Law 95-91.

In consistence with the law and as defined in the 1980 agreement, Western has the following responsibilities:

- Planning, designing, constructing, operating, and maintaining the transmission system;

- Marketing the excess federal power; and

- Setting power rates to ensure sufficient revenues to repay all the allocated investment.

Western is also responsible for all power dispatch functions, such as the assignment of load to specific generating stations and other sources of supply, provided these functions are carried out within water and operating constraints set by Reclamation. Western also agreed to provide transmission, switching, necessary wheeling arrangements, and substation service to Reclamation's projects, including project use power. In executing these responsibilities, Western relies on certain federal power marketing policies that provide a framework for Western programs.

\subsubsection{Primary Federal Power Marketing Policies}

Section 302 of the DOE Organization Act provides that Reclamation's power marketing functions shall be carried out by the administrator of a "separate and distinct administration." The authority residing in the administrator resulting from this act was further defined in Western 
Order 6120.1, Power Marketing Policy, Functions, and Dèlegation (November 30, 1987), and detailed in Western's Power Marketing Policy Guidelines and Procedures, March 1988.

According to Section 4 of Western's Power Marketing Policy Guidelines and Procedures, the primary power marketing policies are defined as follows:

Within very broad statutory guidelines, Western has wide discretion as to whom and on what terms it will contract for the sale of Federal power as long as preference is accorded to statutorily defined public bodies. Sales of power cannot impair the efficiency of the project for irrigation purposes. Power must be sold in such a manner as will encourage the most widespread use at the lowest possible rates consistent with sound business principles. Discretion may be limited by the provisions of project-specific legislation.

\subsubsection{Preference and the Reclamation Project Act of 1939}

Section 9(c) of the Reclamation Project Act states:

That in said sales or leases, preference shall be given to municipalities and their public corporations or agencies; and also to cooperatives and other nonprofit organizations financed in whole or in part by loads made pursuant to the Rural Electrification Act of 1936 and any amendments thereof.

Western implements this statutory limitation in marketing criteria by establishing contractor eligibility requirements and reviewing contractor preference status before allocation.

\subsubsection{Widespread Use and the Flood Control Act of 1944}

Section 5 of the Flood Control Act of 1944 requires that federal power be marketed "so as to encourage the most widespread use thereof." This section applies to the transmission and sale of electric power and energy generated at reservoir projects under the control of the U.S. Department of the Army. Although the SLCA/IP dams are not Army reservoir projects, Western does achieve widespread use by marketing CRSP power to about 81 utilities serving more than one million ultimate consumers in six states. 


\subsubsection{Lowest Possible Rate and Sound Business Principles}

The ongoing policy of Western has been to charge the lowest possible rates consistent with sound business principles. In a letter dated May 15, 1965, then-Secretary of the Interior Morris Udall explained the foundation of that policy to Wayne Aspinall, then-Chairman of the House Committee on Interior and Insular Affairs, as follows:

The basic provision in the Reclamation laws pertaining to power rates is section 9(c) of the Reclamation Project Act (43 USC 485h[c]). It provides that power from Reclamation projects shall be sold by the Secretary "at rates as in his judgement will produce power revenues at least sufficient to cover an appropriate share of the annual operation and maintenance cost, interest on an appropriate share of the construction investment at not less than 3 percent per annum, and such other fixed charges as the Secretary deems proper." In effect, section 9(c) spells out the "sound business principles" that are applicable. Although those principles are stated in terms of the minimum charge for power, they are also clearly intended to set the maximum charge. The Government of the United States markets power to serve the public interest, not to make a profit. We believe that the public interest is best served by marketing power at the lowest possible rate consistent with the orderly repayment of all proper costs and we believe that is what the Congress intended.

Western is precluded from conducting any studies relating or leading to the possibility of changing from "at cost" to a "market rate" or any other noncost-based method for the pricing of hydroelectric power (Appropriation Act, Title V, Section 506, 102 Public Law 104; 1991 House Rule 2427; 105 Statute 510, August 17, 1991).

These policies are implemented in the marketing criteria through the establishment of the rates charged for individual services.

\subsubsection{Other Statutory Constraints}

\subsubsection{Administrative Procedures Act}

Before DOE was created, no statutory requirement existed for a public process before promulgation of final marketing criteria. The Administrative Procedures Act (APA), which mandates public participation before adoption of rules by a federal agency, did not apply to rules relating to public property and contracts (5 USC 553[a][2]). Formal public involvement in the development of Western's marketing criteria, however, was sought before 1977 because of the value of comments 
from customers and the interested public. In addition, at least one court held that a public process was constitutionally required for rate setting pursuant to reclamation law.

With the passage of the DOE Organization Act in 1977, the public property exception to the APA was abolished for all DOE rulemaking. Since Western's creation, marketing plans have been treated as rules, with full opportunity for public comment.

\subsubsection{Paperwork Reduction Act of 1980}

If information is to be collected from customers, a clearance from the Office of Management and Budget (OMB) is required. A request for applicant profile data, as requested in DOE (1983), is one such example. The OMB has approved the gathering of this information. However, further OMB review may be required if additional information from applicants is needed.

\subsubsection{Regulatory Flexibility Act of 1980}

When the APA requires a federal agency to publish a proposed rule, that agency is further required by the Regulatory Flexibility Act (5 USC 601 et seq.) to prepare and make available for public comment a final regulatory flexibility analysis to describe the impacts of the proposed rule on small entities. Under 5 USC 601(2), services are not considered rules within the meaning of the act. Western interprets this definition to mean that no flexibility analysis is required in the promulgation of new or different marketing criteria.

\subsubsection{Executive Order 12291}

Executive Order 12291 (46 FR 13193, February 19, 1981) requires regulatory impact analyses for major rules and regulations. The DOE has determined that the new marketing criteria are not a major rule because they do not meet the criteria of Section 1(b) of the order. Further, Western is exempt from Sections 3, 4, and 7 of the order.

\subsection{OBLIGATIONS AFFECTING HYDROPOWER AVAILABILITY}

Western has obligations that affect the quantity of hydropower plant capacity and energy available for the SLCA/IP marketing programs. Western must account for system losses and resources reserved for special purposes that have priority over preference customer use. These priority uses are as follows: (1) capacity and energy reserved for project use, (2) capacity required for Western Area Upper Colorado (WAUC) regulation control services, and (3) capacity needed for 
primary and secondary spinning reserves to satisfy Western System Coordinating Council (WSCC) reliability requirements. These factors consume up to 292 MW of capacity in summer (April-September) and $155 \mathrm{MW}$ in winter (October-March). They can also consume up to $340 \mathrm{GWh}$ of electricity in summer and $47 \mathrm{GWh}$ in winter.

\subsubsection{Plant Use}

Plant use, or station service, is power that is consumed at electric generating plants to maintain and operate critical equipment, such as generation control equipment, lighting, heating, and ventilation. The amount of power required varies among generation stations, but it is typically a small percentage of the gross generation from each facility. Gross generation, adjusted for plant use, is called net generation at plant or simply net generation.

\subsubsection{Project Use}

The CRSP Act of 1956 authorized certain participating projects. Power requirements for the operation of lift pumps for gravity irrigation, salinity control, and other uses are considered project use and must be satisfied before Western markets any power pursuant to its marketing programs.

Since this authorizing legislation, several projects have been developed in the Upper Basin. These projects include the Silt Water Conservancy District, the Navajo Indian Irrigation Project, the Dolores Project, the Bonneville and Jensen units of the Central Utah Project, and the Paradox Project (authorized under the Salinity Control Act).

Reclamation coordinates projected power needs for project use with individual project managers. Electrical demand for project use is chiefly related to lift pumps for gravity irrigation and does not increase after full development of the project. Project use may also include service to project camps as well as for any other purpose authorized by Congress. The policy and basic requirements of federal irrigation pumping are found in Reclamation Instructions, Part 221, Chapter 3. Reclamation recently requested reservation of additional electrical demand for growthrelated loads, such as pressurization pumps for sprinkler irrigation, and for municipal and industrial uses. The latter category of demand has been classified as other priority use.

When formulating marketing criteria and developing projections of capacity and energy from the CRSP hydropower plants, Reclamation provides an estimated schedule of development for each participating project and estimates of electrical demand for both project use and other priority use. The peak and average winter and summer demand and the seasonal energy requirements by project are provided to Western. The schedule reflects the estimated plan for development of the 
projects; demand is typically greater in summer during the peak irrigation season. The annual power demand is projected to increase to an ultimate-development level.

On August 25, 1983, during the development of the post-1989 marketing criteria, Reclamation provided Western with a schedule that estimated the demand and energy needs for the participating projects through the then-proposed contract period ending in 2004. Western conservatively reserved the maximum amount of capacity (or peak demand) and energy needed for both project use and other priority use in 2004. It was understood that loads could grow at either a faster or slower pace than projected (51 FR 4868, Appendix A, Derivation of Marketable Resources, footnote 4).

The maximum reservations for project use were $38.860 \mathrm{MW}$ with $47,100 \mathrm{MWh}$ in winter and $175.620 \mathrm{MW}$ with $339,560 \mathrm{MWh}$ in summer. These reservations amounted to approximately $12 \%$ of the total capacity and energy in summer and less than $2 \%$ of the capacity and energy in winter. Reclamation requested that Western reserve roughly $30 \%$ of these total reservations for other priority use (11.60 MW with $14,340 \mathrm{MWh}$ in winter and $48.90 \mathrm{MW}$ with $88,830 \mathrm{MWh}$ in summer).

Since August 1983, projections of project and other priority uses have increased. The current projections through 2004 are $34.260 \mathrm{MW}$ with $46,570 \mathrm{MWh}$ in winter and $178 \mathrm{MW}$ with $320,180 \mathrm{MWh}$ in summer. For this technical memorandum, the August 1983 reservations for project and other priority uses were retained.

\subsubsection{System Losses}

Projections of the gross energy generated by the SLCA/IP hydropower plants are based on the projected water release through each power plant. Gross generation adjusted for plant use is commonly called net power plant generation. Because of the physical limitations of transmission elements, some energy is lost during transmission and is therefore unavailable to serve load. These energy losses are often expressed as some percentage of the net power plant generation.

System loss factors vary among interconnected systems, depending on the unique physical characteristics of the generation or transmission system. For the CRSP transmission system, the loss factor has typically been on the order of $7 \%$ of net power plant generation. For the post-1989 marketing criteria, a system loss factor of $7 \%$ was assumed. Applying this loss factor to the estimated annual average SLCA/IP net generation of 6,601,430 MWh results in a loss of approximately $462,100 \mathrm{MWh} / \mathrm{yr}$.

System loss factors change when physical components of the generation or transmission system are added or modified. The CRSP system has undergone many changes since completion of 
the post-1989 marketing criteria. However, the system loss factor remains about $7 \%$ of net generation.

The amount of capacity needed to make up for losses is also 7\%. Historically, Western has not accounted for losses in its capacity marketing strategy because peak demands among Western's customers do not occur simultaneously. The difference between the coincidental peak and the noncoincidental peak is approximately $7 \%$. The diversity in loads among customers and the losses in capacity due to transmission offset each other. For this study, it was assumed that no capacity is reserved for transmission losses.

\subsubsection{Maintenance}

Unit maintenance, whether scheduled or unscheduled, has a significant effect on the net operable capacity of the CRSP. Reclamation is responsible for both routine and extraordinary operation and maintenance of all generating facilities for the SLCA/IP (CRSP, Collbran, and Elephant Butte). In the past, Reclamation has cooperated with Western in the development of annual CRSP maintenance calendars, which usually include projections for a 2- to 3-year maintenance cycle. Routine or periodic maintenance and extraordinary maintenance activities, such as rewinding and uprating generating units, are scheduled weekly. Routine annual maintenance, such as inspection of wearing rings, is scheduled throughout the year. Extraordinary maintenance, such as unit uprating, is typically scheduled during the shoulder months in winter when electric demand is low.

Scheduled maintenance requirements are predictable and known far in advance. However, at times, a significant amount of capacity can be off-line because of maintenance requirements. Therefore, maintenance scheduling should be considered when marketing LTF capacity. Insights into maintenance scheduling of CRSP units were drawn from conversations with W. Paine of Reclamation and from Allen (1990).

Scheduled maintenance can be divided into two categories: routine and nonroutine. Routine maintenance is generally performed on an annual basis. On CRSP units, this type of maintenance takes no more than two working weeks (maintenance crews do not work on weekends). Nonroutine maintenance is more involved, sometimes requiring replacement or reconditioning of a major component, and it can take weeks or months to complete. However, this type of maintenance is generally performed once and then is not needed again for another 15-20 years, depending on the projected life of the equipment.

Maintenance scheduling for CRSP generating units is governed by several concerns, one of which is Western's contracts. Western has peak loads in both summer (July/August) and winter (December/January). Therefore, routine maintenance is not normally scheduled in these periods, particularly in summer when the higher load peak occurs. In addition, an attempt is made to schedule 
maintenance during periods of low flow, so that water is not spilled for lack of capacity. Also, maintenance may have to be scheduled so that impacts on fish are held to a minimum; this concern was specifically mentioned for Flaming Gorge. Finally, because outside contractors normally perform maintenance, their other commitments can affect maintenance scheduling.

Figure 2 shows average CRSP capacity on annual routine maintenance by month. This figure was derived from the Reclamation maintenance schedule for CRSP units for 1990-1994. Little routine maintenance was scheduled between May and August. This period corresponds with Western's summer peak. Routine maintenance was performed mainly in spring and fall, which correspond to low Western peak loads as well as low water releases by Reclamation. Some routine maintenance was scheduled in winter. A significant amount of maintenance was performed in January, which is a high peak load month.

Figure 3 shows maintenance totals (both routine and nonroutine) for all CRSP units for 1992 (a high total maintenance year) and 1993 (a high routine maintenance year). Up to $170 \mathrm{MW}$ of nonroutine maintenance in 1992 was due to the uprating of Flaming Gorge and Morrow Point.

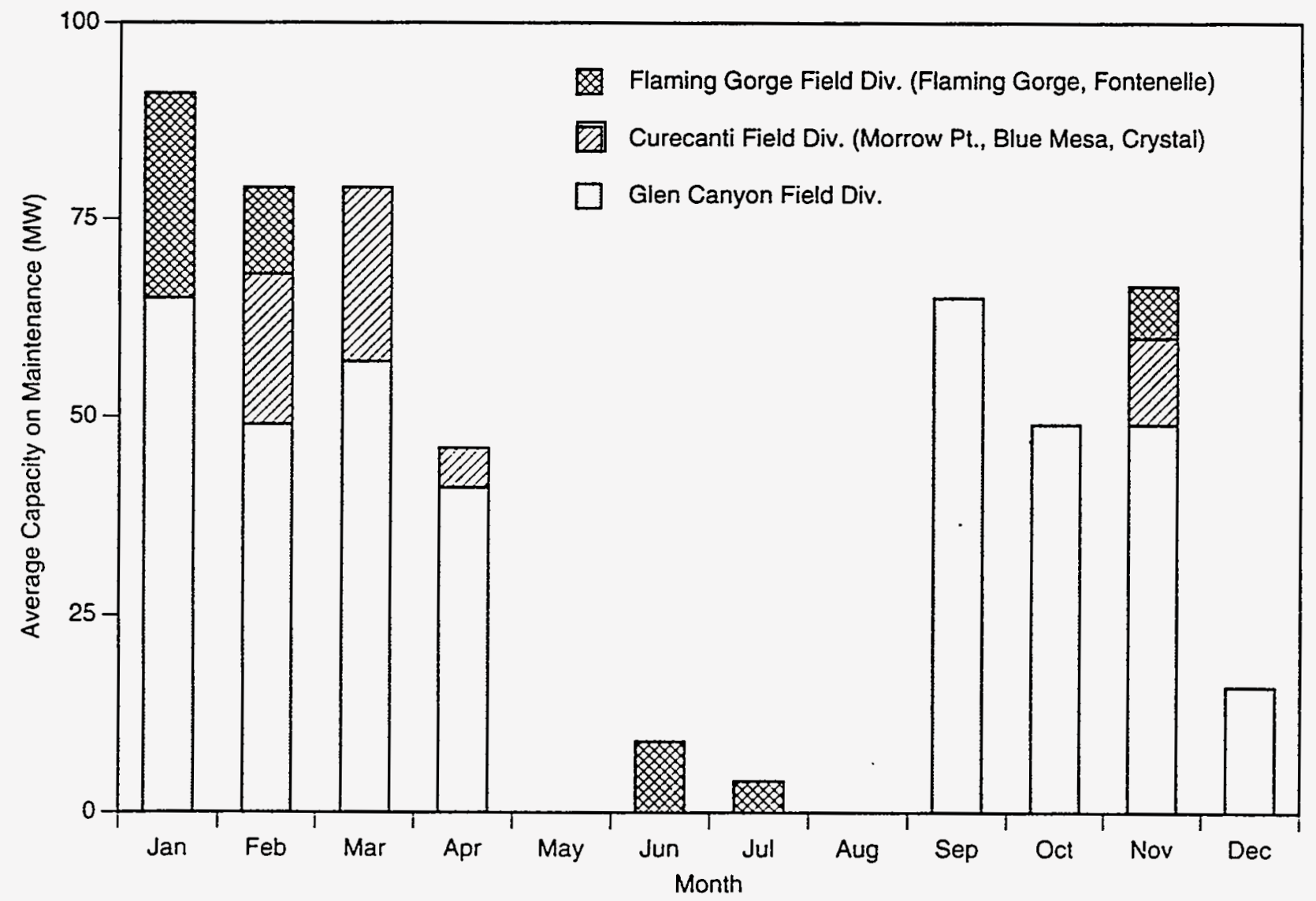

FIGURE 2 Five-Year Average of Capacity on Scheduled Annual Routine Maintenance by Month: 1990-1994 


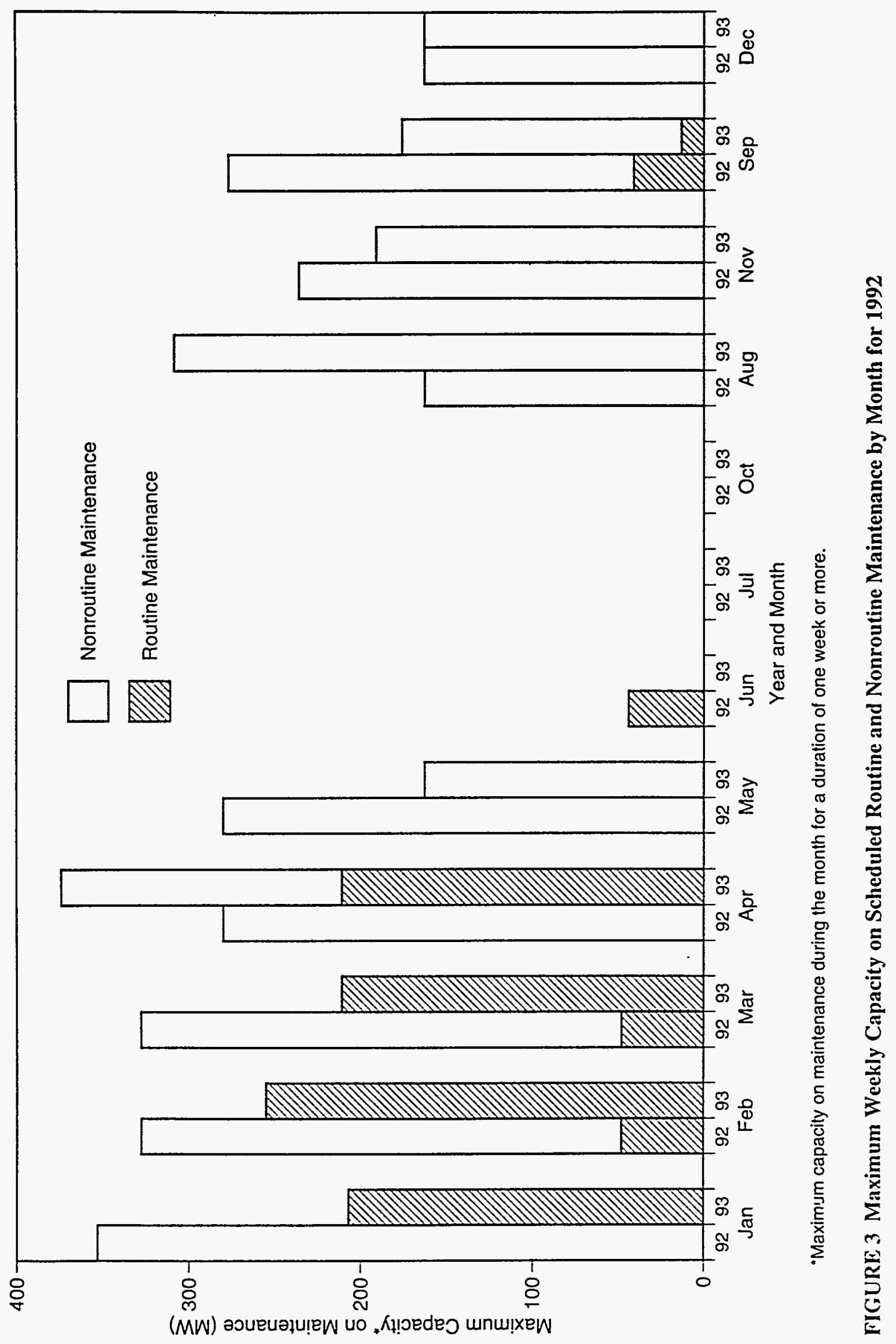


The maximum maintenance level for uprating was scheduled for the last week in January 1992. Figure 3 shows that maintenance was minimized during the summer peak period, when electricity produced by SLCA/IP hydropower plants has the highest value. An attempt is also made to minimize maintenance during the peak winter month of December. Figure 3 shows that most of the maintenance is performed during spring or fall.

Western requests the latest CRSP maintenance schedule to be used as an input to the Colorado River Simulation System (CRSS) control data file to consider the best known information regarding monthly unit availability. The CRSS model output then reflects Reclamation's planning for maintenance at all CRSP facilities on a monthly basis, and it is used to estimate future capacity and energy available from CRSP.

For the post-1989 marketing criteria, the then-current maintenance schedule was used in CRSS model runs in July 1984. As noted in DOE (1986b), although upratings were scheduled during the contract period, Western decided not to include the additional capacity in the derivation of marketable CRSP resources because these upratings were still in the planning stages at that time. For this technical memorandum, the July 1984 CRSS model results of projected capacity and energy were retained.

\subsubsection{Control Area Functions, Reserves, and Power Pooling}

\subsubsection{Power Pooling}

Principally to reduce reserve capacity requirements, utilities have established power pools to allow for reserve sharing. coordination of translations, and other benefits. Generally, the benefits of power pooling are as follows:

- Reduced aggregate reserve requirements through collective consideration of load and hazard conditions (reserve sharing);

- Increased efficiency and economy of use of generating facilities;

- Reduced likelihood of curtailment of load under emergency conditions; and

- Enhanced ability to promote, coordinate, and facilitate planning and development of future system additions or modifications.

Western and 21 other utilities in the Western states make up the IPP. The intent of the IPP is to meet or exceed the most current WSCC minimum operating reliability criteria, power supply 
design criteria, and reliability criteria for system design. In addition to reserve sharing, the IPP Agreement provides for additional services, such as emergency assistance, scheduled outage assistance, economy energy, and transmission service.

In the original IPP Agreement, dated May 6, 1974, the United States was a party as a single entity, acting through Reclamation. In November 1983, the IPP Agreement was revised to reflect the transfer of power control functions and operations of the transmission facilities from Reclamation to Western in 1977, after creation of the DOE. The agreement was also revised to reflect the subsequent redistribution of power control functions within Western among the Boulder City Area (referred to as United States-BCA, now the Phoenix Area), the Loveland-Fort Collins Area (referred to as United States-LFCA, now the Loveland Area), and the Salt Lake City Area (referred to as United States-SLA).

\subsubsection{Control Area Functions}

In 1968, after the Northeast Blackout, electric utilities formed what has become the North American Electric Reliability Council (NERC). The purpose of NERC is to promote the reliability, adequacy, and security of bulk power supply in North American electric utility systems. NERC consists of nine regional reliability councils that cover most of North America; Western is a member of the WSCC.

The WSCC has developed reliability criteria for the design and operation of bulk electric power systems. These reliability criteria are intended to help contain power outages, protect equipment during outages, and restore the system as quickly as possible.

A primary reliability requirement is that each utility must either operate a control area or be within a control area operated by another utility system. Within WSCC, Western operates four separate but interconnected control areas: the Western Area-Upper Colorado (WAUC), the Western Area-Lower Colorado, the Western Area-Lower Missouri, and the Western Area-Sacramento control areas. All of the SLCA/IP hydropower plants are within the WAUC control area.

The amount of capacity required for WAUC load control services to respond to instantaneous changes in frequency has historically been about 50-56 MW. However, no additional net energy is required for this service because the energy needed to correct low-frequency events is offset by reduced generation during high-frequency events. In addition to frequency responses, unscheduled internal load changes can require generation changes of up to $150 \mathrm{MW} / \mathrm{h}$. Although internal load control assistance is occasionally requested during the morning hours, when system loads increase rapidly, Western is not obligated to provide this service. Thus, it is not necessary to reserve capacity for this service. 


\subsubsection{Operating Reliability Criteria and Reserves}

The WSCC has established minimum operating reliability criteria that establish performance standards for its members to use in operating the interconnected system. These criteria serve as a basis and guideline for developing more specific and stringent operating criteria for each system, control area, or power pool. A component of these criteria, the general operating reliability criteria, which govern normal operations, requires each utility and control area operator to maintain reserves.

Reserves, or operating reserves, are defined as the classification of all or a portion of the generating capacity of a utility or control area operator into varying degrees of readiness to provide for regulation within the hour to cover load variations and power supply reductions. By WSCC definition, each control area operator must maintain two distinct types of operating reserves: spinning and nonspinning. Spinning reserve is that portion of operating reserve that is synchronized to the system, can respond automatically to fluctuations in system frequency, and can assume load instantaneously. Nonspinning reserve is that portion of the operating reserve that can be connected to the system and loaded within 10 minutes. According to WSCC criteria, the spinning and nonspinning reserve requirements depend on the individual characteristics of the system (regulation), the magnitude of the largest single contingency of the system, the magnitude and nature (interruptible or noninterruptible) of the load served, and other system obligations.

Through reserve sharing, Western's reserve responsibility is approximately $5 \%$ of the maximum capacity needed to fulfill primary and secondary spinning reserve requirements for IPP. Although these requirements vary over time, reserves have historically accounted for approximately 45-60 MW. Western's requirements are based on numerous factors, such as the size of the single largest hazard and WAUC's share of the load. On the basis of an examination of spinning reserve requirements for selected months from 1988 through mid-1990, it appears that $60 \mathrm{MW}$ of capacity is generally adequate to meet the spinning requirements.

Table 2 gives Western's spinning reserve requirements under different capacity commitments as estimated by the IPP spreadsheet model. For purposes of long-range planning, conservative (i.e., relatively high) estimates of spinning reserves were used. Peak loads input into the PPP spreadsheet calculation were based on various levels of Western LTF commitment. The LTF energy sales were constant and assumed to remain at current levels. Capacity at Glen Canyon, assumed to be 1,300 MW, was used as the single largest hazard.

When a utility requires spinning reserves to generate electricity in an emergency, Western has an obligation to provide assistance. Western is frequently requested to provide such assistance. In the 32-month period from January 1989 to August 1991, Western provided emergency outage assistance to customers in 27 months. 
TABLE 2 Inland Power Pool Spinning Reserve Requirements $^{\mathrm{a}}$ (MW)

\begin{tabular}{lcccc}
\hline & \multicolumn{5}{c}{ Contract Rate of Delivery (MW) } \\
\cline { 2 - 5 } Season & 1,450 & 1,000 & 750 & 550 \\
\hline & 73 & 51 & 38 & 28 \\
Summer & 73 & 51 & 38 & 28 \\
Winter & &
\end{tabular}

a These figures were calculated on the basis of relatively low estimates of monthly peak loads and total demand for other IPP members, which resulted in relatively high (i.e., conservative) estimates of spinning reserve requirements.

Western is obligated to provide emergency outage assistance for up to 72 hours. If an IPP member requires assistance beyond the 72-hour period or needs to replace capacity and energy for a unit that is going to be off-line because of scheduled maintenance, Western has the option to sell the member scheduled outage assistance but has no firm obligation to do so.

\subsection{WESTERN'S PROGRAMS}

Western's programs include a wide range of marketable services, which are provided in various contractual forms. Each contractual form includes the four basic elements of contracting: (1) offer, (2) acceptance, (3) consideration, and (4) ability to contract.

\subsubsection{Agency Discretion in Power Marketing}

Western has wide discretion regarding with whom and on what terms it will contract for the sale of federal power, as long as preference is accorded to statutorily defined public bodies. Sale of power cannot impair the efficiency of the project for irrigation purposes. Power must be sold in a manner that will encourage its most widespread use at the lowest possible rates consistent with sound business principles. Discretion may be limited by the provisions of project-specific legislation.

General reclamation law does not require that all preference entities be treated equally (City) of Santa Clara v. Andrus, 572 F.2d 660 [9th Circuit 1978]). The general authority to make contracts includes the power to choose with whom and on what terms contracts will be made. When Congress grants authority to contract by statute, that grant constitutes general authority to contract unless a limit is specified (Arizona v. California, 373 U.S. 546 [1963]). Nothing in reclamation law suggests 
that Congress intended to limit Western's discretion in making decisions regarding the way it will sell power except in terms of preference, impairment of the project for irrigation purposes, and rate setting. Some judicial decisions, however, have held that the marketing of power can be reviewed to determine whether arbitrary or capricious acts are involved (Greenwood v. Hodel, 764 F.2d 1459 [11th Circuit, 1985]).

Although Western has wide discretion in selling power, it must act in accordance with the terms of the adopted marketing criteria. Contract commitments vary, depending on the party with whom Western is contracting, the duration of the agreement, and the nature of the agreement. Western uses formal contracts, interagency agreements, intra-agency agreements, letter agreements, inter-area agreements, amendments, exhibits, implementing agreements, escrow agreements, license agreements, contracts and grants of easement, and right-of-way and grant agreements. Each agreement is a legally binding commitment.

Under Western Order 6120.1, Power Marketing Policy, Functions, and Delegations, dated November 30, 1987, certain authorities regarding the negotiation, review, execution, and administration of power marketing contractual documents have been delegated to varying levels of Western management. These authorities are described in the following sections.

The services discussed here may be furnished to contractors concurrently with other contracted electric services. The schedule log maintained by the dispatchers in Western's Montrose District Office tracks all activities by service type, individual contractor or utility, and each hour of each day.

\subsubsection{Long-Term Firm Electric Service}

Electrical power generation is only one part of a project constructed for a variety of purposes, which are identified in the authorizing legislation. Those purposes may also include flood control, navigation, irrigation, recreation, municipal water, and fish and wildlife. Power is typically incidental to the other purposes under the provisions of the applicable law.

The relationships of hydropower generation to the other purposes of the project and its physical characteristics (height of the dam, hydrology, storage capacity of the reservoir, and installed generation) determine the amount of power available for marketing. Maximum and minimum release rate requirements and plant maintenance schedules also influence the amount of power available. The capacity and energy available for marketing are derived in part by subtracting the reserves and losses from the total capacity and energy. A factor may be added to account for the diversity among the loads to be served. Project use power is also deducted before the amount of power to be marketed is finally determined. Western then establishes the amount of power available for LTF service. Western is not limited by SLCA/IP resources and can market more capacity and energy on a LTF 
basis than can be produced by the hydropower plants. However, to meet its customers' demands reliably, Western may have to enter into purchase agreements.

Also called firm power sales, LTF service is the primary wholesale, long-term, noninterruptible electric service provided to qualified preference entities. The term "wholesale" reflects the nature of the rate charged. The term "noninterruptible" (firm) explains the commitment by the supplier to provide this electric service without interruption under a wide range of system conditions. "Long-term" means that the service is contractually committed for a period of more than 1 year but less than 40 years. This service includes a contractual commitment of both capacity and energy.

Under this type of contract, a contractor (or customer) has energy and capacity allocations from Western for each month of the year for a specified term. In recent post-1989 contracts, the term is 15 years. The duration of the commitment is a balance between Western's desire to limit its responsibility and risk and the contractor's desire for as much certainty as possible about future power resources. In addition, both parties desire to avoid the costly administrative burden of the reallocation process (DOE 1986b).

The allocation of firm power can be used at the contractor's discretion, subject to certain maximum and minimum limits and contractual restrictions. The maximum energy (expressed in kilowatt-hours [kWh]) and maximum capacity (expressed in kilowatts [kW]) that Western commits are called the monthly energy and monthly capacity, respectively. The maximum amount of firm capacity that Western commits and that a contractor is entitled to receive in the peak months of each season is called the contract rate of delivery (CROD).

Western uses two 6-month service seasons: a winter season extending from the first day of the October billing period through the last day of the March billing period of the following year and a summer season extending from the first day of the April billing period through the last day of the September billing period. The service seasons reflect Western's interest in providing more or less contract commitment during periods when more or less power is available, to maximize the value of the resource in both seasons.

The quantity of firm energy that Western must provide and that a contractor is entitled to receive in a season is called the seasonal energy, energy entitlement or commitment, or energy take. Under existing scheduling procedures, a contractor is required to prepare a preseason schedule that reflects a load-patterned request to Western for delivery of firm power on the basis of the most recent 3-year average total load of the contractor.

The minimum quantity of capacity that Western must provide and that a contractor shall accept is specified on an hourly basis and is called the minimum schedule requirement or minimum hourly delivery. The minimum schedule requirement provides assurance of adequate load to 
accommodate minimum release requirements from the generating facilities during all hours and to allow sufficient ability for Western to purchase energy during off-peak periods to the maximum extent possible. At the request of a contractor, Western may waive the minimum schedule requirement. In recent contracts, the minimum schedule requirement has been set at $35 \%$ of the seasonal CROD or at the contractor's load delivery rate, whichever is less.

Because of the noninterruptible nature of the commitment, if Western is unable to supply sufficient firm capacity or energy from its own hydroelectric resources, it must purchase the deficit from an outside resource (i.e., another utility) for delivery to the contractor. The expense of this purchased power has been shared by all contractors (blended) and reflected in a general increase in the total operation and maintenance expense for SLCA/IP. Under the post-1989 marketing criteria, however, the cost of this purchased power could be assigned directly to a specific contractor (passthrough cost [PTC]), and Western would be reimbursed directly by the contractor. This option was subsequently removed from the interim contract by Judge Green in his decision of November 6,1989. However, had the pass-through option been left intact, the maximum deficit energy or capacity purchase would have been limited to an established baseline. For energy, this baseline was the projected average seasonal energy generation levels for the CRSP. For capacity, this baseline was the projected seasonal capacity under adverse conditions for CRSP. This capacity was measured as the difference between the contract commitment level and the historical generation from CRSP under adverse conditions. When these limits or modifications are placed on the potential purchase expense to the contractor, this purchase approach is described as a modified PTC concept.

The capacity that Western purchases on behalf of its contractors is called PTC capacity. Similarly, energy that Western purchases on behalf of its contractors is called PTC energy. In recent contracts, the maximum PTC capacity that Western may purchase is $109,000 \mathrm{~kW}$ in winter and $95,000 \mathrm{~kW}$ in summer. The maximum PTC energy that Western may purchase in a year is $400,000,000 \mathrm{kWh}$. The costs of PTC capacity and energy are passed on to contractors on a prorated basis.

A contractor may choose not to receive PTC capacity and energy. That contractor notifies Western in writing that it does not want Western to purchase PTC energy and capacity on its behalf during the next two seasons. Western then reduces its seasonal energy and CROD commitments to the contractor accordingly. In a typical contract without PTC capacity, the winter CROD might be reduced from $18,866 \mathrm{~kW}$ to $17,447-18,866 \mathrm{~kW}$, and the summer CROD might be reduced from $19,523 \mathrm{~kW}$ to $18,150-19,523 \mathrm{~kW}$. Similarly, for that contract, without PTC energy, Western's seasonal energy commitment for winter might be reduced from $45,931,000 \mathrm{kWh}$ to $41,118,254 \mathrm{kWh}$, and the commitment for summer might be reduced from $44,283,860 \mathrm{kWh}$ to $43,675,986 \mathrm{kWh}$.

Contracts for LTF electric service also include provisions for adjusting individual or collective commitments at some point within the contract term. Individual commitments can be adjusted through an annual exchange (i.e., between seasons) of energy or capacity among Western's 
LTF customers. If two similarly situated customers want to exchange energy or capacity between seasons, they must submit the desired range of exchange energy or capacity to Western by a specified date. Western will then review requests on the basis of its operational requirements; if its operational requirements permit, Western may then revise the contract to increase or decrease the seasonal energy and CROD. Any annual exchange is at Western's discretion.

Marketing criteria provisions specify that after 10 years of a 15 -year contract term, Western can adjust collective commitments "based upon the marketable resources upon 3 years advance notice." This adjustment option is a compromise in that it allows an attractive contract term (15 years) yet provides a means to adjust commitment levels within the contract period without further administrative process if marketable resources from SLCA/IP increase or decrease.

Western uses various rates to meet the repayment requirements of the project for which it markets power and to accommodate special marketing situations. Rates state the unit cost of the services marketed by Western. The nature of the service dictates the type of rate. Most rates are based on the revenue requirements of a single project. However, multiproject rates may result from (1) project integration as provided for by administrative determination or law or (2) project blending, which is a policy determination.

A rate may include charges for capacity, energy, or transmission service; however, it does not include leasing fees, service facility charges, or other types of facility use charges.

\subsubsection{Short-Term Firm Electric Service}

In the past, during favorable hydropower conditions, after all project use and LTF commitments have been served, additional energy or capacity has been available for marketing to LTF contractors and others on a monthly or seasonal basis. This STF service is similar to LTF service but is different in the following ways:

- The term of the contract is less than one year, and it may be either seasonal or monthly.

- Allocation of available surpluses is based on contractor demand and may be a simplified proportional allocation.

- Western's risk assumptions are based solely on the most probable forecast from Reclamation for near-term operations at SLCA/IP hydropower plants. 
- Western may choose to recover additional costs from a contractor.if service cannot be supplied entirely with Western's hydroelectric resources and if Western must purchase energy or capacity from outside resources.

Three types of STF electric service have been offered in the past: (1) surplus energy, (2) excess capacity, and (3) a combination of surplus energy and excess capacity. The rate charged for STF service is the same rate charged for LTF service.

Surplus energy is additional hydroelectric generation from SLCA/IP hydropower plants that is assumed to be available as a result of projected increased reservoir releases by Reclamation within a specified period. As a result of this increased reservoir release and associated increased hydroelectric generation, Western has extended energy-only offers to existing LTF electric service contractors. The increased energy commitment, when accepted by the contractors, results in an increase in seasonal load factors associated with their seasonal CROD under existing LTF electric service contracts. This energy is valued at the same energy component as the established LTF power rate.

Excess capacity is additional unmarketed capacity-only offers that become available as a result of unit maintenance, such as unit uprating. In the past, excess capacity offers have chiefly been the result of the availability of Glen Canyon uprates and favorable hydropower conditions (full reservoirs). Additional capacity is first offered to existing LTF electric service contractors as an increase in their monthly or seasonal CROD. Because the capacity is without energy, all energy scheduled and delivered under this capacity increase is accounted for as return energy; that is, it must be returned in like amounts over a specified period of time.

A STF capacity purchase increases the LTF customer's minimum schedule requirement. Without additional SLCA energy, the STF capacity purchase effectively reduces the amount of SLCA energy that can be used during on-peak hours.

In the past, to permit a longer, higher valued commitment of available excess capacity and to minimize the risk of increased purchased power expenses, Western has committed to a seasonal offer of excess capacity provided that it can supplement the excess capacity offer with thermal purchases if shortages occur in any month. These supplemental purchases are then passed through to the contractors desiring the seasonal commitment.

Under the extremely wet hydropower conditions that occurred in the mid-1980s, Western extended combined offers of excess capacity and associated surplus energy. Essentially, these offers have been an increased commitment of firm electric service, both CROD capacity and energy commitment, for the specified period. 


\subsubsection{Short-Term Non-Firm Energy Service}

The two types of short-term non-firm electric energy services offered by Western are (1) fuel replacement energy service and (2) economy energy service. These non-firm, or interruptible, energy-only services are similar in many respects but differ from each other in the rates charged to the contractor.

The fuel replacement (or oil conservation) program began under Reclamation during the Arab oil embargo, to encourage the substitution of oil and gas-fueled generation with hydroelectric generation. When possible, Western and a contractor agree in advance to schedule delivery of nonfirm energy within a specified period. The period of delivery may vary from a specified hour within a day to all hours within a period of days. The term "non-firm energy" indicates that the delivery is agreed to be an energy-only delivery that is interruptible on 15-minute notice. The contractor is to use this non-firm energy to supplant the operation of its highest auxiliary cost resource, whether it be its own generating facility or a purchased resource. The value of this service is negotiated with each utility to reflect $85 \%$ of the highest auxiliary supply. The result is a $15 \%$ savings to the contractor and a reduction in use and dependence on a nonrenewable supply.

During a fuel replacement transaction, the contractor is required to maintain sufficient capacity reserves to meet firm load because, as noted earlier, these services can be interrupted at the sole discretion of Western by telephone notice to the contractor's dispatcher or other authorized representative.

\subsubsection{Interchange of Energy}

The purposes of interchange of energy are to achieve efficient use of productive capacity and to improve system reliability. A party (Western or a contractor) may request surplus energy from the other party, and the other party may, at its discretion, deliver such energy at mutually agreed points of interconnection. Energy so delivered is credited to the supplier in an interchange (bank) energy account, which distinguishes between energy delivered during on-peak periods and energy delivered during off-peak periods. For energy delivered by one party to the other to be considered interchange energy, a prior agreement for such delivery between the parties must exist.

Unless otherwise agreed upon, interchange energy should be returned to the supplier as promptly as circumstances permit, kilowatt-hour for kilowatt-hour, during a corresponding period (on-peak or off-peak). However, the parties may agree to postpone return of the energy to a more suitable time. For example, energy can be banked with a contractor for anticipated return in the future. If energy is not returned during a corresponding period, the energy interchange agreement may provide that energy not be returned kilowatt-hour for kilowatt-hour. For example, the agreement 
can provide that if energy furnished during an on-peak period is returned during an off-peak period, then $1.5 \mathrm{kWh}$ should be returned for each kilowatt-hour delivered.

Interchange energy agreements provide that if an account remains unbalanced in favor of the same party for a year or an agreed upon period, the creditor party can demand payment (in money) to balance the interchange energy account. In such contracts, a net balance due a contractor may be priced at a percentage (e.g., 115\%) of the contractor's average fuel cost plus variable operation and maintenance costs at its power plants during the most recent 12-month period. A net balance owed to Western may be priced at the average sale price of economy and fuel replacement energy during the most recent 12 -month period.

\subsubsection{Regulation Service}

Western's SLCA Office operates the WAUC control area. The primary function of a load control area is to ensure that each utility or group of utilities generates or imports the exact amount of power to meet its load and exports responsibilities (and frequency and voltage requirements) within a limited tolerance.

At times, an individual utility may not have sufficient reserve capacity to meet large instantaneous changes in its demand. Regulation, or control area service, offered by Western provides the required operating generation to meet instantaneous changes in load in addition to that required by Western to satisfy its own regulation requirements.

Western currently provides load control services to the City of Farmington, the ColoradoUte Electric Association, and the Deseret Generation and Transmission Cooperative. The regulation to be provided for this service is determined by formula within a control area services contract and is based on a ratio of the contractor's generation facility to the generating facilities within WAUC. The value of this service is similar to the demand charge of the existing SLCA LTF power rate.

\subsubsection{Breakdown or Emergency Service}

\subsubsection{Assistance to Non-Independent Power Producers}

If a specified contractor suffers a system emergency or forced outage of a unit, Western agrees to support that contractor by furnishing capacity or energy. This service is available only to contractors with small generating capacities, such as those operating small hydropower plants. Western's obligation is interruptible (non-firm) and contingent on Western having enough energy or capacity available after its obligations to other customers and its own reserve requirements have 
been met. Western may provide this service for a number of days. Western's price for capacity under this service is determined by a rate schedule; its price for emergency energy is Western's average, seasonal energy purchase price applicable for the period being billed.

\subsubsection{Assistance to Independent Power Producers}

As part of its IPP commitments, Western offers scheduled and emergency outage assistance to IPP members. Scheduled outage assistance is requested of a member utility when a unit is expected to be down for planned maintenance or after an initial emergency period (72 hours) following a forced outage. The supplying utility delivers firm capacity or energy to the requesting utility, as needed. The IPP has set a price, or schedule, for the capacity charge; the two members involved agree on whether the energy used will be returned or purchased. Because of its central location within IPP and the flexibility of its hydroelectric resources, Western frequently provides scheduled outage assistance.

When an IPP member has a forced (or unplanned) outage, other members are obligated to provide emergency outage assistance in energy and capacity in an amount up to the member's spinning reserve capacity pool obligation. This obligation may last for up to 72 hours. The assisted utility is required to pay for the energy received during this 72-hour emergency period or to return it, depending on the agreements reached.

The amount of energy needed for emergency outage assistance (i.e., when reserves are no longer spinning but are contributing energy to the grid) varies significantly over time. In the worst case, the amount of energy consumed would equal the spinning reserve capacity requirement multiplied by the number of hours in a month (approximately $44.5 \mathrm{GWh}$ of energy). Because Western is obligated to provide emergency assistance for a maximum of 72 hours, this situation is very improbable because there would have to be at least 11 consecutive forced outages to consume the maximum amount of emergency energy. However, Western has frequently been called upon to provide emergency assistance. Between January 1989 and August 1991, an average of approximately $1.3 \mathrm{GWh}$ of electricity per month was used for emergency outage assistance. A maximum monthly emergency outage assistance of $6.6 \mathrm{GWh}$ occurred in January 1990. Historically, Western has not accounted for the amount of energy that is consumed by the emergency outage assistance services when formulating its power marketing plan.

\subsubsection{Firm and Non-Firm Transmission Service}

Western's transmission system has approximately 16,550 circuit miles of lines with voltage ratings of $115 \mathrm{kV}$ or less and $138,230,345$, and $500 \mathrm{kV}$. The SLCA portion of Western's transmission system consists of 297 circuit miles of $138-k V$ lines, 790 circuit miles of $230-\mathrm{kV}$ lines, 
and 378 circuit miles of 345-kV lines. In addition, SLCA has 156 circuit miles of lines with voltages of $115 \mathrm{kV}$ or less (DOE 1992). The power transfer capability of a transmission line depends on the voltage of the line: $138-\mathrm{kV}$ lines can carry about $140 \mathrm{MW} ; 230-\mathrm{kV}$ lines can carry about $300 \mathrm{MW}$; $345-\mathrm{kV}$ lines can carry about $500 \mathrm{MW}$; and 500-kV lines can carry about 1,000 MW. Parts of Western's system have two lines going between the same point. In this case, the maximum load that can be transferred between the two points is approximately the sum of the amount that each line can carry individually.

In a contract for firm transmission service, Western will accept power and energy scheduled by a contractor at specified points of receipt and voltages. Use of the SLCA transmission capacity may be scheduled in advance on an hourly basis. Western transmits and delivers an equivalent amount of power and energy, minus transmission losses, at specified points of delivery at rates of delivery (in kilowatts) up to a maximum amount specified in the contract. The cost of this service to the contractor is based on the maximum rate of delivery. In a typical contract, Western has the right to use, on an interruptible basis, any portion of the transmission capacity reserved but not being used by the contractor. In addition, Western reserves the right to grant the use of capacity to others, on an interruptible basis, during the times the contractor does not schedule use of its capacity.

A contract for firm transmission service may not have a fixed term but may instead give each party the right to terminate the contract when the other party is given sufficient advance notice. Also, Western must give the contractor sufficient advance notice of any contemplated changes in transmission facilities that may affect the contractor's ability to receive energy transmitted pursuant to the contract.

Western also offers non-firm transmission service, which is provided at its sole discretion and may be reduced or withdrawn on notice by telephone to the contractor's load dispatcher or other authorized representative.

Non-firm transmission involves no firm commitment of transmission capacity on the part of Western. No maximum hourly rate of delivery of energy is shown because schedules are made on an if, when, and as available basis. The rate is normally in mills per kilowatt-hour with no annual capacity charge. The current rates for non-firm transmission service are based on the pricing for this service within the interconnected system. Western and the purchasing entity mutually agree to the specific rate in advance.

Western's SLCA Office has transmission service contracts with Public Service of New Mexico (PNM), Colorado-Ute Electric Association, and Western's Loveland Area Office. Its generation displacement service contract is with the Salt River Project (SRP) and is also known as the SRP Exchange Agreement. The transmission service contract with PNM calls for Western to accept $84 \mathrm{MW}$ of power from the Palo Verde nuclear plant at the Pinnacle Peak substation and to wheel the power to New Mexico. In exchange, PNM wheels $140 \mathrm{MW}$ of power for Western to its 
customers in New Mexico. Furthermore, Western has the option to receive an additional $107 \mathrm{MW}$ of power wheeled to its New Mexico customers by PNM at a predetermined price. This contract is very favorable to Western because PNM wheels more power for Western (140 MW) than Western wheels for PNM (84 MW). The transmission service contract with Colorado-Ute Electric Association calls for Western to accept up to $100 \mathrm{MW}$ of power at the Craig/Hayden substation and to wheel that power to the Gunnison/Poncha and Midway substations. Finally, the contract with Western's Loveland Area Office calls for about $20 \mathrm{MW}$ to be wheeled from Craig/Hayden to the Midway substation.

\subsubsection{Generation Displacement Service: Salt River Project Exchange Agreement}

Original plans for CRSP included construction of an extensive transmission system to deliver Glen Canyon generation to load centers in Colorado, New Mexico, Utah, and Wyoming. At the same time, SRP was planning to build large amounts of generating capacity to meet its load growth in Arizona. The SRP was investigating the feasibility of constructing mine-mouth coal-fired power plants in Colorado and New Mexico and transmitting the power to Arizona. Planners from Reclamation and SRP realized that an exchange agreement between the two parties, in which SRP generation in Colorado and New Mexico was offset by Glen Canyon generation, could result in significant savings to both parties. This exchange of generation would eliminate the need for most of the transmission system then planned.

Consequently, SRP and Reclamation entered into a long-term contract for the exchange of Glen Canyon generation for SRP generation at Craig and Hayden in Colorado and at Four Corners in New Mexico. The agreement also provides for limited transmission of SRP power when the exchange cannot function. Operation of the exchange depends on Glen Canyon. When Glen Canyon is generating, power flows from Glen Canyon to SRP. At the same time, an equivalent amount of power generated by SRP is dispatched to Western's loads. This exchange is valuable to Western because of the distance between the Glen Canyon Dam, which is the main source of Western's generation, and Western's firm loads. Furthermore, the transmission line between Glen Canyon, Kayenta, and Shiprock is currently limited to a power transfer capability limit of about 380-480 MW, and Western would not be able to serve its loads east of Glen Canyon without overloading this line. The exchange with SRP allows Western to serve the contracts without overloading this line.

\subsubsection{Conservation and Renewable Energy Program}

In 1980, Western initiated its conservation and renewable energy (C\&RE) program. The C\&RE program has two major components: (1) an in-house program to improve the efficiency of 
Western's operations and facilities and (2) a customer-oriented program, which includes customer assistance, equipment loans, and workshops (U.S. Department of the Interior, 1989, Appendix D).

The objective of the C\&RE program is to ensure that federal hydropower is used wisely by Western's customers and to encourage energy conservation and development of renewable resources. The C\&RE program requirements are mandatory for all LTF power customers purchasing federal power from Western and members of customer organizations. A provision within Western's power sales contracts requires compliance with $C \& R E$ guidelines and acceptance criteria. Congressional legislation reinforcing Western's program is included in Title II of the Hoover Power Plant Act of 1984 (42 USC 7275-76).

The current $C \& R E$ program requires customers to submit a plan for developing and implementing programs for efficient energy production and conservation goals. There is a list of suggested activities for customer consideration, and a customer's program must contain a minimum number of annual ongoing or planned program activities based on the customer's size and classification (i.e., cooperative, public utility district, etc.). Customers may offer substitutes for the listed activities. A customer's program is updated every 2 years and evaluated as a whole after 4 years, on the basis of a good faith effort, which is defined as a customer having committed annual resources and made a reasonable attempt to achieve its program goals and schedules. Customers that do not achieve at least $70 \%$ of their goals may be subject to a penalty of a reduction of up to $10 \%$ in their Western power entitlement.

Customers participate in a variety of $C \& R E$ programs. Conservation programs, such as street light replacement and home weatherization, are very popular and result in reduced use of electricity. Load management control, such as automated switching of water heaters and other equipment, is practiced by many customers and results in lower peak demand on their systems. Distribution system improvements (e.g., installation of capacitors, use of efficient transformers, and system rebuilding) reduce losses in customer systems. Additionally, many customers conduct education programs to keep consumers informed of developments in the efficient use of electricity.

Several customers have also been active in the development of renewable energy resources. The most popular project has been the development of small hydroelectric generating plants to help meet supply needs. Customers have also developed a geothermal generating plant, and some have investigated the possibility of developing wind-powered generation. 


\section{HYDROPOWER AUGMENTATION AND MARKETING FIRM CAPACITY AND ENERGY}

When marketing LTF capacity and energy, Western must consider both known factors, such as hydroelectric generator nameplate capacities and transmission limitations, and external elements that are beyond its influence, such as hydropower variability, unscheduled outages, downed transmission lines, erratic acts of nature, and the imposition of stringent constraints on hydropower plant operations. These external factors are unpredictable to some degree, and each introduces uncertainties about the level of electricity generation from SLCA/P hydropower plants and Western's transmission capabilities. Because of these external influences, resources marketed by Western are highly variable over time. Therefore, Western is at risk of not fulfilling its contractual obligations when it offers firm capacity and energy to its customers. In general, as Western offers larger quantities of energy and capacity to its customers, it faces a higher risk that it will not meet its contractual commitments with SLCA/IP hydropower plants. From a long-term perspective, one of the largest uncertainties is the amount of capacity and energy that will be available from SLCA/IP hydropower plants in any one future month. The level of uncertainty increases as a function of time.

Western minimizes its risks in various ways. Western is a member of the IPP and can request emergency services from other members if it cannot meet firm demands because of forced outages. Western's purchasing programs allow it to draw on excess generating capacity and energy from neighboring electric utility systems when adverse hydropower conditions exist, but they can be costly. Another vehicle is a contract clause, such as the one in the post-1989 marketing criteria, which allows Western to conditionally alter its commitment level to reflect changing resource conditions and to pass through costs to its customers.

\subsection{HISTORICAL CRSP HYDROPOWER VARIABILITY AND HOURLY OPERATIONS}

The amount of electricity that can be produced by hydropower plants in the Colorado and Rio Grande river basins fluctuates as a function of time. These fluctuations are caused by variability in several factors: (1) amounts of precipitation in the watershed; (2) terrestrial absorption rates; (3) evaporation rates; and (4) water diversion for municipal, industrial, and irrigation uses. In recent years, annual electricity generation from CRSP and the Seedskedee Project hydropower plants has varied by more than a factor of 2 . Figure 4 shows that under wet hydropower conditions (i.e., a high gross head and large reservoir releases), such as during water year 1984, generation was high, approximately $11,000 \mathrm{GWh}$. On the other hand, in 1990, under poor hydropower conditions (i.e., low gross head and low release levels), electricity generation dropped dramatically, to less than 4,600 GWh. The CRSP and the Seedskedee Project constitute a large portion of the electricity generating resources of the SLCA/IP: approximately $98 \%$ of the nameplate capacity and $97.5 \%$, on 


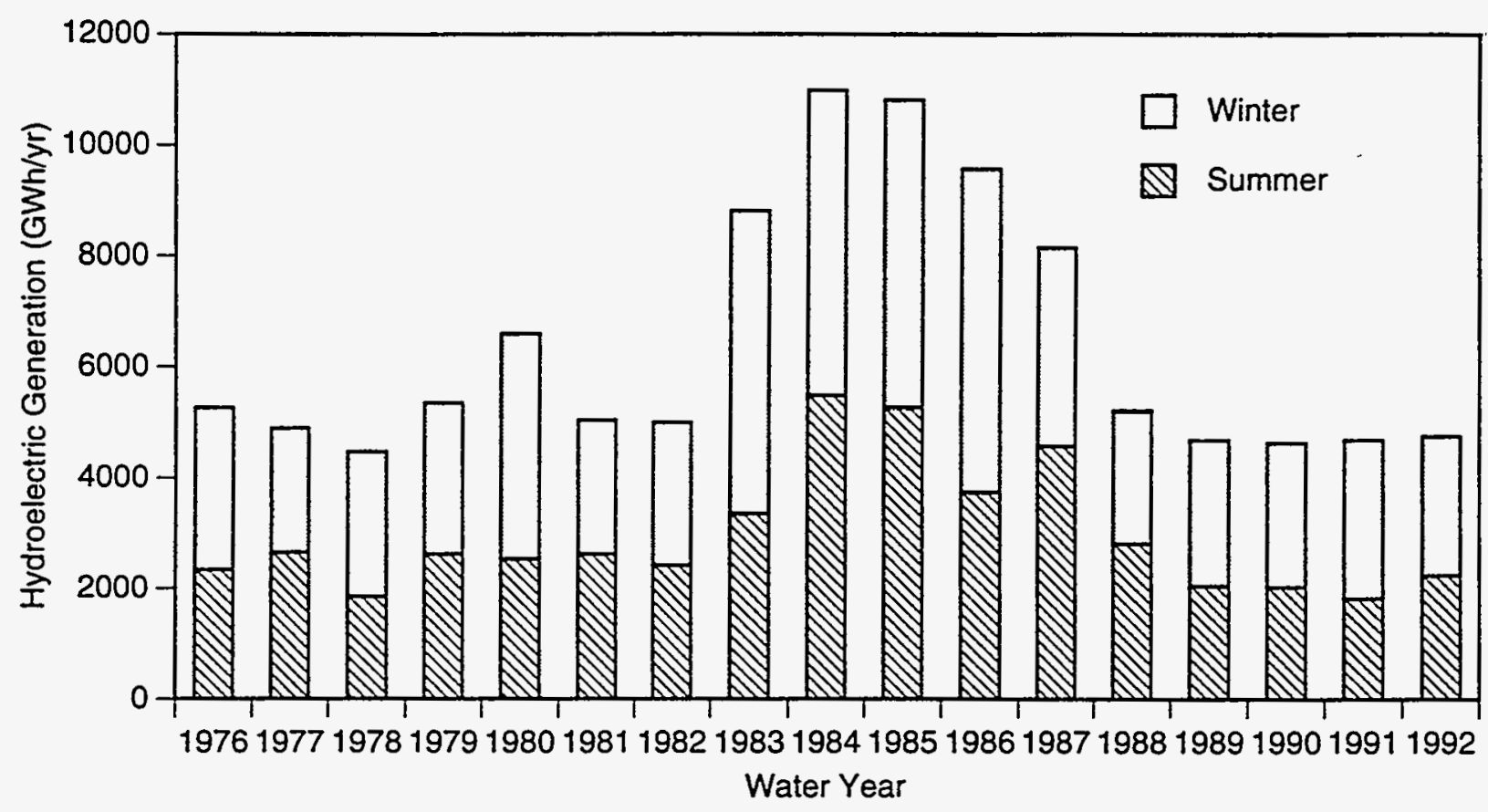

FIGURE 4 Historical Total Electricity Generation for CRSP: 1976-1992

average, of the energy. The wide range of electricity generation levels over the 1976-1992 period is a reflection of past large fluctuations in SLCA/IP hydropower conditions. It also highlights the large degree of uncertainty inherent in SLCA/IP resources for any given future year.

Operations of SLCA/IP hydropower plants must also take into consideration the legal constraints imposed on their operation. Under terms of Section 7 of the Endangered Species Act (16 USC $\$ \$ 1531)$, Western is required to consult with the U.S. Department of the Interior, U.S. Fish and Wildlife Service (USFWS), to ensure that any action carried out by Western is not likely to jeopardize the continued existence of any endangered species or threatened species or result in the destruction or adverse modification of the critical habitat of such species. Section 7(b) of the act requires the USFWS to issue a written statement setting forth its opinion detailing how the agency actions affect listed species or critical habitat. Biological assessments are required under Section 7(c) of the act if listed species or critical habitat may be present in an area affected by any "major construction activity." No construction is contemplated under the proposed action, any alternatives, or any proposed operational scenario; therefore, Western is not required to ask for a species list or prepare a biological assessment. However, since hydropower operations affect the timing and release of flows from existing dams and thus might affect downstream aquatic and terrestrial environments, the USFWS recommends that Western prepare a biological opinion (Harris 1991; DOE 1996).

Hydropower conditions have a significant impact on hourly hydropower plant operations. Figure 5 shows hourly water releases from Glen Canyon Dam under low (dry), average (normal), and 


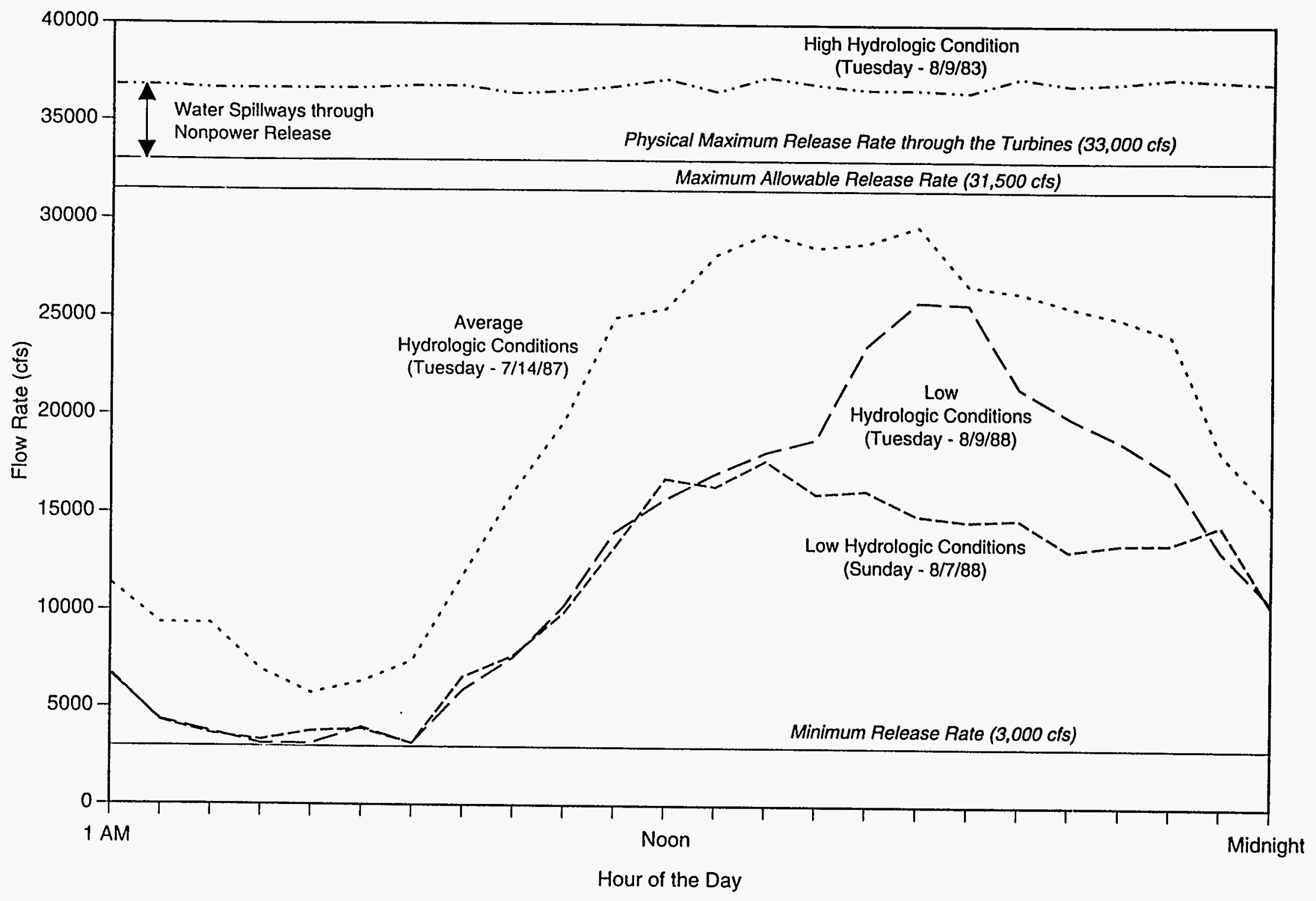

FIGURE 5 Historical Hourly Flow Rates under High, Average, and Low Hydropower Conditions 
high (wet) hydropower conditions. Under average conditions, oni-peak water releases approach the maximum allowable release rate through the turbines. Releases do not increase to the maximum operating capacity because approximately 100-110 MW of capacity is needed for spinning reserves and regulation. That is, releases from Glen Canyon must be approximately $4,000-4,500 \mathrm{ft}^{3} / \mathrm{s}$ lower than the maximum allowable release rate because that level of water release is needed to increase generation in response to load control area frequency drops and emergency assistance requests from IPP members. Water releases during on-peak hours under normal conditions are higher than releases under low hydropower conditions, and they remain at a high rate for a longer period (i.e., approximately 11 a.m. to 10 p.m.). This pattern reflects the larger amount of water available to produce electricity during peak hours under normal hydropower conditions.

Maximum water releases on Sunday (an off-peak day) tend to be lower than those on weekdays because the value of electricity is higher on weekdays than on Sundays. Water is "saved"so that it can be used to generate electricity when it is more valuable. Also, Western's hourly firm loads tend to be significantly lower on Sundays, and spot market prices for non-firm sales are generally low.

Under low hydropower conditions, water releases from Glen Canyon Dam are near the minimum release requirement during weekday off-peak hours and significantly greater than the minimum during on-peak hours. However, under average conditions, water releases during off-peak hours are higher than the minimum release rate because of regulation services and economics. When Glen Canyon Dam provides regulation services, about $56 \mathrm{MW}$ must be available to compensate for changes in load in the WAUC load control area. That is, releases from Glen Canyon must be approximately $2,400 \mathrm{ft}^{3} / \mathrm{s}$ higher than the minimum release rate because that amount $\left(2,400 \mathrm{ft}^{3} / \mathrm{s}\right)$ of water decrease is required to reduce generation in response to frequency spikes. Under dry conditions, Western will also purchase power to serve firm loads during off-peak hours when the price is relatively cheap. Therefore, Western minimizes the amount of higher priced energy it purchases during on-peak hours.

Under very wet hydropower conditions, water releases at Glen Canyon can exceed the design maximum flow rate of the turbines during most hours of the month. Therefore, water must be released through the spillways. High levels of release are required around the clock to comply with Reclamation's monthly release requirements and to keep water from spilling over the top of Glen Canyon Dam. Therefore, under very wet conditions, water release fluctuations are minimal.

Figure 6 shows frequency histograms of hourly releases from Glen Canyon under low, average, and high hydropower conditions. The histograms include only weekday hours for the months indicated on the bar charts. Under low hydropower conditions, there are relatively large numbers of hours with low releases (less than $6,000 \mathrm{ft}^{3} / \mathrm{s}$ ) and with high releases $\left(16,000-24,000 \mathrm{ft}^{3} / \mathrm{s}\right)$. Low release rates occur during the off-peak hours, and high releases occur during the on-peak hours. Because ramping between off-peak and on-peak hours tends to be rapid, 

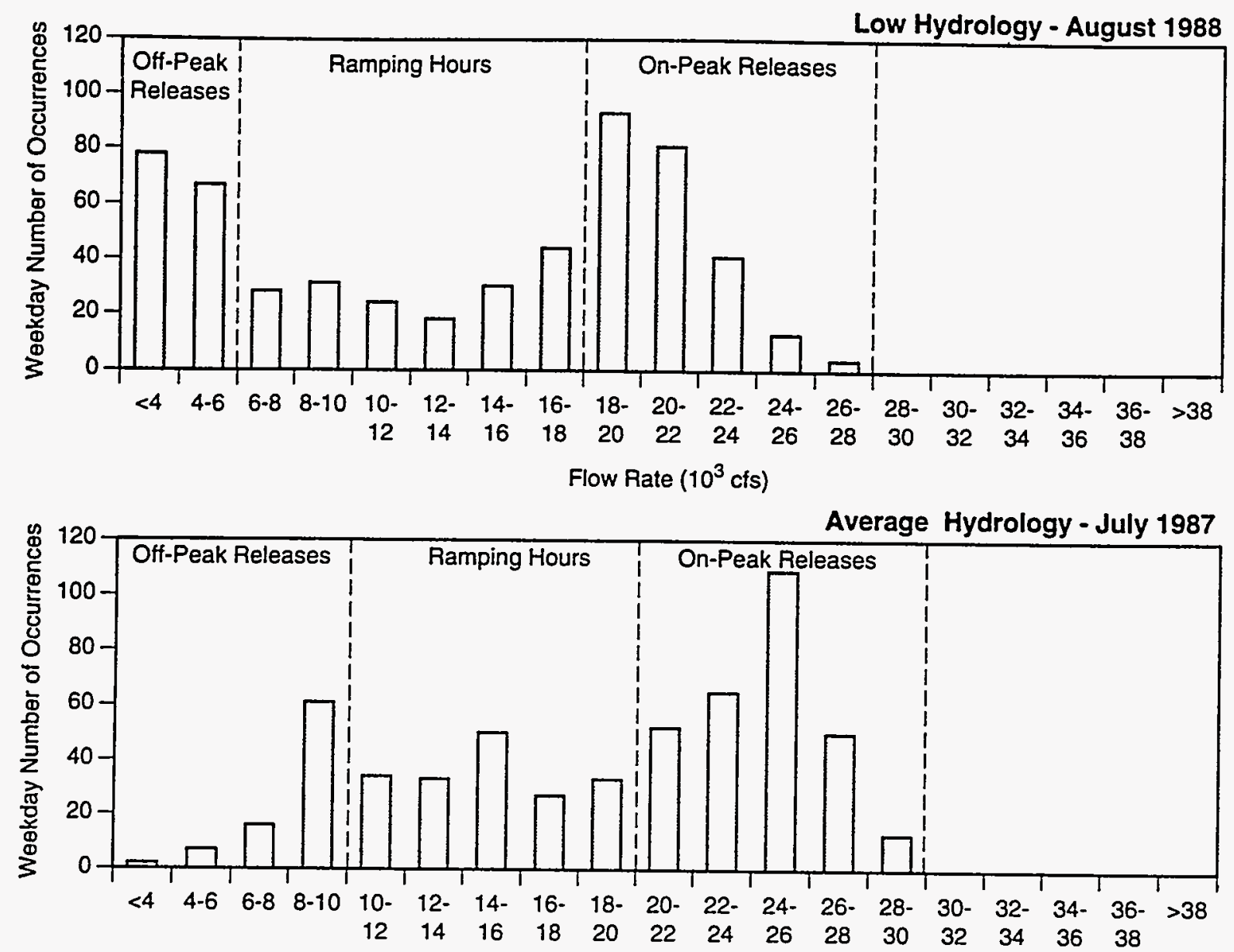

Flow Rate $\left(10^{3} \mathrm{cfs}\right)$

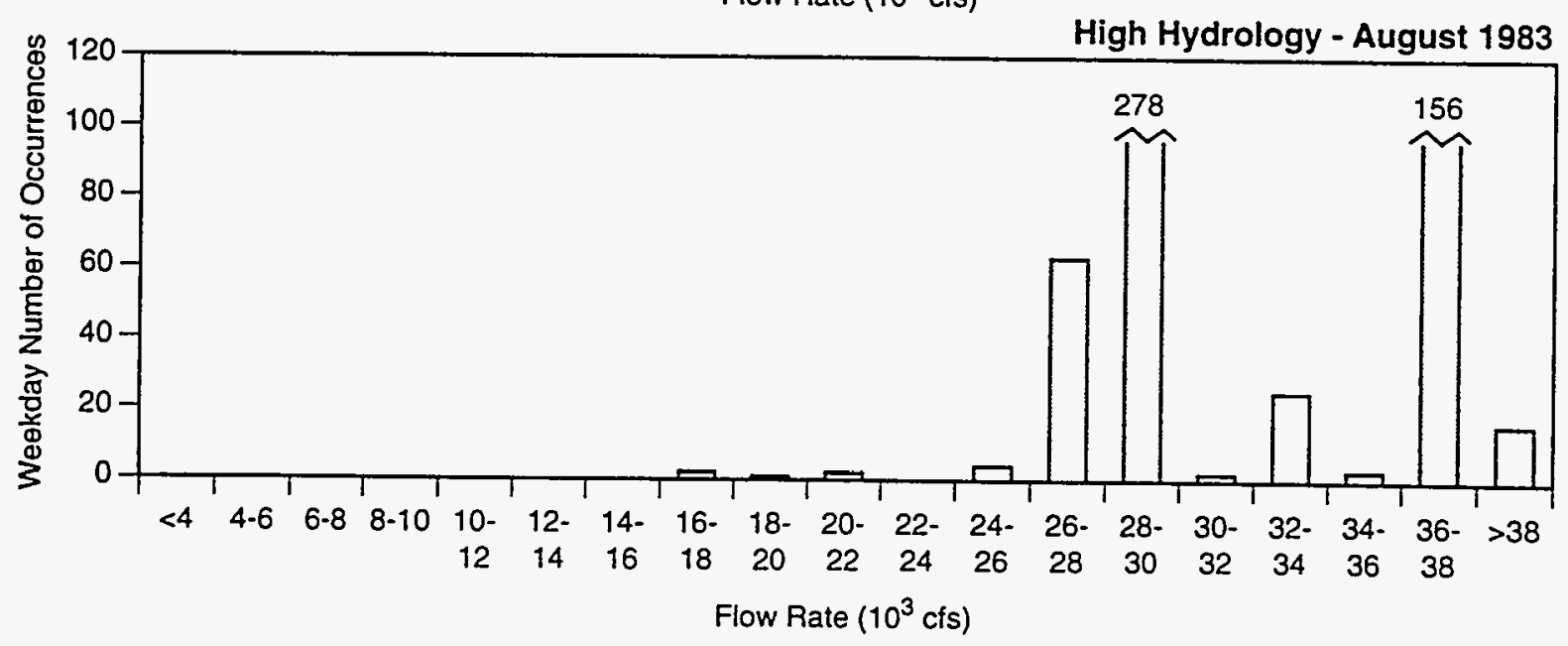

FIGURE 6 Frequency of Weekday Flow Rate Occurrences under Low, Average, and High Hydropower Conditions 
flow rates between 6,000 and $16,000 \mathrm{ft}^{3} / \mathrm{s}$ are relatively rare. Therefore, high ramp rates between onpeak and off-peak hours tend to form a bimodal frequency distribution. Under average hydropower conditions, there are fewer low hourly water releases and more high hourly water releases. Releases under very wet conditions are very high for all weekday hours of the month.

Figure 7 shows water release frequency histograms for fall, winter, and spring under low hydropower conditions. Each graph exhibits a bimodal distribution that is less pronounced than the frequency distribution for summer. Firm loads tend to fluctuate less in fall, winter, and spring than in summer, and the difference between on-peak and off-peak prices tends to be smaller in those seasons than in summer. This pattern is, in part, due to a smaller incentive to shift water releases from off-peak periods to on-peak periods. Price differences between off-peak and on-peak hours tend to be lowest in spring and fall; however, on-peak spot market prices can increase significantly during low load months when large nuclear or coal units are down for maintenance or have unscheduled outages. Frequency distribution patterns also tend to be less pronounced in those months than in summer because regional loads fluctuate less in spring and fall.

\subsection{PROJECTED SLCA/IP CAPACITY AND ENERGY RESOURCE VARIABILITY}

As discussed earlier, the CRSP hydropower plants have historically had large fluctuations in annual electricity production that significantly affect hourly operations. Large annual fluctuations in both capacity and energy are expected to continue in the future.

\subsubsection{CRSP and Seedskedee Hydropower Variability}

The hydropower variability of the CRSP and the Seedskedee Project was assessed with the CRSS model. The CRSS, a deterministic model developed by Reclamation, estimates monthly water releases from dams in accordance with all the laws of the river, including the requirements of operating criteria for maintaining equal storage in Lake Powell and Lake Mead as long as sufficient Upper Storage Basin capacity exists for a targeted release of at least 8.23 million acre-feet from Glen Canyon Dam. For the 1985 power marketing environmental assessment (DOE 1985a), the model used data from 1906 through 1978 to simulate river basin flows and end-of-the-month reservoir levels. The model has since been updated with data from more recent years. However, this analysis uses the CRSS model runs made for the 1985 environmental assessment.

The CRSS estimates were used to construct capacity and energy exceedance probability curves for CRSP and the Seedskedee Project. Figures 8 and 9 show the capacity exceedance curves, and Figures 10 and 11 show the energy exceedance curves. The exceedance probabilities are based 

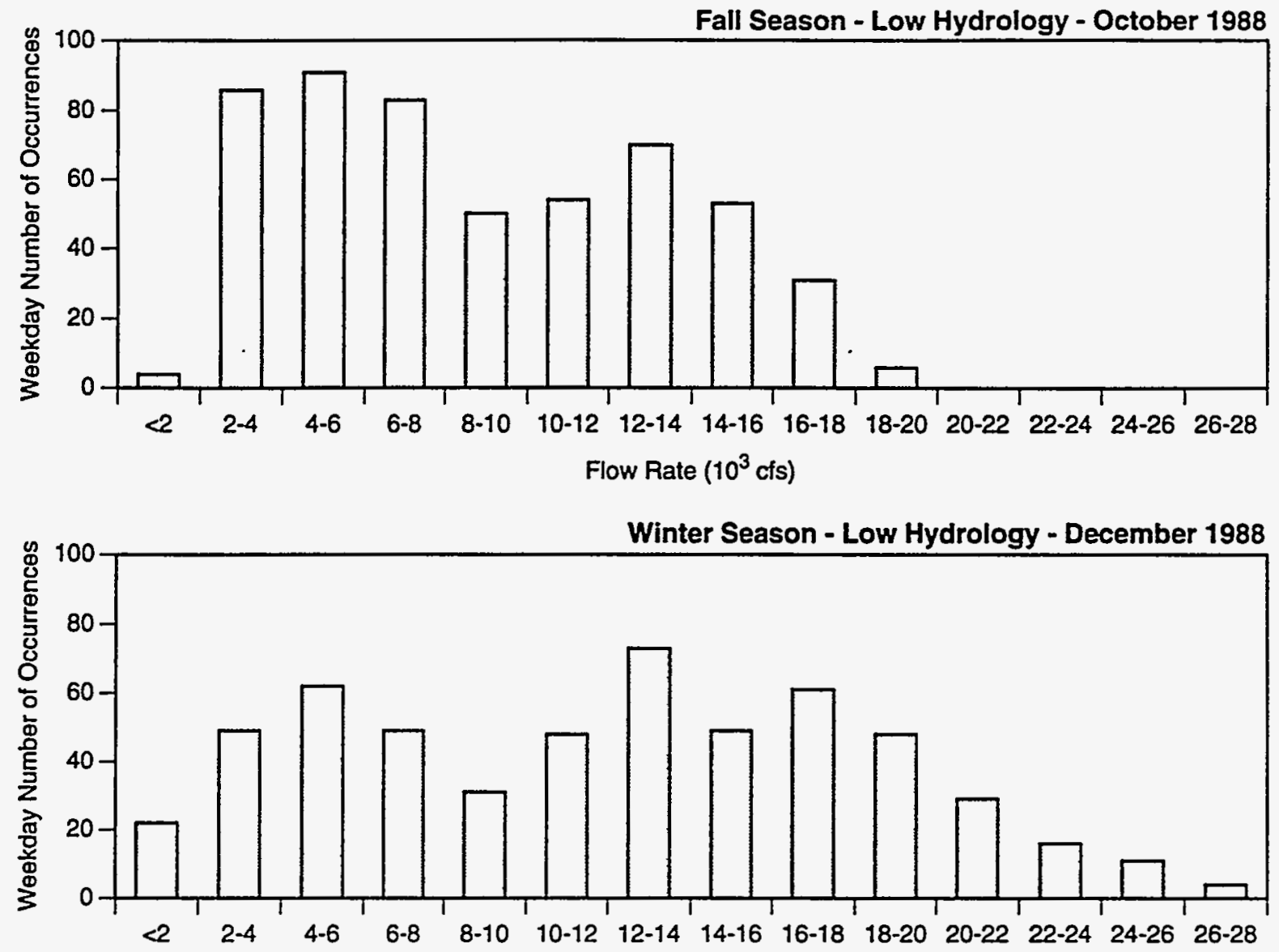

Flow Rate $\left(10^{3}\right.$ cfs $)$

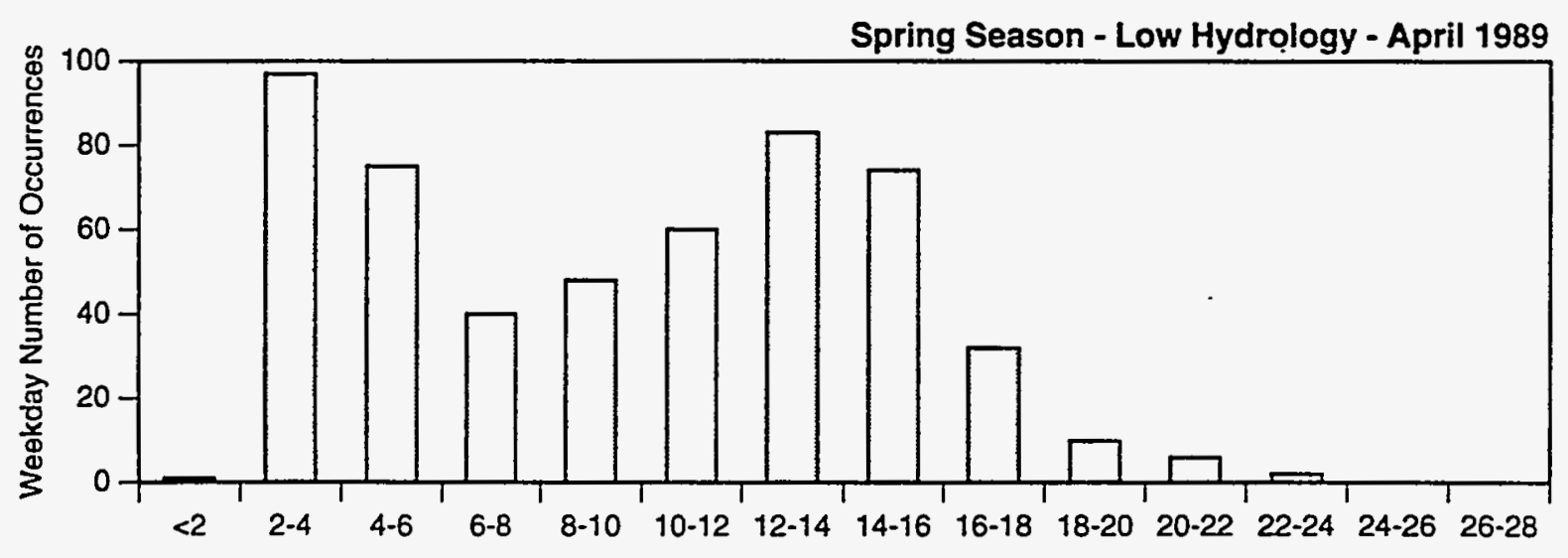

Flow Rate $\left(10^{3} \mathrm{cfs}\right)$

FIGURE 7 Frequency of Weekday Flow Rate Occurrences during Low Hydropower Conditions in Fall, Winter, and Spring 


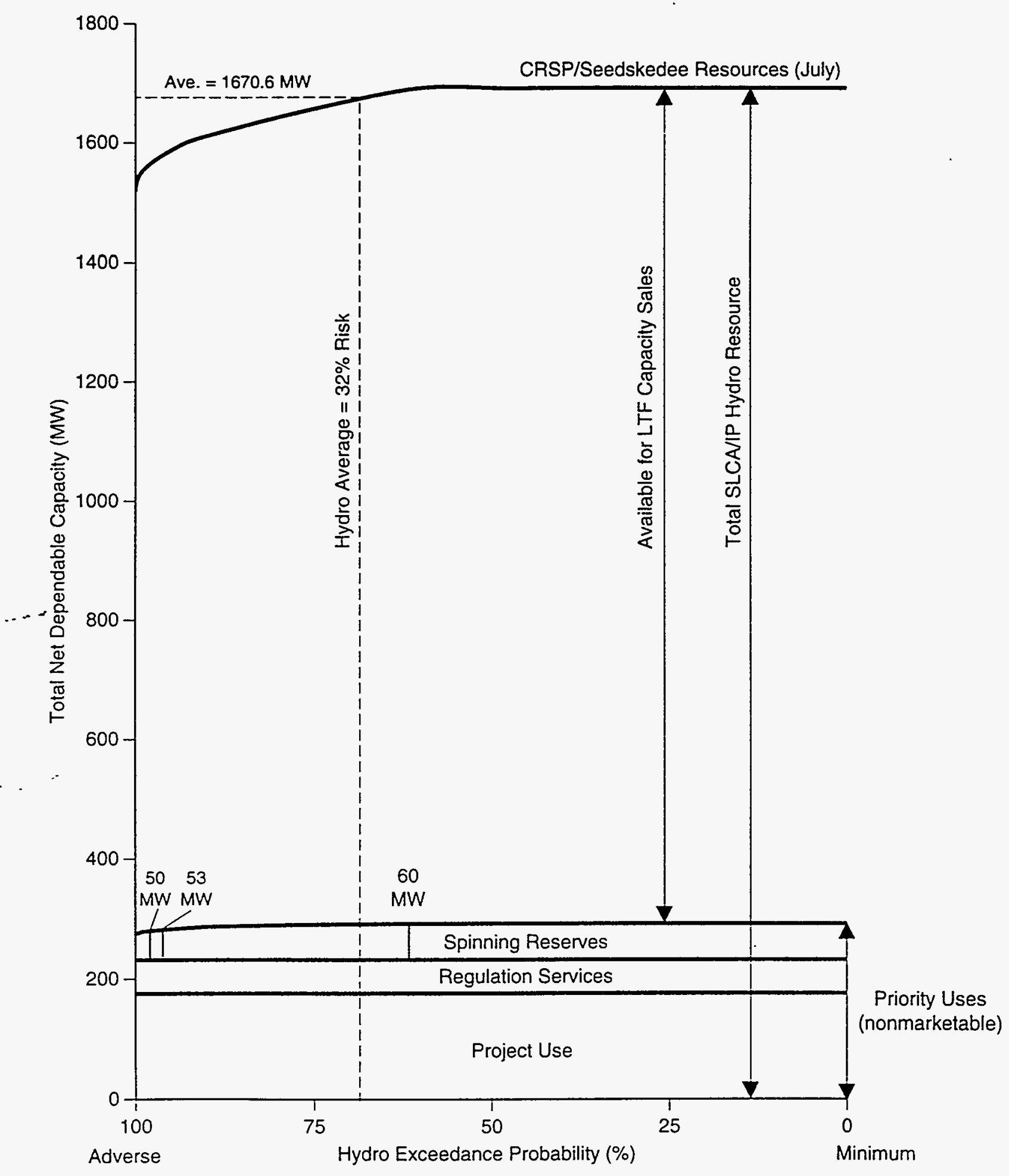

Note: Capacity from Collbran and Rio Grande projects are not sufficiently reliable to be included.

FIGURE 8 Total Hydropower Capacity Exceedance Probability Curves for July (Summer) 


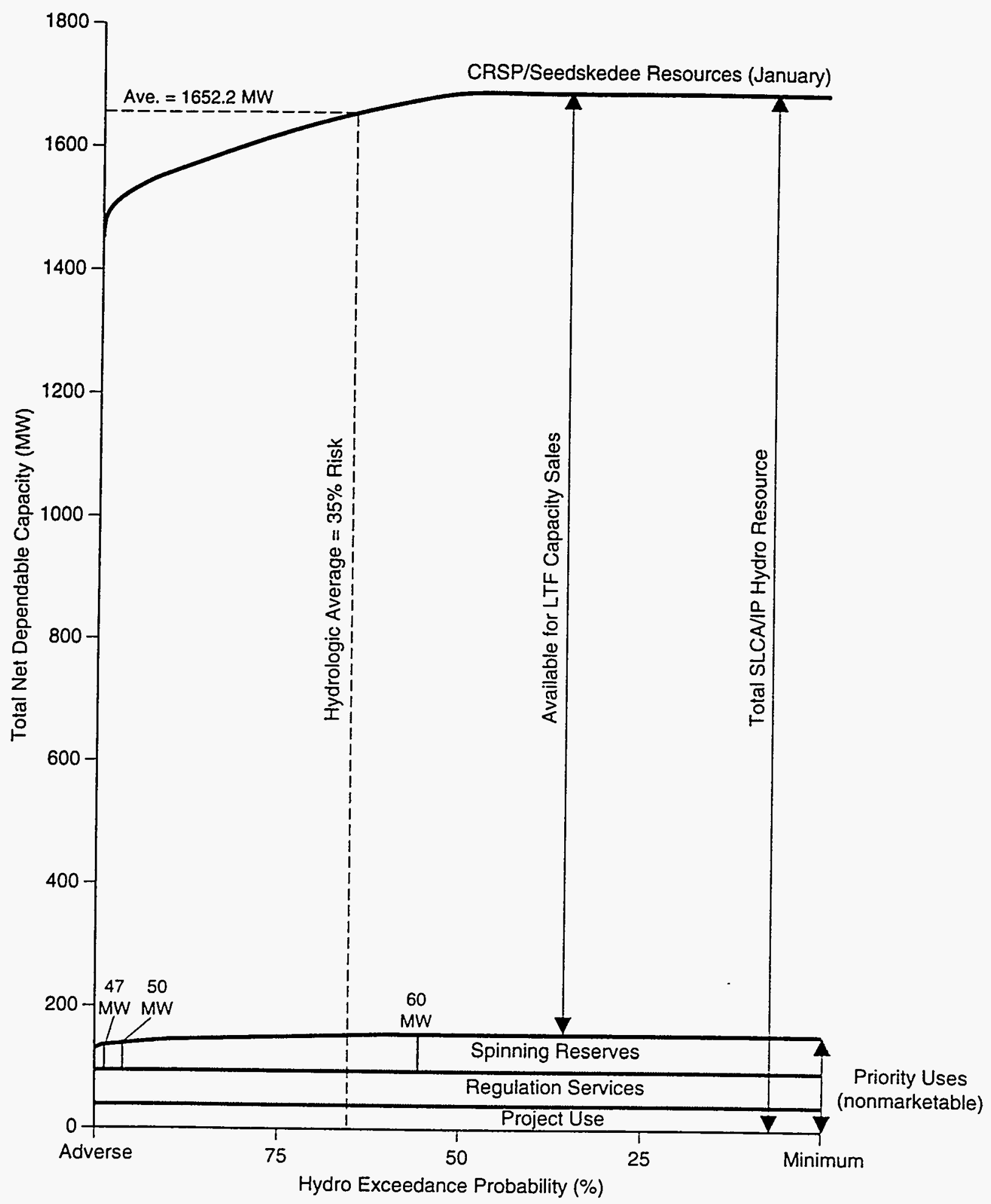

Note: Capacity from Collbran and Rio Grande projects are not sufficiently reliable to be included.

FIGURE 9 Total Hydropower Capacity Exceedance Probability Curves for January (Winter) 


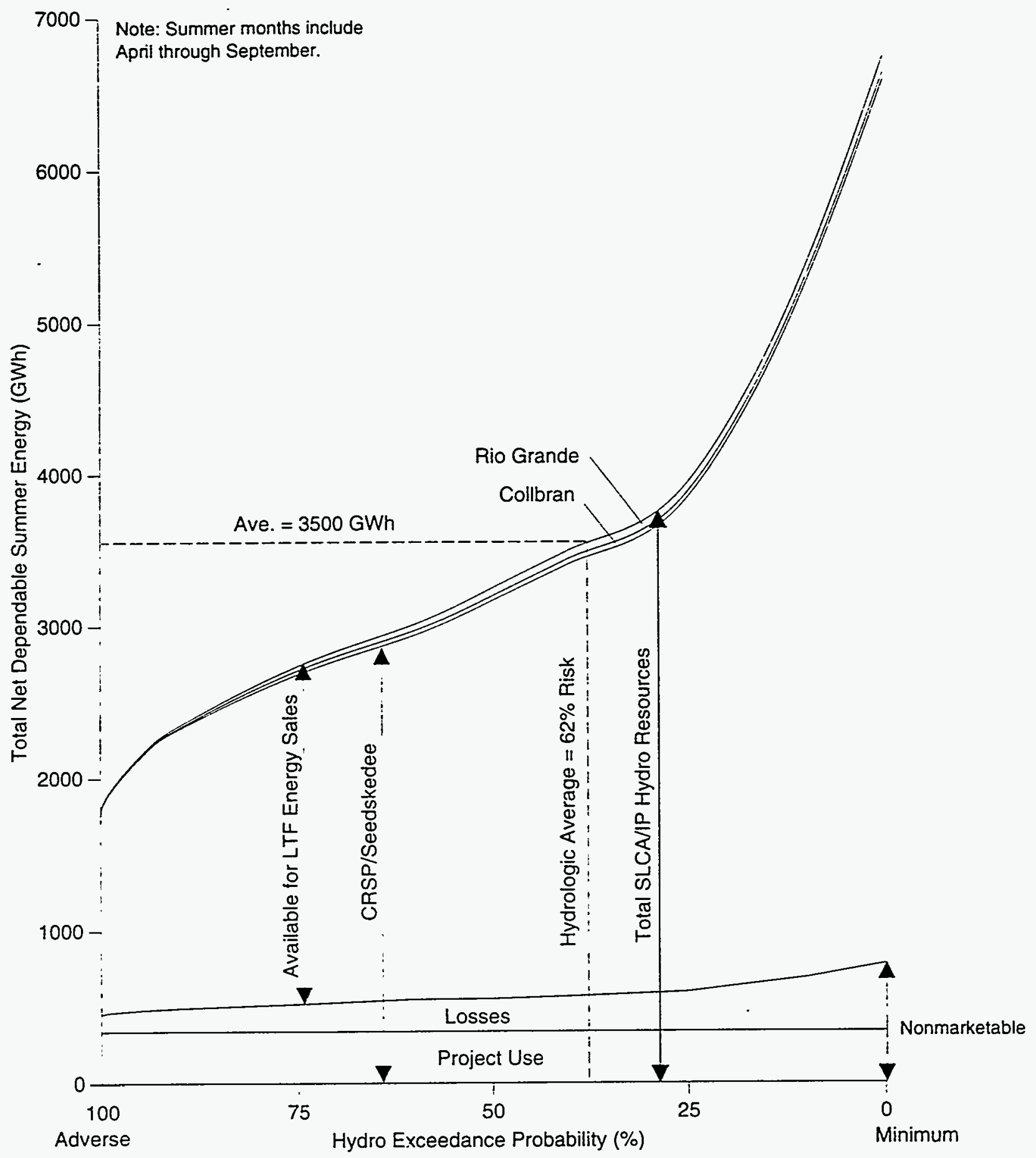

FIGURE 10 Total Energy Production Exceedance Probability Curves for Summer Months 


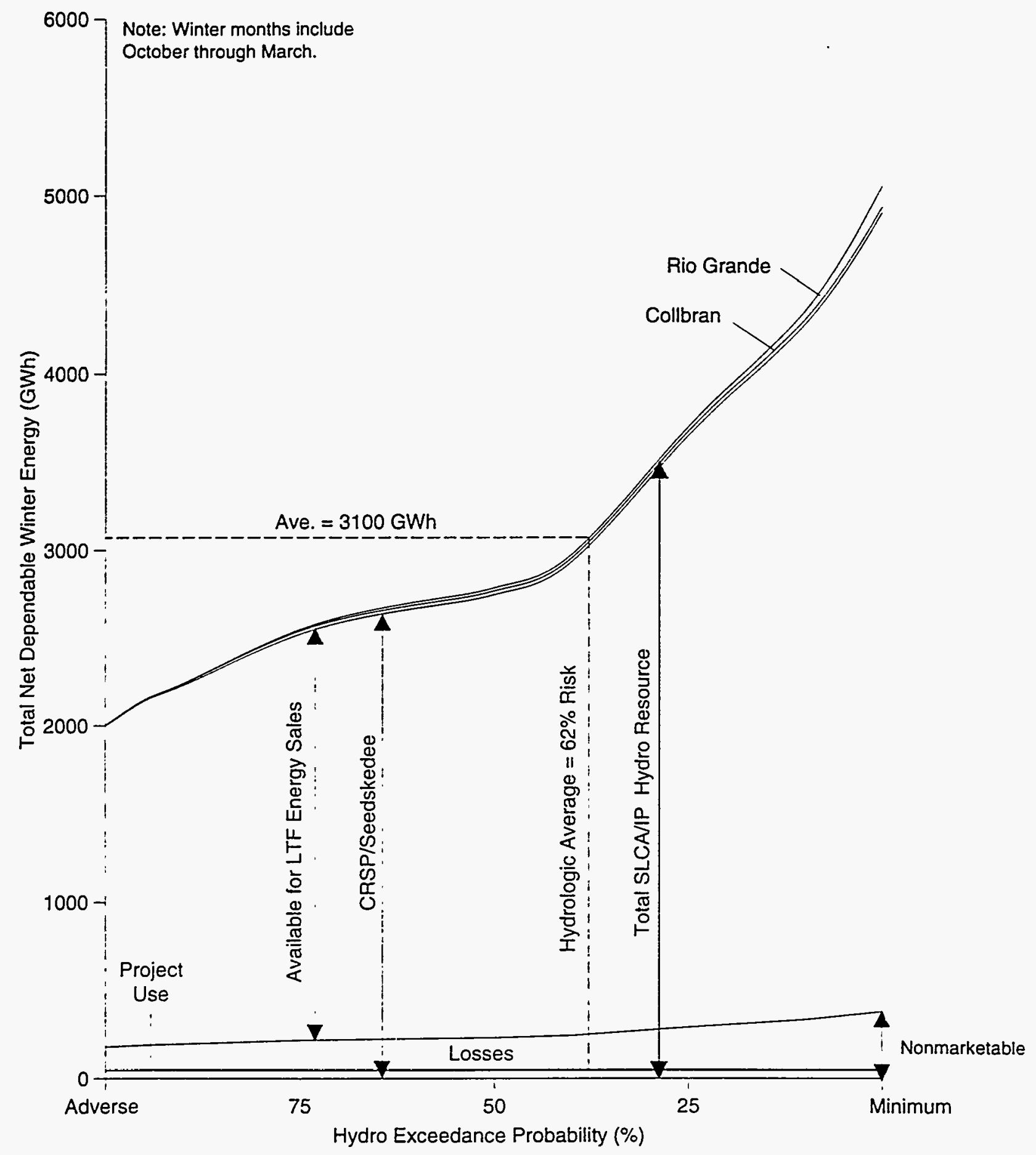

FIGURE 11 Total Energy Production Exceedance Probability Curves for Winter Months 
on projections of resource levels over 15 years, 1985-1999. The cumulative probability curve represents an average probability level over time. Because of depletion effects, capacity is normally higher than the time-averaged curve during the early years of the contract period and lower than the time-averaged curve later in the contract period. However, because of current dry hydropower conditions, capacity is expected to be lower in the near term despite greater water depletion rates in the future. The LTF capacity and energy contracts under the post-1989 marketing criteria will begin sometime after 1993 and extend to 2007. Because CRSP estimates are based on depletion schedules from 1985 through 1999 and do not include current low hydropower conditions, the CRSS exceedance probabilities compiled for the 1985 environmental assessment slightly overestimate the capacity and energy probabilities.

The seasonal exceedance energy curves presented in Figures 10 and 11 were estimated by combining monthly probability curves across each exceedance level. For example, the summer level under adverse conditions was estimated by adding energy estimates at the adverse exceedance level for the months of April-September. A more detailed explanation of the CRSS model and the methods used to construct the exceedance curves is contained in DOE (1985b). This methodology assumes that all summer months with adverse hydropower conditions occur in the same year. Likewise, all summer months with maximum exceedance levels occur in the same year. A seasonal exceedance probability usually covers months having different exceedance probabilities. For example, a dry season may include some months that are classified as very dry and others that are close to normal. The method used here to estimate the energy exceedance curve tends to underestimate dry hydropower conditions (i.e., the estimate is too dry) and overestimate wet hydropower conditions. However, because the CRSS simulations used in this study did not contain data for recent years, including the present drought conditions, the estimates of low hydropower conditions in the summer are reasonable. In the summer of 1991, CRSP and Seedskedee Project generation was $1,820 \mathrm{GWh}$. This amount is between the generation under adverse hydropower conditions and that under the $99 \%$ exceedance probability level as projected by CRSS: 1,751 and 1,892 GWh, respectively.

Seasonal capacity exceedance curves were constructed by using a peak load month in each season. Winter is represented by January, and summer is represented by July. Because the exceedance curves are based on hydrological data for the years 1906-1978, CRSP capacity is currently lower than that under adverse conditions as projected by CRSS. Therefore, the points on the monthly capacity exceedance curves that represent adverse conditions are overly optimistic.

When the probability distributions used for this report were constructed, CRSS simulations based on hydrological data for recent years were not readily available, and only monthly summaries from an older version of the model were available. Thus, it was impossible to construct more accurate probability distribution curves. However, detailed outputs from updated CRSS simulations were used to analyze power marketing alternatives selected by Western for examination under the power marketing EIS (Veselka et al. 1995). 


\subsubsection{Hydropower Probability Distributions for the Collbran and Rio Grande Projects}

Hydropower exceedance curves for the Collbran Project were constructed from historical data for 1977-1990. The Rio Grande Project distribution curves were based on data for 1944-1990. Because the energy exceedance curves for these two projects were based solely on historical data, future changes that occur in the river basins cannot be quantified. Because of depletion effects, future generation levels are expected to be smaller than past generation levels. Therefore, probability values estimated by using historical data are somewhat higher than those expected to occur in the future. Another shortcoming of the use of historical data is that information is somewhat limited, especially for the Collbran Project. Because the data set is small, a relatively large potential for error exists when these curves are used to project the future.

\subsubsection{Combined Probability Distributions}

Aggregate SLCA/IP energy curves were constructed by adding together the curves for CRSP/Seedskedee and the Collbran and Rio Grande Projects. This simple method differs somewhat from that used to analyze EIS power marketing alternatives (Veselka et al. 1995). It also tends to underestimate capacity and energy under dry hydropower conditions and overestimate capacity and energy under wet hydropower conditions. However, because the Collbran and Rio Grande Projects account for only $2 \%$ of SLCA/IP hydropower plant generation, potential errors in the total resource curve resulting from the simplistic methods described here are relatively small in comparison to potential errors for estimates of future CRSP resources.

Through conversations with Western staff at the dispatch center in Montrose, Colorado, it was learned that the Collbran and Rio Grande Projects are not a dependable capacity source. Therefore, for the purpose of estimating the amount of capacity that can be used for LTF sales, the capacity associated with these projects is not included in the SLCA/IP capacity exceedance curves. These two projects are not reliable sources of firm capacity for the following reasons: (1) the Rio Grande plant is not on automatic generation control (AGC); (2) Collbran has only a few hours of storage capacity; and (3) Rio Grande releases are dictated by irrigation.

\subsection{LONG-TERM FIRM COMMITMENTS AND HYDROVARIABILITY}

When Western formulates LTF marketing strategies, it relies on results from the CRSS model and historical data to project capacity and energy from SLCA/IP hydropower plants. As noted earlier, Western cannot market all of these resources on a LTF basis. Western must also account for physical factors and priority uses, which include the following: (1) plant use, (2) system losses, (3) IPP spinning reserve requirements, (4) area load control, (5) project use, and (6) hydroelectric 
system maintenance requirements and reliability. Although each of these factors is important in terms of LTF marketing, hydropower conditions ultimately dictate the amount of energy that can be produced by the hydropower plants.

\subsubsection{Long-Term Firm Capacity Commitments}

Historically, the amount of capacity and energy that Western marketed was based on its hydropower resources. With the exception of PTC, this marketing philosophy prevailed through the implementation of the post-1989 marketing criteria. To a certain extent, however, Western's LTF marketing strategy is independent of its hydropower resources; that is, Western has discretion over its LTF programs and can market either more or less LTF capacity and energy than is produced by the SLCA/IP hydropower plants. If Western markets more capacity and energy than is supplied by its hydropower plants, Western must make purchases or have some other mechanism in place (i.e., capacity and energy exchanges) to meet its firm contractual obligations. Depending on the situation, purchases and other arrangements can be made on a LTF or short-term non-firm basis.

Figures 8 and 9 show probability exceedance distributions for SLCA/IP hydropower capacity for summer and winter, respectively. These seasonal curves are represented by a high load month in each season. Winter is represented by January, and summer is represented by July. The figures show that under adverse hydropower conditions (i.e., the driest projected conditions), the amount of SLCA/IP hydropower plant capacity that can be used to serve LTF capacity commitments is approximately 1,225 MW during the representative winter month and 1,300 MW during the representative summer month. If capacity is marketed at this relatively low level, Western can almost always meet its contractual obligations without supplementing SLCA/IP hydropower plant capacity in peak load months.

At a hydropower exceedance probability of 50\%, SLCA/IP hydropower plant capacity to serve LTF commitments increase to approximately 1,535 MW in the representative winter month and 1,400 MW in the representative summer month. At this exceedance level, capacity reserved for project use is much higher in the summer; thus, the level of marketable capacity is higher in the winter than in the summer. If capacity is marketed at the 50\% level, Western must augment SLCA/IP capacity through contractual agreements or capacity additions to meet its LTF capacity commitments consistently. Without capacity augmentation, Western cannot meet its contractual obligations on a firm basis $50 \%$ of the time during the two representative months. However, if energy is available on the spot market, Western can purchase energy during on-peak hours but is at risk of having the nonfirm contract abruptly stopped. From a reliability standpoint, the use of non-firm purchases to serve firm loads on a long-term basis is risky and unacceptable.

Because CRSS projects hydropower resources to be at or near reservoir capacities $50 \%$ of the time in January and July, capacity levels do not increase above the $50 \%$ probability level. When 
Western uses load-following techniques to market its capacity, months other than the two representative peak months have a different probability of hydropower augmentation.

\subsubsection{Unscheduled Outages}

In addition to hydrological variability, unscheduled outages due to mechanical failures compound uncertainties associated with SLCA/IP capacity levels. Although the probability of an outage at any individual SLCA/IP unit is rather small, there is a much higher probability that one or more units will not be available at any given moment in time. On the basis of historical equivalent forced outages for all hydropower units in the United States averaged over the past 5 years, equivalent forced outage rates of $2.9 \%$ for hydropower units of more than $30 \mathrm{MW}$ and $3.8 \%$ for hydropower units of $30 \mathrm{MW}$ or smaller were used. These outage rates were obtained from NERC's Generating Availability Report (NERC 1991). Conversations with A. Anderson of Reclamation indicated that the estimates of equivalent forced outages used in this study are conservative. Although Reclamation did not furnish the precise number of forced outages for each facility, it did estimate that equivalent forced outages were probably "no more than three percent." Therefore, estimates of cumulative outage probabilities for SLCA/P hydropower units presented in this study are probably high.

Figure 12 shows two cumulative probability distribution curves of the amount of time that SLCA/IP hydropower plant capacity (in terms of nameplate capacity) is on-line; one situation assumes no units are on scheduled maintenance, and the other situation assumes a large number of units are on scheduled maintenance. When no units are on scheduled maintenance, all hydropower units will be fully operational approximately $50 \%$ of the time. This situation implies that at least some amount of generating capacity will be unavailable $50 \%$ of the time because of full or partial unscheduled outages. There is a very small probability (less than $1 \times 10^{-30} \%$ ) that all units will simultaneously be out of service because of forced outages.

When a forced outage occurs, it may or may not have an adverse effect on Western's ability to meet firm capacity obligations. If an outage is short in duration and occurs during off-peak hours, other units at the facility can be used to generate electricity. However, if several units are out of service for a longer time that spans several peak demand periods, the electricity generation during this critical period is lost, and Western may have to request emergency assistance from an IPP member. The cumulative probability distribution curve in Figure 12 shows that during $19 \%$ of the time, approximately $170 \mathrm{MW}$ will be out of service because of unscheduled outages. 


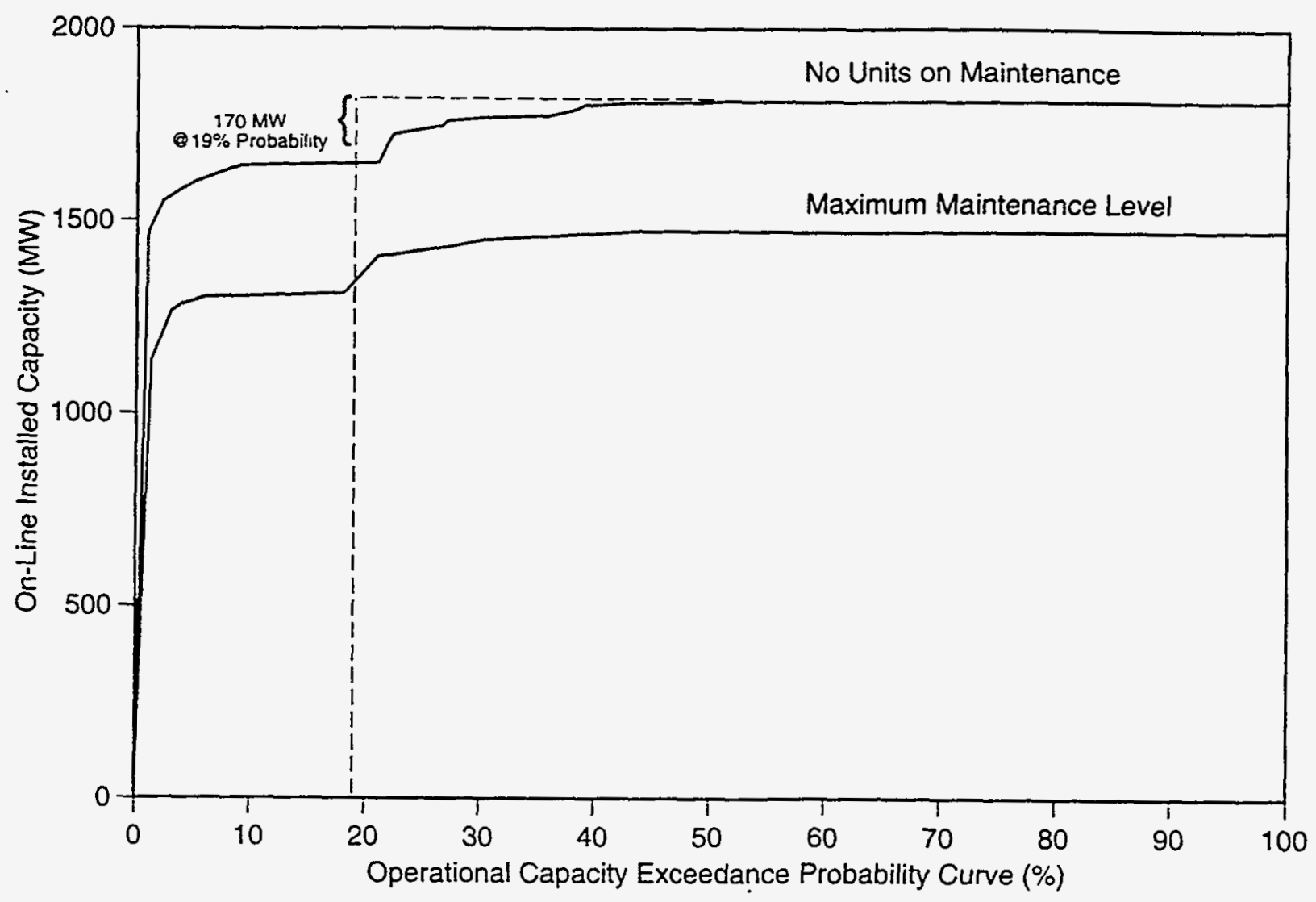

FIGURE 12 Effects of Forced Outage Rates on Availability of Installed Capacity

\subsubsection{Long-Term Firm Energy Commitments}

Hydropower plant capacity is a function of gross head, turbine efficiency, and maximum instantaneous water release rate (usually expressed in cubic feet per second). Electricity production is a function of hydropower plant capacity and the total amount of water released through the turbines over a specific time period (i.e., 1 month). As shown in Figure 10, the amount of SLCAIP energy available for LTF sales in the summer ranges from 1,310 GWh under adverse hydropower conditions to more than $5,960 \mathrm{GWh}$ in very wet years. In winter, SLCA/IP energy ranges from $1,830 \mathrm{GWh}$ to more than 4,680 GWh (see Figure 11). Note that SLCA/IP energy in summer varies by a factor of 4.5 (i.e., energy levels associated with adverse conditions compared with energy levels associated with a zero exceedance level), while SLCA/IP energy in winter varies by a factor of 2.5. Variations in SLCA/IP energy are much larger than the $15-20 \%$ variations in seasonal capacity.

The shapes of the curves in Figures 10 and 11 are affected by both random natural occurrences and human influences. Since a minimum of 8.23 million acre-feet of water must be released annually from the Glen Canyon Dam, changes in SLCA/IP energy at high exceedance probability levels are primarily related to changes in gross head at the dam and the scheduling of 
water between seasons. High levels of energy production from SLCA/IP hydropower plants occur infrequently because the following two conditions must be met simultaneously: (1) dam reservoirs must be near capacity levels (this occurs approximately $50 \%$ of the time), and (2) there must be a relatively large inflow of water into the reservoirs. When inflows are large and dam reservoirs are low, water releases are kept relatively low to fill the reservoirs. If the minimum release requirement did not exist, reservoirs would be near maximum capacity more frequently. A higher probability of high-electricity-generation occurrences and more frequent low-generation occurrences would also be likely.

Filling reservoirs and storing excess water during high hydrological periods for use during dry periods results in a negatively skewed distribution of electricity production (Figure 13). The average generation level over all events is significantly larger than the mode. This situation contrasts with conditions before human intervention, which suggest a near-normal frequency distribution of water flows at Lee's Ferry. Before the dam was built, the median and the mean were almost identical (14.90 million acre-feet/yr for the median compared with 14.93 million acre-feet/yr for the mean). The tail end of the probability distribution curve for high flows is only slightly larger than the tail end of the probability distribution for low flows. Also, note that in Figures 10 and 11, the average hydrological level has an exceedance level significantly higher than the 50th percentile level.

\subsection{DIMINISHING RESOURCES OVER TIME}

Depletion of Upper Colorado River water resources is projected to increase by more than 1,500 million acre-feet over 1990 levels by 2040 because of increasing water allotments for industry, municipalities, and irrigation. Therefore, in the long term, Western will have less SLCA/IP capacity and energy available to serve firm commitments. Figure 14 shows a projection of the increase in annual energy production loss above current levels as a result of water diversions. The figure reflects projected loss at the Glen Canyon hydropower plant only. Additional losses due to depletion effects are expected to occur at other SLCA/IP hydropower plants. By 2020, additional water depletion will reduce annual generation at the Glen Canyon power plant by more than $700 \mathrm{GWh}$.

In addition to lower SLCA/P resources, capacity reserve margins in the region are projected to decrease substantially (WSCC 1991). Excess capacity in the region is shrinking, and it will be more difficult and expensive to purchase energy and capacity. Western may also be called on to assist with system emergencies more often as demand growth in the region outstrips the expansion of electricity generating capacity. NERC projects that the summer capacity reserve margin in the Arizona-New Mexico area will drop from its 1991 level of $27.0 \%$ to $15.5 \%$ by 2000 . This projection is based on a low annual peak demand growth rate of $1.9 \%$. This rate is much lower than the $4.5 \% / \mathrm{yr}$ growth the pool experienced from 1985 through 1990. Other regions in the western United States are also expected to experience significantly lower capacity reserve margins by 2000 . For example, 
56
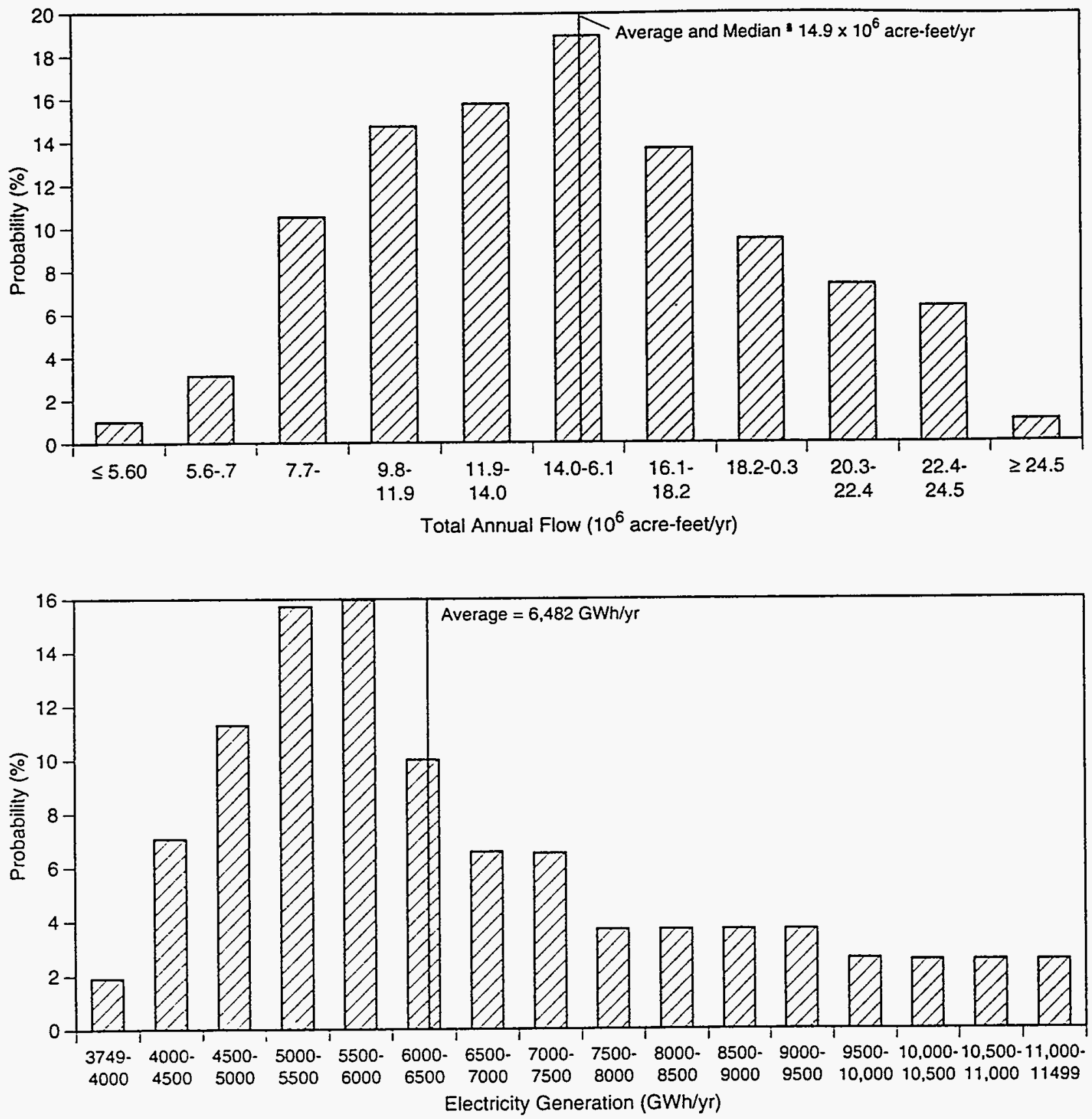

FIGURE 13 Comparison of Total Annual Flow before Dam Construction with Annual Electricity Generation after Dam Construction 


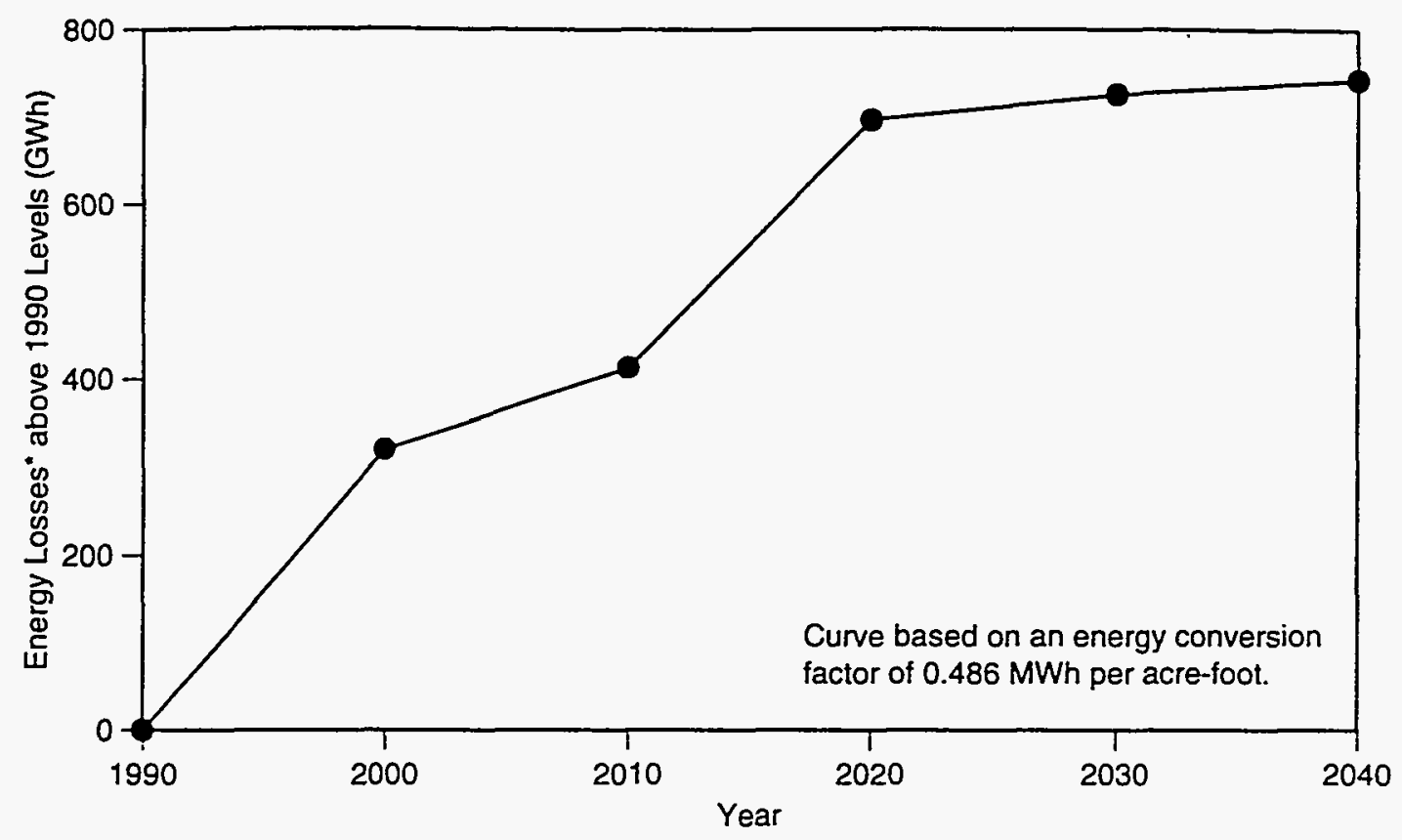

"Losses only apply to Glen Canyon. Additional losses at other hydroelectric facilities are projected to occur.

\section{FIGURE 14 Projected Energy Losses above 1990 Levels Due to Depletion Effects}

on the basis of an annual growth rate of $1.2 \%$, the northwest subregion of WSCC is projected to experience a decrease in winter capacity reserve margin from the 1991 level of $24.9 \%$ to $18.4 \%$ by 2000. Even the Rocky Mountain power area is expected to experience a decrease in its capacity reserve margin to $21.2 \%$ from the 1991 level of $27.9 \%$. Larger than projected peak demands, delays in construction schedules for new units, and the early retirement of existing units could lower capacity reserve margins even further.

\subsection{MONTHLY HYDROLOGICAL VARIABILITY AND MARKETING RISKS}

The previous subsections discussed hydrological variability and the amount of capacity and energy available for LTF sales. This subsection and the next explore SLCA/IP resource variability on a monthly basis. The upper half of Figure 15 shows SLCA/IP hydropower plant capacity levels by month at various hydropower exceedence levels. For a given level of capacity, exceedance probabilities are greatest in summer (June-August) and lowest in spring (February-April). For example, at the 1,600-MW resource capacity level, hydropower exceedance is approximately $77 \%$ in March and $94 \%$ in July. This pattern reflects Reclamation's monthly release pattern of water from SLCA/IP dams. That is, reservoir levels are lowered in the early spring to accommodate the highrunoff periods later in the season. Reclamation then attempts to fill the reservoirs by July to store 

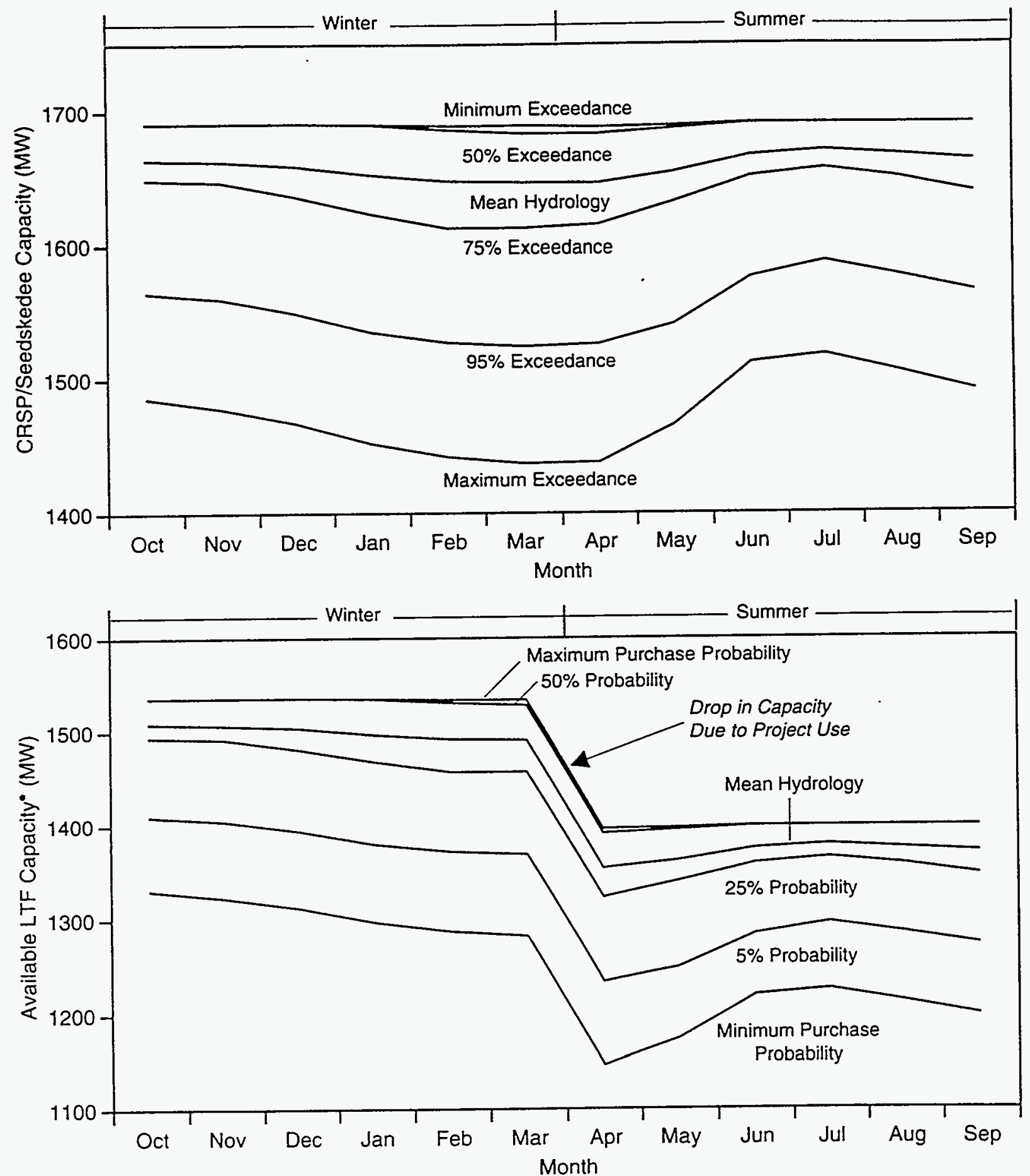

-Does not include project use, regulation services, and spinning reserve requirements. Also does not include Collbran and Rio Grande projects.

FIGURE 15 Monthly Total Hydroelectric Capacity and Capacity Augmentation Probability 
water for the dry season, which extends from late summer through winter. The greatest variability in power plant capacity levels occurs in spring when capacity ranges between a minimum of approximately 1,440 MW and a maximum of 1,690 MW.

The lower half of Figure 15 shows the amount of capacity that can be used to serve firm demands as a function of month and hydropower augmentation probability. The large drop in capacity between winter and summer is due to the larger amounts of hydroelectric resources reserved for project use in summer.

The upper half of Figure 16 shows SLCA/P hydropower plant energy by month at various hydropower exceedance levels. Hydropower variability differs significantly across months. In December, the generation range is relatively small, 400-550 GWh. From December through June, hydropower variability steadily increases. From June until July, the range increases rapidly until it reaches a maximum of approximately $840 \mathrm{GWh}$, varying from about 420 to $1,260 \mathrm{GWh}$. From May through November, the mean hydrology is significantly higher than the $50 \%$ exceedance level, on a monthly basis. The upper half of Figure 15 shows SLCA/IP hydropower plant capacity levels by month at various hydropower exceedance levels. For a given level of capacity, exceedance indicating a negatively skewed probability distribution during these months. From December through May, the mean and the 50\% exceedance level are approximately equal, signifying that hydropower events for these months may form a normal distribution.

The lower half of Figure 16 shows the amount of SLCA/IP hydropower plant energy that can be used to serve firm loads. This graph is similar to the upper half of Figure 16, but it has been adjusted for project use and losses. For a given exceedance level, LTF energy levels can change significantly between months within a season. However, these variations are much smaller at lower exceedance levels than at high exceedance levels. At the $0 \%$ exceedance level, the maximum amount of energy available for LTF sales varies from a high of approximately $430 \mathrm{GWh}$ in January to a low of $180 \mathrm{GWh}$ in April and May (a difference of $250 \mathrm{GWh}$ ). At the $100 \%$ exceedance level, the maximum energy available for LTF sales varies from approximately $530 \mathrm{GWh}$ in December to $1,130 \mathrm{GWh}$ in July (a difference of approximately $600 \mathrm{GWh}$ ).

\subsection{MONTHLY LONG-TERM FIRM CAPACITY AND ENERGY ALLOCATIONS}

This section describes two different methods for determining customers' monthly LTF capacity on the basis of CRODs and for distributing customers' seasonal energy allocations over each month in the season. The first method, which is currently used by Western, patterns monthly LTF energy and capacity levels on the basis of each customer's load. This method is called load patterning. The second method patterns monthly LTF energy and capacity on the basis of monthly 

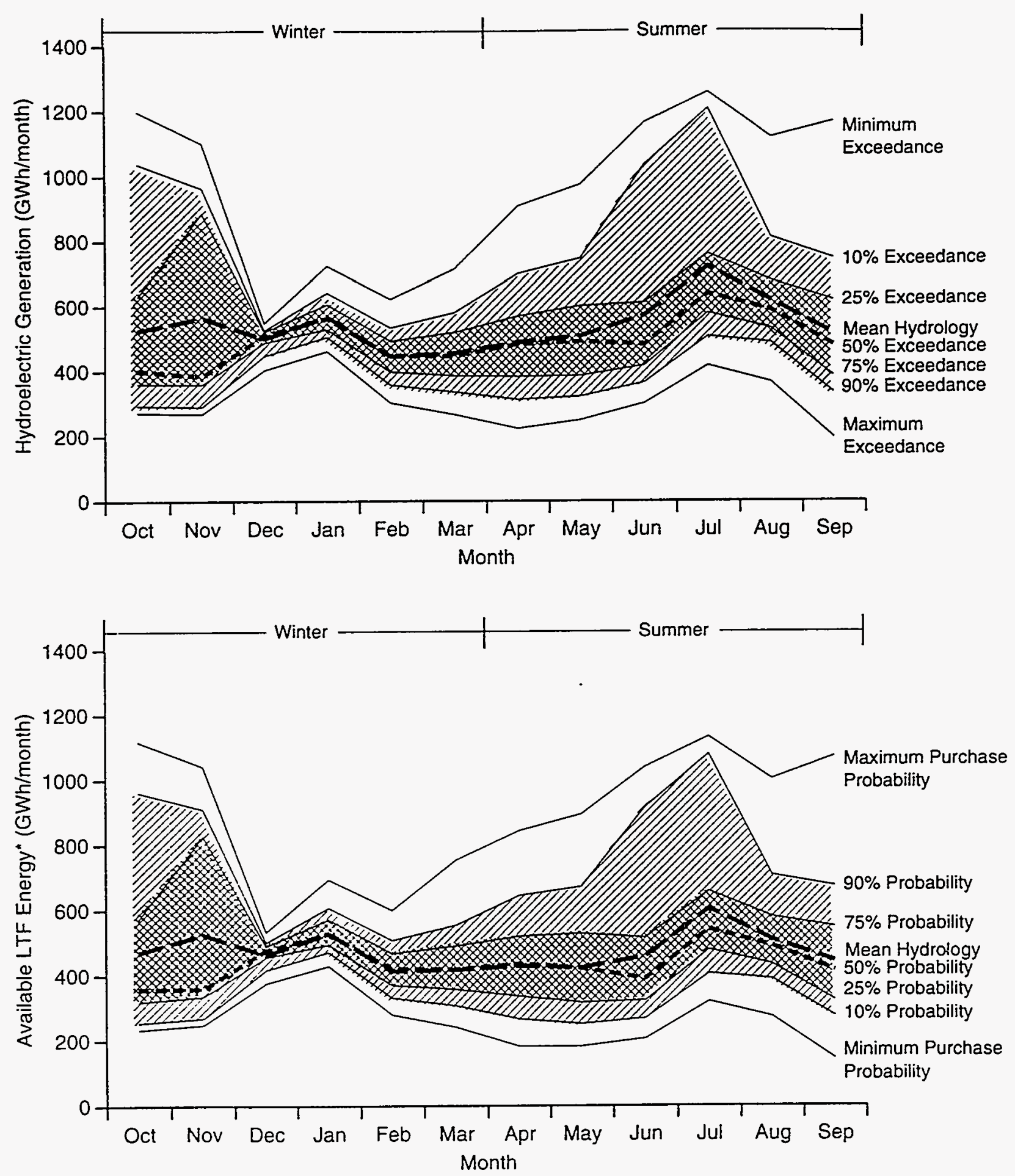

-Assumes losses of $7 \%$ and excludes monthly project use.

FIGURE 16 Monthly Total Hydroelectric Generation and Energy Augmentation Probability 
SLCA/IP hydropower plant capacity and energy. It is referred to as resource patterning. Load-patterned and resource-patterned methods for distributing seasonal LTF sales result in significantly different monthly levels of energy and capacity. For this study, Western's monthly firm capacity and energy load patterns were derived from interim post-1989 allocations as revised on March 11, 1991.

Load patterning distributes a customer's monthly energy and capacity deliveries so that the deliveries are proportional to the utility's monthly load. For example, if a utility's CROD is $100 \mathrm{MW}$ and its historical peak summer demand (based on a 3-year average) is in July, the utility will receive its full allocation of capacity for that month. The amount of capacity the utility receives in the other summer months depends on the ratio of the peak demand in a given month to the peak demand in July. If the utility's peak demand in July is 1,000 MW and it drops to $950 \mathrm{MW}$ in August, the customer's LTF capacity is reduced to $95 \mathrm{MW}$ (i.e., $95 \mathrm{MW}=100 \mathrm{MW} \times 950 \mathrm{MW} / 1,000 \mathrm{MW}$ ).

The customer's seasonal energy allocation is distributed over the months in a similar manner. The only difference is that the energy pattern is benchmarked by the utility's total system load for each month instead of by the monthly peak demand. For example, if a utility's system load in July is $50 \mathrm{GWh}$, and it is allocated $5 \mathrm{GWh}$ of SLCA/P LTF energy, the customer's energy would be reduced to $4.5 \mathrm{GWh}$ in August when its load drops to $45 \mathrm{GWh}$ (i.e., $4.5 \mathrm{GWh}=$ $5 \mathrm{GWh} \times 45 \mathrm{GWh} / 50 \mathrm{GWh}$ ).

In resource patterning, the probability of hydropower augmentation for each month in a season is constant; that is, Western's firm monthly commitments are based on changes in SLCA/IP resources. In contrast, under the load-patterning method, the probability of hydropower augmentation varies as a function of month. As shown in Table 3, both methods result in identical probabilities of hydropower augmentation in the month of the maximum seasonal demand (December in winter and July in summer). During these two peak months, the amounts of capacity available for LTF are identical. When the load-following method is used, the augmentation probability levels in most of the other months of the year are lower than those during the peak load month. However, probabilities are slightly higher (1-4\%) than those of the peak load month in January and August. In winter, this situation occurs because SLCA/P capacity declines slightly faster (Figure 15) than customers' peak loads do from December to January. In other winter months, either SLCA/IP capacity is greater than the December level (October and November) or SLCA/IP capacity declines at a slower rate than customers' peak demands (February and March).

In summer, hydropower augmentation probability levels in April, May, and June are lower than those of the peak month (i.e., July) because aggregate customer peak loads increase at a faster rate than hydropower capacity. Between July and August, hydropower capacity declines at a slightly greater rate than aggregate customer peak loads do, which results in a slightly higher probability of hydropower augmentation. 
TABLE 3 Long-Term Firm Capacity by Seasonal Capacity Augmentation Probability Level under the Load-Following and Resource-Following Methods

\begin{tabular}{|c|c|c|c|c|c|c|c|c|c|}
\hline \multirow[b]{2}{*}{ Month } & \multicolumn{3}{|c|}{ Minimal } & \multicolumn{3}{|c|}{$10 \%$} & \multicolumn{3}{|c|}{$25 \%$} \\
\hline & $\begin{array}{l}\text { Load } \\
\text { Following } \\
\text { Capacity } \\
\text { (MW') }\end{array}$ & $\begin{array}{c}\text { Load } \\
\text { Following } \\
\text { Probability } \\
\text { (\%) }\end{array}$ & $\begin{array}{c}\text { Resource } \\
\text { Following } \\
\text { Capacity } \\
(<W)\end{array}$ & $\begin{array}{l}\text { Load } \\
\text { Following } \\
\text { Capacity } \\
\text { (MW) }\end{array}$ & $\begin{array}{c}\text { Load } \\
\text { Following } \\
\text { Probability } \\
\text { (5) }\end{array}$ & $\begin{array}{c}\text { Resource } \\
\text { Following } \\
\text { Capacity } \\
\text { (MW) }\end{array}$ & $\begin{array}{l}\text { Load } \\
\text { Following } \\
\text { Capacity } \\
\text { (MW) }\end{array}$ & $\begin{array}{l}\text { Load } \\
\text { Following } \\
\text { Probability } \\
\text { (\%) }\end{array}$ & $\begin{array}{c}\text { Resource } \\
\text { Following } \\
\text { Capacity } \\
\text { (MW) }\end{array}$ \\
\hline $\mathrm{Oct}$ & 1,119 & $\mathbf{a}$ & 1,331 & 1,211 & $\mathbf{a}$ & 1,434 & 1,263 & a & 1.494 \\
\hline Nov & 1.227 & a & 1,323 & 1.329 & Min & 1.429 & 1,386 & 3 & 1,492 \\
\hline Dec & 1.312 & Min & 1.312 & 1.420 & 10 & 1,420 & 1,481 & 25 & 1.481 \\
\hline Jan & 1.303 & $\mathrm{Min}$ & 1.297 & 1,411 & 31 & 1,406 & 1,471 & 26 & 1,465 \\
\hline Feb & 1,278 & $a$ & 1.287 & 1,384 & 7 & 1,397 & 1.443 & 22 & 1,457 \\
\hline Mar & 1.194 & a & 1.282 & 1,292 & $\mathrm{Min}$ & 1,391 & 1,348 & 2 & 1.457 \\
\hline Apr & 1.000 & a & 1,146 & 1.078 & a & 1.256 & 1,113 & a & 1,323 \\
\hline May & 1.043 & a & 1.174 & 1,124 & $\mathrm{a}$ & 1,275 & 1.162 & a & 1,340 \\
\hline Ји & 1.148 & a & 1.220 & 1.236 & 1 & 1,305 & 1,278 & 5 & 1.359 \\
\hline Jul & 1.226 & Min & 1.226 & 1,320 & 10 & 1.320 & 1.365 & 25 & 1.365 \\
\hline Aus & 1.226 & $M i n$ & 1.213 & 1.320 & 14 & 1,308 & 1,365 & 27 & 1,358 \\
\hline Sept & 1.141 & a & 1.199 & 1.229 & 1 & 1,296 & 1.271 & 5 & 1,347 \\
\hline
\end{tabular}

\begin{tabular}{|c|c|c|c|c|c|c|}
\hline \multirow[b]{2}{*}{ Month } & \multicolumn{3}{|c|}{$50 \%$} & \multicolumn{3}{|c|}{ Mean Capacity } \\
\hline & $\begin{array}{l}\text { Load } \\
\text { Following } \\
\text { Capacity } \\
\text { (AiW) }\end{array}$ & $\begin{array}{c}\text { Load } \\
\text { Following } \\
\text { Probability } \\
(\pi)\end{array}$ & $\begin{array}{c}\text { Resource } \\
\text { Following } \\
\text { Capacity } \\
\text { (MW) }\end{array}$ & $\begin{array}{l}\text { Load } \\
\text { Following } \\
\text { Capacity } \\
(\mathrm{MW})\end{array}$ & $\begin{array}{l}\text { Load } \\
\text { Following } \\
\text { Probability } \\
\text { (\%) }\end{array}$ & $\begin{array}{c}\text { Resource } \\
\text { Following } \\
\text { Capacity } \\
\text { (MW) }\end{array}$ \\
\hline $\mathrm{Oct}$ & 1.310 & a & 1.536 & 1,282 & $\mathbf{a}$ & 1,508 \\
\hline Nov & 1.437 & 12 & 1.536 & 1,407 & 5 & 1.507 \\
\hline Dec & 1.536 & 50 & 1,536 & $1.50-4$ & 32 & 1,503 \\
\hline Jan & 1.526 & 45 & 1.535 & 3,493 & 33 & 1.497 \\
\hline Feb & 1.497 & 37 & 1,531 & 1.465 & 27 & 1.492 \\
\hline Mas & 1.398 & 12 & 1.528 & 1,369 & 5 & 1,491 \\
\hline Apr & 1.141 & a & 1.391 & 1.124 & a & 1,354 \\
\hline Masy & 1.191 & 1 & 1,395 & 1.173 & $\mathbf{a}$ & 1.362 \\
\hline Juภ & 1.310 & 11 & 1.399 & 1.291 & 7 & 1.375 \\
\hline Jul & 1.399 & 50 & 1.399 & 1,379 & 31 & 1.379 \\
\hline AuE & 1.399 & 40 & 1.399 & 1.378 & 32 & 1.375 \\
\hline Sept & 1.302 & 12 & 1.399 & 1,283 & 7 & 1.371 \\
\hline
\end{tabular}

- Augmentatuon probability $\lll$ less than the minumum level projected by the CRSS model runs

Table 4 display's the amount of LTF energy by hydropower augmentation probability for both patterning methods. Under the load-following method, the hydropower augmentation probability is higher than the seasonal augmentation probability in about half of the months. Under the load-following method, the hydropower augmentation probability can differ substantially from the seasonal probability. For example, at a seasonal augmentation probability of $50 \%$, the monthly augmentation probability is approximately $8 \%$ in January, and it increases to about $62 \%$ in October. 
TABLE 4 Long-Term Firm Energy by Seasonal Capacity Augmentation Probability Level under the Load-Following and Resource-Following Methods

\begin{tabular}{|c|c|c|c|c|c|c|c|c|c|}
\hline \multirow[b]{2}{*}{ Month } & \multicolumn{3}{|c|}{ Minimal } & \multicolumn{3}{|c|}{$10 \%$} & \multicolumn{3}{|c|}{$25 \%$} \\
\hline & $\begin{array}{l}\text { Load } \\
\text { Following } \\
\text { Energy } \\
\text { (GWh) }\end{array}$ & $\begin{array}{c}\text { Load } \\
\text { Following } \\
\text { Probability } \\
\text { (\$) }\end{array}$ & $\begin{array}{l}\text { Resource } \\
\text { Following } \\
\text { Energy } \\
\text { (GWh) }\end{array}$ & $\begin{array}{l}\text { Load } \\
\text { Following } \\
\text { Energy } \\
\text { (GWb) }\end{array}$ & $\begin{array}{c}\text { Load } \\
\text { Following } \\
\text { Probability } \\
\text { (F) }\end{array}$ & $\begin{array}{c}\text { Resource } \\
\text { Following } \\
\text { Energy } \\
\text { (GWh) }\end{array}$ & $\begin{array}{l}\text { Load } \\
\text { Following } \\
\text { Energy } \\
\text { (GWh) }\end{array}$ & $\begin{array}{l}\text { Load } \\
\text { Following } \\
\text { Probability } \\
\text { (\%) }\end{array}$ & $\begin{array}{c}\text { Resource } \\
\text { Following } \\
\text { Energy } \\
\text { GWh) }\end{array}$ \\
\hline OcI & 278 & 15.5 & 233 & 316 & 24.3 & 254 & 360 & 52.0 & 319 \\
\hline Nov & 286 & 14.0 & 248 & 325 & 22.8 & 268 & 370 & 51.1 & 335 \\
\hline Dec & 323 & b & 375 & 366 & b & 416 & 417 & 10.0 & 455 \\
\hline Jan & 326 & b & 428 & 370 & b & 470 & 422 & b & 493 \\
\hline Feb & 289 & 1.0 & 278 & 328 & 9.3 & 330 & 374 & 27.4 & 369 \\
\hline Mas & 298 & 7.6 & 240 & 338 & 19.6 & 306 & 385 & 35.6 & 356 \\
\hline Apr & 191 & 0.4 & 181 & 271 & 11.3 & 265 & 323 & 22.4 & 335 \\
\hline May & 199 & 0.9 & 181 & 283 & 17.5 & 250 & 338 & 31.1 & 316 \\
\hline Jun & 214 & 0.5 & 205 & 305 & 204 & 267 & 364 & 43.4 & 322 \\
\hline Jul & 245 & b & 319 & 348 & 1.9 & 405 & 415 & 12.1 & 478 \\
\hline Aug & 245 & b & 272 & 348 & 6.0 & 388 & 416 & 19.3 & 433 \\
\hline \multirow[t]{2}{*}{ Sept } & 207 & 3.1 & 143 & 295 & 16.4 & 274 & 352 & 33.5 & 323 \\
\hline & \multicolumn{3}{|c|}{$50 \%$} & \multicolumn{3}{|c|}{$75 \%$} & \multicolumn{3}{|c|}{$90 \%$} \\
\hline Month & $\begin{array}{l}\text { Load } \\
\text { Following } \\
\text { Energy } \\
(G W h)\end{array}$ & $\begin{array}{c}\text { Load } \\
\text { Following } \\
\text { Probability } \\
(\boldsymbol{k})\end{array}$ & $\begin{array}{c}\text { Resource } \\
\text { Following } \\
\text { Energy } \\
\text { (GWh) }\end{array}$ & $\begin{array}{l}\text { Load } \\
\text { Following } \\
\text { Energ! } \\
\text { (GWh) }\end{array}$ & $\begin{array}{l}\text { Load } \\
\text { Following } \\
\text { Probability } \\
\text { (๘) }\end{array}$ & $\begin{array}{c}\text { Resource } \\
\text { Following } \\
\text { Energy } \\
\text { (GWh) }\end{array}$ & $\begin{array}{l}\text { Load } \\
\text { Following } \\
\text { Energy } \\
\text { (GWh) }\end{array}$ & $\begin{array}{c}\text { Load } \\
\text { Following } \\
\text { Probability } \\
(\mathscr{F})\end{array}$ & $\begin{array}{c}\text { Resource } \\
\text { Following } \\
\text { Energy } \\
\text { (GWh) }\end{array}$ \\
\hline Oet & 395 & 61.7 & 357 & 528 & 71.8 & 570 & 625 & 77.1 & 962 \\
\hline Nor & 406 & 54.7 & 359 & 542 & 63.4 & 827 & 641 & 67.4 & 910 \\
\hline Dec & 458 & 27.6 & 476 & 612 & c & 489 & 724 & c & 500 \\
\hline Jan & 463 & 8.1 & 526 & 618 & 91.4 & 570 & 731 & c & 606 \\
\hline $\mathrm{Feb}$ & 410 & 45.3 & 419 & 548 & 946 & 466 & 648 & c & 506 \\
\hline Mar & 422 & 51.7 & 417 & 564 & 90.6 & 489 & 668 & 958 & 552 \\
\hline Apr & 394 & 400 & 434 & 489 & 674 & 518 & 686 & 92.2 & $6+3$ \\
\hline May' & 411 & 48.0 & 421 & 511 & 714 & 527 & 717 & 921 & 670 \\
\hline Jun & 443 & 592 & 389 & 551 & 764 & 514 & 772 & 847 & 915 \\
\hline Sul & 505 & 400 & 540 & 628 & 692 & 657 & 881 & 830 & 1.079 \\
\hline Aug & 506 & 55.3 & 489 & 629 & 81.0 & 578 & 883 & 960 & 706 \\
\hline Sept & 428 & 53.3 & 415 & 532 & 726 & 547 & 747 & 919 & 672 \\
\hline
\end{tabular}


TABLE 4 (Cont.)

\begin{tabular}{|c|c|c|c|c|c|c|}
\hline \multirow[b]{2}{*}{ Month } & \multicolumn{3}{|c|}{ Maximum } & \multicolumn{3}{|c|}{ Mean Geperation } \\
\hline & $\begin{array}{l}\text { Load } \\
\text { Following } \\
\text { Exergy } \\
\text { (GWh) }\end{array}$ & $\begin{array}{c}\text { Load } \\
\text { Following } \\
\text { Probability } \\
\text { (\%) }\end{array}$ & $\begin{array}{c}\text { Resource } \\
\text { Following } \\
\text { Energy } \\
\text { (GWh) }\end{array}$ & $\begin{array}{l}\text { Load } \\
\text { Following } \\
\text { Energy } \\
\text { (GWh) }\end{array}$ & $\begin{array}{c}\text { Load } \\
\text { Following } \\
\text { Probability } \\
\text { (\%) }\end{array}$ & $\begin{array}{c}\text { Resource } \\
\text { Following } \\
\text { Energy } \\
\text { (GWh) }\end{array}$ \\
\hline Oct & 733 & 81.2 & 1,118 & 435 & 64.8 & 469 \\
\hline Nov & 752 & 71.9 & 1,042 & 447 & 58.8 & 525 \\
\hline Dec & 849 & $b$ & 532 & $504^{\circ}$ & 91.3 & 462 \\
\hline Jan & 858 & c & 693 & 509 & 37.0 & 527 \\
\hline Feb & 760 & c & 598 & 451 & 67.2 & 412 \\
\hline Mar & 783 & c & 752 & 465 & 66.6 & 416 \\
\hline Apr & 876 & c & 842 & 419 & 46.2 & 428 \\
\hline May & 915 & c & 893 & 438 & 54.3 & 442 \\
\hline Jun & 985 & 95.6 & 1,039 & 471 & 65.2 & 457 \\
\hline Jul & 1,124 & 98.5 & 1.132 & 538 & 50.0 & 603 \\
\hline Aug & 1,127 & c & 1,002 & 539 & 64.7 & 508 \\
\hline Sept & 953 & 97.0 & 1.072 & 456 & 60.0 & 443 \\
\hline
\end{tabular}

2 Under the resource-following method. the augmentation probability level in each month is identical to the seasonal augmentation probability level.

b Augmentation probability is less than the minimum level projected by the CRSS model nuns.

c Augmentation probability is more than the maximum level projected by the CRSS model nuns. 


\section{PURCHASE FLEXIBILITY AND HYDROPOWER OPERATIONS}

Currently, Western's purchasing program is a means of hydropower augmentation designed to achieve two goals: meeting contractual obligations when an insufficient amount of capacity or energy is available from SLCA/P hydropower plants and maximizing the value of hydroelectric resources. Western accomplishes these goals by buying relatively inexpensive energy during off-peak hours and storing water in reservoirs. This stored water is then released during on-peak hours when the electricity it produces is more valuable. This section describes the general relationships between Western's programs and SLCANP hydropower plant operations. Although the relationships are presented in quantitative terms, the numeric values should be viewed as gross estimates. Estimates of capacity and energy were made by simplistic simulation models and on the basis of information, data, and documents supplied by Western and Reclamation. For a more detailed discussion of the relationships between power marketing alternatives and SLCA/IP hydropower plant operations, see Veselka et al. (1995).

Historically, Western's operating philosophy has been consistent with the CRSP Act. Section 7 mandates that hydroelectric power plants authorized under the act shall be operated in conjunction with other federal power plants so as to produce the greatest practicable amount of power and energy that can be sold at firm power and energy rates. Section 7 further states that this authority shall not affect or interfere with the operation of the provisions of the Colorado River Compact, the Upper Colorado River Compact, the Boulder Canyon Project Act, the Boulder Canyon Project Adjustment Act, and any contract lawfully entered into under said compacts and acts. In keeping with the intent of the CRSP Act, Western strives to maximize the value of SLCA/IP hydropower plants and transmission resources. When Western's resources have been affected by operational limitations, such as past and current interim flow restrictions, Western has continued to maximize the value of the water resource within the constraints imposed on SLCA/IP hydropower plants.

Western's objectives are, in part, carried out through guidelines that provide general direction to personnel at the dispatch center in Montrose, Colorado. These guidelines, which are issued monthly, specify operating constraints and objectives (see, for example, DOE 1991). Operational constraints include (1) mandatory monthly water releases at each dam as dictated by Reclamation, (2) minimum and maximum release rates at each dam, (3) transmission limits on various buses, and (4) IPP spinning reserve requirements.

Dispatchers are also given general guidance regarding when, with whom, how many, and at what price spot market purchases should be made. The guidelines also specify the conditions under which spot market sales are to be made and the prior arrangements and agreements for energy interchanges. Energy purchases and interchanges are made only when they do not lead to violations of minimum flow requirements at any dam or exceed transmission capabilities. In addition, spot 
market sales are made only when firm loads have been met and the energy can be sold above a specified threshold price (i.e., $24 \mathrm{mill} / \mathrm{kWh}$ ). Through purchase and interchange practices, Western attempts to maximize the value of the SLCA/IP hydropower and transmission resources under its control.

The model simulation results and the conclusions reached in this section are based on the assumption that Western maximizes the value of SLCA/IP hydropower resources within current legal and statutory limits. In part, Western maximizes the value of resources through dispatching practices as reflected in the monthly operating guidelines.

\subsection{THE PEAK SHAVING ALGORITHM}

The peak shaving algorithm was used to estimate hourly hydropower plant operations under a specified set of physical, institutional, and legal constraints and to gain insights into key relationships between Western's programs and SLCA/IP power plant operations. The algorithm was developed by the Environmental Defense Fund and subsequently modified by Argonne National Laboratory. It maximizes hydroelectric generation during on-peak hours and minimizes the peak demand on thermal units. Through this process, the algorithm approximates the optimal use of one or more hydroelectric power plants by replacing generation from units with high variable costs (usually oil and gas peakers) with hydroelectric generation.

Although the peak shaving algorithm is useful for gaining insights into complex interactions among hydropower plants and institutional and legal constraints, it makes several simplifying assumptions. The algorithm does not account for transmission limitations and many of the interactions between thermal and hydropower plants. The algorithm also assumes that dispatchers have perfect foresight of future system loads and that operations at one hydropower plant do not affect operations at other hydropower plants (i.e., cascading effects). Because of these simplifying assumptions, results from the algorithm are rough approximations of actual operations and should be applied only to hydroelectric systems that have large storage capacities with minimal cascading effects. Also, the algorithm considers neither non-firm energy demands nor spot market prices.

Figure 17 shows a diagram of the algorithm's inputs and outputs. The algorithm requires information on maximum generating capacity, minimum flow requirements, the amount of energy that can be released from the dam in a specified time period, and ramp rate restrictions for each hydropow'er plant. System hourly loads are also input to the algorithm. Because of the proprietary nature of customers' hourly loads and load forecasts, typical hourly load shapes were used in this study. These typical hourly loads were extracted from the EPRI Regional Systems Database (1989) for each month of the year for the western United States. 


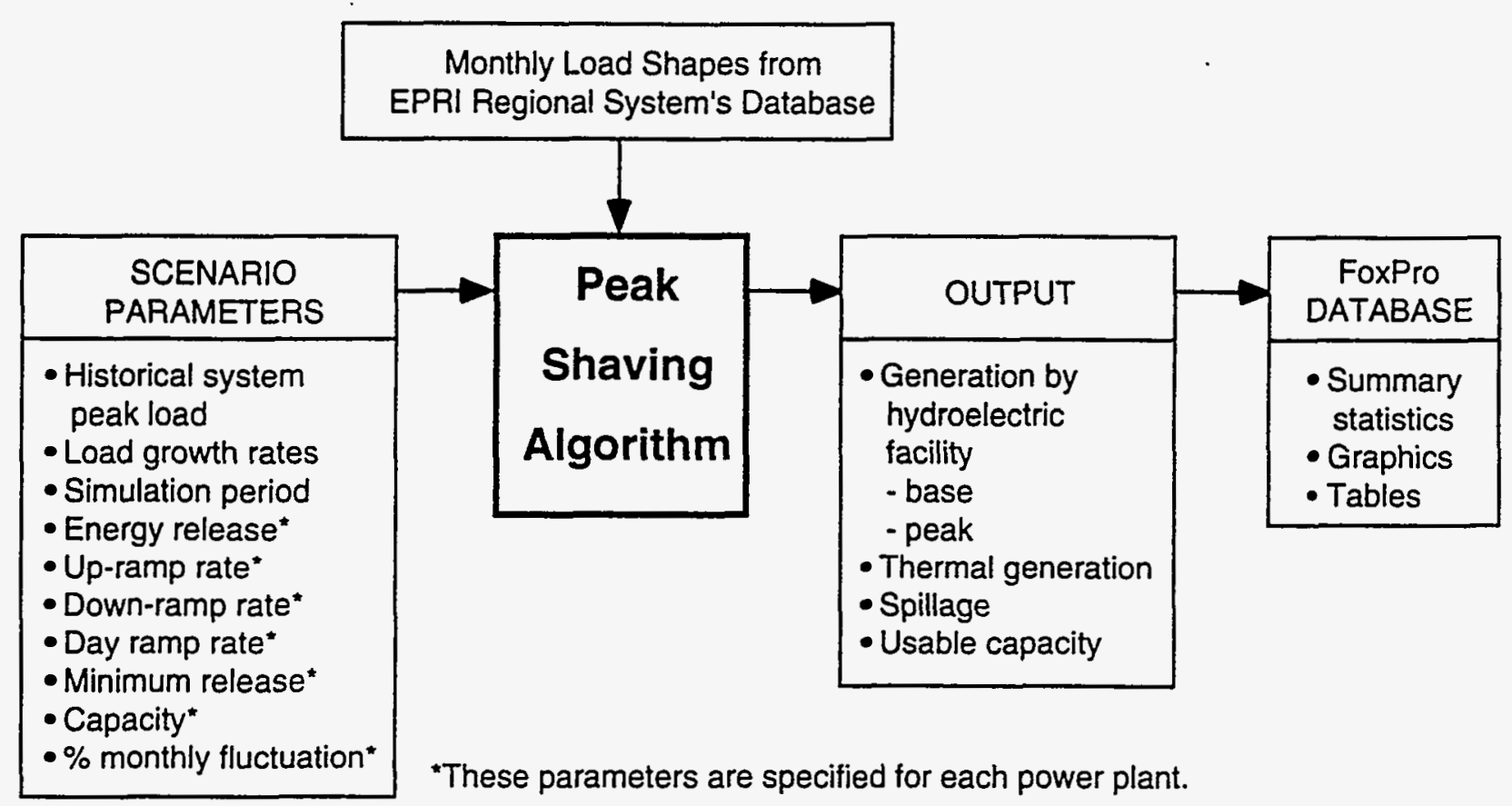

FIGURE 17 Inputs and Outputs of the Peak Shaving Algorithm

The peak shaving algorithm outputs hourly estimates of hydroelectric and thermal generation and spillage for each hydropower plant. It also estimates usable hydropower plant capacity for a specified time (i.e., 1 month). Outputs produced by one or more simulations are summarized in the form of tables and graphs through the use of the FoxPro database software package.

\subsection{PURCHASES FOR MEETING LONG-TERM CONTRACTS}

When its ability to purchase capacity and energy is limited, Western is, at best, able to market LTF capacity and energy on the basis of adverse hydropower conditions. Other factors, such as forced outages, scheduled maintenance, and unscheduled unit outages, must be estimated conservatively. Western's LTF commitment levels must be very low to ensure that its contractual obligations are met. SLCA/IP hydropower plant capacity and energy production must be greater than LTF contracts in all years. Excess resources can be offered to customers under STF contracts or sold on the spot market.

When purchases are unrestricted, Western is able to market both LTF capacity and energy above the amount of energy and capacity that would be produced by SLCA/IP hydropower plants under adverse hydropower conditions. That is, Western can purchase capacity and energy to meet LTF contractual commitments when SLCA/IP resources are insufficient. Through the purchase of 
LTF contracts, Western can offer more capacity and energy than is available from SLCAJP hydropower plants under very favorable hydropower conditions. Flexibility in purchasing allows Western to maximize the value of SLCA/IP hydroelectric and transmission resources.

Even when SLCA/IP resources are adequate to meet LTF contracts, Western purchases energy to satisfy a portion of its contractual obligations during off-peak hours. These purchases enable Western to store water and use it to generate electricity during on-peak hours. Western is able to sell this stored energy during on-peak hours at a rate much higher than the cost of purchases during off-peak hours. Through this practice, Western maximizes on-peak energy sales and hence the value of its hydroelectric resources. This practice also results in hourly SLCA/IP generation patterns that differ from Western's firm hourly loads.

\subsection{PURCHASE FLEXIBILITY AND DAM OPERATIONS}

When Western (1) can purchase a sufficient amount of off-peak energy, (2) has a buyer for the stored energy during on-peak hours, and (3) has sufficient transmission capabilities to deliver the energy, Western's dispatch of energy from SLCA/IP hydropower plants is, within certain limits, independent of its firm hourly loads. For example, if Western increased the minimum schedule requirement in its LTF contracts to $50 \%$ from the present level of $35 \%$, Western would not have to generate more hydroelectric energy during off-peak hours. Instead, Western could satisfy higher offpeak firm obligations through additional energy purchases. A $50 \%$ minimum schedule requirement significantly reduces the amount of energy a customer can use at its discretion. Customers usually consume this discretionary energy during on-peak hours. As depicted in Figure 18, hydropower plant operations are the same under both marketing strategies. However, Western's non-firm sales would be greater when its customers' minimum schedule requirements are higher.

Although, in theory, operations may be similar under both minimum schedule requirements (35 and 50\%) when the three conditions mentioned earlier are met, hourly generation patterns may differ in practice. The highest priority of the dispatchers is to meet firm loads under the physical and institutional constraints imposed on SLCAIP hydropower plants. Many of these constraints are outlined in monthly operating guidelines (e.g., DOE 1991), which specify a target profit margin for shifting energy from off-peak to on-peak periods. Because of uncertainties about the future and because profit margins are sometimes below a minimum target, the level of energy shifting depicted in Figure 18 does not always occur, and SLCA/IP generation more closely matches hourly firm load (Veselka et al. 1995).

If more restrictions were placed on Western's purchasing and interchange programs, a much stronger relationship would exist between LTF marketing programs and hydropower plant operations. The marketing elements that affect hydropower plant operations include, but are not 


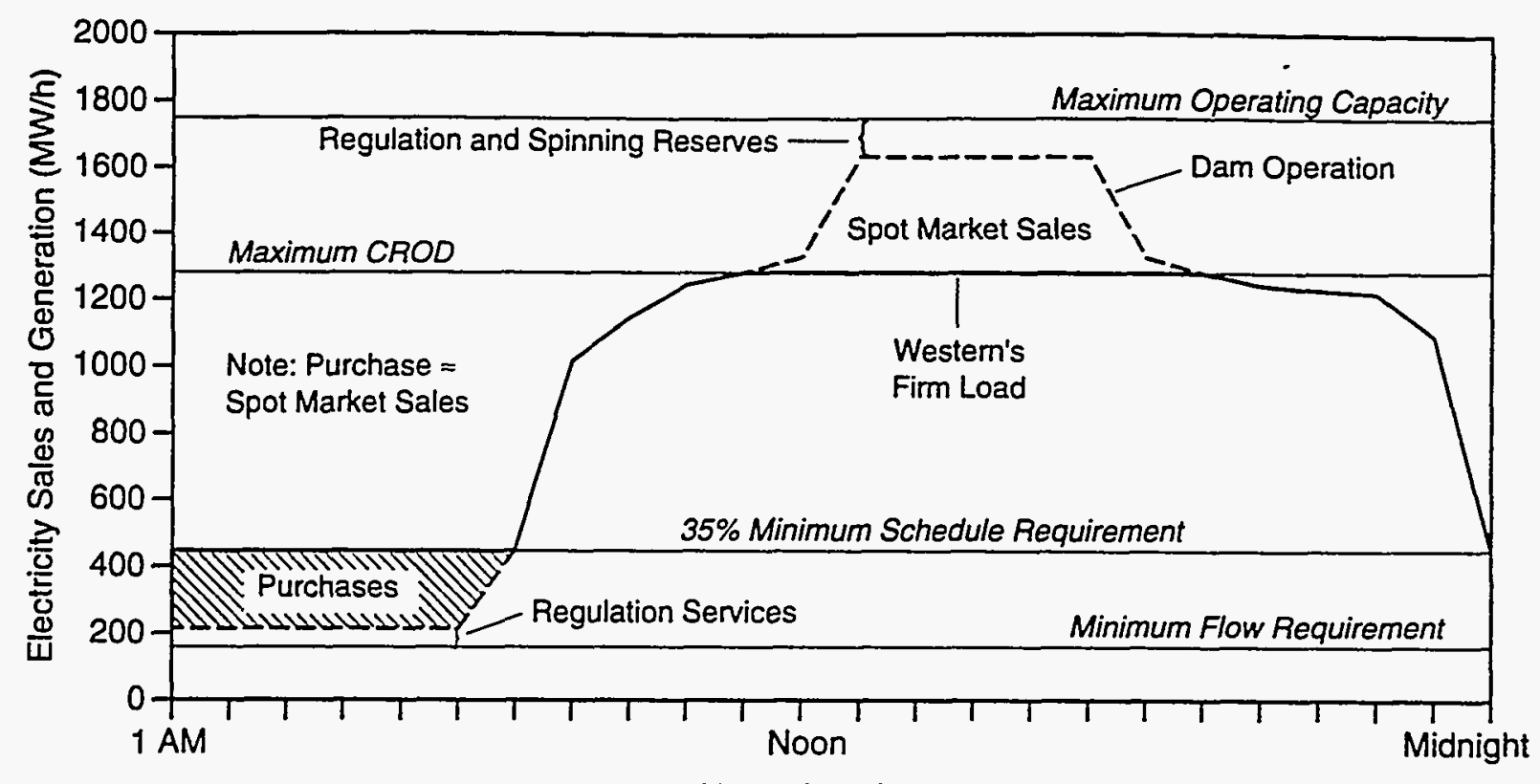

Hour of the Day

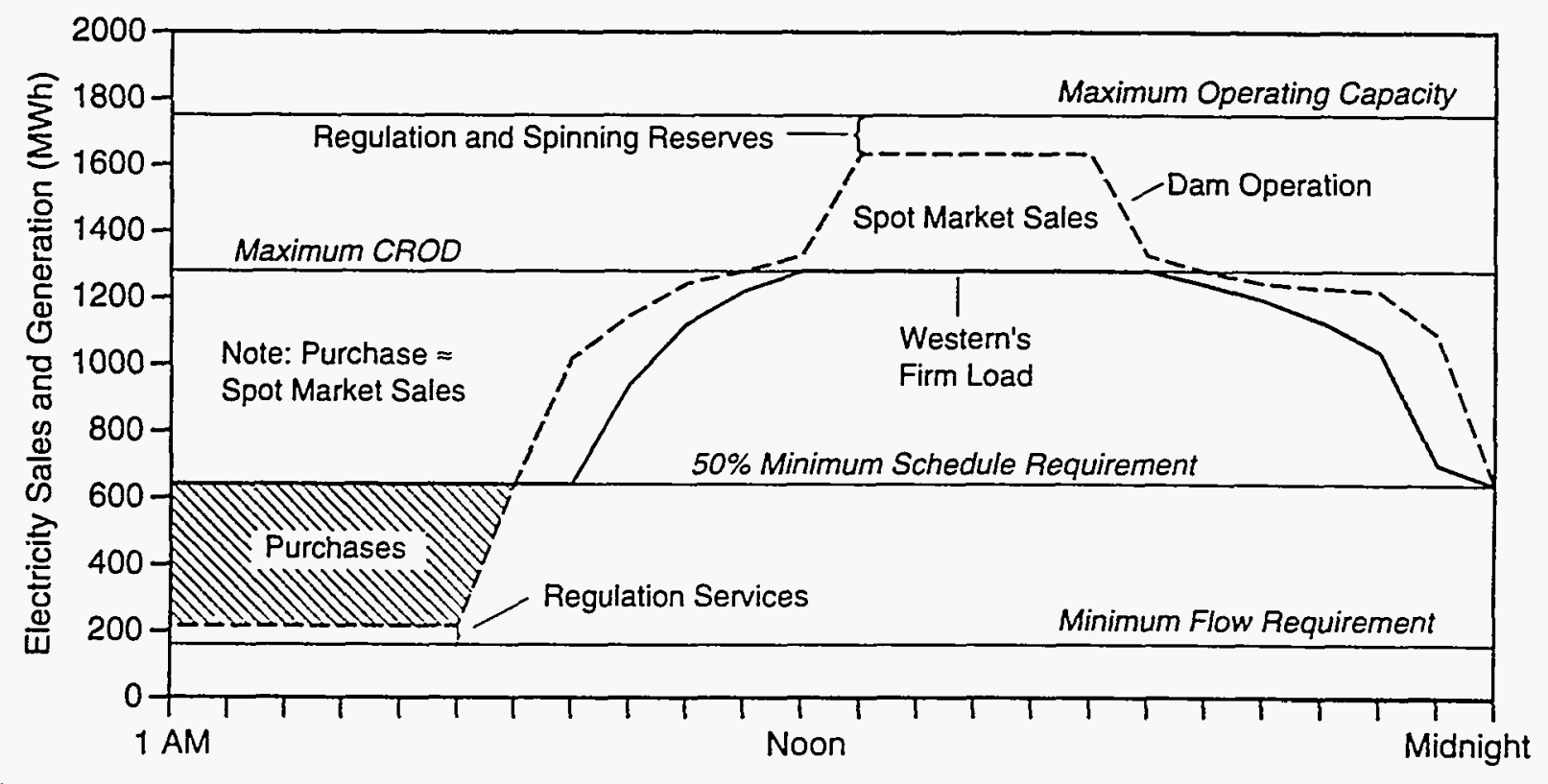

Hour of the Day

FIGURE 18 Hourly SLCA/IP Electricity Generation and Sales for 35\% and 50\% Minimum Schedule Requirements 
limited to, the following: (1) minimum schedule requirements, (2) amount of LTF and STF capacity and energy sales, and (3) maximum schedule change specified in Western's sales contracts. The maximum schedule change is a restriction that has not been implemented by Western; it was introduced in this study as a means of reducing hourly fluctuations in generation at SLCA/IP hydropower plants. The maximum schedule change limits fluctuations (both increases and decreases) in LTF energy deliveries from one hour to the next. These marketing elements, as well as several different types of purchasing programs, are discussed in the following subsections.

In examining the effects of purchasing programs on SLCA/IP hydropower plant operations, three levels of purchase flexibility were defined: (1) no purchases, (2) conditional purchases, and (3) unconstrained purchases. Under all three levels, it was assumed that customers would purchase all of their LTF energy allocations from Western. Such a situation would occur if the price of energy were relatively inexpensive compared with other energy sources, or if the contract had a take-or-pay energy clause. The no-purchase scenario prohibits both capacity and energy purchases. Interchanges are allowed if they are instantaneous one-for-one trades, but daytime energy cannot be traded for nighttime energy under the no-purchase scenario.

Under the conditional purchasing program, Western's purchases are restricted to specific types and times. For this study, two conditional purchase programs were defined. Under both programs, purchases are limited to hydropower conditions under which Western cannot meet LTF contracts with SLCA/IP resources.

The first program limits most purchases tu on-peak hours through the following conditions: (1) purchases are limited to the amount of energy needed to meet LTF contracts; (2) purchases can be used only to serve discretionary loads; and (3) when SLCA/IP energy is not sufficient to meet minimum schedule requirements (i.e., nondiscretionary loads), purchases to serve minimum schedules must be baseloaded. Under the current minimum schedule requirement (i.e., $35 \%$ of the CROD with interim post-1989 capacity allocations), SLCA/IP hydropower plants produce enough electricity to serve the minimum schedule under all hydropower conditions. However, if the minimum schedule requirement were significantly increased, Western would not be able to meet this load with SLCA/IP hydropower plant resources under some hydropower conditions. This type of conditional purchasing program in conjunction with large minimum schedule requirements would have a significant impact on power plant operations. These conditions would require Western to make purchases during on-peak hours and thus decrease the value of SLCA/IP hydropower resources.

The second type of conditional purchasing program requires a firm capacity purchase with a $100 \%$ load factor; however, Western would not be required to take energy when total minimum schedules are lower than the firm capacity purchase. 
The unconstrained purchasing program represents Western's current purchasing program. That is, Western can purchase power during off-peak hours and use the stored water to generate electricity during on-peak hours.

\subsection{MINIMUM SCHEDULE REQUIREMENT}

\subsubsection{No Purchases}

The minimum schedule requirement would have a large impact on hydropower plant operations if purchases were prohibited. Currently, this restriction requires each customer to take at least $35 \%$ of its seasonal CROD at all times. If purchases were not permitted, all of the energy for the minimum schedule requirement would come from SLCA/IP hydropower plants. The minimum schedule requirement plus project use during off-peak hours minus regulation services would then directly translate into a collective minimum SLCA/IP power output. Generation would sometimes be greater than this minimum level during off-peak hours because additional water releases may be required for scheduled outage assistance. Also, all customers would have to be at the minimum schedule requirement simultaneously. Under wet hydropower conditions, constant higher releases may be required to meet the Reclamation monthly release requirement.

Although collective generation from the SLCA/IP hydropower plants may be at or near the minimum for several consecutive hours during off-peak hours, generation levels from individual plants could fluctuate significantly. For example, Morrow Point and Blue Mesa could ramp down by a total of $200 \mathrm{MW}$ between 1 and 2 a.m. to lower Crystal's reservoir water level, while Glen Canyon ramps up by $200 \mathrm{MW}$. Morrow Point and Blue Mesa could then be operated more during on-peak hours without violating Crystal's reservoir maximum. Because of the trade-offs that can be made between power plants, minimum schedule requirements do not directly translate into specific minimum generation levels at each power plant. However, physical and practical limits on the tradeoffs that can be made between power plants bound the possible range of minimum flows from each dam. Because of limitations on the Glen Canyon-Kayenta-Shiprock transmission line during on-peak hours, an economic incentive exists to maximize daytime generation from SLCA/IP hydropower plants in Colorado, northern Utah, and Wyoming (see Section 7.4).

A higher minimum schedule requirement decreases the amount of energy available during on-peak hours. Figure 19 shows the amount of SLCA/IP energy remaining after minimum schedule requirements are satisfied under adverse hydropower conditions. Generation levels vary widely according to time of the year and minimum schedule requirement. Figure 19 does not show minimum flow releases that exceed $300 \mathrm{MW}$ in the fall. If releases exceed $300 \mathrm{MW}$, the Reclamation monthly release limit would be violated. That is, at a constant generation rate of $300 \mathrm{MW}$ for all hours of the month, water releases would exceed monthly Reclamation-mandated releases from 


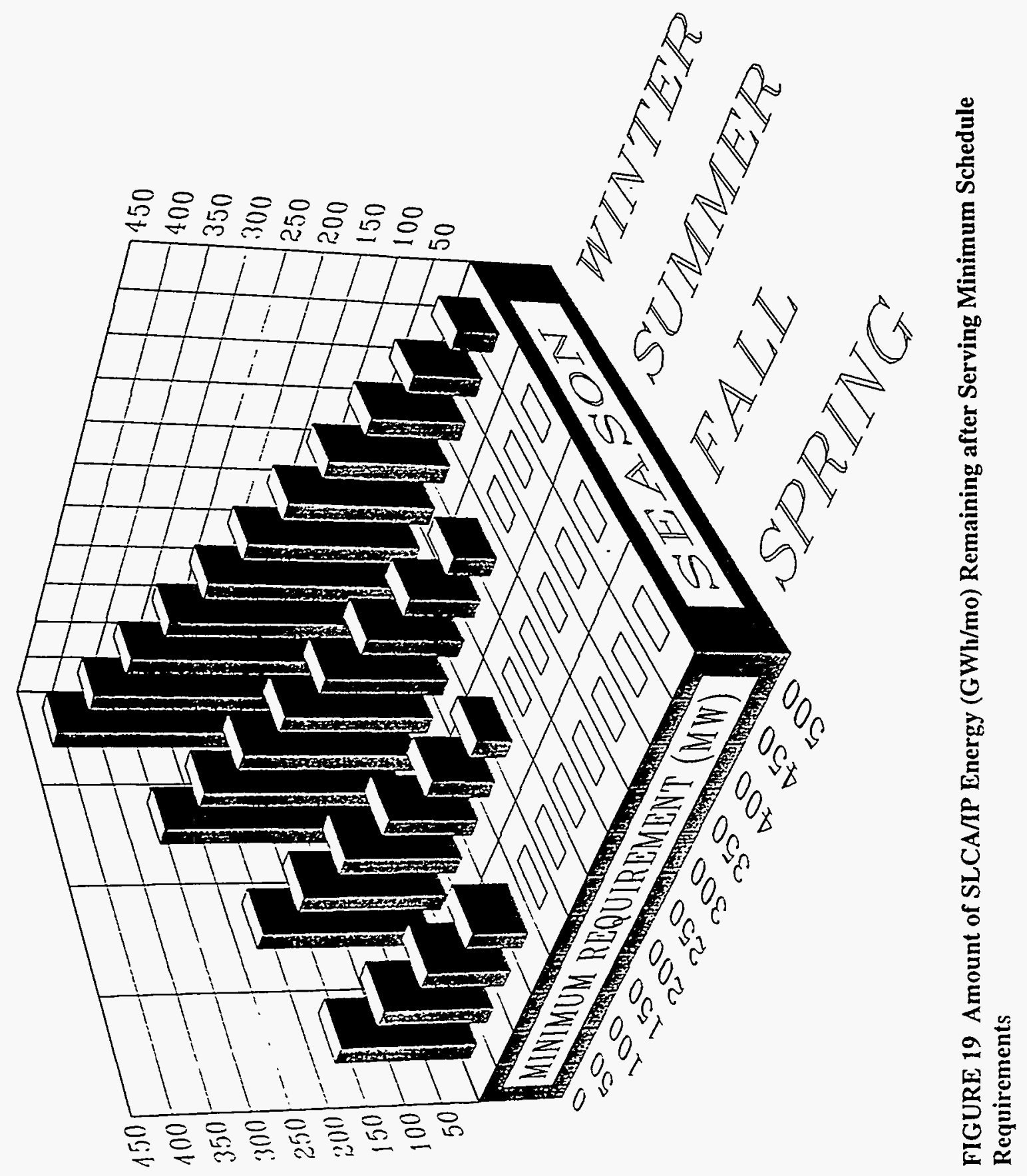


SLCA/IP dams. When minimum schedule requirements require that all of the energy produced by SLCA/IP hydropower plants be used to serve this load, no energy would be available for generation during on-peak hours; that is, the generation level to serve firm energy loads would be constant. Because hydropower conditions fluctuate over time, Reclamation monthly release levels change substantially. Therefore, a specific minimum schedule requirement can lead to different hydropower plant operations. To reduce water release fluctuations, minimum schedule requirements could be determined on a monthly basis so that minimum releases reflect the hydropower condition.

The minimum schedule requirements specified in LTF contracts cannot exceed the maximum amount of energy produced by SLCA $/ \mathbb{P}$ power plants under adverse hydropower conditions. If Western adopted these upper limits, excess energy would be available for sale under STF contracts or on the spot market in all but the driest years. When the excess energy is offered on the STF market as a baseload contract, fluctuations in SLCA/P hourly generation would be kept to a minimum. To reduce uncertainties and maximize STF sales, STF contract lengths could be shortened from the current 6 months to 1 month. Therefore, little or no energy would be available for spot market sales, and fluctuations in SLCA/IP hydropower plant generation would be reduced.

When excess energy is sold on the spot market, Western maximizes the value of the energy and sells it during on-peak periods as long as sufficient SLCA/IP capacity is available. This situation would result in significant fluctuations in downstream flows under most hydropower conditions. Exceptions to this general rule occur under either very wet or very dry hydropower conditions. When an extremely large amount of excess energy (e.g., 7,000 GWh/yr) exists, the SLCA/IP hydropower plants operate near their maximum capacities for much of the year, and changes in SLCA/IP generation tend to be relatively small. As indicated earlier, when hydropower conditions are adverse and minimum schedule requirements are at the upper limit, all of the SLCA/IP hydropower plant monthly energy is used to serve minimum schedule requirement loads. Therefore, fluctuations in flows are also minimal.

Stringent minimum schedule requirements can significantly alter the value of the capacity and energy Western sells. Although the quantity of energy Western sells does not vary significantly across the range of minimum schedule requirements, the value of the energy does vary substantially. Discretionary energy, which is typically purchased during on-peak hours, is much more valuable to Western's customers than nondiscretionary energy (i.e., energy that must be used to satisfy minimum schedule requirements). As the minimum schedule requirement increases, the on-peak energy decreases, and customers have to seek alternative on-peak energy and capacity supplies.

Both the quality and quantity of capacity Western markets to its LTF customers decline as a function of increasing minimum schedule requirements. Figure 20 shows that customers' usable capacity is drastically reduced by high minimum schedule requirements. This situation occurs because insufficient amounts of discretionary energy exist for the customer to use LTF capacity to its full potential. Without maximum schedule change clauses (see Section 5.6), the customer could 


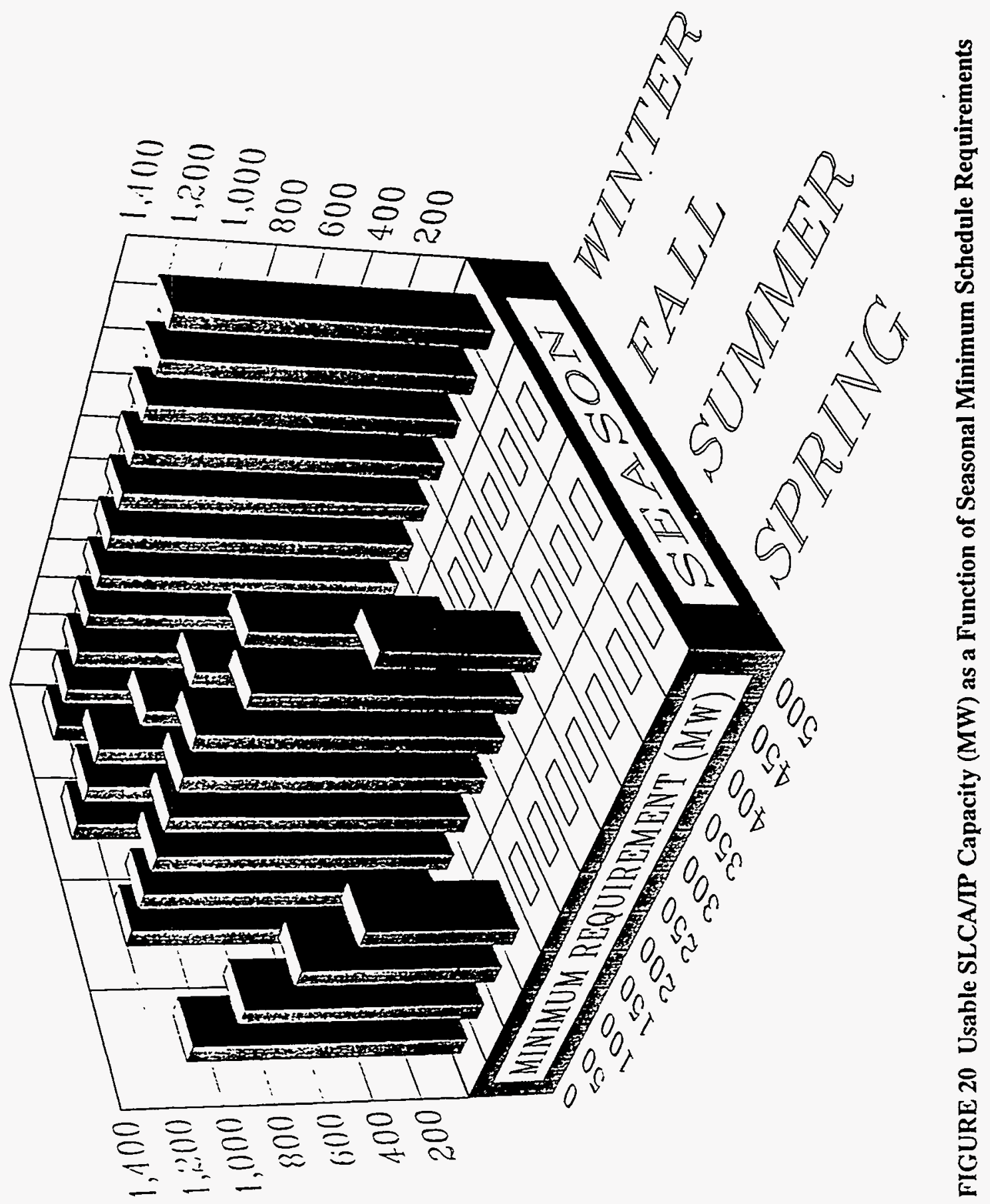


take energy up to its maximum capacity for a short period of time, but in many cases, the customer could not request energy up to the monthly capacity limit. A typical Western customer would attempt to minimize on-peak generation rather than use its monthly discretionary energy in a single hour. To minimize peak demands on thermal units, a customer would tend to use discretionary energy over several on-peak periods during the month.

\subsubsection{Limited and Conditional Purchases}

If purchases are not allowed, Western's LTF marketing plan may not reflect the true value of the SLCA/IP hydropower resources. Western would most likely take a very conservative marketing approach and understate their value. For example, Western may choose to offer its customers only $50 \%$ of the operable capacity of SLCA/IP power plants because of unscheduled outages (see Section 4.3.2), maintenance requirements (see Section 3.2.4), the possibility of unprecedented low hydropower conditions, or the need to accommodate unforeseen or unlikely events (i.e., total destruction of facilities by an act of nature). If Western offers low levels of capacity, its customers would have to build additional generating capacity or make other long-term firm capacity purchases to ensure an adequate and reliable supply of electricity to meet customer load. Western's purchasing programs can be tailored so that they influence hydropower plant operations, have more flexibility, and allow Western to market LTF capacity and energy above the amount projected under adverse conditions. A conditional purchasing program that allows purchases to meet discretionary loads (see Section 5.3) tends to increase minimum generation levels and lower maximum generation from SLCA/IP power plants. For example, an LTF marketing plan that is based on a $50 \%$ exceedance probability level and has a minimum schedule requirement that consumes $100 \%$ of the SLCA/IP energy would result in constant SLCA/IP energy production $50 \%$ of the time. That is, collective hourly generation from SLCA/IP hydropower plants would be constant throughout each month in which hydropower conditions are at or below the $50 \%$ exceedance probability level. Also, Western would purchase energy to meet LTF loads $50 \%$ of the time. The seasonal purchase level and frequency of purchases is shown in Figure 21. When hydropower conditions are above (wetter than) the $50 \%$ exceedance probability level, Western would have excess energy that could be sold on the STF or spot market.

Whereas, in the previous example, Western's LTF marketing plan led to a constant hourly generation from SLCA/IP power plants and limited downstream flow fluctuation $50 \%$ of the time, other marketing programs could be constructed that would lead to more or less downstream flow fluctuation. 

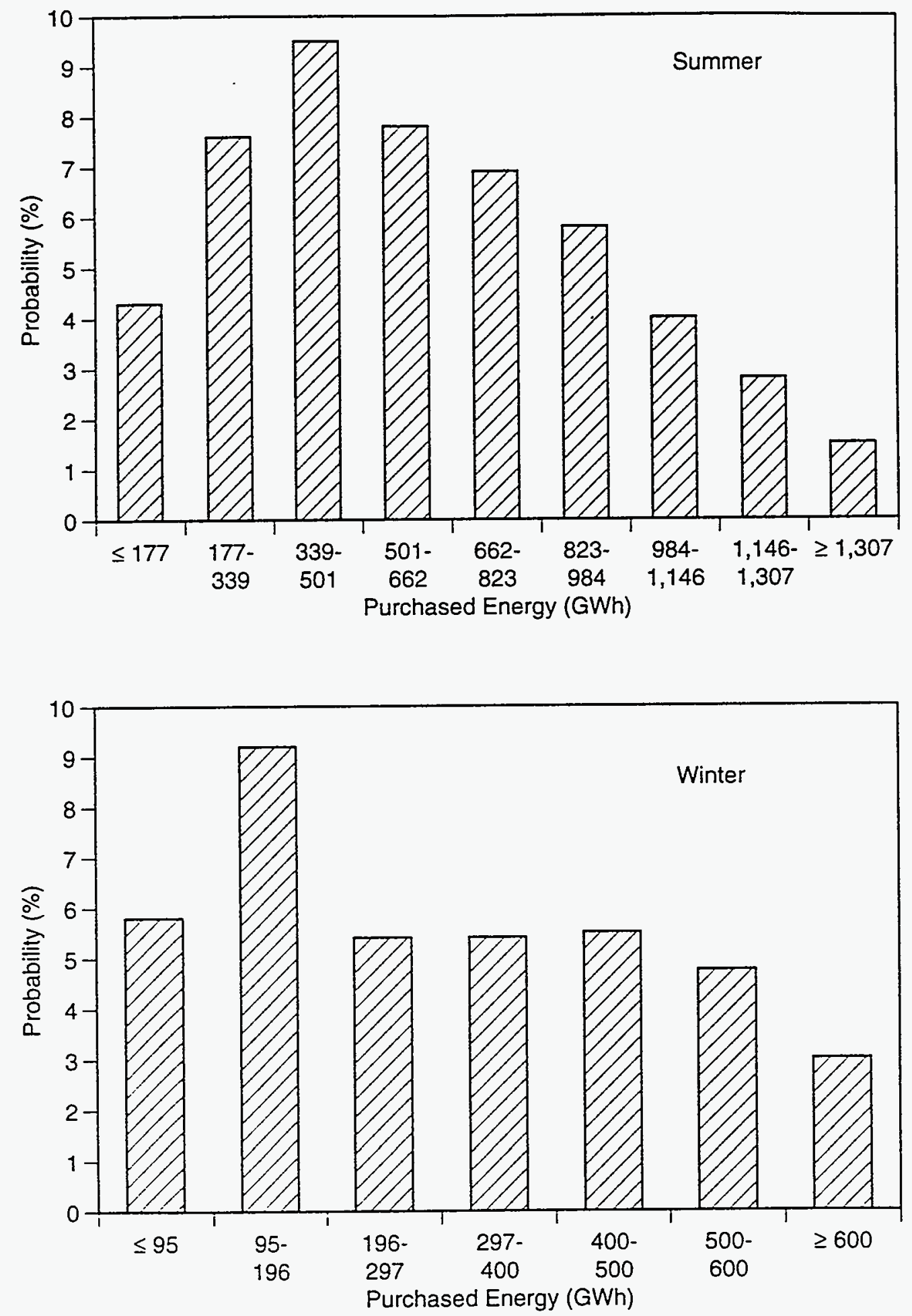

FIGURE 21 Probability of Energy Augmentation to Meet Long-Term Firm Energy Commitments when Marketing at 50\% Exceedance Probability Levels during Summer and Winter 


\subsection{EFFECTS OF FIRM CAPACITY SALES ON HYDROPOWER PLANT OPERATIONS}

\subsubsection{No Spot Market or Reserve Capacity Sales}

Whereas minimum schedule requirements can be used to increase minimum off-peak generation, firm capacity sales can be used to limit maximum on-peak generation. In general, when spot market and reserve capacity sales (i.e., spinning reserves) are not permitted, the lower the amount of LTF capacity that Western offers to its customers is, the lower the maximum generation level is. Without spot market and reserve capacity sales, Western would sell all of the SLCA/IP energy to its preference customers under LTF and STF (i.e., both 6- and 1-month) contracts. The maximum collective energy produced at any instant in time by SLCA/IP hydropower plants is equal to the sum of the following: (1) total contracted firm capacity, (2) capacity for project use (approximately $175 \mathrm{MW}$ in summer and $40 \mathrm{MW}$ in winter), (3) energy losses (approximately $110 \mathrm{MWh}$ at most), (4) capacity used for emergency assistance (approximately 45-70 MW), and (5) capacity for load control area regulation (approximately 50-56 MW).

The smaller the amount of capacity specified in firm contracts is, the smaller the collective maximum water release from SLCA/IP dams for hydropower plant generation will be. Figure 22 shows the maximum amount of water that would be released from Glen Canyon Dam under low reservoir conditions for various levels of firm capacity contracts, assuming that the other SLCA/IP power plants are at the minimum allowance release rate. Maximum flows will generally be somewhat lower because low reservoir conditions require a higher level of water release for a given output level and customer peak demands are usually not coincidental. Also, capacity reserves are frequently in a spinning state.

When hydropower conditions are such that there is more SLCA/IP energy than is needed for LTF energy contracts, Western sells this excess energy to its preference customers on the STF market (i.e., spot market sales are not permitted). If the energy is sold without additional capacity, maximum generation from the SLCA/IP hydropower plants would remain capped. However, Western would have to sell additional STF capacity so that firm sales (both LTF and STF) have a combined load factor less than or equal to $100 \%$. Under wet hydropower conditions, hourly generation fluctuations decrease because customers are at or near their maximum capacity levels much of the time. That is, a customer would have to receive its maximum allowed limit (i.e., LTF capacity level) almost all the time to use its entire energy allocation. If a customer were to request a substantially smaller amount of energy for an extended time, that customer would not be able to use its monthly allocation of energy.

Maximum collective power plant output would be decreased further if some of the services now provided by Western, such as load control responsibilities, were not offered. In addition, capacity rights reserved for project use could be decreased. 


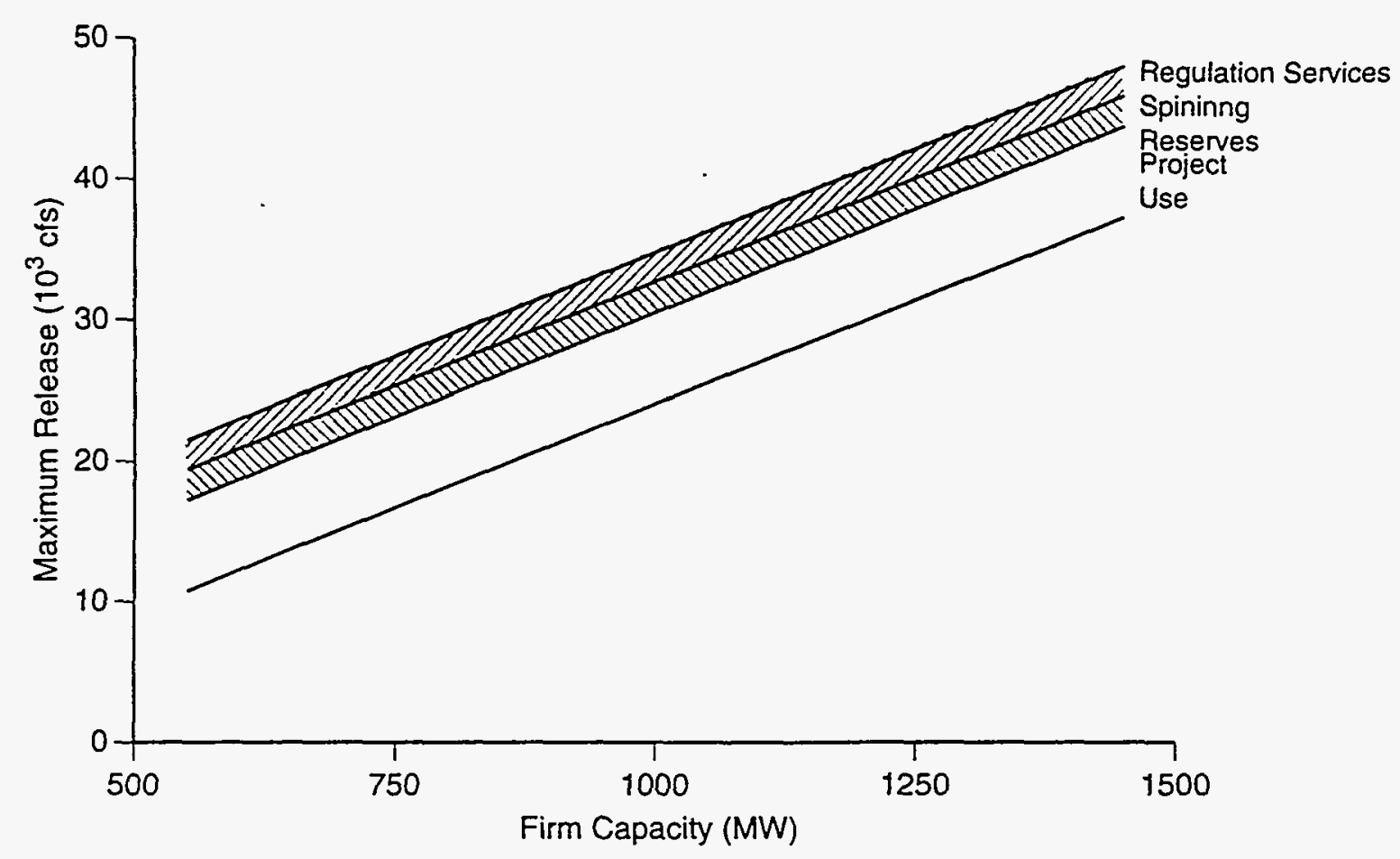

FIGURE 22 Maximum Flow Rates from Glen Canyon Dam as a Function of Firm Capacity Sales

\subsubsection{No Spot Market and Reserve Capacity Sales with Baseload Purchases}

When hydropower conditions are such that generation from SLCA/IP hydropower plants is insufficient to meet LTF energy contracts, Western must make purchases. If these purchases were mandated to be baseloaded (i.e., a constant purchase of energy over the contract period), the maximum collective output from SLCA/IP power plants would be less than the LTF capacity sold to customers. As illustrated in Figure 23, when purchases are baseloaded, the drier the hydropower condition is, the higher the purchase levels are and the lower the SLCA/IP peak output is.

The probability that SLCA/IP energy is either in excess or deficient of LTF commitments depends on Western's LTF marketing program. As LTF energy commitments increase, Western must make larger and more frequent purchases. Also, for a given hydropower condition and LTF capacity commitment, the collective maximum output from SLCA/IP power plants decreases as a function of increasing LTF energy commitments. 


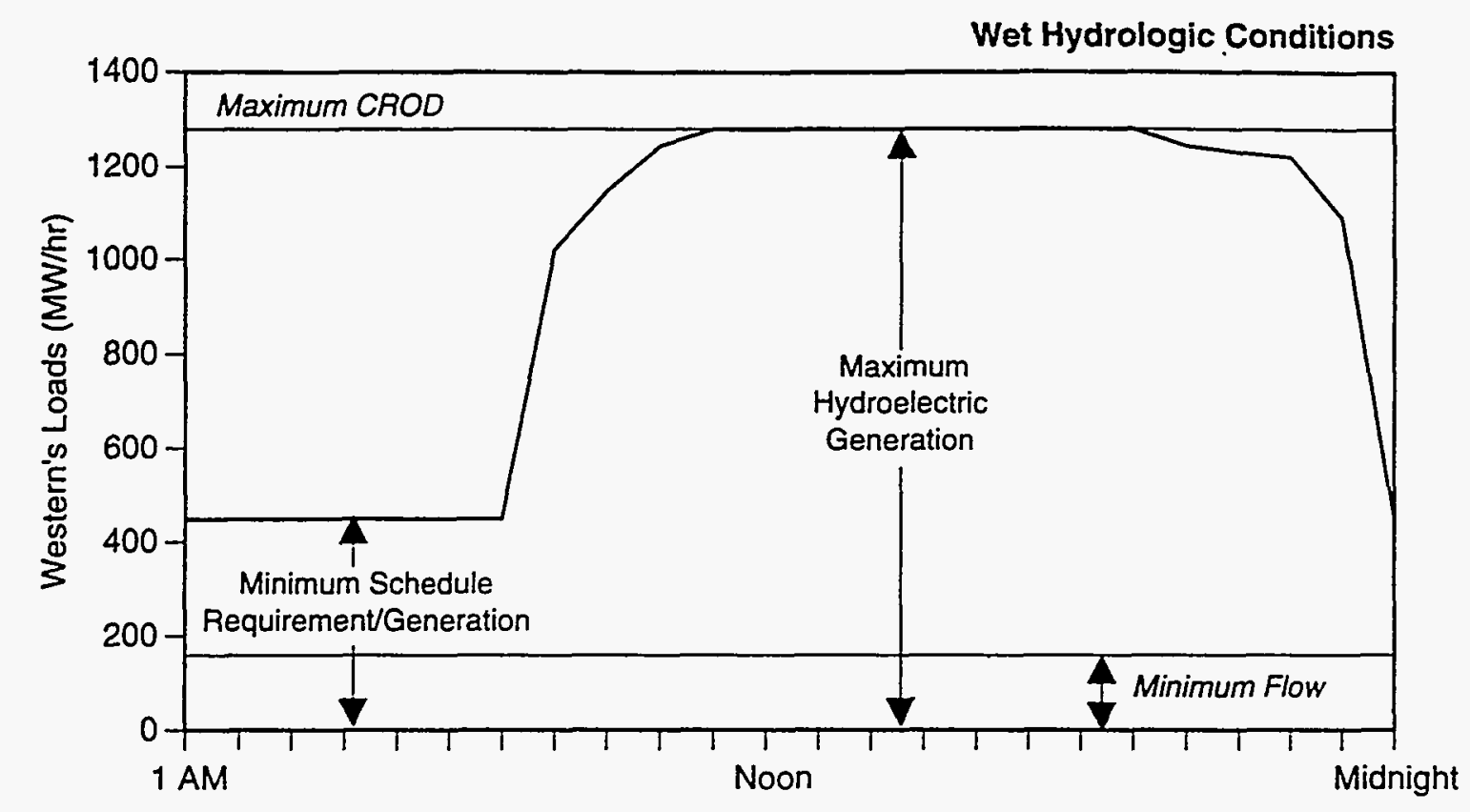

Hour of the Day

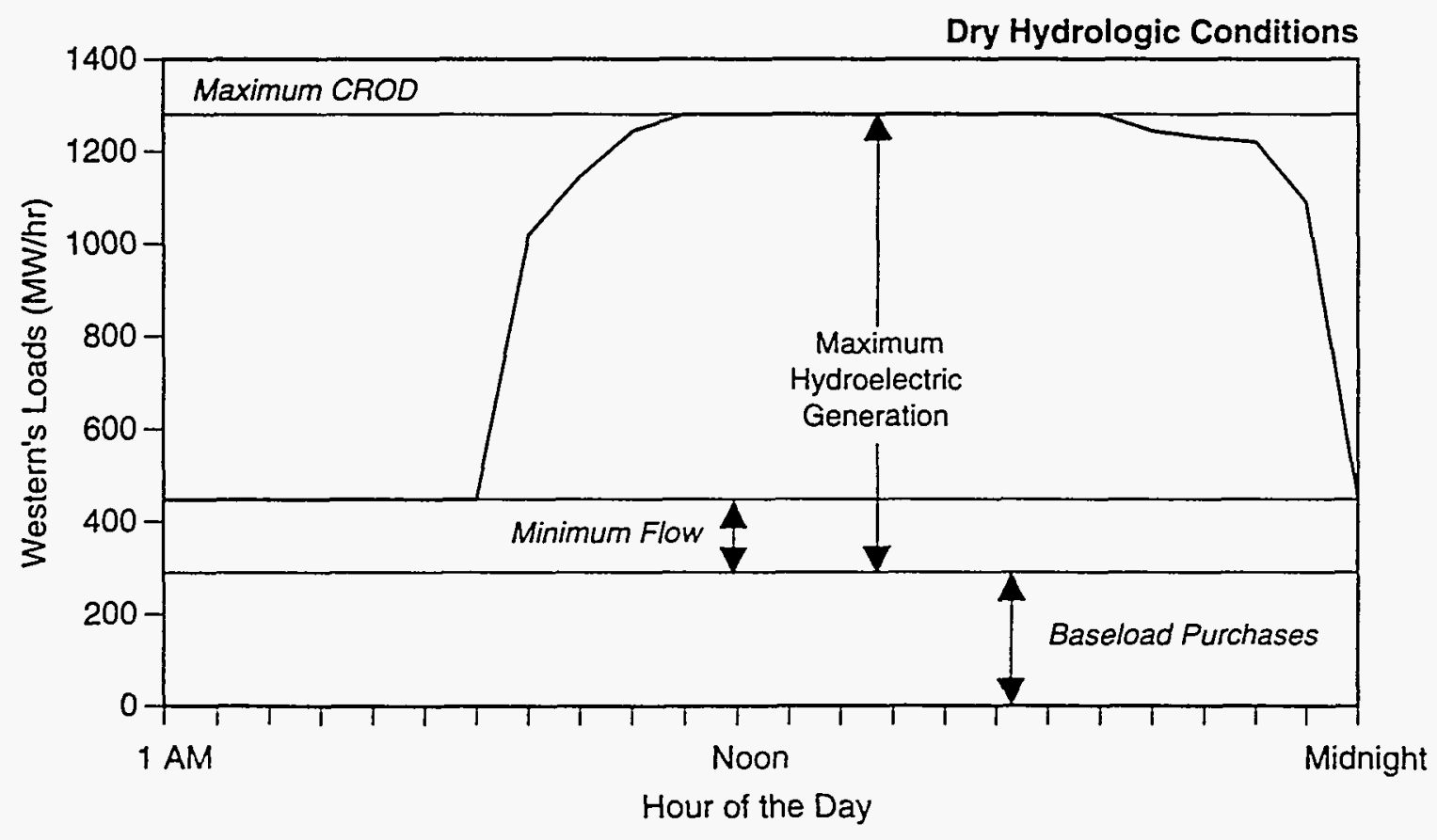

FIGURE 23 Maximum Hourly SLCA Hydroelectric Generation under Wet and Dry Hydropower Conditions 


\subsection{COMBINATIONS OF MINIMUM SCHEDULE REQUIREMENTS AND LONG-TERM FIRM COMMITMENT LEVELS}

As discussed earlier, SLCA/IP hydropower plant operations can be affected by minimum schedule requirements and LTF capacity sales. This section explores strategies that limit the range and frequency of generation fluctuations by setting minimum schedule requirements and LTF capacity levels.

These strategies require purchases to be made to serve discretionary loads but only when SLCA/IP resources are insufficient to meet LTF loads. Non-firm sales are not allowed. Therefore, all energy except for the amount required for project use, regulation, and outage assistance would be sold to preference customers. Figure 24 shows the effects of these restrictions when the collective minimum schedule requirement for all customers is $562 \mathrm{MW}$ and the LTF capacity is $834 \mathrm{MW}$ for the month of August. The graph shows that generation to serve firm loads would be constant $40 \%$ of the time (i.e., constant generation for all hours in the month). This situation occurs because SLCA/IP energy production cannot serve the minimum schedule requirement $20 \%$ of the time (i.e., generation is at or near $418 \mathrm{GWh}$ in July). Under these drier hydropower conditions, purchases would be required to meet discretionary firm loads. The magnitude and frequency of these purchases are shown in diagram $C$ on the lower left side of Figure 24.

SLCA/IP generation would be constant during an additional $20 \%$ of July because, at a constant generation rate of $834 \mathrm{MW} / \mathrm{h}$ an insufficient amount of water would be released through SLCA/IP turbines to comply with the Reclamation monthly water release requirements. Additional excess energy and associated capacity would then be sold to preference customers on a STF market. The STF capacity sales would equal the amount of excess energy above a $100 \%$ load factor divided by the number of hours in the month. Graph $A$ on the upper right side of Figure 24 shows the amount and frequency of STF energy sales.

Generation level would fluctuate to serve LTF discretionary loads during the remaining $60 \%$ of the time. The closer the required monthly energy release level is to the LTF capacity level (i.e., $834 \mathrm{MW} \times 24$ hours $\times 31$ days), the lower the fluctuations in SLCA/IP generation will be. Likewise, if the monthly energy release level is near the minimum schedule requirement, fluctuations in generation tend to be lower. Graph B of Figure 24 shows the amount and frequency of SLCA/IP generation to serve discretionary loads. Figures 25 and 26 show two marketing strategies that are even more restrictive. These strategies increase the minimum schedule requirements and decrease LTF capacity and energy commitments, resulting in a higher frequency of constant generation and STF sales.

Figures 27,28 , and 29 show the effects of minimum schedule requirements and LTF capacity levels for January. Note that the difference between the minimum schedule requirements and the LTF capacity commitments is much smaller in January than in August for the same 


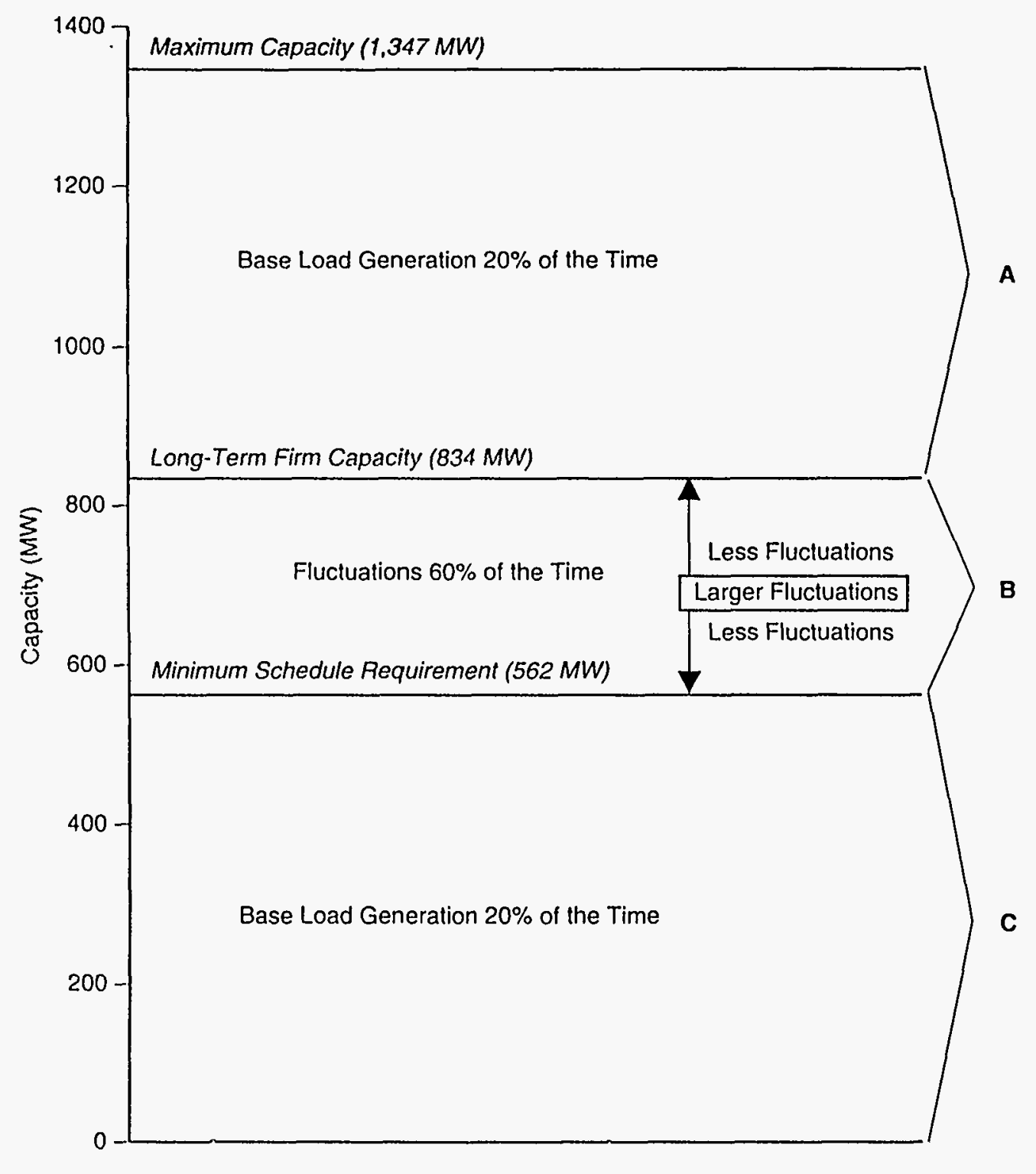

A. Base Load Generation with Short-term Firm Sales

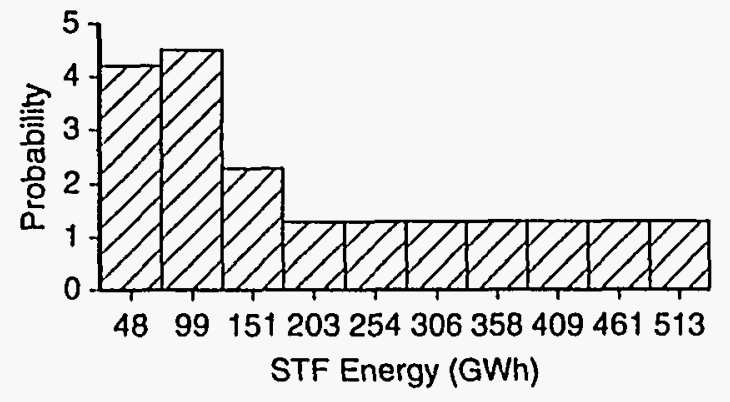

B. Hourly SLCAIP Generation Fluctuations

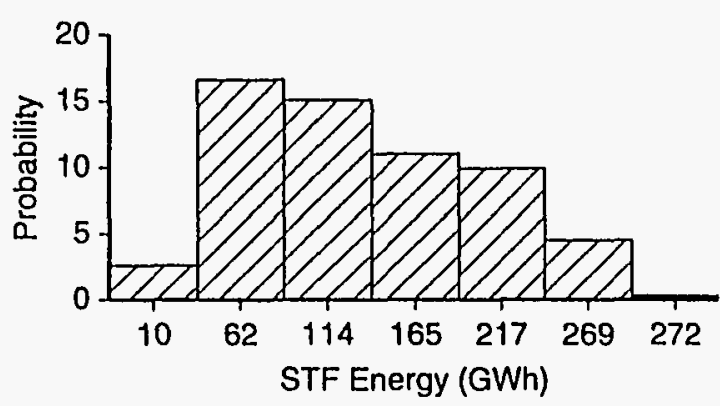

C. Base Load Generation with Base Load Purchases

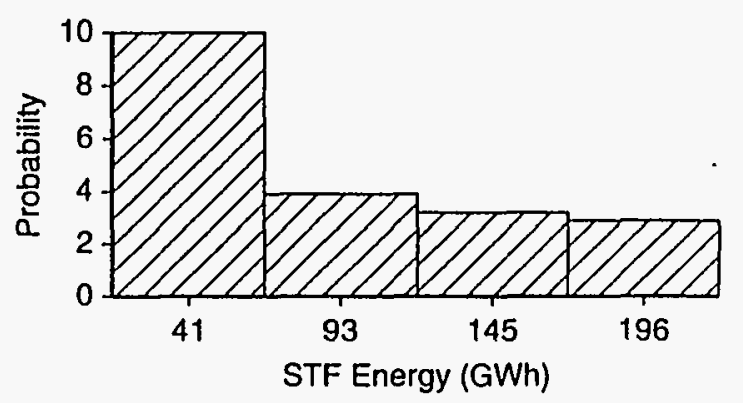

FIGURE 24 Effects of a Minimum Schedule Requirement of $562 \mathrm{MW}$ and an LTF Capacity Level of $834 \mathrm{MW}$ on the Magnitude and Frequency of SLCA/IP Generation Fluctuations: August 


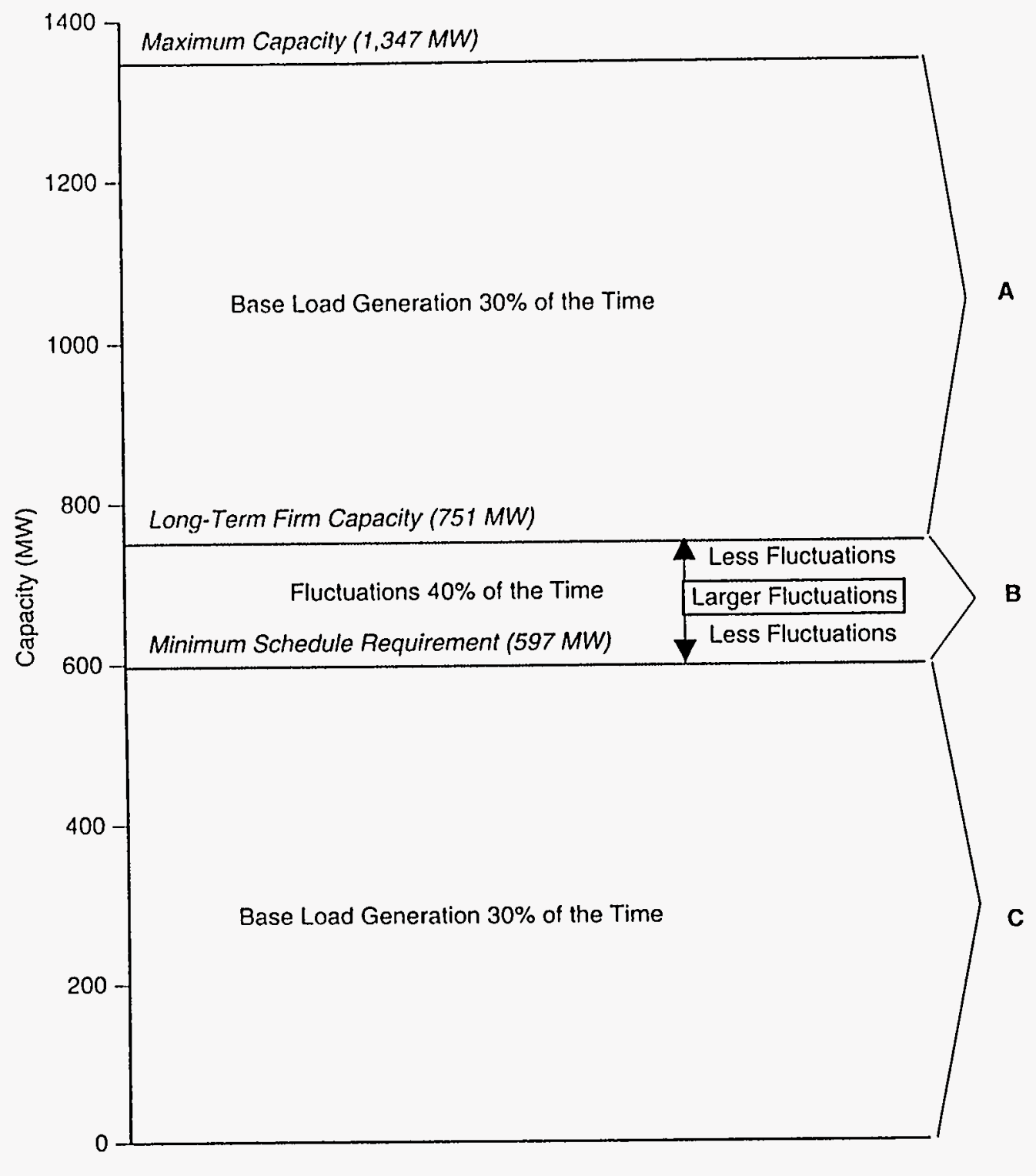

A. Base Load Generation with Short-term Firm Sales

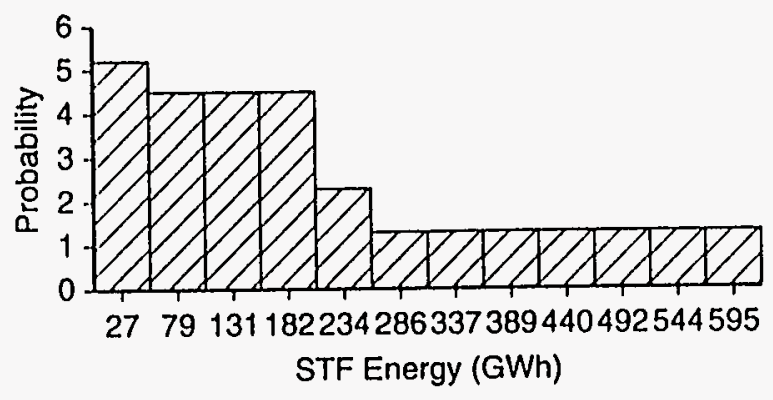

B. Hourly SLCA/P Generation Fluctuations

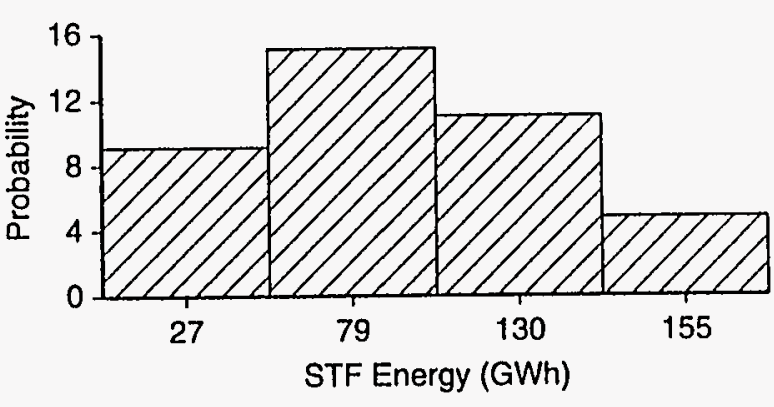

C. Base Load Generation with Base Load Purchases

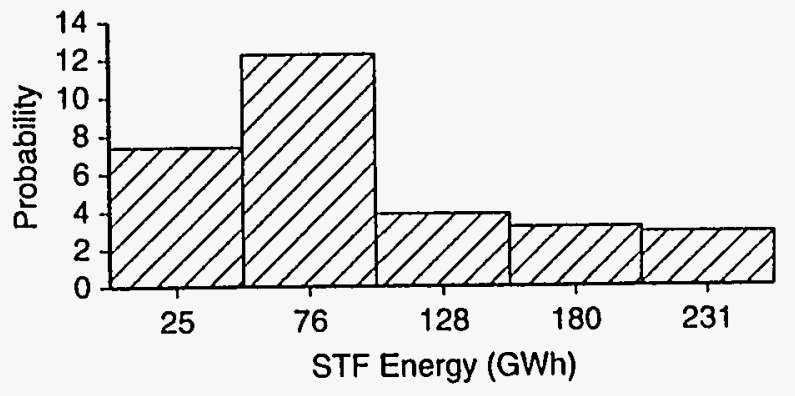

FIGURE 25 Effects of a Minimum Schedule Requirement of $597 \mathrm{MW}$ and an LTF Capacity Level of $751 \mathrm{MW}$ on the Magnitude and Frequency of SLCA/IP Generation Fluctuations: August 


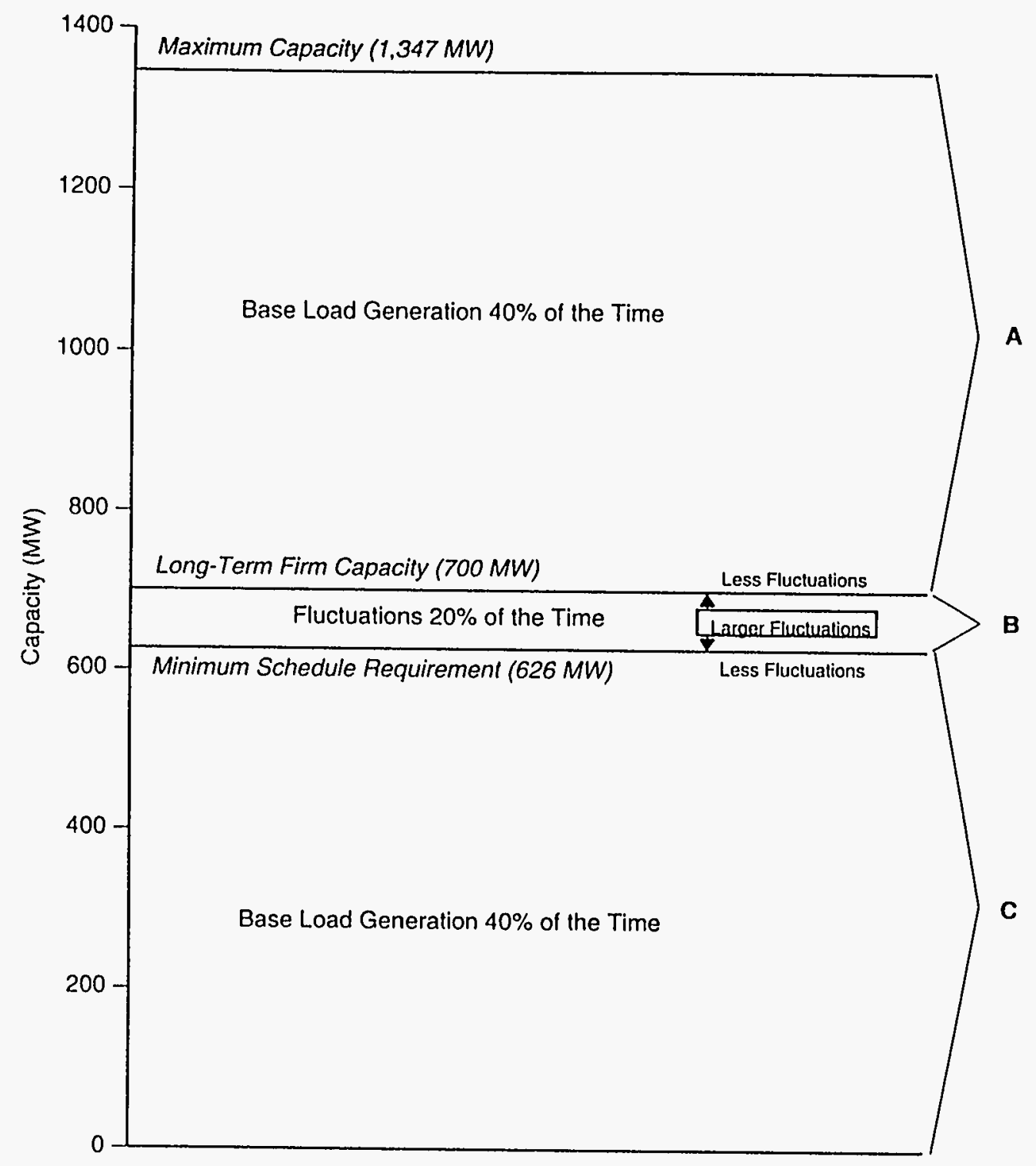

A. Base Load Generation with Short-term Firm Sales

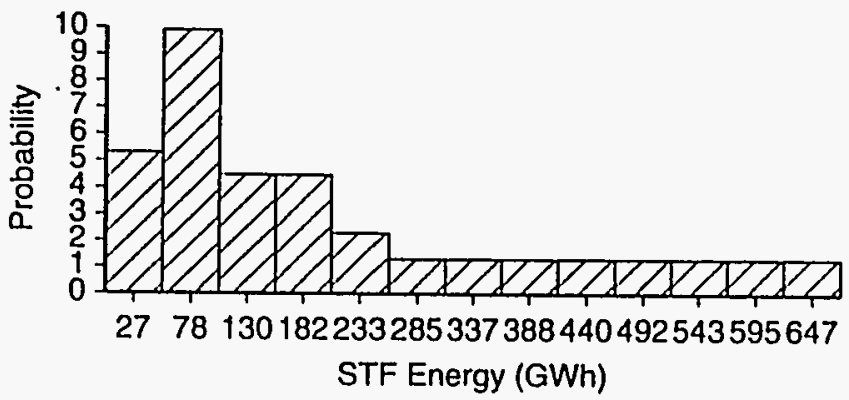

B. Hourly SLCA/IP Generation Fluctuations

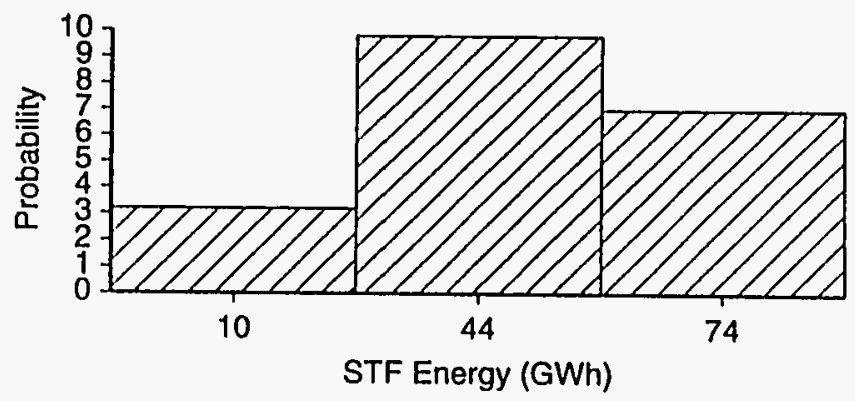

C. Base Load Generation with Base Load Purchases

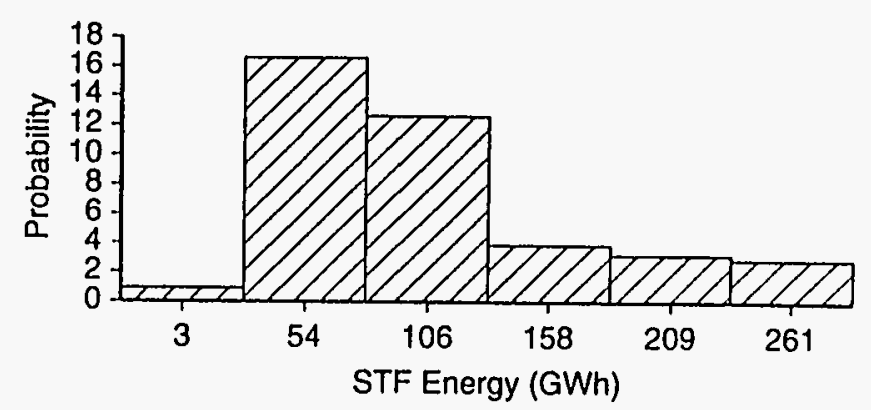

FIGURE 26 Effects of a Minimum Schedule Requirement of $626 \mathrm{MW}$ and an LTF Capacity Level of $700 \mathrm{MW}$ on the Magnitude and Frequency of SLCA/IP Generation Fluctuations: August 


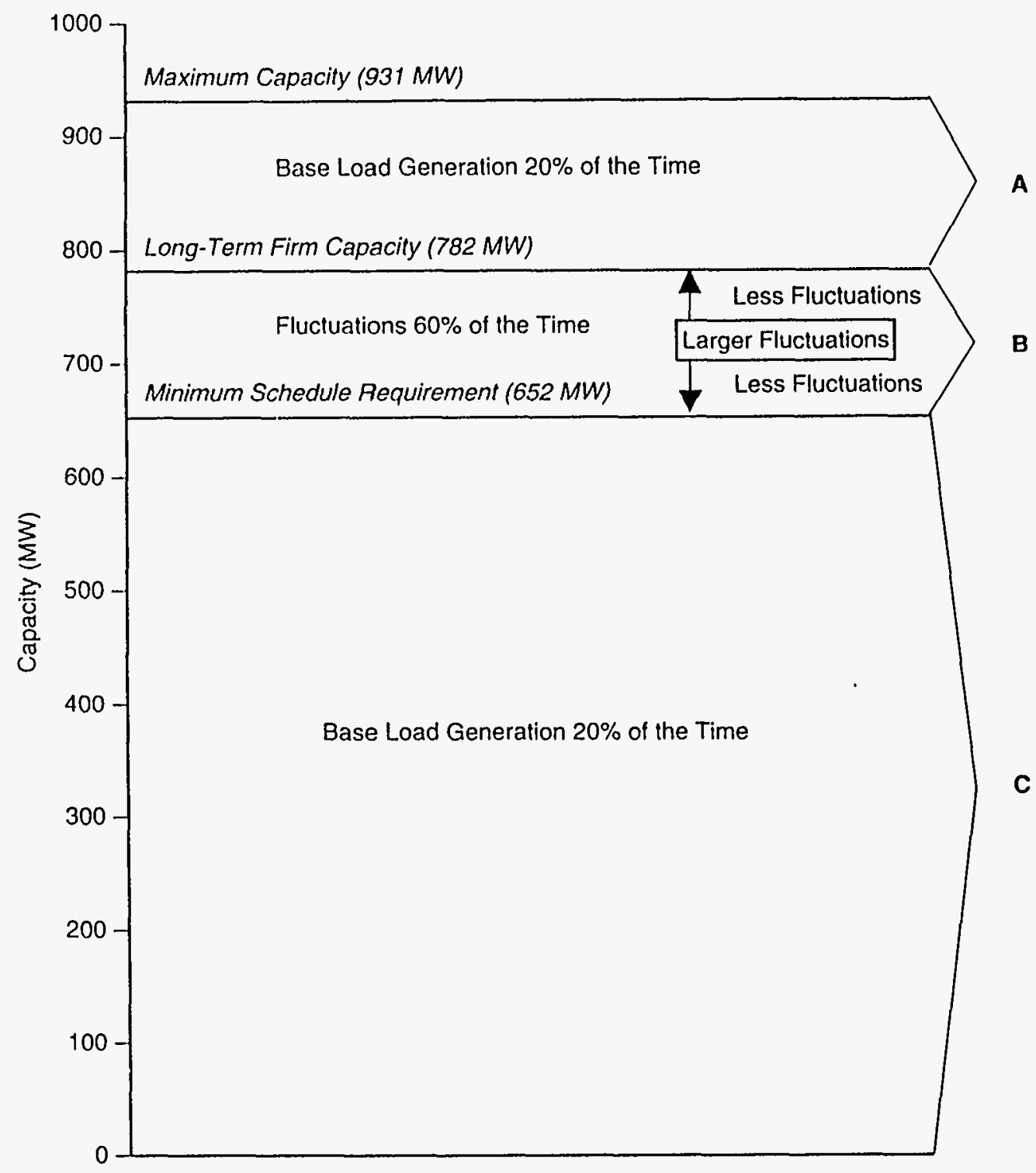

A. Base Load Generation with Short-term Firm Sales

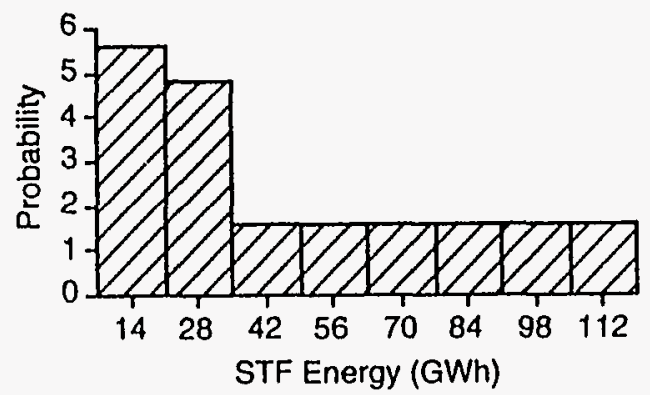

B. Hourly SLCA/IP Generation Fluctuations

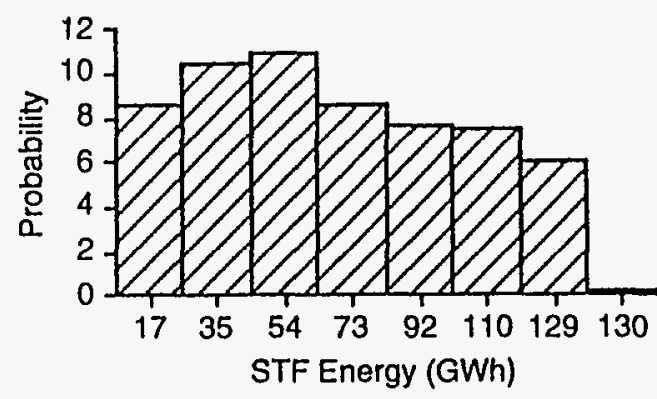

C. Base Load Generation with Base Load Purchases

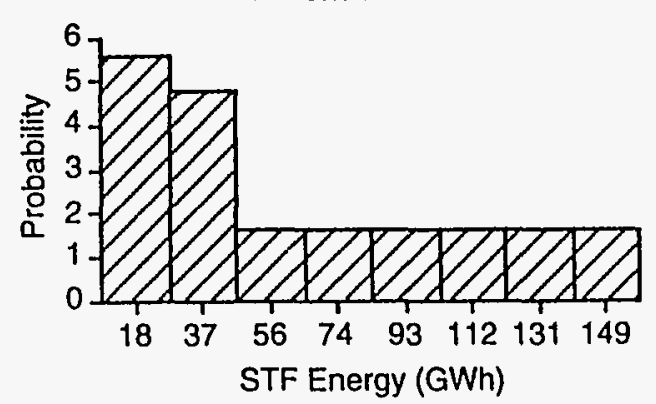

FIGURE 27 Effects of a Minimum Schedule Requirement of $652 \mathrm{MW}$ and an LTF Capacity Level of $782 \mathrm{MW}$ on the Magnitude and Frequency of SLCA/IP Generation Fluctuations: January 


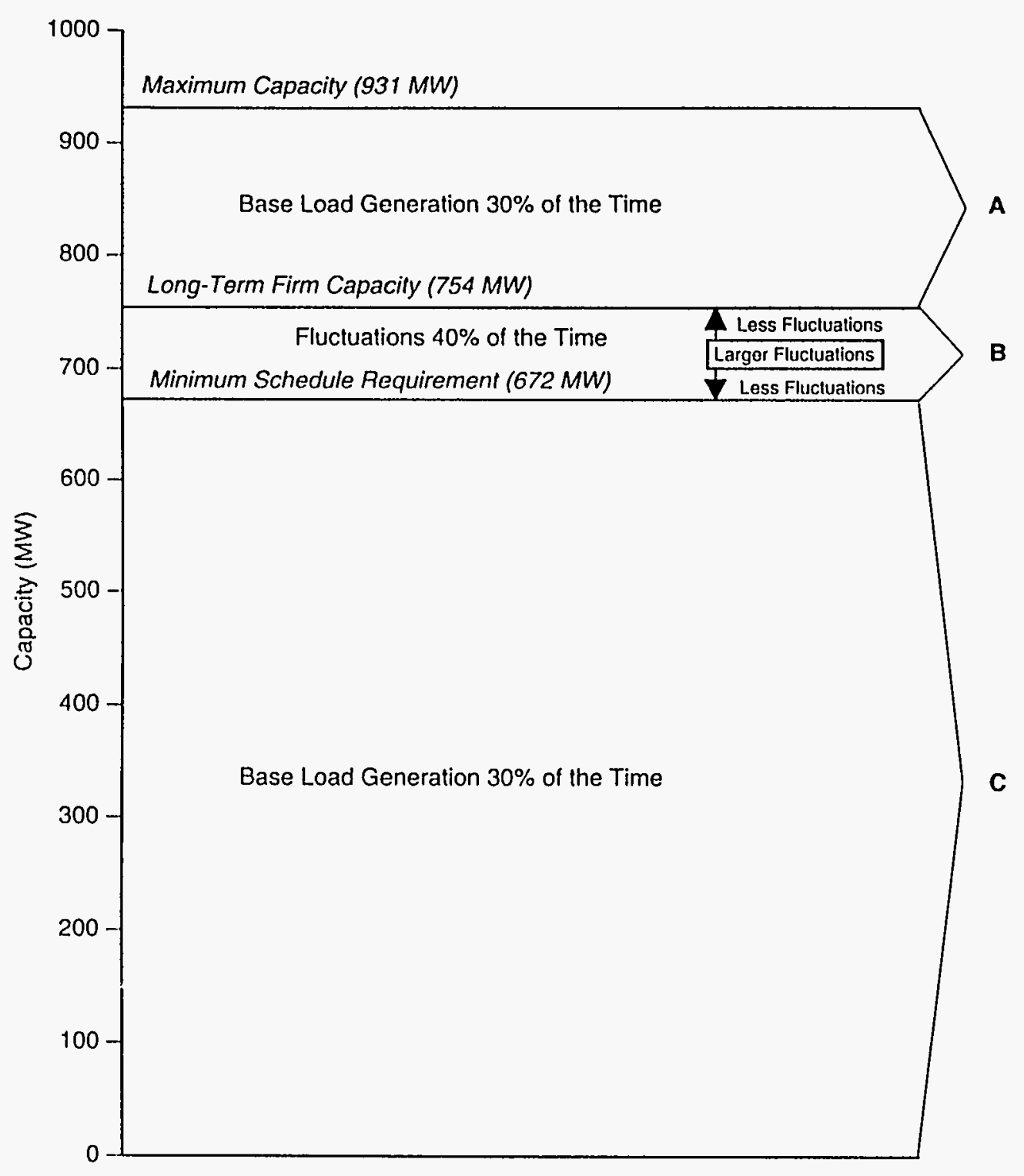

A. Base Load Generation with Short-term Firm Sales

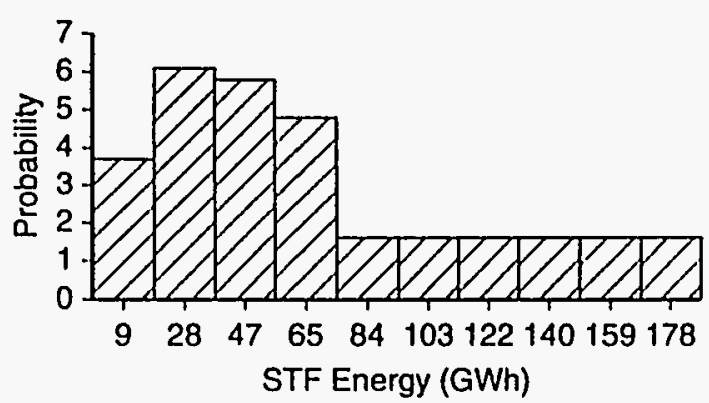

B. Hourly SLCAMP Generation Fluctuations

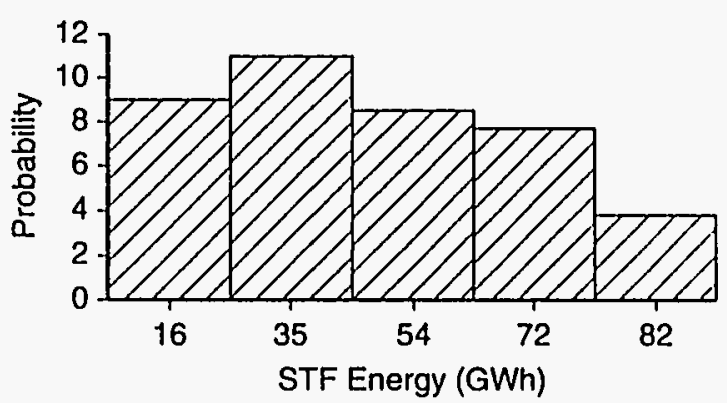

C. Base Load Generation with Base Load Purchases

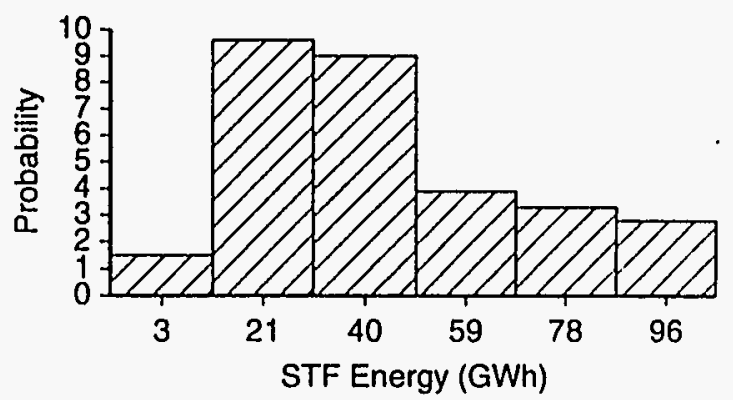

FIGURE 28 Effects of a Minimum Schedule Requirement of $672 \mathrm{MW}$ and an LTF Capacity Level of $754 \mathrm{MW}$ on the Magnitude and Frequency of SLCA/IP Generation Fluctuations: January 


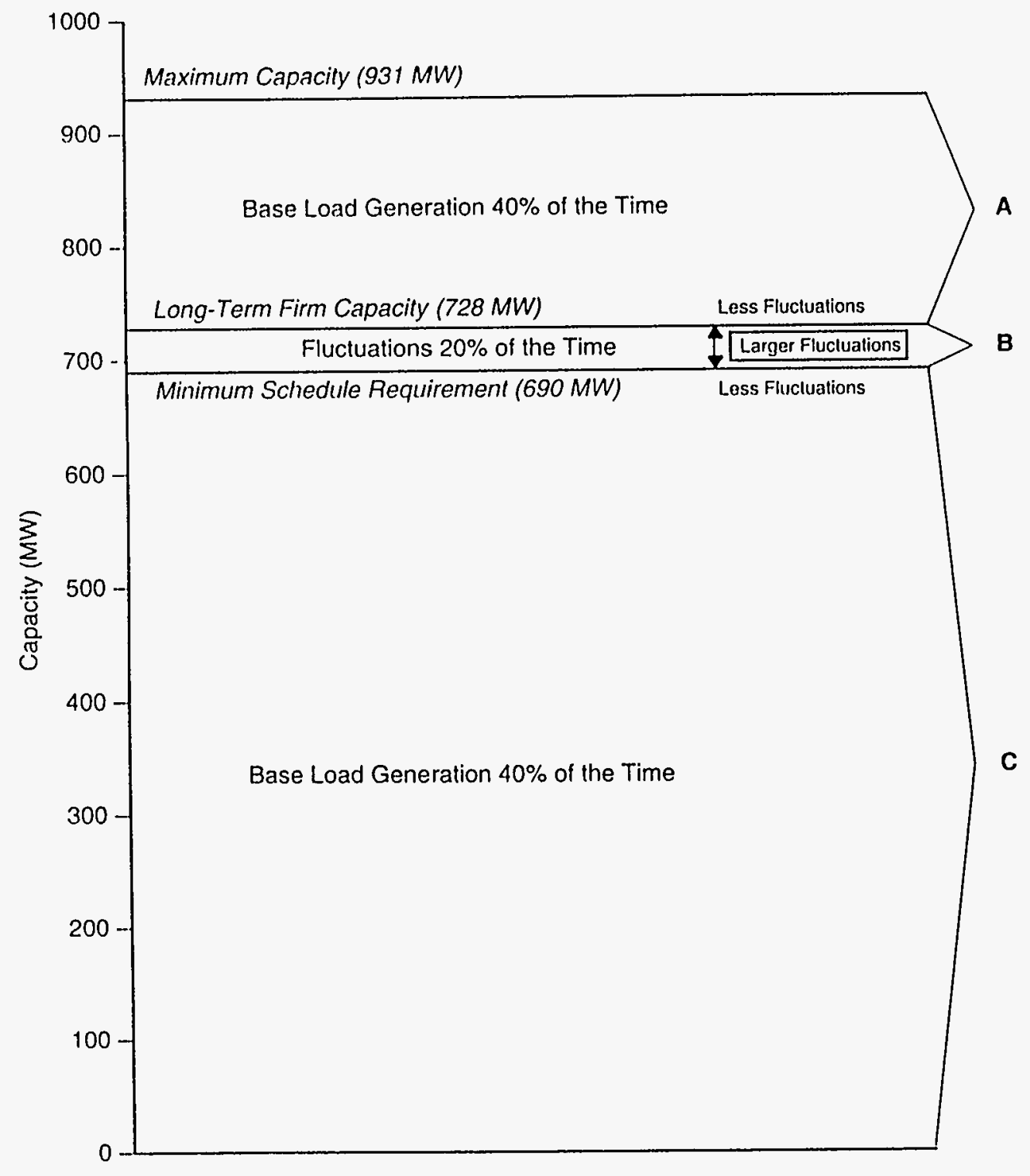

A. Base Load Generation with Short-term Firm Sales

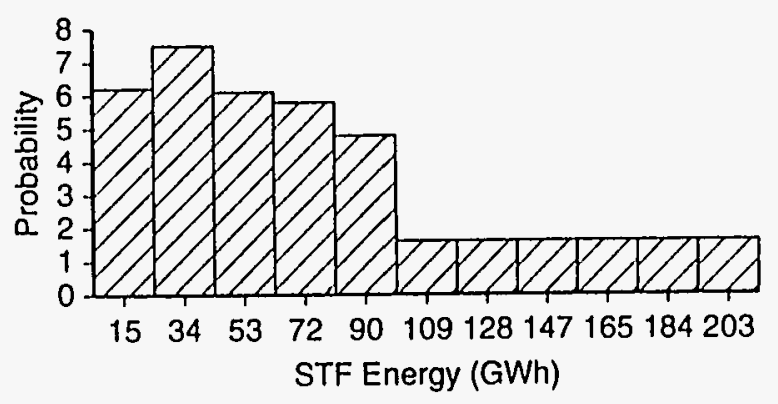

B. Hourly SLCA/IP Generation Fluctuations

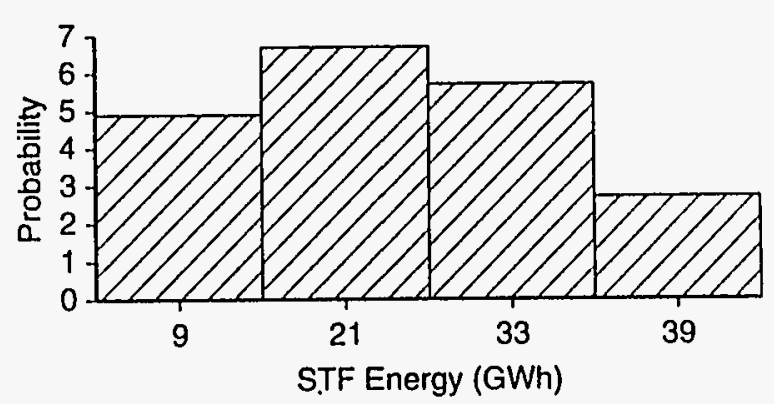

FIGURE 29 Effects of a Minimum Schedule Requirement of $690 \mathrm{MW}$ and an LTF Capacity Level of $728 \mathrm{MW}$ on the Magnitude and Frequency of SLCA/IP Generation Fluctuations: January 
frequency of constant generation (i.e., 40,60, and 80\%). This situation occurs because there is greater hydropower variability in August than in January.

Figure 30 shows the minimum schedule requirement and the maximum CROD by month for three frequencies of constant generation. This figure shows that as the frequency of constant generation increases, the maximum daily fluctuation in generation decreases. The figure also shows that the maximum daily fluctuations tend to be highest in summer and fall.

If the level of daily fluctuation is held constant, the frequency of constant generation changes across months. The upper half of Figure 31 shows that if the maximum daily fluctuation is set at $140 \mathrm{MW}$ (i.e., the difference between the LTF capacity and the minimum schedule requirement), the frequency of constant generation with purchases and with STF sales varies significantly across months. For example, in January, a minimal probability exists that purchases will be required to meet the minimum schedule requirement. However, in February and June, purchases would be required approximately $50 \%$ of the time.

\subsection{MAXIMUM SCHEDULE CHANGE}

\subsubsection{No Purchases}

If purchases are not permitted, a maximum schedule change clause that limits each customer to a maximum change in energy deliveries from one hour to the next would have a direct influence on hourly SLCA generation. Separate maximum schedule change clauses could be specified for the rate at which a customer could increase or decrease energy deliveries from Western. If Western could not purchase power, the maximum change in the collective output from SLCA/IP hydropower plants to serve LTF loads would equal the sum of individual customers' maximum schedule changes. This maximum rate of change would not usually occur because changes in customers' energy deliveries would not be coincidental. However, there would be additional fluctuations in generation from SLCA/IP hydropower plants to perform the following functions: (1) provide energy for project use, (2) provide area load control regulation, (3) provide emergency assistance, and (4) sell energy on the spot market.

As indicated earlier, the level of long-term commitment Western could offer under a nopurchase scenario is relatively low (i.e., equal to the amount of energy and capacity that could be supplied under adverse hydropower conditions). Therefore, there will generally be significant amounts of excess energy and capacity to be sold on the STF or spot markets. When energy and capacity are sold on the STF market and the customers' maximum schedule changes are not increased, collective maximum changes in generation for the SLCA/IP hydropower plants are limited 

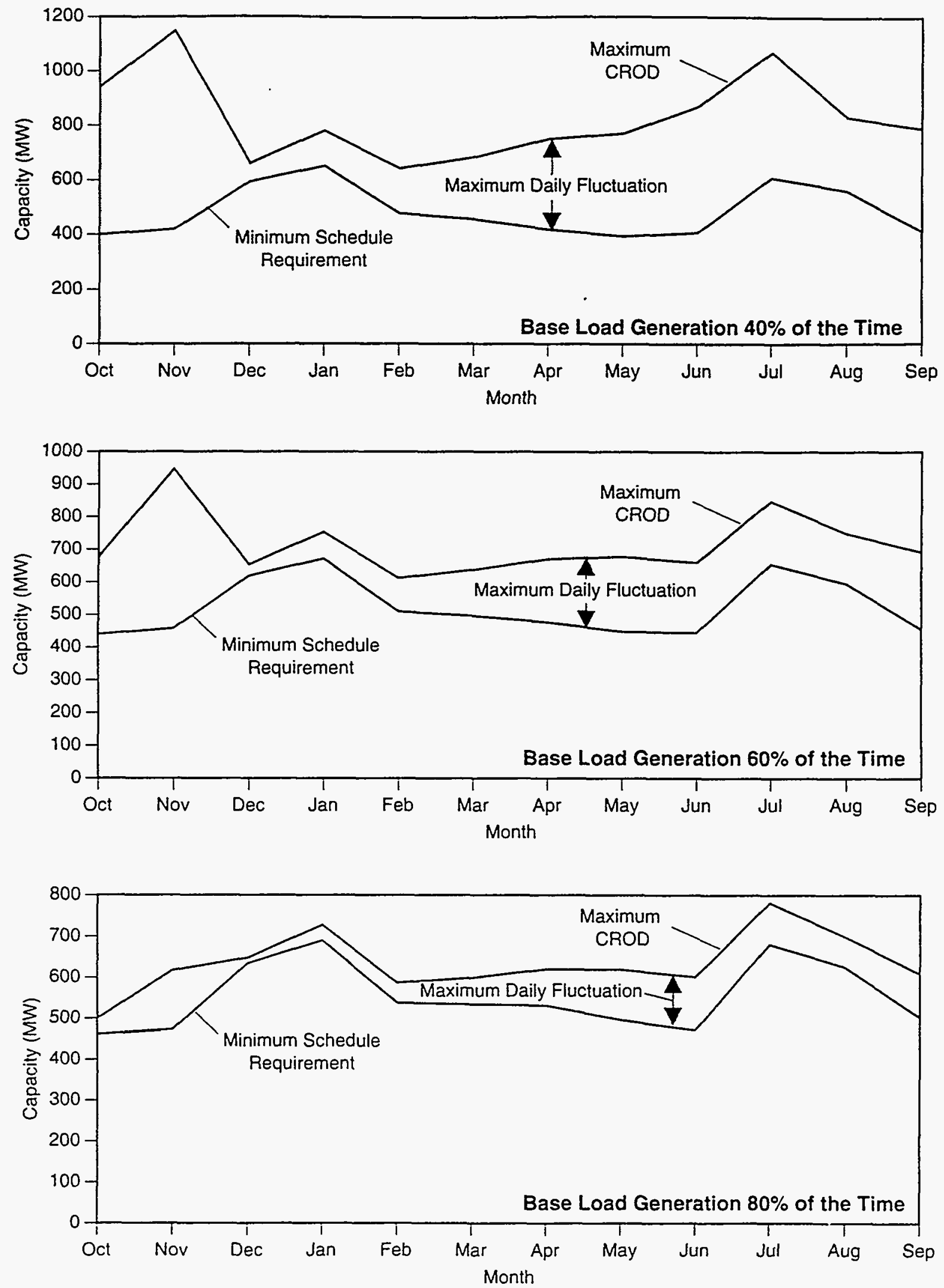

FIGURE 30 Maximum Fluctuations in Generation from SLCA/IP by Month under Three Restrictive Marketing Strategies 

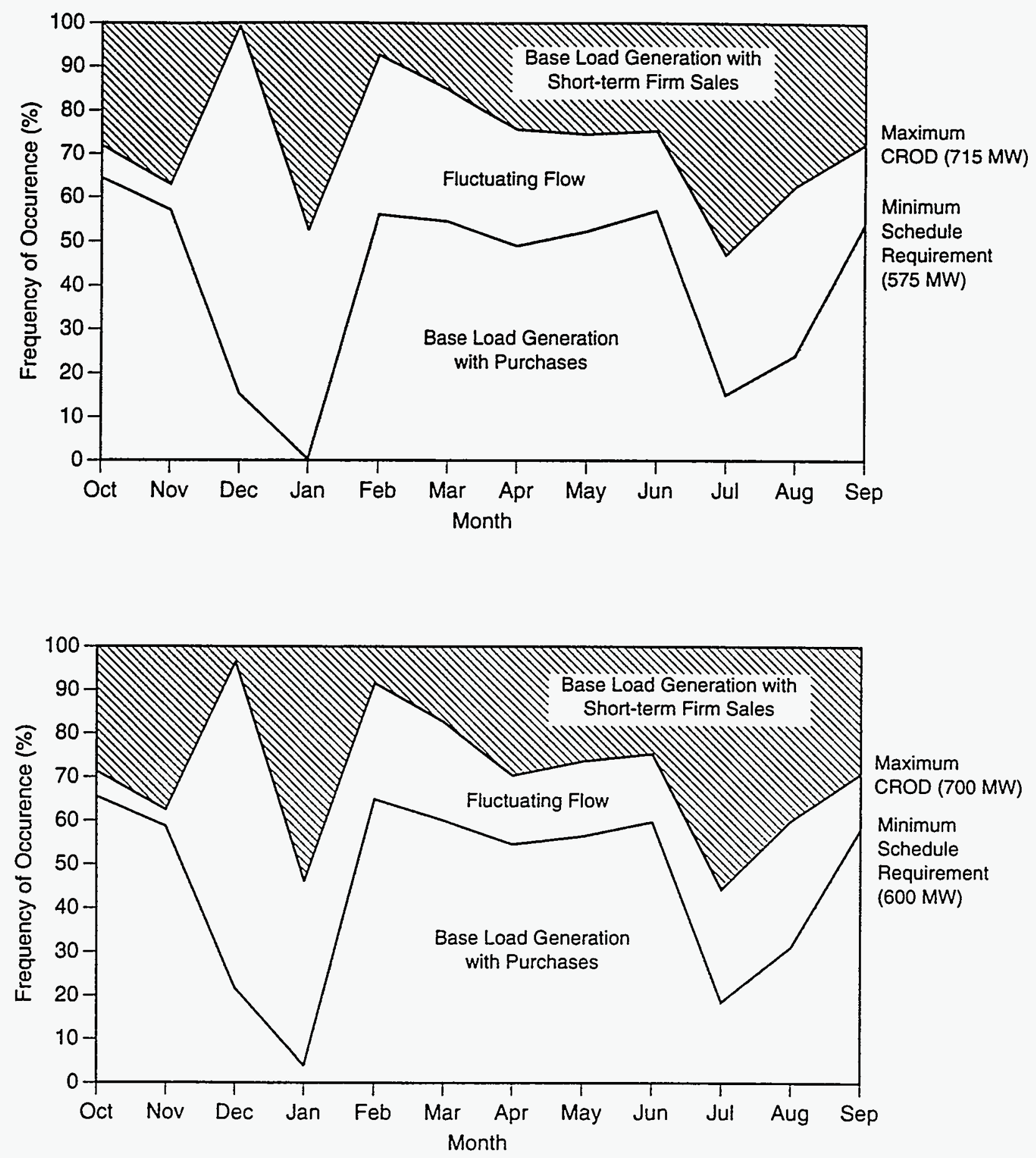

FIGURE 31 Frequency of Baseload Generation from SLCA/IP by Month under Two Restrictive Marketing Strategies 
by the maximum schedule changes. If the excess energy is sold on the spot market, fluctuations in collective SLCA/IP hydropower generation depend on the amount of excess energy available.

Fluctuations in collective SLCA/IP energy output will decrease further if some of the services now provided by Western, such as area load control, are not offered. In addition, similar maximum schedule change agreements could be imposed on project use loads.

\subsubsection{Limited and Conditional Purchases}

Limited purchases to serve discretionary loads would give Western the flexibility to offer its customers LTF capacity and energy above the amount that would be available under adverse hydropower conditions. Limited purchases in conjunction with maximum schedule change clauses would affect SLCA/IP generation in the same way as the no-purchase case would affect generation.

Stringent maximum schedule changes can significantly decrease the value of the capacity and energy Western sells. Although the amount of SLCA/IP energy does not vary significantly across the range of maximum schedule changes, the value of the energy does vary significantly. Energy sold during on-peak hours is much more valuable to Western's customers than off-peak energy. Figure 32 shows that customers will purchase more SLCA/IP energy during off peak-hours as the maximum schedule changes become more restrictive. Also, many of Western customers use discretionary energy for load following. Maximum schedule change clauses could severely limit the ability of customers to use LTF energy for on-peak load following, thereby significantly lowering its value.

Both the quality and quantity of usable capacity that Western markets will decline as a function of more stringent maximum schedule changes. Figure 33 shows that from the customer's perspective, usable capacity could be reduced significantly by stringent maximum schedule changes. The figure assumes low levels of LTF capacity and energy (i.e., average hydropower conditions). It also assumes that no STF energy and capacity are offered (i.e., a very dry year). A customer may not be able to use its allocated capacity because its maximum schedule change will not allow it to ramp up to the capacity limit. When more energy is made available to the customer through STF contracts, the amount of energy the customer takes during off-peak hours will increase, and less ramping will be required to reach the capacity limit.

Hence, stringent maximum schedule changes greatly reduce customers' usable capacity. From a long-term planning perspective, customers will not be able to rely on STF capacity and energy purchases and will have to base estimates of usable capacity on LTF capacity and energy allocations. Because of the uncertainty in forecasting the exact time of the peak demand, the value of the capacity to the customer is further reduced. Customers must begin to ramp up to satisfy peak demand hours before they are predicted to occur. 


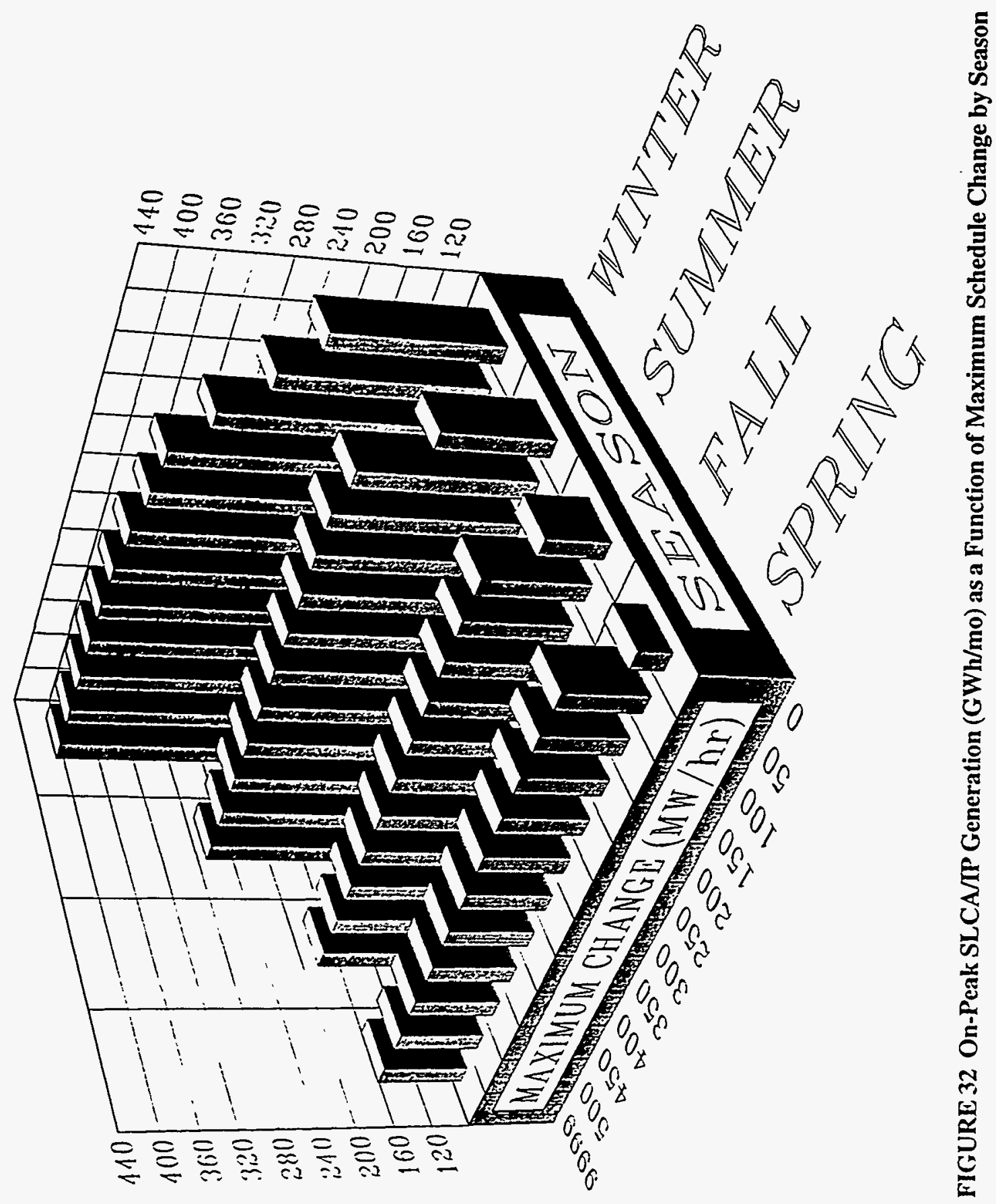




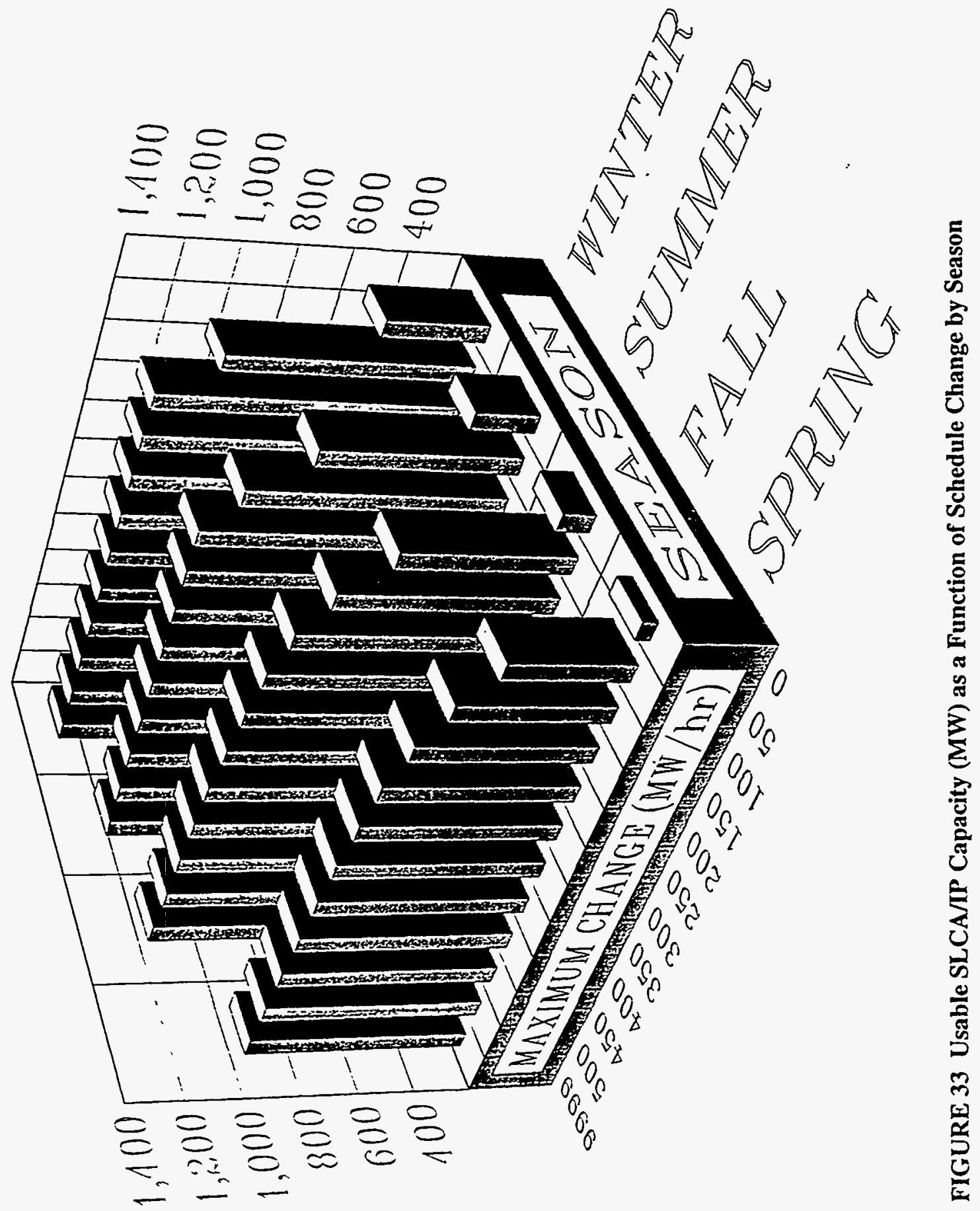




\subsection{COMBINED MARKETING STRATEGIES}

Previous sections discussed the general effects of alternative purchasing program configurations on the following three aspects of SLCA/IP hydropower plant operations: (1) maximum output levels, (2) minimum output levels, and (3) maximum schedule change. Identifying all the possible configurations of Western's programs is a multidimensional problem that involves complex interactions among those programs. This section briefly touches upon some possible combinations of Western's programs and discusses their effects on hourly SLCA/IP generation and the value of the capacity and energy to Western's customers.

Both minimum and maximum SLCA/IP generation levels can be affected by combinations of Western's purchasing programs and marketing techniques, which involve setting minimum schedule requirements and CRODs as currently practiced by Western. However, the following limitations would also be placed on Western's programs: (1) purchases of electricity and capacity would not be permitted; (2) LTF capacity and energy commitments would be based on adverse hydropower conditions; and (3) excess energy and capacity above LTF commitments could be sold only to preference customers on a STF basis (both 6- and 1-month contracts). Figure 34 shows the total amount of usable capacity for summer on which Western's customers could rely for long-term planning purposes under these terms as a function of minimum schedule requirement and capacity level. Figure 35 show's usable capacity for spring. Figures 36 and 37 present the average monthly generation of on-peak electricity delivered to customers under very dry hydropower conditions for summer and spring, respectively. Under more favorable hydropower conditions, on-peak electricity generation would be higher.

Another combined strategy is to set both minimum schedule requirements and maximum schedule change requirements. Given the three program limitations specified earlier, the value of both capacity and energy to the customer would be decreased significantly, as shown in Figures 38 and 39 .

A third combined strategy would be to limit firm capacity and establish maximum schedule change requirements. As in the previous two cases, the value of both energy and capacity to the customer would be decreased significantly, as shown in Figures 40 and 41. 


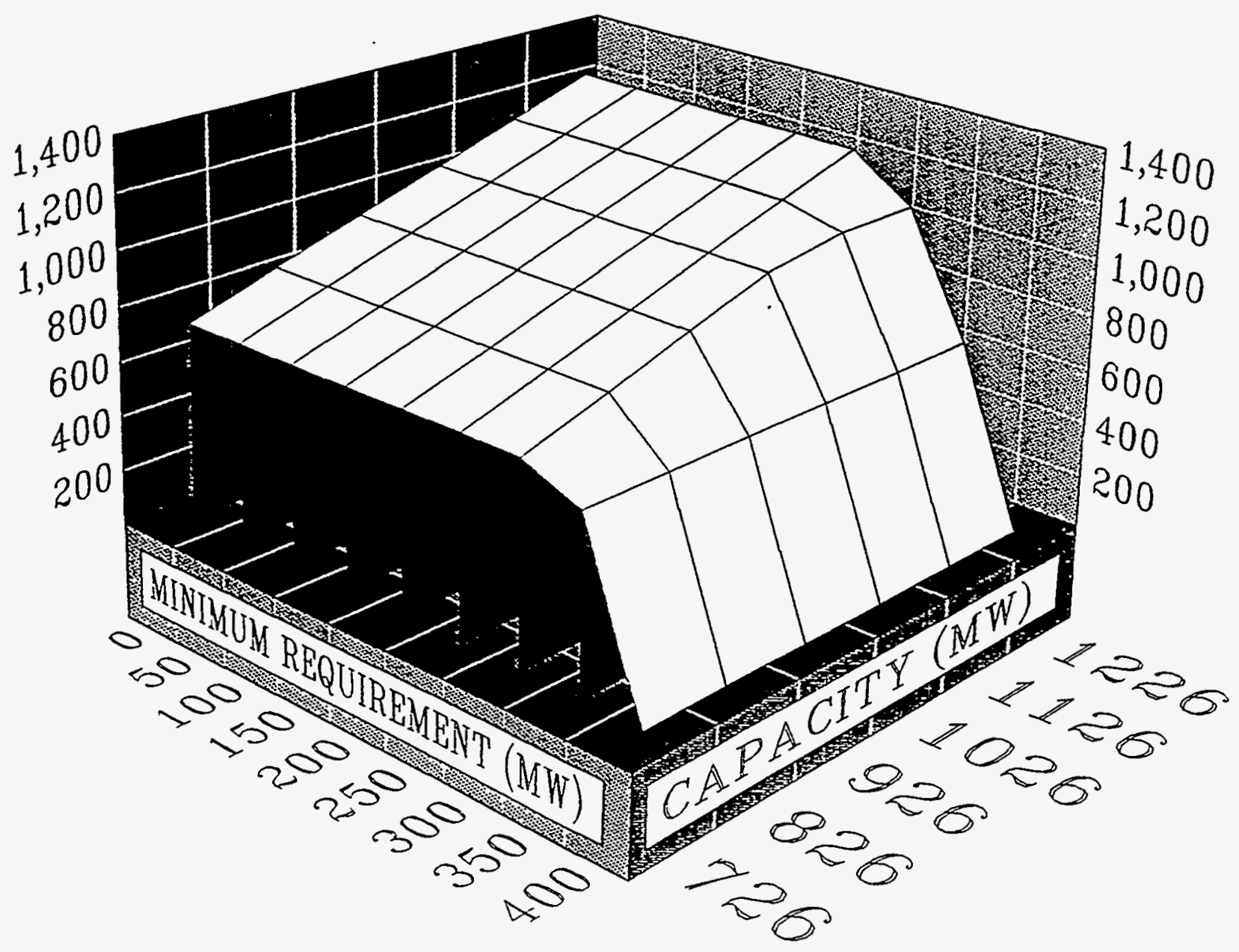

FIGURE 34 Usable SLCA/IP Capacity (MW) as a Function of Minimum Schedule Requirement and Firm Capacity Level: Summer 


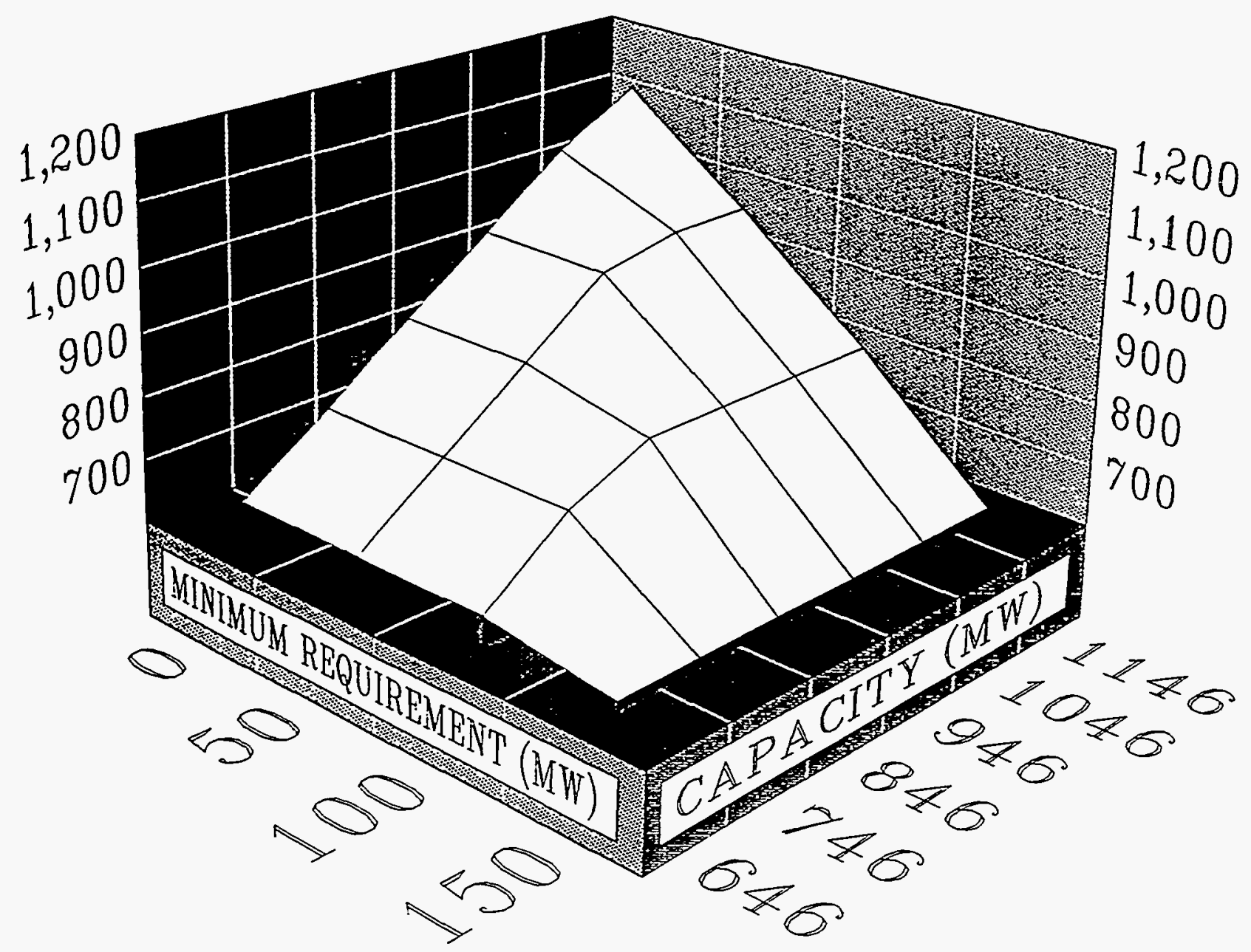

FIGURE 35 Usable SLCA/IP Capacity (MW) as a Function of Minimum Schedule Requirement and Firm Capacity Level: Spring 


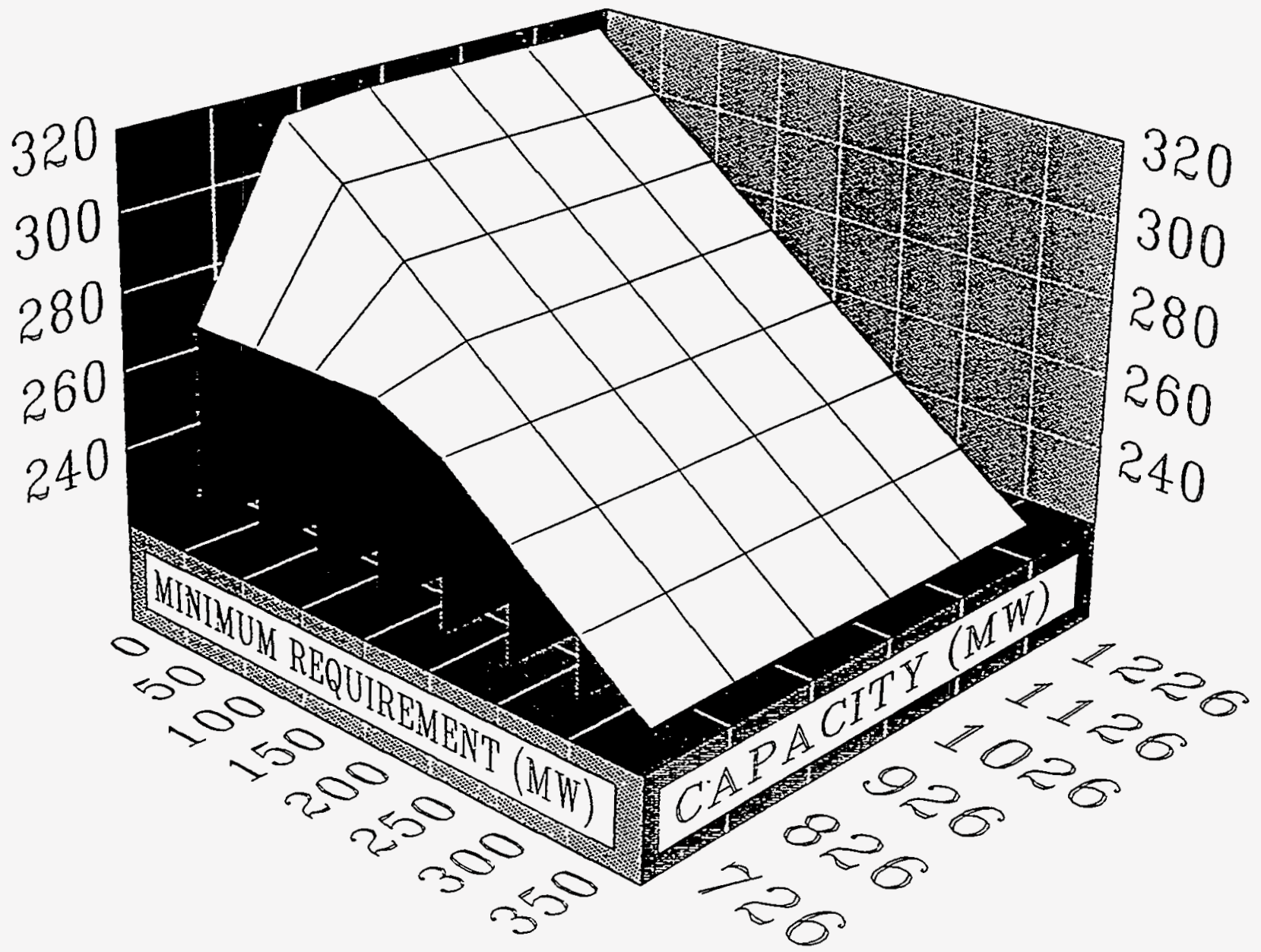

FIGURE 36 On-Peak SLCA/PP Generation (GWh/mo) as a Function of Minimum Schedule Requirement and Firm Capacity Level: Summer 


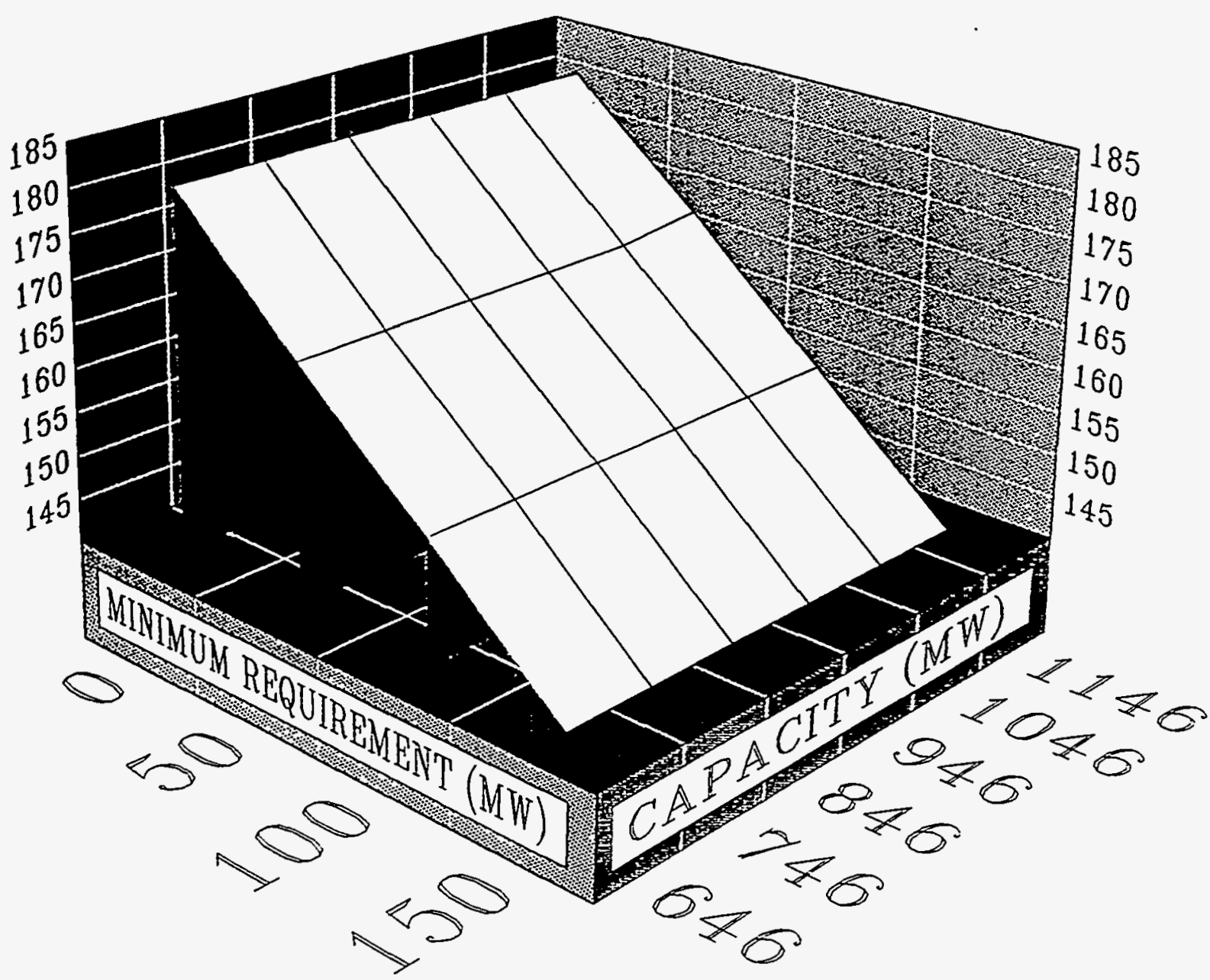

FIGURE 37 On-Peak SLCA/IP Generation (GWh/mo) as a Function of Minimum Schedule Requirement and Firm Capacity Level: Spring 


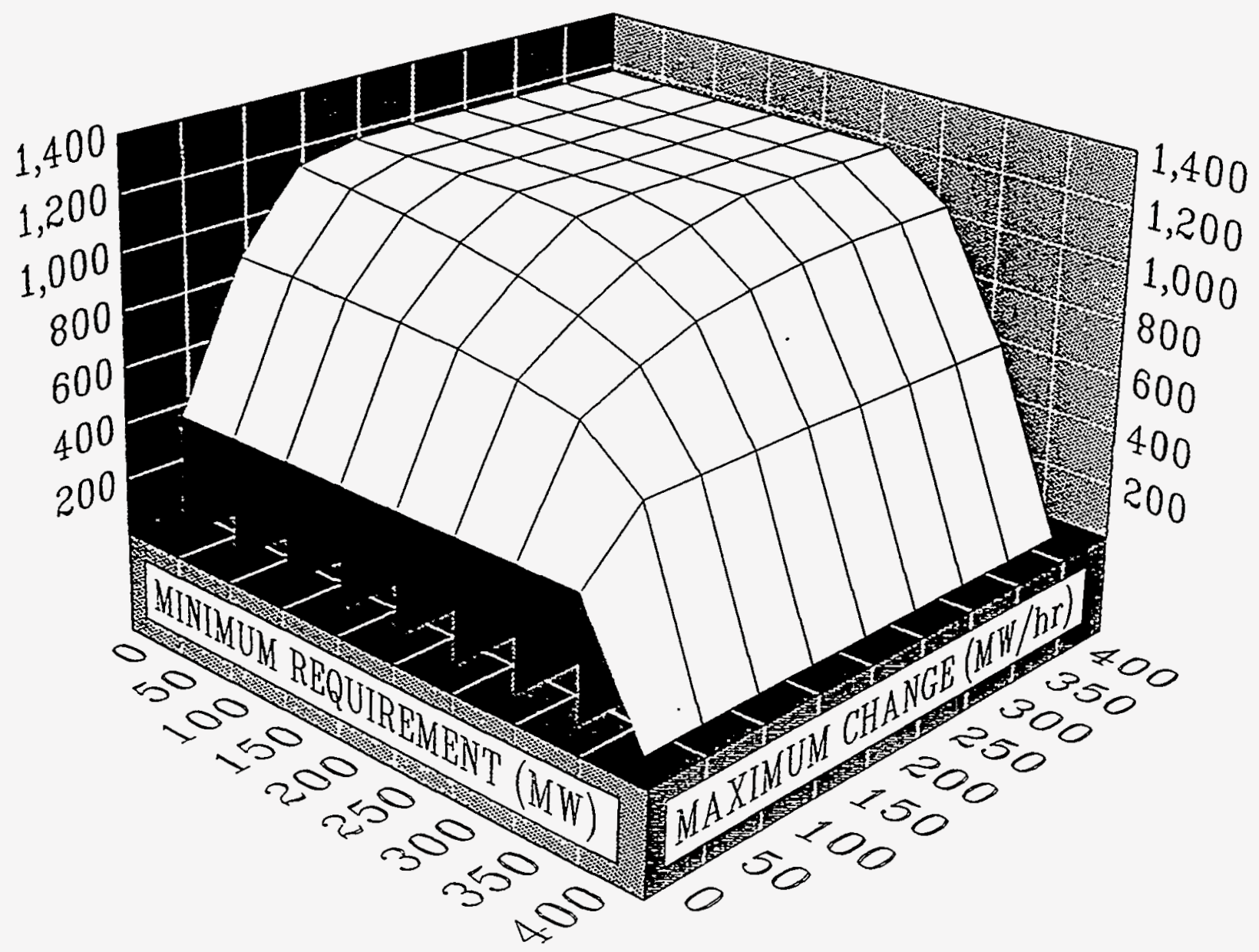

FIGURE 38 Usable SLCA/IP Capacity (MW) as a Function of Minimum Schedule Requirement and Firm Capacity Level: Summer 


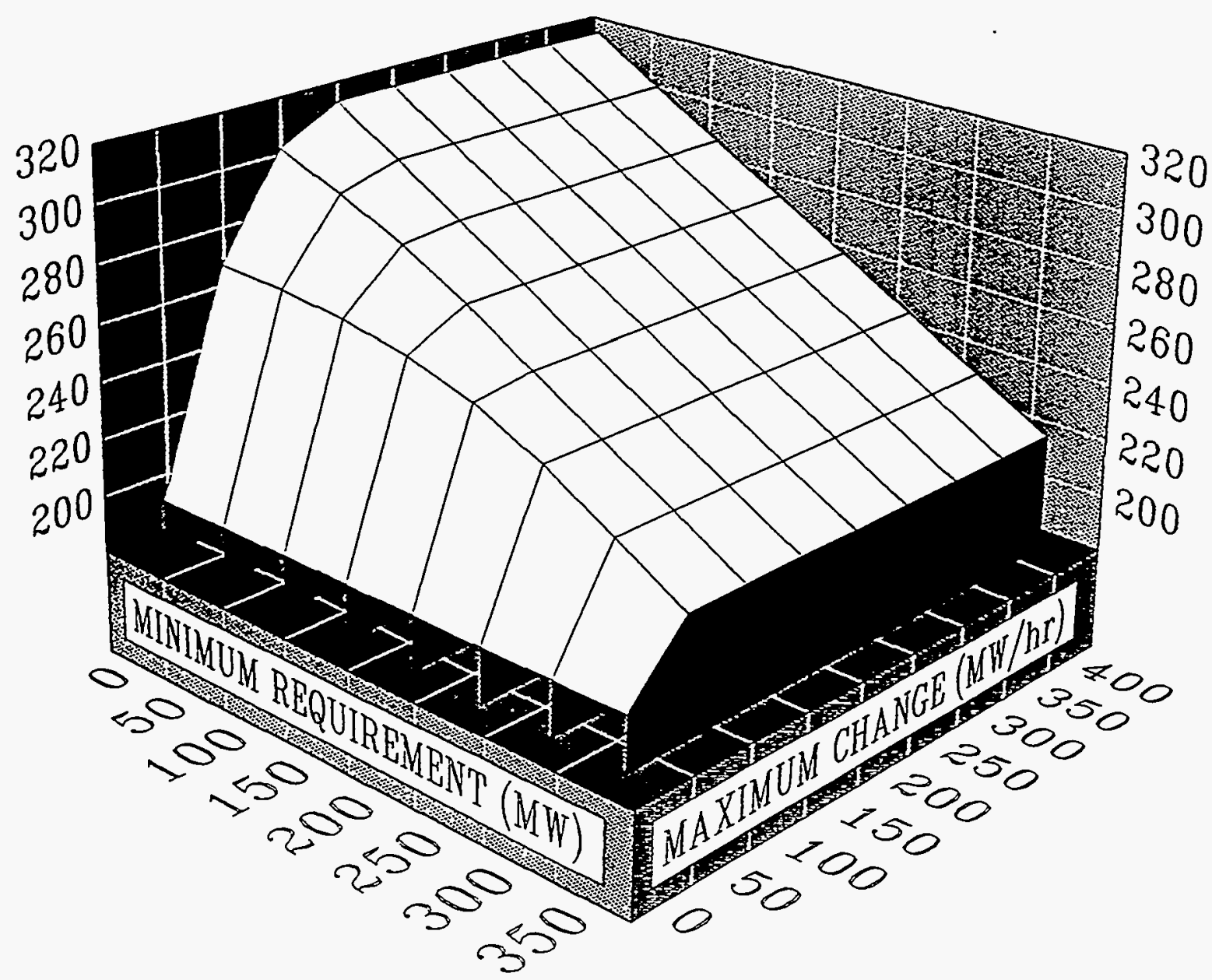

FIGURE 39 On-Peak SLCA/IP Generation (GWh/mo) as a Function of Minimum Schedule Requirement and Firm Capacity Level: Summer 


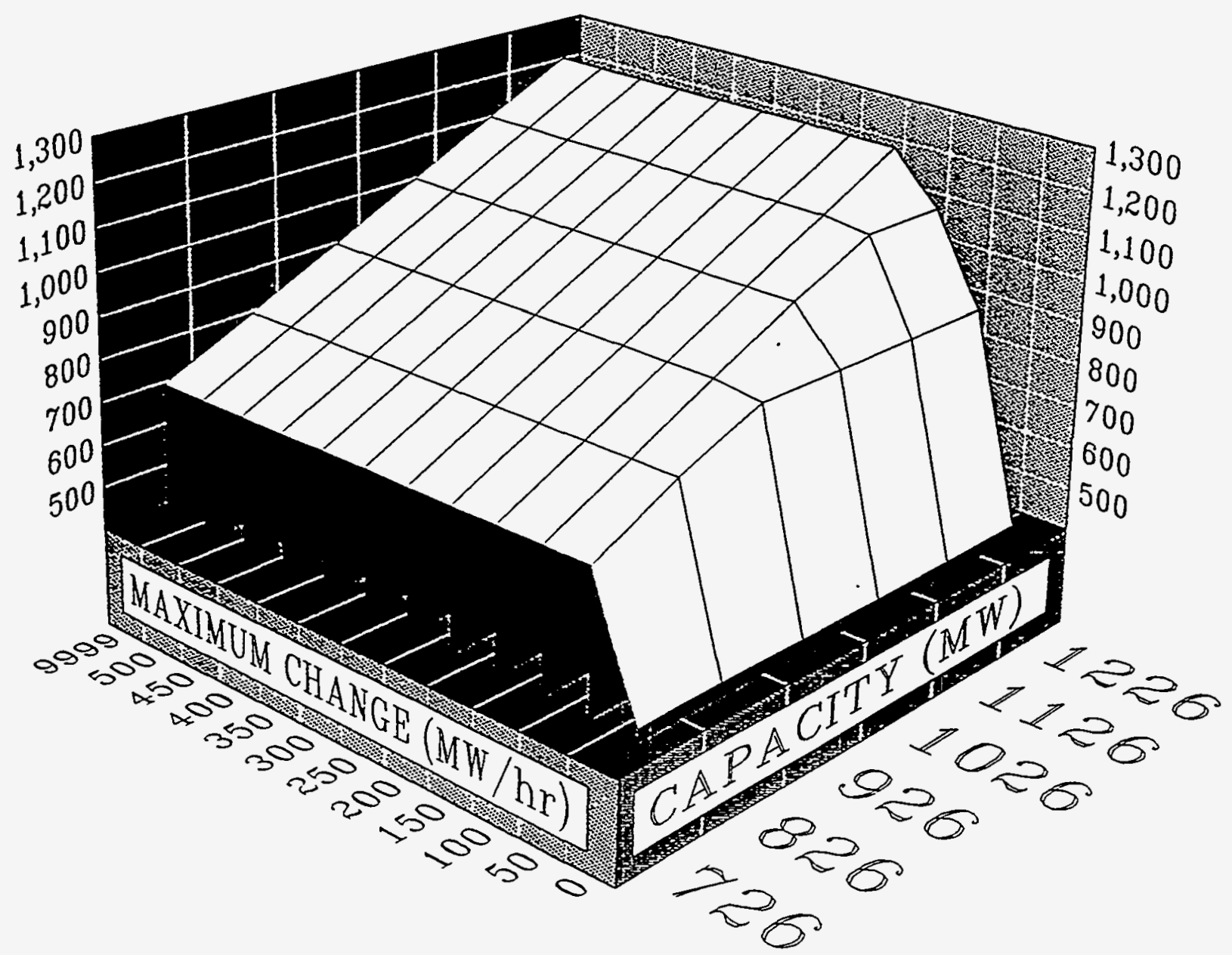

FIGURE 40 Usable SLCA/IP Capacity (MW) as a Function of Minimum Schedule Requirement and Firm Capacity Level: Summer 


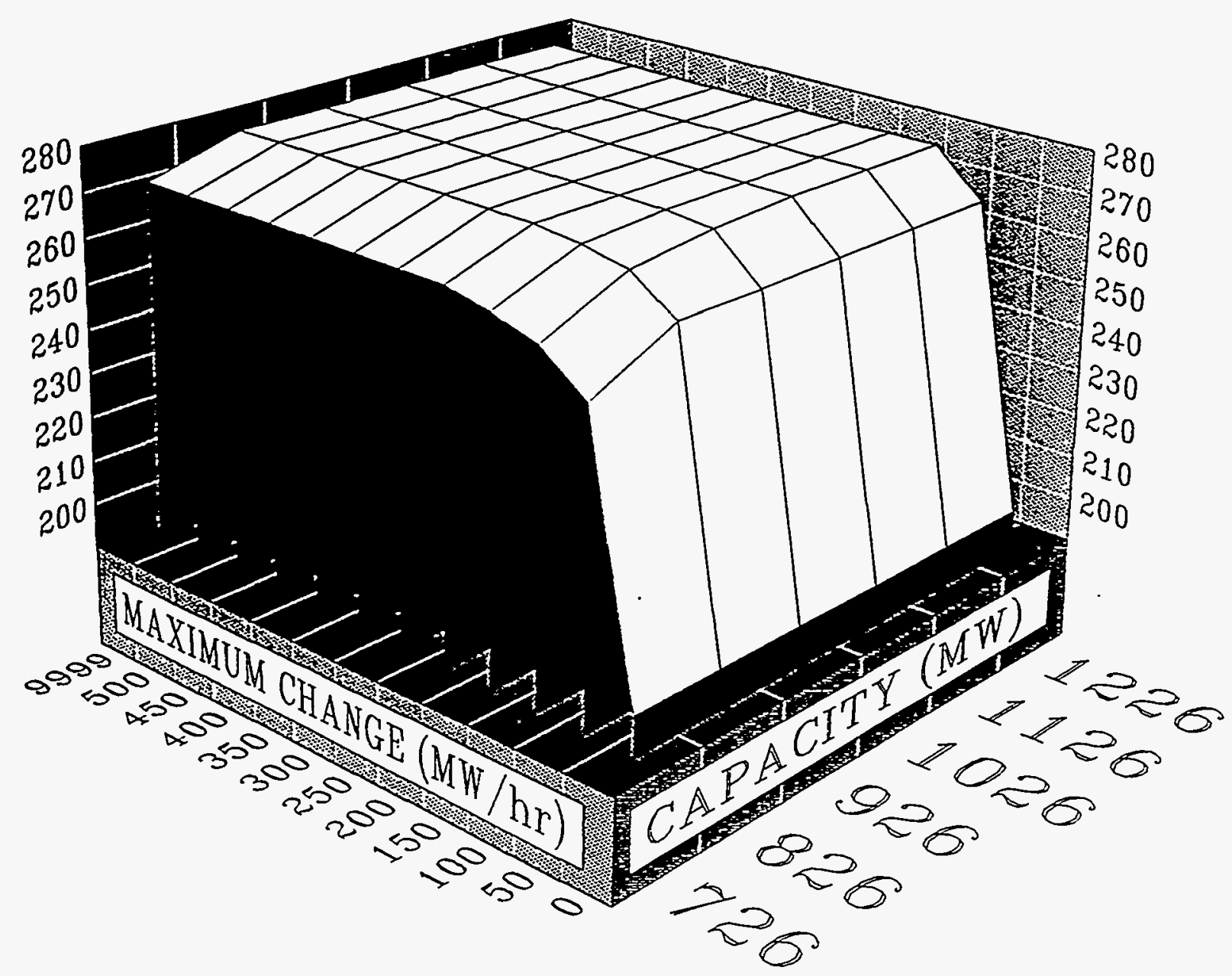

FIGURE 41 On-Peak SLCA/IP Generation (GWh/mo) as a Function of Firm Capacity and Maximum Schedule Change: Summer 


\section{LONG-TERM FIRM CONTRACT TERMS}

This section discusses several different types of LTF contract terms (other than LTF capacity and energy commitments and minimum schedule requirements) and the impact of these provisions on customers and SLCA/IP power plant operations. Some of the contract provisions analyzed in this study include contact length, pricing methods, and customer energy and capacity allocations.

\subsection{MODIFIED PASS-THROUGH COSTS COMPARED WITH BLENDED COSTS}

When Western purchases capacity or energy on behalf of its customers, it can either blend (share) the expenses among all of its customers or pass the costs through to those customers that do not want reductions in capacity or energy when SLCA/IP hydropower projects are under low hydropower conditions. Modified PTC limits the potential purchase expense to the customer. The use of both modified PTC and blended costs was studied to determine their effects on SLCA/IP hourly firm loads and power plant operation. These billing options are described in more detail in Section 3.3.2.

Under the modified PTC billing option, not all purchase costs are passed through to customers. Anticipated energy purchases up to average generation are blended into the rate base. Additional energy purchases up to $400 \mathrm{GWh} / \mathrm{yr}$ are on a pass-through basis. Purchases above $400 \mathrm{GWh} / \mathrm{yr}$ are blended into the rate.

Required capacity purchases up to the $90 \%$ exceedance level are blended into the firm power rate. Purchases greater than the $90 \%$ probability level are on a pass-through basis. The maximum PTC purchase Western may make on behalf of its customers is $109 \mathrm{MW}$ in winter and $98 \mathrm{MW}$ in summer.

When costs are blended or shared by all customers, the true cost of purchasing the last increments of power or energy for a particular customer are not accurately reflected in that customer's cost; it is averaged in with all other power or energy purchase costs. Blending could lead the customer to purchase more energy during on-peak hours when the blended rate is lower than the marginal purchase price. Consequently, because of the higher peak demands, the SLCA/IP hydropower plants may have higher ramping rates during on-peak hours.

When customers are billed on the basis of a modified PTC, Western can assign a certain portion of the costs of purchasing power or energy directly to a particular customer. In this way, the price the customer is charged is a more accurate reflection of the cost to purchase the power or 
energy. Consequently, the customer pays more for peak power in this case than when blended costs are used and thus tends to purchase less power on-peak. Therefore, because on-peak load demands may be smaller, the power plants would have lower ramping rates during on-peak hours.

\subsection{LENGTH OF CONTRACT AND CONTRACT ADJUSTMENT}

The length of contracts and the contract adjustment period were analyzed to determine their effects on Western and its customers. Contract lengths of 10, 15, and 25 years were considered in the development of marketing alternatives. The length of the contract has a large effect on the customer but only a small effect on SLCANP hydropower plant operations. Contracts written for 10 years would not give the customer as much long-term security about its future generation resource. The customer may still have to plan for additional generating capacity, possibly even make commitments to build its own unit in the near future. However, a 25-year contract would allow a customer to defer construction of new generating capacity.

The terms of the contract may be changed after two-thirds of the contract has passed if 3 years' notice is given. This allowance is valuable from the perspectives of both Western and its customers because it allows changes to be made in the contract period without the additional administrative burden associated with a reallocation process.

\subsection{NORTH AND SOUTH ALLOCATIONS}

Western currently sells $8.5 \%$ of its LTF capacity and energy to the southern division (most of Arizona and southern Nevada) under the post-1989 interim marketing plan. The remaining capacity and energy (91.5\%) are sold to the northern division (northeastern Arizona, Colorado, New Mexico, Utah, and Wyoming). This north/south allocation is different from the 1978 marketing criteria, in which the south received $7 \%$ of the capacity and $8 \%$ of the energy. North/south allocations could affect SLCA/IP hydropower plant operations. Customers in the southern division have high peak summer loads, while some of the customers in the northern division have high winter demand peaks. When allocations among customers are altered, Western's firm load patterns change. If Western's purchasing program is restricted, the allocation of energy and capacity among customers results in relatively higher generation fluctuations at SLCA/IP hydropower plants when more LTF capacity and energy are sold to utilities with low load factors. On the other hand, if more capacity and energy are sold to utilities with high load factors, fluctuations in generation at SLCA/IP hydropower plants would be relatively lower. 


\section{SERVICES PROVIDED BY WESTERN AND SLCA/IP HYDROPOWER PLANT OPERATIONS}

In addition to marketing and supplying preference customers with LTF energy and capacity, Western provides several other services. The SLCA administers WAUC load control services and provides spinning reserves, emergency services, and scheduled outage assistance for WAUC as established by NERC, WSCC, and IPP. Western also offers STF capacity and energy as well as transmission services for both preference and nonpreference customers.

\subsection{AREA LOAD CONTROL}

As discussed in Section 3.2.5.2, Western provides load control service for WAUC. As part of this service, Western must respond to instantaneous changes in system frequency with up to $56 \mathrm{MW}$ of capacity. Therefore, flows below SLCA/IP hydropower plants fluctuate as generation from plants regulates the system frequency. Hydropower plants are well suited for providing regulation services because they can respond very quickly to changes in loads without damaging equipment. If the Glen Canyon power plant is regulating the system, this translates into a maximum flow fluctuation that ranges from $1,300 \mathrm{ft}^{3} / \mathrm{s}$ if the reservoir is full to $1,500 \mathrm{ft}^{3} / \mathrm{s}$ if the reservoir is low. Other SLCA/IP hydropower plants can also provide regulation for WAUC. For example, if the Flaming Gorge power plant is regulating the system, the maximum flow fluctuation is approximately $1,800 \mathrm{ft}^{3} / \mathrm{s}$. If regulation is shared among many SLCA/IP power plants, the fluctuations will be much lower, but the regulation service will remain the same.

\subsection{SPINNING RESERVE REQUIREMENTS AND OUTAGE ASSISTANCE}

Western's spinning reserve requirement for WAUC varies by month; it is approximately 45-60 MW, depending on factors related to IPP loads and resources (see Section 3.2.5.3). Spinning reserves are used to replace generation voids that result from an unscheduled outage; they must be capable of serving loads within 10 minutes of the outage.

If Glen Canyon Dam is providing $60 \mathrm{MW}$ of spinning reserve, then depending on hydropower conditions, an emergency could translate into a maximum flow increase from 1,400 to $1,600 \mathrm{ft}^{3} / \mathrm{s}$ in less than 10 minutes. When $60 \mathrm{MW}$ of capacity from the Flaming Gorge power plant is put into spinning reserves, an emergency would result in a maximum flow increase of approximately $2,000 \mathrm{ft}^{3} / \mathrm{s}$. If spinning reserves are shared among many SLCA $/ \mathrm{IP}$ power plants, fluctuations will be much lower, but the reliability of the system will remain the same. When the service is no longer provided (after a maximum of 72 hours), flow will decrease as a result of the loss in load. 


\subsection{SHORT-TERM FIRM CAPACITY AND ENERGY COMMUTMENTS}

Short-term firm capacity and energy commitments are contractual power agreements that are either seasonal or monthly. Short-term firm sales are offered if projected SLCA/IP resources exceed LTF commitments. Surpluses are first marketed to Western's preference customers. Any remaining excess capacity and energy are then offered to nonpreference customers. Non-firm energy sales are typically of short duration and can be interrupted abruptly. If LTF commitments are low (e.g., based on adverse hydropower conditions), there will often be excess SLCA/IP energy. Thus, Western has numerous opportunities to offer STF sales to its customers. At the other extreme, if Western LTF commitments are based on wet hydropower conditions, excess hydropower resources will occur very infrequently (if ever), and STF sales will be at a minimum. As discussed earlier, the terms under which STF services are offered can significantly affect hourly SLCA/IP power plant generation.

\subsection{TRANSMISSION AND GENERATION DISPLACEMENT SERVICES}

The remainder of this section examines the effects of Western's transmission service contracts (particularly the SRP Exchange Agreement) on power line transfers (particularly on the Glen Canyon-Kayenta-Shiprock line) and SLCA/IP power plant operations. This study analyzed a peak summer case, an off-peak summer case, and a peak winter case. Western's contractual power flow model was used for the analysis.

\subsubsection{Contractual Power Flow Model}

The contractual power flow model estimates the instantaneous maximum amount of energy (on a contractual basis, not parallel power flow) that flows across the SLCA transmission system that connects CRSP power plants to Western's firm loads. The model, written as a Lotus 1-2-3 spreadsheet, is tailored to track power flows over Western's transmission system. The model is used as a simple screening tool to identify transmission buses that could be overloaded as the result of changes in Western's marketing programs or dam operations.

Power flows over system buses are calculated by using elementary circuit theory and the power equivalent of Kirchhoff's current law. Initially, transmission loads are derived from Western's customer electricity demands and generation at Flaming Gorge/Fontenelle and Aspinall. Generation at the Glen Canyon unit is then computed by taking the difference between customer demands and generation from Flaming Gorge/Fontenelle and Aspinall. The model does not account for transmission line losses. 
Power flows are calculated by using nodal analysis. The power out of a node (in this case, a substation or delivery point) must equal the power into a node. The direction in which power flows, either into or out of a node, is important and must be tracked carefully. Nodes having only one unknown transmission line power flow are solved in succession until all lines are solved, beginning at the lines out of Flaming Gorge/Fontenelle and ending at the line going east out of Glen Canyon (i.e., the Shiprock-Glen Canyon line). The sum total of power flows on all transmission lines leading out of Glen Canyon is equal to the power plant's net generation.

\subsubsection{Effects of Transmission Services and Generation Exchanges on Summer Peak Power Flows and Dam Operations}

The first case analyzed the effect of transmission services and generation exchanges on summer peak power flows. Peak summer loads, including transmission interchanges and generation exchanges obtained from the contractual power flow model, were used as the reference case. Figure 42 shows the generation and power flows for this case. No transmission lines are overloaded in this case. Also, because Glen Canyon is generating 1,025 MW, Western can sell an additional $275 \mathrm{MW}$ of STF capacity and deliver this power over any transmission line without overloading it. It is assumed that hydropower conditions allow Glen Canyon to generate its maximum legal limit of $1,300 \mathrm{MW}$.

Next, the elimination of transmission services and generation exchanges was studied to calculate the power Western would transfer over the Glen Canyon-Kayenta-Shiprock to serve its customers. Loads at the substations were reduced and generation at the thermal power plants was set to zero to reflect this scenario, shown in Figure 43. As can be seen, the Glen Canyon-KayentaShiprock transmission line is overloaded by $248 \mathrm{MW}$. Hence, Western must reduce CRODs to customers in the eastern portion of the SLCA/IP marketing area to honor its firm commitments in the absence of transmission services and generation exchanges

Figure 44 shows the effect of limiting the power transfer capability of the Glen CanyonKayenta-Shiprock line to $400 \mathrm{MW}$. To avoid overloading this transmission line, all loads must be reduced by $23 \%$ except those loads served from the Southern Utah, Page, and Pinnacle Peak substations. Consequently, generation capacity at Glen Canyon is reduced by $24 \%$ from the reference case, which means that an additional $523 \mathrm{MW}$ of STF capacity can be offered to customers. However, this additional capacity is available only at the Southern Utah, Page, and Pinnacle Peak substations. Although peak loads are reduced, LTF energy does not have to be reduced. Thus, if the additional capacity is not sold on either the STF or spot market, maximum generation levels at Glen Canyon would be reduced during on-peak hours and minimum generation levels would be increased during off-peak hours to use the water required to flow through the dam. 


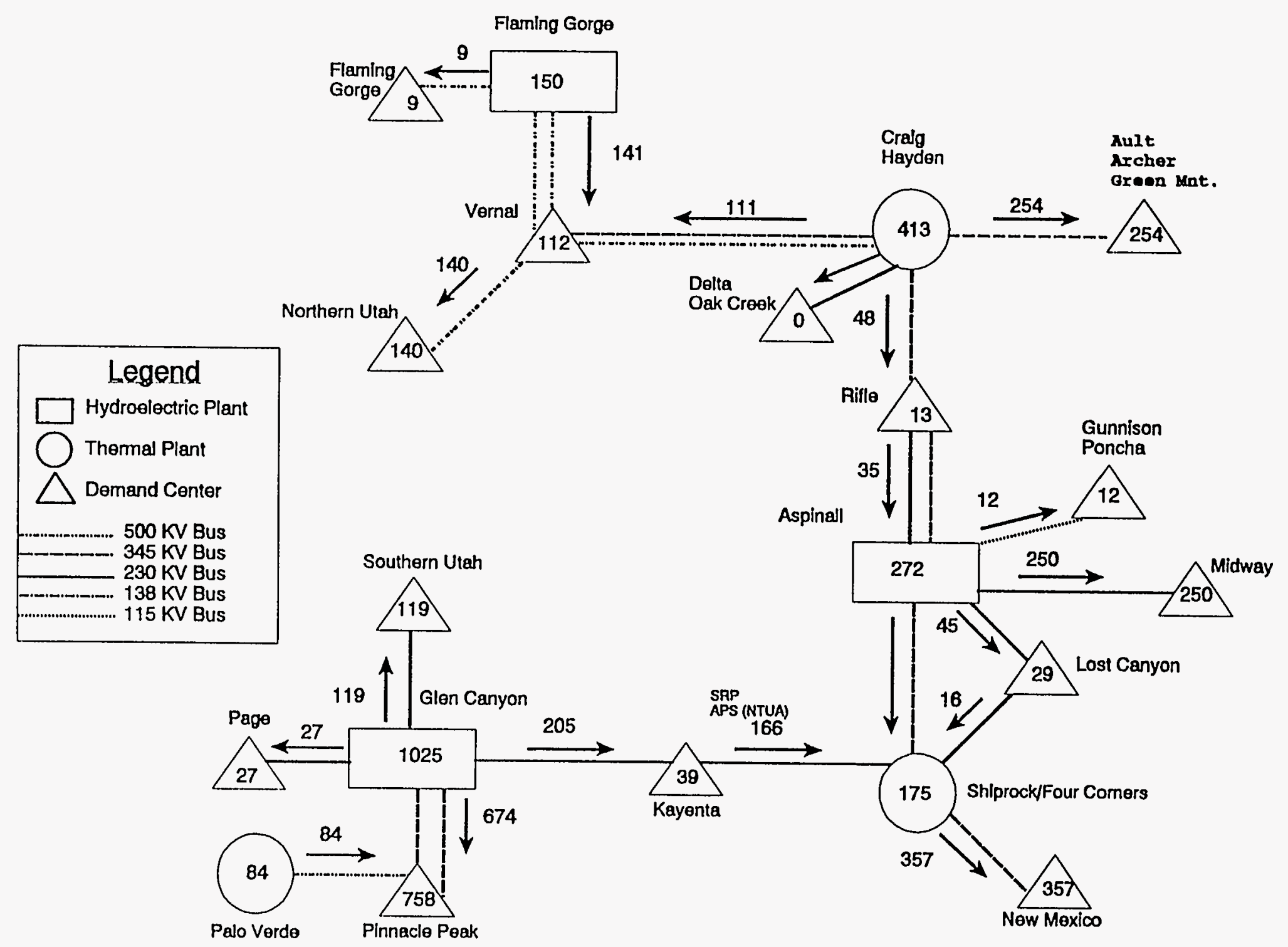

FIGURE 42 CRSP Contractual Power Flow: Summer Peak, Including Transmission Services and Generation Exchanges 


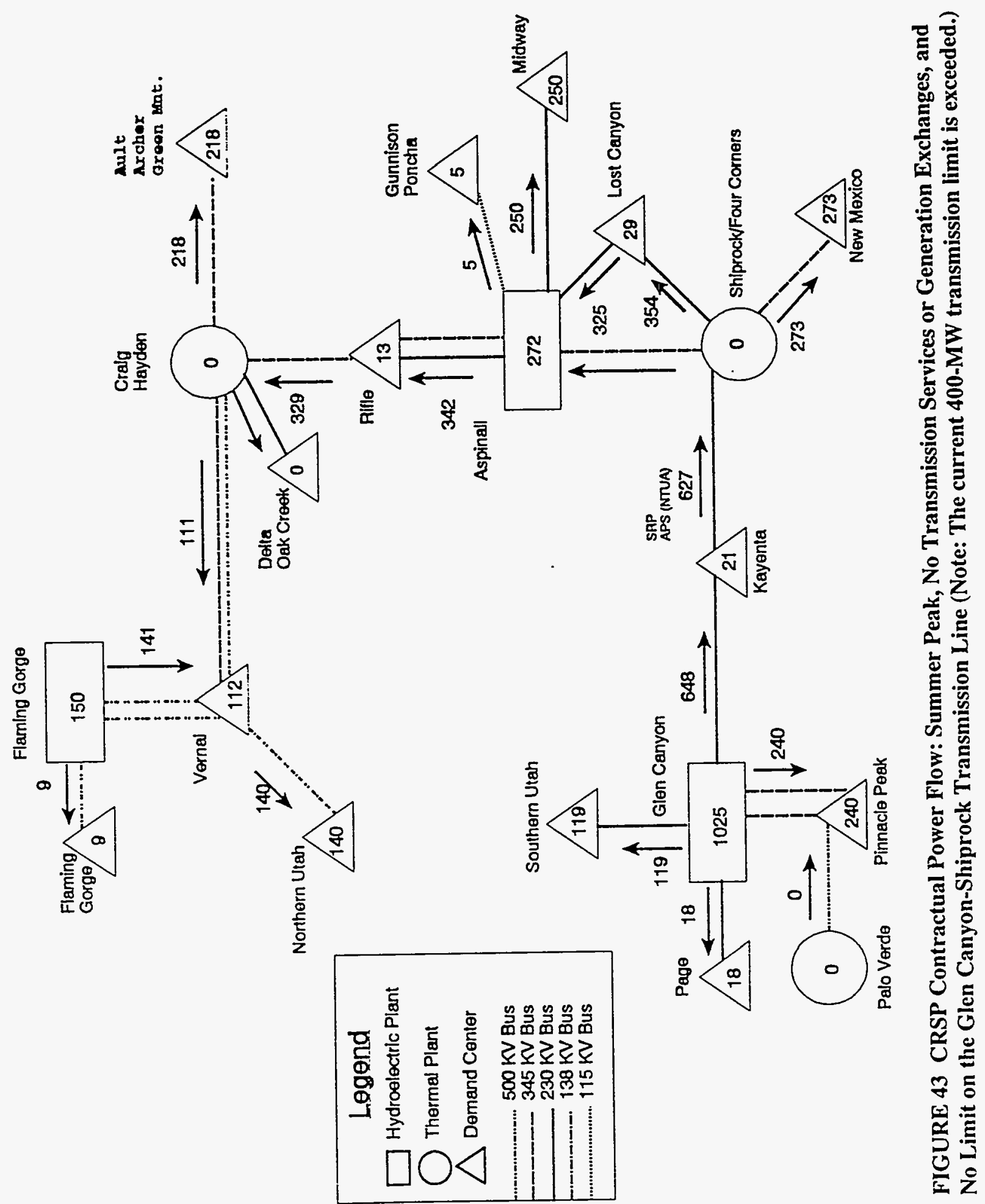




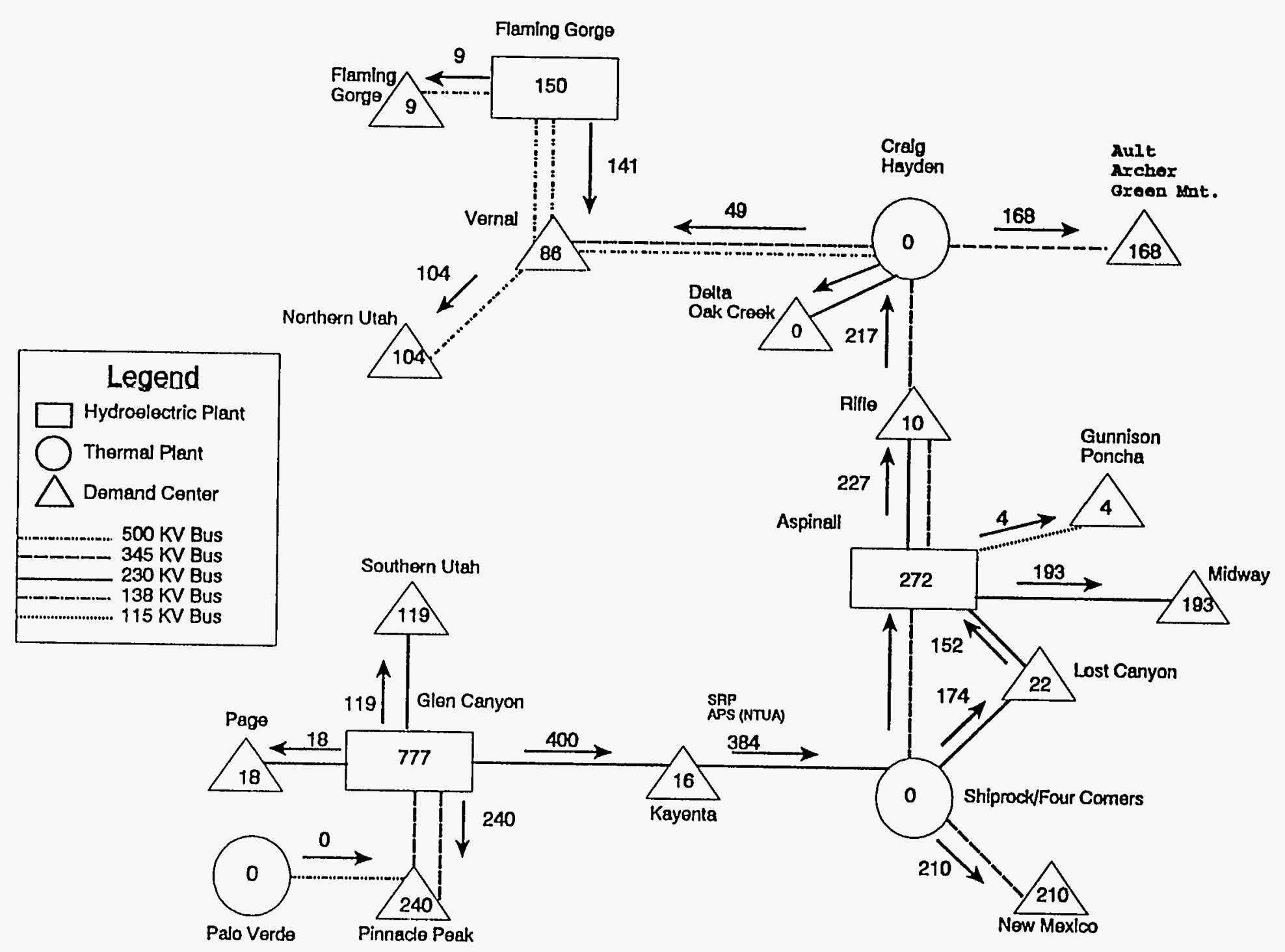

FIGURE 44 CRSP Contractual Power Flow: Summer Peak, No Transmission Services or Generation Exchanges, and Limit on the Glen Canyon-Shiprock Transmission Line 
Finally, the effect of limiting the power flow over the Glen Canyon-Kayenta-Shiprock line to $400 \mathrm{MW}$ and serving all Utah loads through the Southern Utah substation (i.e., no power transferred to the Northern Utah substation) was studied. Operations staff at Western's Montrose Office stated that the Southern Utah substation can handle up to $300 \mathrm{MW}$. Furthermore, such a power transfer was actually performed in the past, but because UP\&L wheels this power for Western, UP\&L needs advance notice of such a large transfer. The transfer is also subject to UP\&L's ability to handle such a transfer. Figure 45 shows the results of this scenario. Loads need to be reduced by only $12 \%$ except for loads served out of the Page, Pinnacle Peak, and Utah substations, which are served in full. Glen Canyon capacity is reduced from $10 \%$ from the reference case; hence, an additional $383 \mathrm{MW}$ is available for STF sale. As stated earlier, if additional capacity is not sold on the STF or spot market, maximum generation at Glen Canyon would be reduced while minimum generation levels would be increased. However, additional power cannot be sold (on a contractual basis) over the Glen Canyon-Kayenta-Shiprock line.

\subsubsection{Effects of Transmission Services and Generation Exchanges on Summer Off-Peak Power Flows and Dam Operations}

The second case analyzed the effect of transmission services and generation exchanges on summer off-peak power flows. Off-peak summer power flows are assumed to be $35 \%$ of peak summer power flows. This case corresponds to the minimum scheduling requirement Western places on its customers. It assumes that Flaming Gorge/Fontenelle and Aspinall generate at their minimum levels, which are 25 and $28 \mathrm{MW}$, respectively. Glen Canyon then generates the remaining amount. This case also assumes that no spot market purchases are made during off-peak hours.

Figure 46 shows the results of this case with no transmission services or generation exchanges, such as would occur when the SRP Exchange Agreement is not working. It can be seen that Western is able to serve all of its loads without overloading any of the transmission lines.

Purchases of transmission services and generation exchanges could alter the capacity available at Glen Canyon to some degree in this case. When the SRP Exchange Agreement is working and in the absence of purchases, generation at Glen Canyon would remain about the same. However, because Glen Canyon would be serving SRP loads through the Pinnacle Peak substation while SRP generation would serve most of Western's loads east of Glen Canyon, the required capacity transfer over the Glen Canyon-Kayenta-Shiprock line would be reduced. Hence, the generation exchange with SRP is still important in this case, but not as important as it is during onpeak hours.

Generation at Glen Canyon could be as low as $150 \mathrm{MW}$ (the minimum requirement) if purchases are made. However, in this case, the SRP exchange may not be feasible because generation at Glen Canyon may not be sufficient to satisfy the SRP loads at Pinnacle Peak. 


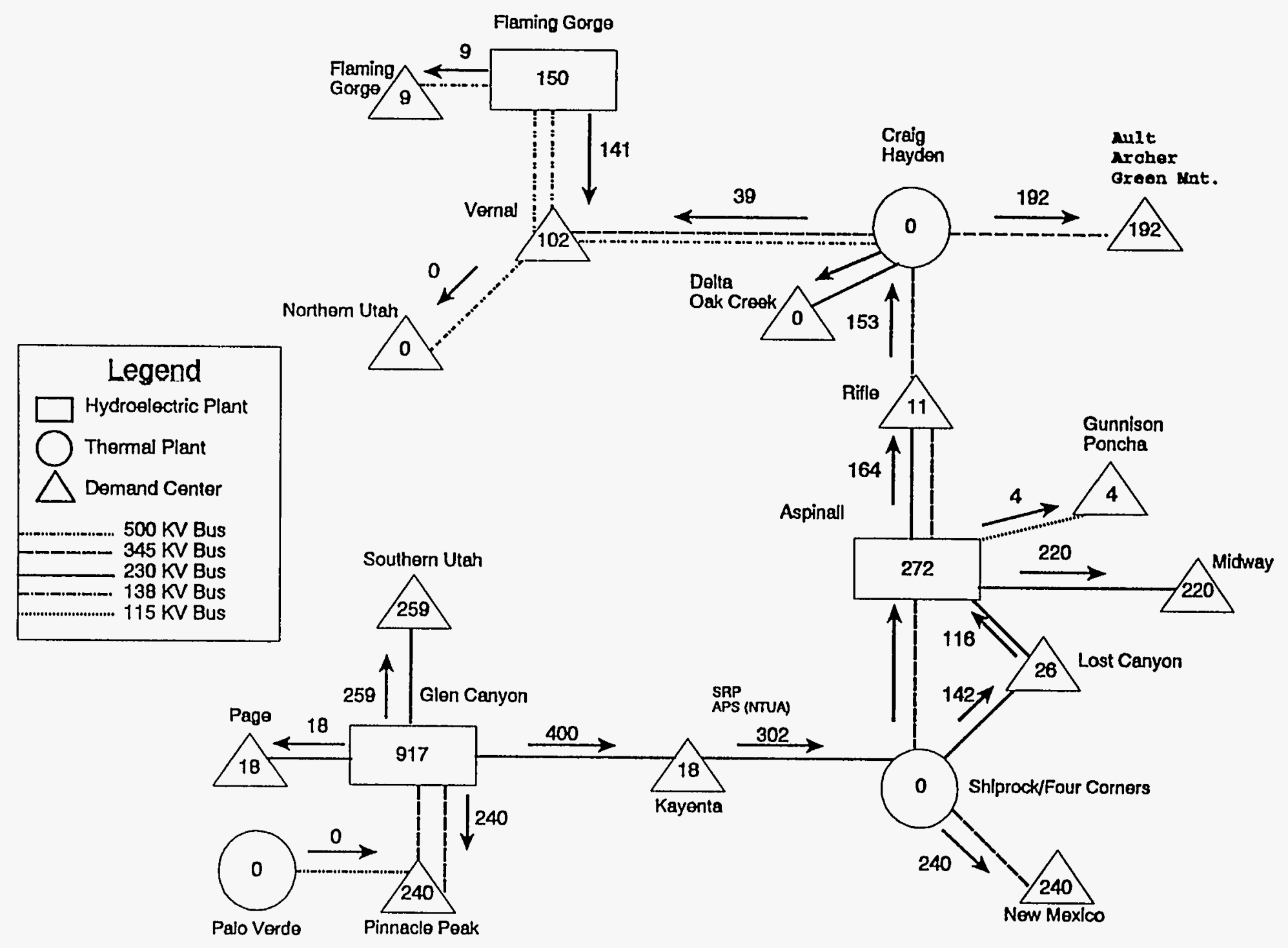

FIGURE 45 CRSP Contractual Power Flow: Summer Peak, No Transmission Services or Generation Exchanges, Limit on the Glen Canyon-Shiprock Transmission Line, and All Utah Loads Served through the Southern Utah Substation 


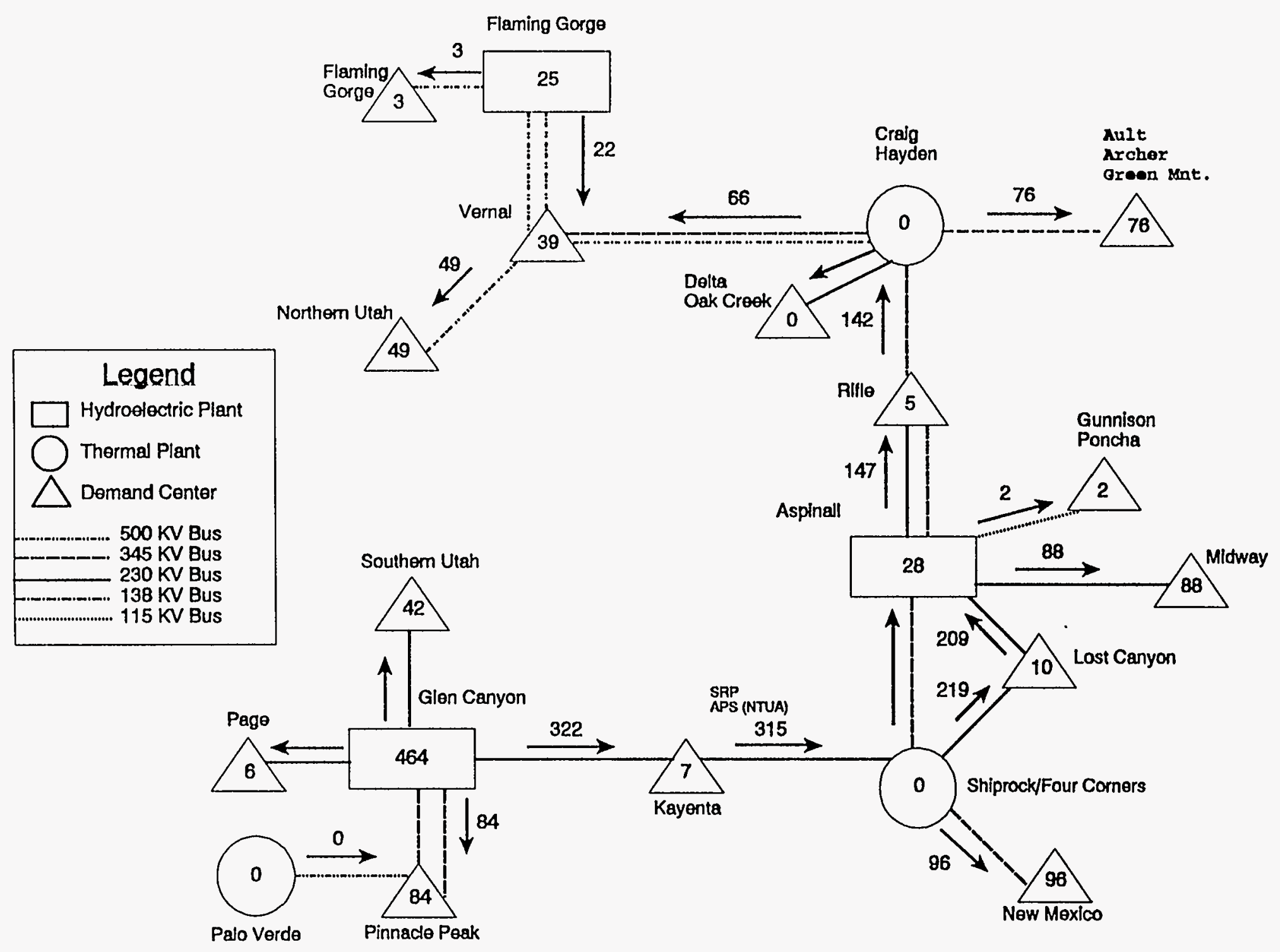


Table 5 summarizes the various scenarios for on-peak and off-peak summer loads. For each project, maximum and minimum generation are shown for combinations of on-peak and off-peak summer loads with and without purchases, transmission services, and generation exchanges and interchanges. Possible additional capacity available during on-peak hours for each project is also shown.

\subsubsection{Effects of Transmission Services and Generation Exchanges on Winter Peak Power Flows and Dam Operations}

The third case analyzed the effect of transmission services and generation exchanges on winter peak power flows. Data on Western's winter loads were obtained from the contractual power flow model. Figure 47 shows the reference case, which assumes that all transmission services and generation exchanges are in operation. No transmission lines are overloaded in this case. Also, Glen Canyon is generating $920 \mathrm{MW}$, which means that Western can market an additional $380 \mathrm{MW}$ for STF sales (assuming favorable hydropower conditions) and deliver this power over any transmission line from Glen Canyon without much concern of overloading lines.

Next, the elimination of transmission services and generation exchanges was studied to calculate the power that Western would transfer over the Glen Canyon-Kayenta-Shiprock line to serve its customers. Loads at the substations and generation at the thermal power plants were reduced to reflect this scenario, which is shown in Figure 48. As can be seen, the Glen Canyon-KayentaShiprock transmission line is overloaded by $235 \mathrm{MW}$. Hence, Western must reduce CRODs to customers in the eastern portion of the SLCA/P marketing area to honor its firm commitments in the absence of transmission services and generation exchanges.

Figure 49 shows the effects of limiting the power transfer capability of the Glen CanyonKayenta-Shiprock line to $400 \mathrm{MW}$. To avoid overloading this transmission line, all loads must be reduced by $21 \%$ except those loads served from the Southern Utah, Page, and Pinnacle Peak substations. Consequently, generation at Glen Canyon is reduced by almost $26 \%$ over the reference case, and an additional $615 \mathrm{MW}$ can be offered for STF capacity sales. Again, if additional STF capacity is not sold, maximum generation levels at Glen Canyon would be reduced while minimum generation levels would be increased to use the water required to flow through the dam. However, this additional power is available only at the Southern Utah, Page, and Pinnacle Peak substations.

Finally, the effect of limiting power flow over the Glen Canyon-Kayenta-Shiprock line to $400 \mathrm{MW}$ while attempting to serve all Utah loads through the Southern Utah substation was studied. This scenario is identical to the one discussed earlier for peak summer loads. However, in this case, not all loads can be served through the Southern Utah substation because a maximum of $300 \mathrm{MW}$ can be transferred. Hence, the remaining $9 \mathrm{MW}$ is transferred to northern Utah. Figure 50 shows this 


\section{TABLE 5 Summary of Project Generation for Combinations of Peak and Off-Peak Summer Scenarios ${ }^{\mathrm{a}}$}

\begin{tabular}{|c|c|c|c|c|c|c|c|c|c|}
\hline \multirow{4}{*}{$\begin{array}{l}\text { Scenario and } \\
\text { Project Name }\end{array}$} & \multicolumn{9}{|c|}{ Generation for Peak Summer Scenario below Combined with Off-Peak Summer Scenario in Stub Column (MW) } \\
\hline & \multirow{2}{*}{\multicolumn{3}{|c|}{ With PTSGE }} & \multicolumn{6}{|c|}{ Without PTSGE } \\
\hline & & & & \multicolumn{3}{|c|}{$\begin{array}{l}\text { Utah Loads Served at Both } \\
\text { North and South Utah Substations }\end{array}$} & \multicolumn{3}{|c|}{$\begin{array}{l}\text { Utah Loads Served at } \\
\text { South Utah Substation Only }\end{array}$} \\
\hline & $\operatorname{Max}^{c}$ & $\operatorname{Min}^{c}$ & Additional ${ }^{d}$ & Maxc & $\operatorname{Min}^{c}$ & Additional ${ }^{d}$ & $\operatorname{Max}^{\mathcal{C}}$ & $\operatorname{Min}^{c}$ & Additional $^{d}$ \\
\hline \multicolumn{10}{|c|}{ Off-Peak Summer Scenario } \\
\hline \multicolumn{10}{|l|}{ With PTSGE } \\
\hline Glen Canyon & 1,025 & 150 & 275 & 777 & 150 & 523 & 917 & 150 & 383 \\
\hline Aspinall & 272 & 28 & 0 & 272 & 28 & 0 & 272 & 28 & 0 \\
\hline $\begin{array}{l}\text { Flaming Gorge/ } \\
\text { Fontenelle }\end{array}$ & 150 & 25 & 0 & 150 & 25 & 0 & 150 & 25 & 0 \\
\hline \multicolumn{10}{|l|}{ Without PTSGE } \\
\hline Glen Canyon & 1,025 & 454 & 275 & 777 & 454 & 523 & 917 & 454 & 383 \\
\hline Aspinall & 272 & 28 & 0 & 272 & 28 & 0 & 272 & 28 & 0 \\
\hline $\begin{array}{l}\text { Flaming Gorge/ } \\
\text { Fontenelle }\end{array}$ & 150 & 25 & 0 & 150 & 25 & 0 & 150 & 25 & 0 \\
\hline
\end{tabular}

a PTSGE refers to purchases, transmission services, and generation exchanges.

b Assumes that power can be wheeled through the Utah transmission system to serve northern loads.

c Assumes that maximum generation occurs during on-peak hours and minimum generation occurs during off-peak hours.

d Peak hours only. 


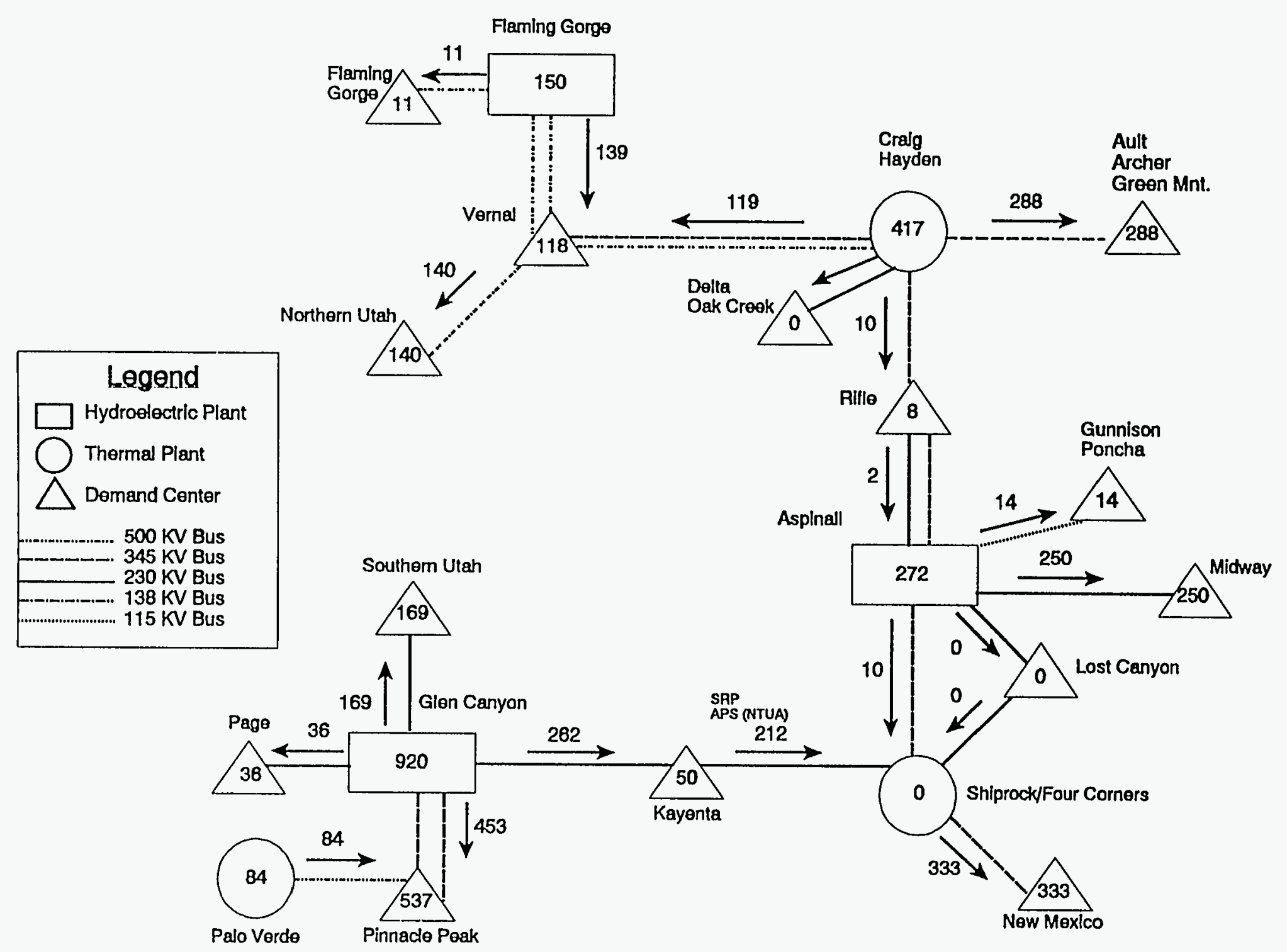

FIGURE 47 CRSP Contractual Power Flow: Winter Peak, Including Transmission Services and Generation Exchanges 


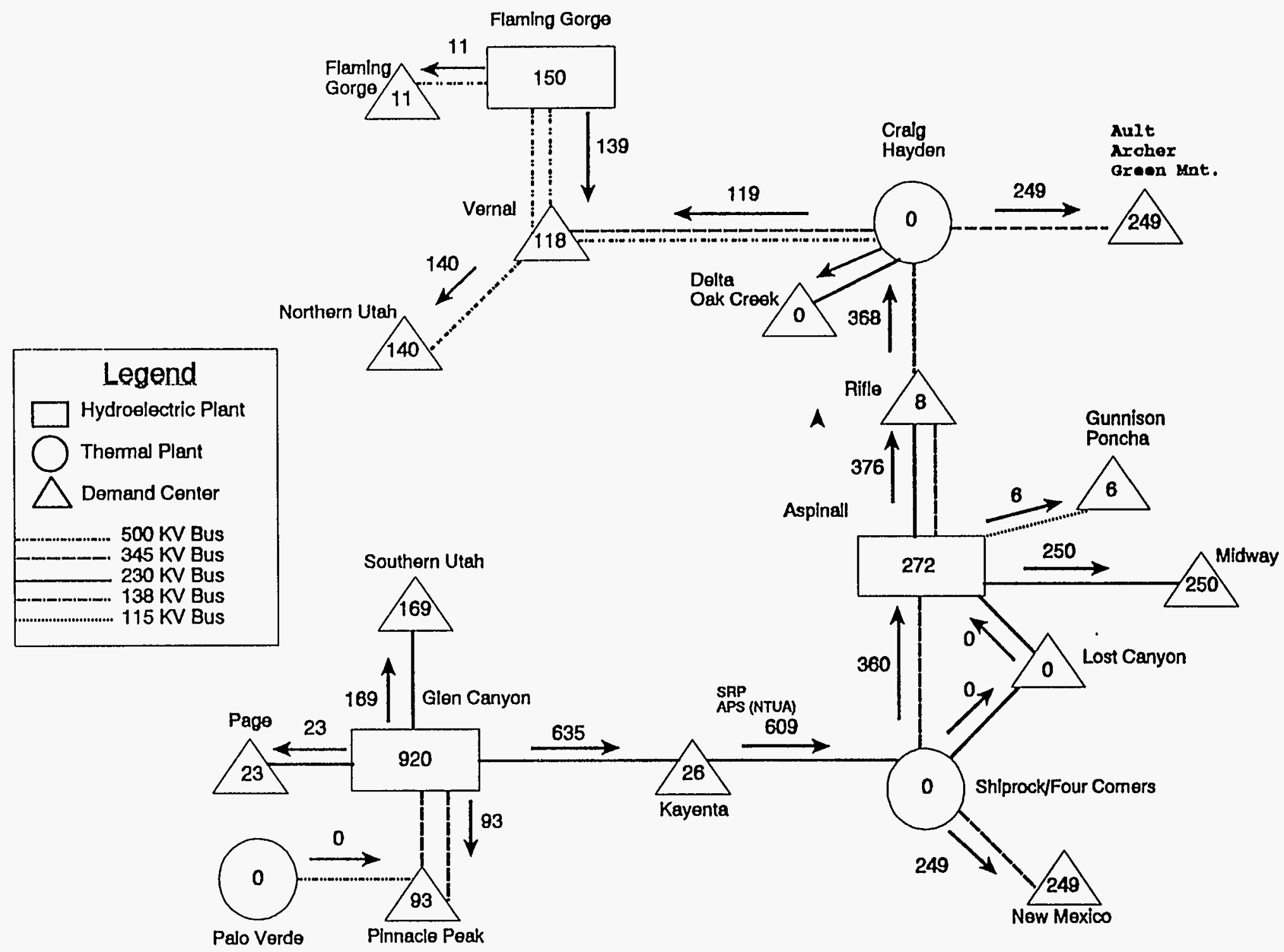

FIGURE 48 CRSP Contractual Power Flow: Winter Peak, No Transmission Services or Generation Exchanges, and No Limit on the Glen Canyon-Shiprock Transmission Line (Note: The current 400-MW transmission limit is exceeded.) 


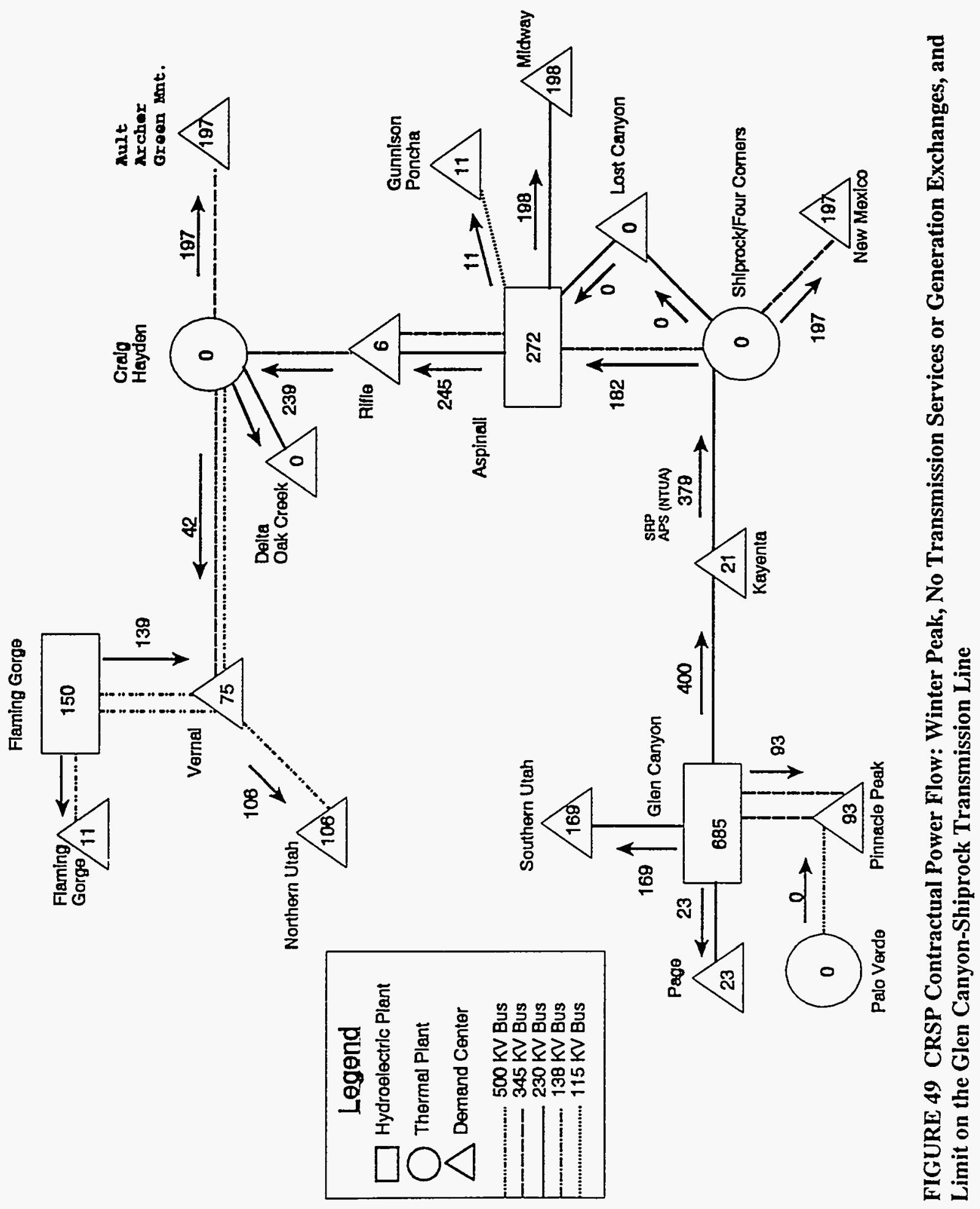




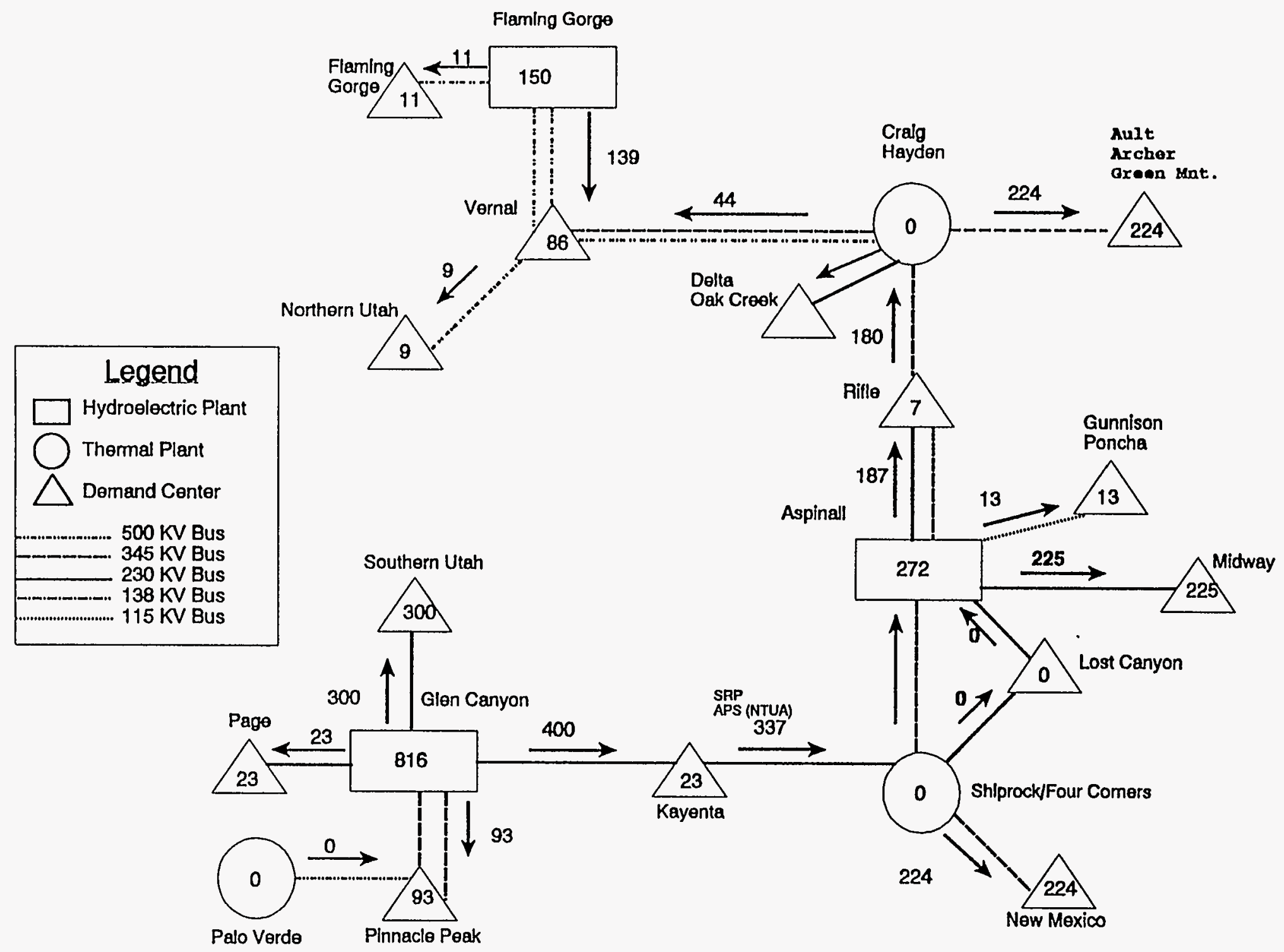

FIGURE 50 CRSP Contractual Power Flow: Winter Peak, No Transmission Services or Generation Exchanges, Limit on the Glen Canyon-Shiprock Transmission Line, and All Utah Loads Served through the Southern Utah Substation 
scenario. On-peak firm loads need to be reduced by only $10 \%$ except for loads served out of the Page, Pinnacle Peak, and Southern Utah substations, which are served in full. Glen Canyon generation is reduced by $10 \%$ over the reference case, and hence, an additional $484 \mathrm{MW}$ is available for STF capacity sales. As stated earlier, if additional capacity is not sold on the STF or spot market, maximum flows at Glen Canyon would be reduced while minimum flows would be increased. However, additional power cannot be sold over the Glen Canyon-Kayenta-Shiprock line. 


\section{SUMMARY}

Western's operating philosophy is consistent with the CRSP Act, which mandates that hydropower plants authorized under the act be operated in conjunction with other federal power plants so as to produce the greatest practicable amount of power and energy that can be sold at firm power and energy rates. In keeping with the intent of the CRSP Act, Western strives to maximize the value of SLCA/IP hydropower plant and transmission resources. When Western's resources are affected by the timing and availability of water resources, such as under the current interim flow restrictions, Western continues to maximize the value of the water resource within the constraints imposed on SLCA/IP power plant operations. In meeting this objective, Western has wide discretion as to whom and on what terms it will contract for the sale of federal power, as long as preference is accorded to statutorily defined public bodies. Sale of power cannot impair the efficiency of the project for irrigation purposes, and power must be sold in a manner that will encourage the most widespread use at the lowest possible rates consistent with sound business principles.

Western maximizes the value of SLCA/PP hydropower resources through its purchasing program. Energy purchases are made on the spot market during off-peak hours to serve a portion of its firm load. The "stored" water is then used to generate electricity during on-peak hours when energy prices are higher than the price of the off-peak purchase. This practice results in hourly SLCA/IP generation patterns that differ from Western's firm hourly loads. Spot market purchases and sales are made by dispatchers in Montrose, Colorado. Dispatchers are given general guidance on when, with whom, how much, and at what price spot market purchases are to be made. The guidelines also specify under what conditions spot market sales are to be made, and they specify prior arrangements and agreements for energy interchanges. Energy purchases and interchanges are to be made only when they do not lead to violations in minimum flow requirements at each dam or exceed transmission capabilities. In addition, spot market sales are to be made only when firm loads have been met and when the energy can be sold above a specified threshold price (e.g., $24 \mathrm{mill} / \mathrm{kWh}$ ). Through purchase and interchange practices, Western is striving to maximize the value of SLCA/IP hydropower plant and transmission resources.

Western's programs affect hydropower plant operations in that they require dispatchers to make meeting firm loads and project use obligations their highest priority. In theory, however, changes in marketing programs only will result in negligible or small operational changes. As long as it is physically possible and a significant economic incentive to hydro shift exists, hydropower plant operations are highly influenced by spot market prices. On the other hand, changes in Western's purchasing and spot market sales programs in conjunction with changes in marketing programs can result in very significant impacts on hydropower plant operations. The influence of marketing programs on hydropower plants is strong when the set of programs requires electricity generation from SLCA/IP hydropower plants to follow Western's firm loads. This situation occurs when conditions or limits are placed on purchasing programs and when spot market sales are not 
permitted. Western's load pattern can also be shaped by setting minimum schedule requirement levels, capacity allocations, and maximum schedule changes. 


\section{REFERENCES}

Allen, A., 1990, "CRSP Generator Maintenance Schedule," letter from Allen, Bureau of Reclamation, Salt Lake City, Utah, to L. Greiner, Western Area Power Administration, Salt Lake City, Utah, Sept. 28.

DOE, 1983, "Request for Applicant Profile Data," U.S. Department of Energy, Federal Register 48:5303, Feb. 4.

DOE, 1985a, Environmental Assessment Revised Proposed General Power Marketing Criteria and Allocation Criteria for Salt Lake City Area, DOE/EA-0265, U.S. Department of Energy, Western Area Power Administration, Salt Lake City, Utah, Dec.

DOE, 1985b, Power Resources Study for the SLCA Post-1989 Power Marketing Criteria, U.S. Department of Energy, Western Area Power Administration, Salt Lake City, Utah, Dec.

DOE, 1986a, "Post-1989 General Power Marketing and Allocation Criteria," U.S. Department of Energy, Federal Register 51:4844, Feb. 7.

DOE, 1986b, "Post-1989 Marketing and Allocation Criteria, Supplementary Information, Contract Term," U.S. Department of Energy, Federal Register 51:4853, Feb. 7.

DOE, 1990, Environmental Impact Statement Information Packet Post-1989 Power Marketing Criteria, DOE/EA-0265, U.S. Department of Energy, Western Area Power Administration, Salt Lake City, Utah, Sept.

DOE, 1991, Operating Guideline for April 1991, Memorandum M9000, U.S. Department of Energy, Western Area Power Administration, Salt Lake City, Utah, April.

DOE, 1992, Western Area Power Administration 1991 Annual Report, U.S. Department of Energy, Western Area Power Administration, Salt Lake City, Utah.

DOE, 1996, Salt Lake City Area Integrated Projects Electric Power Marketing Final Environmental Impact Statement, DOE/EIS-0150, U.S. Department of Energy, Western Area Power Administration, Jan.

EPRI Regional Systems Database: Version 3.0, 1989, EPRI P-6211-SR, Electric Power Research Institute, Palo Alto, Calif., Jan. 
Harris, R.E., 1991, letter from Harris (U.S. Fish and Wildlife Service, Salt Lake City, Utah) to L. Greiner (Western Area Power Administration, Salt Lake City, Utah), July 10.

NERC, 1991, Generating Availability Report (1986-1990), North American Electric Reliability Council, Princeton, N.J., Aug.

U.S. Department of the Interior, 1989, Glen Canyon Environmental Studies Final Report, WA-0017, Bureau of Reclamation, Washington, D.C., May.

Veselka, T.D., et al., 1995, Impacts of Western Area Power Administration's Power Marketing Alternatives on Electric Utility Systems, ANLDIS/TM-10, Argonne National Laboratory, Argonne, Ill.

WSCC, 1991, Coordinated Bulk Power Supply Program 1990-2000, IE-411, Western Systems Coordinating Council, April.

Yin, S.C.L., et al., 1995, Reservoir Release Patterns for Hydropower Operations at the Aspinall Unit on the Gunnison River, Colorado, ANLEAD/TM-5, Argonne National Laboratory, Argonne, Ill. 
